\title{
Functional interrelations of governance elements and their effects on tropical deforestation - combining qualitative and quantitative approaches
}

Dissertation to attain the doctoral degree "Dr. forest."

\author{
of the
}

Faculty of Forest Sciences and Forest Ecology

Georg-August-Universität Göttingen

Submitted by

\section{Richard Fischer}

born on the 15 February 1968

in Harrar, Ethiopia

Göttingen, December 2020 
1. Referee: Prof. Dr. Lukas Giessen

2. Referee: Prof. Dr. Carola Paul

Date of oral examination: 20. November 2020 


\section{Dedication}

I dedicate this work to the

forest dwelling people of

Ecuador, Zambia and the Philippines

\section{Acknowledgements}

I wish to thank Lukas Giessen and Sven Günter for scientific inspiration, highly qualified support, critical but always motivating comments and discussions. I am grateful to the partners of the

LaForeT project. You opened the doors in a true sense of hospitality, enabled extensive field campaigns and provided "ground truthing" for sometimes too theoretical and decoupled scientific considerations. I also thank my employer for patience and leeway to work on this dissertation. Embedded into the Thünen Institute for International Forestry and Forest Economics, the "Forestry Worldwide" team created a perfect environment for research at the science policy interface.

Ich bedanke mich bei meiner Familie.

Es gibt kaum größeren Ansporn als das Leuchten in Euren Augen :) 


\section{Publications of the cumulative dissertation}

Fischer, Richard; Giessen, Lukas; Günter, Sven. 2020. Governance effects on deforestation in the tropics: A review of the evidence. Environmental Science and Policy 105:84-101.

Richard Fischer's contributions:

Lead in development of study design; data capture, management and processing; literary work and writing with minor contributions from co-authors; lead of the publication process.

Fischer, Richard; Tamayo, Fabian; Ojeda Luna, Tatiana; Ferrer Velasco, Rubén; DeDecker, Maria; Torres, Bolier; Giessen, Lukas; Günter, Sven (submitted). Effects of governance elements and their interplay on deforestation in tropical landscapes: Quantitative insights from Ecuador. World Development.

Richard Fischer's contributions:

Development of study design; contributions to data capture and management; main part of statistical analysis; literary work and writing with minor contributions from co-authors; lead of the publication process.

Fischer, Richard; Hargita, Yvonne; Günter, Sven. 2016. Insights from the ground level? A content analysis review of multi-national REDD+ studies since 2010. Forest Policy and Economics 66(1):47-56, DOI:10.1016/j.forpol.2015.11.0031.

Richard Fischer's contributions:

Development of study design; data capture, management and processing; statistical analysis; literary work and writing with minor contributions from co-authors; lead of the publication process.

Nansikombi, Hellen; Fischer, Richard; Kabwe, Gillian; Günter, Sven. 2020. Exploring patterns of forest governance quality: Insights from forest frontier communities in Zambia' s Miombo ecoregion. Land Use Policy 99, 104866.

Richard Fischer's contributions:

Contribution to development of study design; minor contributions to data management and digitization; commenting and helping to endorse the manuscript.

Nansikombi, Hellen; Fischer, Richard; Ferrer Velasco, Rubén; Kabwe, Gillian; Lippe, Melvin; Kanungwe Kalaba, Felix; Günter, Sven (submitted). Can de facto governance influence deforestation drivers in the Zambian Miombo? Forest Policy and Economics.

Richard Fischer's contributions:

Contribution to development of study design; minor contributions to data management and digitization; commenting and helping to endorse the manuscript. 


\section{Abstract}

The global rate of annual net forest loss has slowed from 7.8 mio hectares in the 1990 s to 4.7 mio hectares between 2015 and 2020. Nevertheless, the area of the world's forests continues to decrease specifically in the tropics. Improved governance has come into the focus as a means to help reversing trends of tropical deforestation. Yet, "good governance" remains a normative, broad and often unspecified concept consisting of a wide range of elements and implicit value judgements. Specific knowledge is missing on the relative importance of single governance elements, on their interdependencies and their specific effects on deforestation. Forest governance research to date has a strong focus on qualitative approaches.

This study aims to (i) elaborate on and implement mixed methods for forest governance measurements, (ii) determine functional relationships between forest governance elements based on quantitative data, and to (iii) substantiate and quantify governance effects on tropical deforestation.

The presented research develops a new method called quantitative content analysis with standardized scores. The method is applied in a literature review comprising 28 reviewed publications. This review classifies governance elements based on the framework of the World Resource Institute. It quantifies effects on deforestation for single elements by Likert scores. In addition, this study presents a harmonized landscape level governance assessment methodology which is developed and implemented in research areas covering approximately 500,000 hectares in Ecuador, Zambia and the Philippines. Both methods combine qualitative and quantitative approaches and are shown to be applicable and operational.

In order to analyze functional relationships between governance elements, principal component analysis (PCA) is applied to all data sets. The results show two general main mechanisms. Firstly, there is a joint positive loading of governance elements on the first principal component for all data sets. Governance elements thus function synchronously. They are expressions of a similar underlying mechanism. Secondly, results show that for the review data structural and agency related governance elements are grouped on specific principal components. These components together describe $38 \%$ of the variation of governance elements. For the first time, governance functioning is described by these two aspects based on an empirical data set. However, for neither of the landscape level data sets such a functional structure - agency description is possible. Instead, country specific governance elements have major importance in the landscape level data sets.

Effects of governance on deforestation are analyzed by multiple regression analysis for the data sets from Ecuador and Zambia. Deforestation rates are calculated based on satellite data and are used as target variable. In addition to governance elements, context data on deforestation drivers are assessed in the landscapes and used as explanatory variables. The different models explain approx. $50 \%$ of the variation in deforestation. Direct drivers such as agriculture and infrastructure explain largest shares of deforestation. However, an additional positive effect of single, country specific governance elements can be substantiated. 
The study concludes that for forest governance research mixed method approaches need stronger consideration. Data transformation into quantitative scores enables generalization of knowledge based on a multitude of case studies. Existing studies thus gain added value and should be considered before new field research is implemented. New policy requirements and research questions, however, will necessitate new field studies. These studies need to rely on harmonized approaches to which this study makes an important contribution.

The synchronous function of different governance elements is encouraging for development work and policy. The joint positive loading of governance elements on the first principal components can motivate to concentrate on governance core features that are relevant in the specific context. Possible synergies between governance elements need to be further researched. The structure agency approach can help to select relevant elements. The study shows that both, structure and agency aspects need to be considered. The REDD+ approach is a prominent example for this. Within REDD+, structural measures - in so-called readiness phases, as well as agency related incentives through so-called results based payments need to complement each other.

The structure - agency dualism only became visible within the pan tropical review data set. This can imply that the landscape level is not sufficient to tackle governance issues. Multilevel governance is obviously required spanning from international, to national and local levels.

Direct deforestation drivers like agriculture and infrastructure had stronger effects on deforestation as compared to governance measures, which are regarded as underlying factor. A governance focus alone can thus not compensate effects of direct drivers. However, without governance measures work on direct drivers may not be successful.

Compared to a normative "good" governance approach, the presented analytical approach explores causalities. It is outcome oriented. Based on such an approach, measures can rely on jointly agreed aims instead of input and value oriented principles. This can facilitate development work, because specifically the informal values often differ between actors. 


\section{Contents}

1. Introduction 11

2. Background and theoretical foundations 12

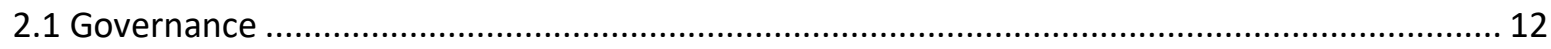

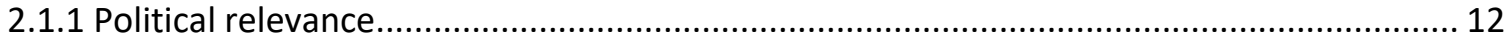

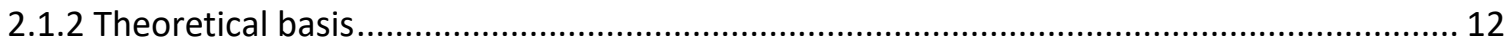

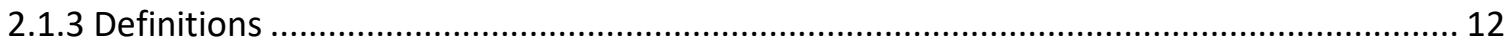

2.1.4 Elements and indicators for "good governance"? .......................................................... 13

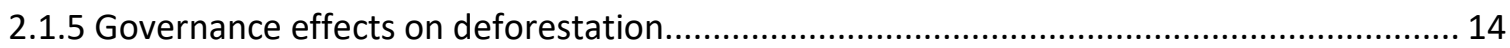

2.2 The context of deforestation drivers and interventions and their interactions ..................... 14

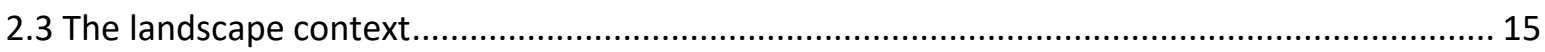

2.4 Qualitative and quantitative methods as a basis for harmonized assessments ...................... 15

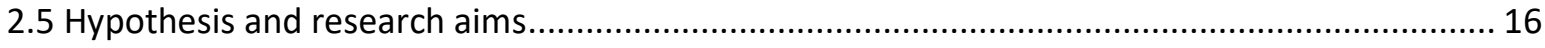

3. Methods......................................................................... 17

3.1 Content analysis as a basis for knowledge extrapolation methods .................................... 17

3.2 Participatory mapping and focus group discussions .................................................... 17

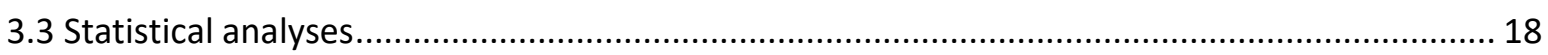

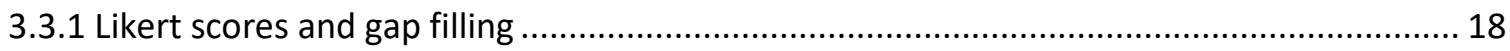

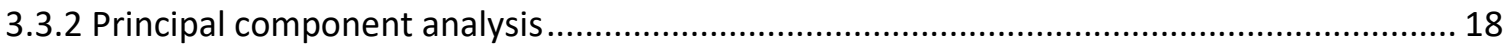

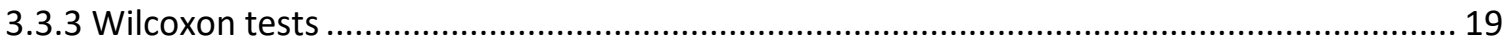

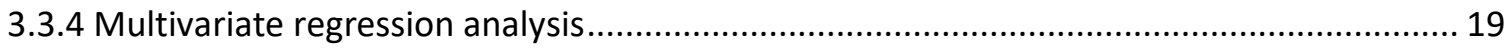

4. Results ...................................................................... 21

4.1 Development and application of methods for governance assessments ............................. 21

4.1.1 Quantitative content analysis with standardized scores (Fischer et al., 2020)................. 21

4.1.2 Harmonized landscape level governance assessments (Nansikombi et al., 2020; Fischer et al., submitted) .................................................................................................... 27

4.2 Functional relationships between governance elements .............................................. 33

4.2.1 Underlying governance factors explained by agency and structure elements ................. 33

4.2.2 Other independent factors and governance elements explaining them ......................... 39

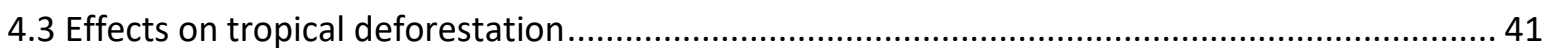

4.3.1 Governance effects on deforestation and most decisive governance elements ................ 41 
5. Discussion

5.1 Methodological considerations

5.1.1 Quantitative content analysis with standardized scores ......................................... 47

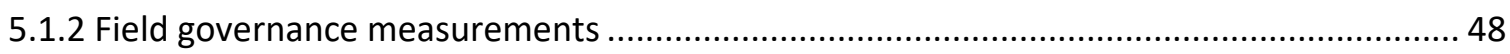

5.1.3 Principal component analysis as tool for evaluating the inherent governance structure ... 51

5.1.4 Evaluating governance effects with multiple regression analysis................................. 52

5.2 Functional relationships between governance elements .............................................. 52

5.2.1 The agency and structure concept as theoretical foundation .................................... 52

5.2.2 Other independent factors and single elements explaining forest governance................53

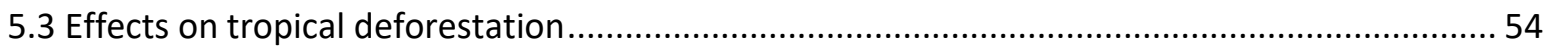

5.3.1 Governance effects on deforestation............................................................. 54

5.3.2 The role of context factors for governance effects on deforestation ...............................56

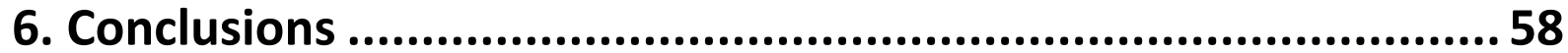

6.1 Mixed governance assessment methods serving the science policy interface .......................58

6.2 Synchronous governance elements can encourage development policies ...........................58

6.3 An agency - structure based understanding provides a changed perspective for e.g. REDD+

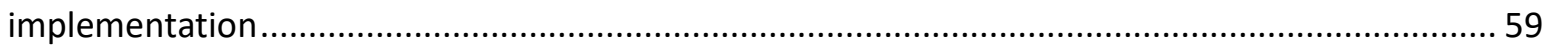

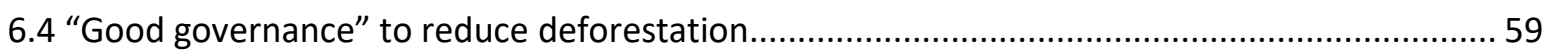

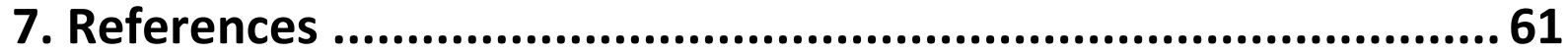

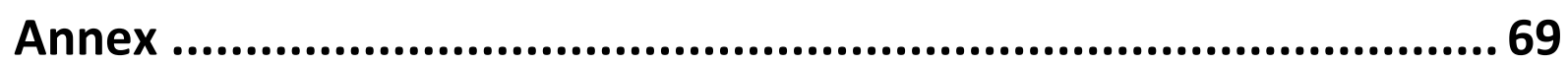

Annex 1: Forest ownership and tenure in Ecuador, Zambia and The Philippines......................... 70

Annex 2: Governance elements with indicators as implemented in assessments in Ecuador (ECU),

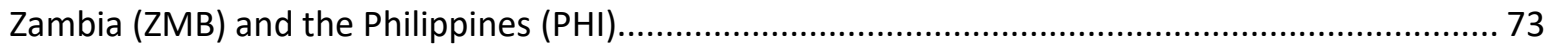

Annex 3: Publications of the cumulative dissertation ........................................................ 79 


\section{Introduction}

Even though the pace of net forest loss has slowed, the area of the world's forests continues to decrease. The rate of annual net loss of forest has slowed from 7.8 mio hectares in the 1990s to 4.7 mio hectares between 2015 and 2020 (FAO, 2020). Improved governance has come into the focus as a general mechanism that might be a promising tool to reverse globally observed trends of tropical deforestation. Therefore, in international forest policy, governance is increasingly taken into account (Singer and Giessen, 2017), even though it is clear that forest governance alone is certainly not sufficient to address drivers of deforestation and degradation (Larson, 2011; Busch and FerrettiGallon, 2017). After periods of first state-centered and then market-oriented development perceptions (Ansell and Torfing, 2016; Brass, 2016) the recent governance paradigm (Arts and Visseren-Hamakers, 2012; Broekhoven et al., 2012; Brass, 2016) is understood as an approach that does not only take these both aspects into account, but also relies on civil society inputs, as well as on interrelations of all these actors and which also considers the bio-physical effects. The modern forest governance approach thus provides a wider and more comprehensive basis for sustainable development. However, a theoretical understanding of the complex interactions of its multiple elements is challenging. In addition, instead of simply postulating "good" governance as a valuedriven and thus political concept (Broekhoven et al., 2012), governance needs to be measured against outcomes, in order to evaluate if the approach is effective. To date, such information is only partially available: governance remains a normative, broad and often underspecified concept consisting of a wide range of elements and implicit value judgements (Giessen and Buttoud, 2014). There are numerous forest governance definitions and catalogues of indicator frameworks for its assessment (see section 2.1.3) which are applied with either qualitative or quantitative methods. Mixed method approaches are hardly available (see section 2.4). Indications of positive effects of single governance elements on deforestation have been published, mostly based on case studies (see section 2.1.5). Systematic and comprehensive evaluations have only recently been published (Fischer et al., 2020; Fischer et al., submitted; Nansikombi et al., submitted), but are needed in order to advance the scientific understanding of forest governance functioning and of its effects as a basis for efficient policy measures. Only if the interrelations and functioning of single elements are understood, and only if their specific effects on deforestation are substantiated, decision makers and practitioners in the field can select, decide on and implement targeted action. 


\section{Background and theoretical foundations}

\subsection{Governance}

\subsubsection{Political relevance}

Governance has gained importance as a general paradigm for sustainable development (Arts, 2014; Ansell and Torfing, 2016). Within the United Nations' Sustainable Development Goals a governance agenda is not only seen as "a goal in itself, but also an essential enabler for the achievement of all other goals" (UN, 2020). It is one out of six UN Forest Goals (UN, 2019) and plays a core role in international programs aiming to reverse the global deforestation trend, such as the REDD+ ("Reducing Emissions from Deforestation and Forest Degradation") process and the European Union's FLEGT ("Forest Law Enforcement, Governance and Trade") program to which it lends its name. It has an undoubted significance on the international forest policy agenda and has consequently come into the focus of related research activities.

\subsubsection{Theoretical basis}

The main theoretical basis of forest governance has been claimed to consist of two mainstream models: rational choice and neo-institutionalism, otherwise described as agency - structure concept, which provides a theoretical basis to better understand and describe governance approaches (Arts et al., 2014). The agency approach postulates that it is mainly self-interested actors, with their specific motivations, intentions, goals, actions and resources, that take active agency (Archer, 2003) and, hence, drive land use decisions. Land users are assumed to take rational choices in order to maximize their economic or political benefits. Broadly, this school of thought assumes that "man's natural proclivity is to pursue his own interests" (Brennan and Buchanan, 1985) and follows the logic of consequences of behavior (March and Olsen, 2004). On the other side, laws, regulations, plans, cultural conventions and norms shape land use decisions providing a structural frame. Hence, this approach broadly follows the logic of appropriate behavior (March and Olsen, 2004). It has to be taken into account that usually neither structure nor agency alone drive human behavior. (March and Olsen, 1998) consider the need to study "which settings in practice enable the dominance of one logic over all others" and (Giddens, 1984b) formulates that agents - groups or individuals - draw upon structures to perform social actions but at the same time structure is the result of these social practices. This "feedback-feedforward" system has been adapted to forest governance by (Arts et al., 2014) in a so-called practice based approach described by the metaphor of a dance or theatre performance in which actors are on one side driven by scripts (structures) which they on the other hand constantly re-interpret.

\subsubsection{Definitions}

Numerous definitions have been proposed for forest governance (Larson and Petkova, 2011; Broekhoven et al., 2012; Davis et al., 2013b; Giessen and Buttoud, 2014; de Graaf et al., 2017; Mansourian, 2017). The recent definitions all understand governance as a broad and comprehensive concept that goes far beyond governments. For (Larson and Petkova, 2011) and (Broekhoven et al., 
2012) forest governance is centered around decisions on forest management. (de Graaf et al., 2017) emphasize rules and decisions. (Wehkamp et al., 2018) and (Davis et al., 2013b) focus on different dimensions by introducing levels and horizontal dimensions or components and principles. Taking into account the numerous definitions that have been proposed for governance, a conceptual study needs a wide governance perspective (Mansourian, 2016), because it should not exclude specific results only because of different definitions. Such a broad definition is formulated by (Giessen and Buttoud, 2014) according to which "forest governance comprises a) all formal and informal, public and private regulatory structures, i.e. institutions consisting of rules, norms, principles, decision procedures, concerning forests, their utilization and their conservation, b) the interactions between public and private actors therein and c) the effects of either on forests". The following study is based on this definition because it is broad enough to comprise specific aspects that are in the focus of the other definitions and it has a clear classification into structures (part "a"), agency described as actors and their interactions (part " $b$ ") and their effects (part " $c$ "). This reflects the current theoretical understanding of the concept.

\subsubsection{Elements and indicators for "good governance"?}

Whatever definition applied, governance comprises a multitude of different elements specified by numerous indicators. Handbooks and toolboxes list governance indicators but without substantiation of effects for each of them. (de Graaf et al., 2017) provide a methodology for landscape level assessments based on four performance criteria that are specified by 18 indicators. The performance indicators include (i) inclusive decision-making in the landscape, (ii) culture of collaboration in the landscape, (iii) coordination across landscape sectors, levels and actors, (iv) sustainable landscape thinking and action. (Worldbank, 2006) provides six aggregate indicators aiming to describe national governance, including (i) voice and accountability, (ii) political stability and absence of violence, (iii) government effectiveness, (iv) regulatory quality, (v) rule of law, (vi) control of corruption. (Kishor and Kenneth, 2012) provide an assessment tool designed for forest sector governance assessments at country of subdivision level. Data are structured into 130 indicators under three pillars, including (i) policy, legal institutional, and regulatory frameworks, (ii) planning and decision-making processes, (iii) implementation enforcement and compliance. (Davis et al., 2013a) is the basis for the methodology developed in this study. This framework provides a description of 126 indicators structured under 24 sub themes, which are referred to as elements in this study, and 6 thematic areas.

In practice, such indicator frameworks are inherently normative, with "good sores and bad scores" (Kishor and Kenneth, 2012). "Good governance" in this context is a normative concept. It is based on principals such as effectiveness, efficiency, transparency, accountability, legitimacy, lack of corruption, stability, empowerment, social justice, equity, environmental and social sustainability of impact (Ansell and Torfing, 2016). In this normative approach the principal question of "who has the right to define them" remains open (Secco et al., 2011). In practice, the views reflect formal international agreements. The United Nations' Global Forest Goal No 5 (UN, 2019) is an important source in this respect requiring e.g. "enhanced" law enforcement and "strengthened" institutions, that implicitly are perceived as "good". "Good governance" thus becomes the promotion of reform of the public sector and/or of corporate management, as among others advocated by the European Union, the International Monetary Fund and World Bank.

In contrast, analytical studies are concerned with the mere reflection of these phenomena and their explanation and strive for developing value-free methodological frameworks (Giessen and Buttoud, 
2014). In this sense, the following study is understood as an analytical study. This does not mean that assessment frameworks cannot be applied. On the contrary, the study applies (Davis et al., 2013b) because this framework comprises a broad spectrum of elements that are understood to make up forest governance. However, these elements are used to study interrelations between them and are analyzed with respect to an outcome, namely effects on deforestation. Their high or low performance is not a priori understood as good or bad.

Previous studies also rely on such indicator descriptions and analyze effects of single governance components on deforestation (see section 2.1.5), but an understanding of the inherent structure of different governance components and how they interact is missing until today. It is also not clear which of the multiple components are the most decisive ones with regards to effects on deforestation. This, however, would be important for the scientific understanding of governance functioning. It would also have practical implications, as policy requires information on which of the multiple components to concentrate and practitioners need to know if additional governance components are affected when they are working on one of them.

\subsubsection{Governance effects on deforestation}

Scholars have produced an increasing number of (i) case studies analyzing governance effects on the ground (Andersson et al., 2014; Schusser et al., 2015; Subhan Mollick et al., 2018) (ii) statistical evaluations of governance effects using regional or global panel data sets (Umemiya et al., 2010a) and (iii) reviews of existing research results (Bhagwat et al., 2017; Wehkamp et al., 2018; Fischer et al., 2020). Existing results on governance effects show positive relations between improved governance and reduced deforestation (Bottazzi and Dao, 2013; Ceddia et al., 2014; Liu et al., 2016); (Kanninen et al., 2007; Korhonen-Kurki et al., 2014; Stickler et al., 2017) and the prevailing conclusion in such studies is that improved forest governance will at least contribute to reduced deforestation. However, as there is no common definition of governance and as each study has an individual focus, such effects are reported for individual governance elements only. It is not clear if there are most decisive governance elements with respect to deforestation outcomes or if elements are functionally related in their effects.

\subsection{The context of deforestation drivers and interventions and their interactions}

Theories about what drives deforestation date back as far as Johann Heinrich von Thünen's quantitative spatial model, in which economic returns determine how land is allocated between forests and agriculture (von Thünen 1826 cited after (Busch and Ferretti-Gallon, 2017). Research on causes of deforestation specifically in the tropics has been intensified in recent years. (Geist and Lambin, 2002) group drivers of deforestation into three key categories (i) proximate (direct), (ii) underlying causes and (iii) other drivers. The proximate drivers are the human activities that directly affect the environment like infrastructure, agriculture and wood extraction. Governance is understood as underlying cause. More recent scholars have as well used this framework (Umemiya et al., 2010b; Hosonuma et al., 2012; Fischer et al., submitted; Nansikombi et al., submitted). Another theoretical framework for analyzing the relations of context factors and governance effects has been developed by (Fischer et al., 2020). It specifies governance effects on deforestation and then relates context factors to these effects. In addition to governance elements and direct drivers, interventions are assumed to affect deforestation. Actions explicitly undertaken to counter land use changes have 
been classified as such interventions (Agrawal et al., 2014; Fischer et al., 2020). Summarizing these concepts, context factors for studying governance effects on deforestation can be understood as comprising direct drivers, other underlying causes and interventions. The classification of context factors can benefit from numerous publications that name and identify possible deforestation drivers (Geist and Lambin, 2002; Hosonuma et al., 2012; Wehkamp et al., 2015; Busch and Ferretti-Gallon, 2017) and interventions (Agrawal et al., 2014). The situation is, however, more complex than such a simplified scheme may suggest, because context factors as well as governance elements not only affect deforestation but interact between themselves. Also, the effects of a number of governance elements are controversially discussed. This includes e.g. tenure security and public participation which on one side may motivate sustainable management, but on the other can stimulate exploitation of forest and land conversion under short term economic interest (Ostrom, 1999; Agrawal et al., 2014). Such complexity of governance effects made (Wehkamp et al., 2018) exclude governance variables with "different directions of causality" from the analysis and only evaluate those that had a clear causal direction, even though that in their data base such complex cases accounted for one fifth of all reported cases. This shows the need for evaluating interacting context factors and governance effects on deforestation.

\subsection{The landscape context}

Deforestation depends on the scale that is under consideration, because in multifunctional landscapes with a mosaic of land uses and land cover types, different stakeholders with differing interests are involved (Watts and Colfer, 2011). (Agrawal et al., 2014) emphasize the interspersed nature of agricultural and forest land uses and the potential for different pathways of land cover change. Whereas a number of context factors and governance elements may be of direct local importance, others are effective across larger spatial scales. Therefore, the so called landscape approach has been proposed in order to research and manage areas where agriculture, mining, and other productive land uses compete with environmental and biodiversity goals. A landscape has been defined as an arena in which entities, including humans, interact according to rules that determine their relationships (Sayer et al., 2013). Even though that landscapes are thus understood in broad conceptual terms rather than simply as a physical space (Farina, 2000) it implies that larger areas need to be considered in most cases in order to capture interactions between governance elements, different drivers, interventions and deforestation.

\subsection{Qualitative and quantitative methods as a basis for harmonized assessments}

Both, quantitative and qualitative approaches have been applied in forest governance research. Quantitative data is any data that is in numerical form and analyzed by the use of statistics and that can on this basis be generalized (Given, 2008). Qualitative research, on the other hand, inquires deeply into specific experiences, describing and exploring meaning and functioning through text or observations, but which develops themes exclusive to a specific sample population (Glesne, 2011) (Ratner, 2002; Austin and Sutton, 2014). The ongoing debate on methodological issues in forest governance research is not conclusive. At least for the so-called practice based approach, (Arts et al., 2014) favor qualitative methodologies and postulate that at the core for deeper understanding "we need qualitative interpretative methodologies". (Stevanov et al., 2016; Maryudi et al., 2018) recommend a stronger focus on quantitative methods. (Krott et al., 2014; Kleinschmit et al., 2016) 
argue for a more balanced application and state that both, "quantitative and qualitative methods are capable of producing rigorous, realistic empirical findings". Integrated mixed method approaches have hardly been followed (Schusser et al., 2012; Fischer et al., 2020). Instead, recent research and methodological reviews focus on either qualitative (Laraswati et al., 2020) or quantitative studies (Stevanov et al., 2016).

Standardized methods for forest governance assessments that can be and have been applied in a larger number of cases are rare. (IFRI, 2011) provides a standardized approach to assess forestry resources and institutions based on the research approach of (Ostrom, 1999) on a cross country scale. This approach, however, has a focus on single forests and is largely qualitative descriptive. (Ravikumar et al., 2015) and (CIFOR, 2015) provide governance interview guidelines for a cross country study of the Centre for International Forestry Research (CIFOR). These are as well largely qualitative descriptive.

\subsection{Hypothesis and research aims}

The research presented is based on two main hypotheses

(i) The structure - agency concept provides a basis for the functional understanding of complex interactions of governance elements (Giddens, 1984a; March and Olsen, 2004; Arts et al., 2014).

(ii) Specific governance elements are related to reduced deforestation (Umemiya et al., 2010b; Bottazzi and Dao, 2013; Ceddia et al., 2014; Stickler et al., 2017).

Under these hypotheses three specific aims with research questions are subsumed.

Aim 1: Analyze and further elaborate on methods for forest governance assessments.

What are appropriate qualitative and/or quantitative methods to provide a basis for generalization relevant information from the multitude of existing case studies, reviews and theoretical governance studies? Can an operational and harmonized method for landscape level governance assessments be developed, that provides a basis for policy relevant cross country comparisons and input to further scientific analysis of governance elements?

Aim 2: Determine functional relationships between forest governance elements.

Can theoretical foundations of governance - as postulated in the agency and structure concept - empirically be substantiated through results of applied governance research? Are there other independent factors that summarize and explain patterns in the complex structure of governance elements? Are single governance elements more predominantly characterizing overall governance than others?

Aim 3: Substantiate and quantify governance effects on tropical deforestation.

Does the hypothesized relation between governance and deforestation hold true? Are there most decisive governance elements that have an effect on reduced deforestation? What is the relation between context factors, including interventions and direct drivers, and governance as underlying cause on deforestation? 


\section{Methods}

\subsection{Content analysis as a basis for knowledge extrapolation methods}

The development of a method for extrapolating knowledge from a multitude of case studies (see section 4.1.1) builds on qualitative content analysis as a method for analyzing text from various sources that is then extended by quantitative components (Mayring, 2014). The central idea of qualitative content analysis is to assign categories to text passages as an interpretive act. These are then combined with elements of quantitative content analysis - mainly by counting frequencies. Within deforestation research the method has been used by (Geist and Lambin, 2002). Within the presented research, the quantitative part of the method was expanded by not just counting frequencies but by applying standardized Likert scores to findings within the categories (see section 3.3.1). This can increase comparability and statistical power (Rudel, 2008; Magliocca et al., 2018).

\subsection{Participatory mapping and focus group discussions}

Participatory mapping, elsewhere referred to as public participatory GIS (PPGIS) (Martin et al., 2012), was used to produce maps at the landscape level from the perspective of individuals on topics such as land use and governance. Participatory mapping was included as a module for the development of a field governance assessment method (see section 4.1.2). This mapping method has been widely used in geography to provide a voice to marginalized communities, such as indigenous peoples, and to document members' perspectives on different places or spaces (Elwood and Ghose, 2011; Martin et al., 2012; Freund et al., 2016). Letting community members produce maps through a participatory approach, creates a collaborative research-participant dynamic. Mapping was carried out in workshops assembling representatives from the research landscapes. In order to prepare workshops, scoping visits were conducted that enabled to establish contact to representatives from communities and major stakeholder groups. Participants comprised men, women, young people and long-term members of the community. PPGIS has been described to include (i) appreciative interviewing prior to the mapping, aiming to familiarize participants, create awareness and build confidence (ii) create sketch maps with the main contents (iii) transferring the contents to Google maps (iv) and verifying the data (Martin et al., 2012). Within the study this approach was modified as instead of sketch maps and digitizing on Google maps, polygons were delineated on print outs of satellite images of approximately $80 * 120 \mathrm{~cm}$. All mapped information was digitized by project staff after the workshops using QGIS 2.18 (QGIS, 2018).

Focus group discussions for collecting land use and governance data were used as one module of the field governance assessment (see section 4.1.2). For the focus group discussions the approach of (Nyumba et al., 2018) was applied. Focus group discussions were conducted in the same workshops as the participatory mapping. This had the advantage that participants were already familiar with the project context and a trustful atmosphere had already been created. Facilitators were team leaders of the project field campaign that were familiar with the local ethnic, socio economic and biophysical conditions. The moderators were responsible for the discussions not only by managing existing relationships but also by creating a relaxed and comfortable environment for participants. The assistant's role was observing non-verbal interactions and the impact of the group dynamics, and 
documenting the general content of the discussion. The main methods of data collection during a focus group discussion included audio and tape recording, note-taking and participant observation. The discussions were split into sessions no longer than 1-1.5 hrs as participants are likely to suffer from fatigue when discussions are longer.

\subsection{Statistical analyses}

\subsubsection{Likert scores and gap filling}

Likert scores (Likert, 1932) were used to quantify results of the qualitative content analysis. Mean governance effects on deforestation and mean effect of context factors per study as well as mean governance scores in the field assessments were calculated as the arithmetic mean of the Likert scores of all original governance elements and context factors for each of the reviewed studies or for the assessed governance arrangements in the field. Likert scores were treated as ordinal, respectively metric values in principal component analysis and multiple regression analysis following (Manley, 2005) and (Leard, 2020).

Gaps in the data sets of the review study occurred because not all elements and context factors, occurred in each of the studies. For conducting principal component analysis and multiple regression analysis, gaps were filled with the mean Likert scores for governance elements, drivers and interventions respectively following (Dray and Josse, 2014).

\subsubsection{Principal component analysis}

Principal component analysis (PCA) (Dunteman, 1989; Jolliffe, 2002 ) reduces the dimensionality of a multivariate data set by producing linear combinations (principal components) of the original variables (e.g. governance elements) that summarize the predominant patterns in the data (PeresNeto et al., 2003). Principal components are determined ('loaded') by several original variables and explain more variation than these single variables. Loadings as presented in loading matrices, are the simple correlations between the components and the single variables. Principal component analyses were applied in order to identify independent gradients within the data sets of the review analysis, and within the data sets of the field governance assessments.

Assumptions for applying PCA were checked following (Pallant, 2010; Leard, 2020). They require (i) metric data or at least ordinal data with e.g. a five point Likert scale (ii) linear relationships between all variables, (iii) sampling adequacy with 5 cases per variable (iv) suitability for data reduction, i.e. adequate correlations between the variables, (v) no significant outliers, i.e. max 3 time standard deviation.

The first assumption for applying PCAs is that data need to be metric or at least ordinal. Five or seven point Likert scale data are explicitly mentioned as such (Pallant, 2010; Leard, 2020). The governance data thus fulfilled this requirement. The second assumption of linear relationships between the single variables was checked following (Leard, 2020 ) by randomly selecting variable combinations and calculating Pearson correlation coefficients. Sampling adequacy is an additional assumption with at least 5 cases per variable mentioned as rule of thumb. With 21 governance elements and 28 studies as a basis for the review this rule has been violated. However, (Jolliffe 2016) report that datasets with fewer observed entities than variables are becoming increasingly frequent and that "nothing prevents the use of PCA in such contexts" However, the interpretation has to take into 
account that the results typically have a very small number of structured components, and very many noise dimensions, i.e. components with very low eigenvalues. A fourth precondition for PCA refers to the fact that data need to be suitable for data reduction, i.e. adequate correlations between the variables are needed. The data in this study fulfil this condition. Correlation matrices were calculated and single correlation results are reported in the results section where they contributed specific explanations and interpretations of the data. Taking into account the final precondition, no outliers had to be removed after analyzing the data distribution.

\subsubsection{Wilcoxon tests}

In order to compare governance scores between governance arrangements in the field assessments non-parametric Wilcoxon tests comparing multiple pairs were applied. A non-parametric test was applied as in a number of cases the assumption of normality in the data was not given. The test explores how the distribution of a continuous $Y$ variable like governance scores differs across multiple categorical groups defined as $X$ variable (Siegel, 1988). Mean governance in the field studies was calculated as the mean of the single governance elements across all polygons.

\subsubsection{Multivariate regression analysis}

Multivariate regression analyses (Kenney and Keeping, 1962; Rencher and Christensen, 2012) with backward elimination were applied in order to check for potential relationships between (i) single context factors (predictors) and governance (target variable) in the review data and (ii) between governance and proximate drivers (predictors) and deforestation (target variable) in the field data sets from Zambia and Ecuador. Backward elimination is appropriate for selecting those factors that contribute most strongly to the regression model, when the number of variables is high (Hocking, 1976), as was the case in these analyses. Within backward selection, explanatory variables were successively removed that were not significant and that did not decrease the $r^{2}$.

For the field data set from Ecuador, governance information was extrapolated from 25 governance arrangements patches with field assessments of governance to additional 59 patches based on the expert knowledge of the field teams and in order to increase the sample size. Extrapolation was only carried out in cases where patches were comparable in terms of land use and land use history and governance mechanisms. A statistically significant difference in annual deforestation between patches with originally assessed and extrapolated governance scores could not be determined, a bias due to the method of determining governance performance can thus be excluded.

For the field data set from Zambia only 80 of the 91 observations were included in the regression analyses due to absence of governance data for the private arrangements. A non-parametric Kruskal Wallis test was conducted to compare the annual rate of deforestation between the excluded and considered observations. The test verified the absence of elimination bias from exclusion of the private arrangements.

From the original 84 patches that we used as basis for regression analysis in the Ecuadorian data set, four outliers were removed. Outliers were patches with more than three times standard deviation of deforestation.

Multicollinearity refers to the condition in which two or more predictors are highly correlated with one another which can make it difficult to determine the effect of each predictor on the target variable. Multicollinearity of predictors was checked by calculating variance inflation factors (VIF) for each of the predictors. VIFs quantify the severity of multicollinearity by providing an index that 
measures how much the variance of an estimated regression coefficient is increased because of collinearity. VIFs above 10 are commonly regarded to signify high multicollinearity, VIFs above 5 express at least moderate multicollinearity (PennState, 2019). VIFs in our analysis were in all cases below 5 and we thus excluded multicollinearity which is a precondition to run a valid multiple regression analysis.

Normal distribution of the residuals (homoscedasticity) was analyzed by plotting and comparing the distribution of the residuals against a standardized normal distribution. Plotting residuals against predicted values helped identifying possible relationships between these. However, in none of the cases there were statistical significant linear relationships between the residuals and the predicted values. We also assured for homoscedasticity applying the Breusch-Pagan test.

In the field studies of Ecuador and Zambia variables were measured at different scales. Z score standardization was thus carried out to normalize data. The original variables were rescaled to have a mean of zero and standard deviation of one by subtracting the mean of the original variable from the raw value and then dividing it by the standard deviation (Dytham, 2011).

In the Zambian data set (Nansikombi et al., submitted), the dependent variable, average annual rate of deforestation, was found positively skewed via a Shapiro-Wilk test with a p-value $<.0001$ and was therefore transformed with a square root function to ensure normal distribution (Freeman and Tukey, 1950; Thacker and Bromiley, 2001). All statistical evaluations were carried out using the statistical software package of JMP 12 (SAS, 2015). 


\section{Results}

\subsection{Development and application of methods for governance assessments}

\subsubsection{Quantitative content analysis with standardized scores (Fischer et al., 2020)}

Deforestation is a global phenomenon, but published results are mostly case dependent. Expanding observations and inferences from individual case studies requires quantitative methodologies for generalizing locally specified knowledge. A methodology was therefore developed that extends qualitative content analysis (Mayring, 2014) by combining it with standardized quantitative scores within the single categories in order to increase comparability and to open possibilities for statistical evaluations (Magliocca et al., 2018). In summary, the method includes

1. literature review and identification of articles focusing on governance effects on deforestation

2. content analysis with iterative development and application of categories for text analysis

3. quantitative scoring of the content within the categories.

The method is named quantitative content analysis with standardized scores.

\subsubsection{Literature review}

Peer reviewed English articles containing empirical results from forest governance studies were selected through a literature search in Scopus in March 2017. The search focused on studies published after 2000. Given the wide range of applied forest governance definitions the study was not focused on search terms that are elements of different definitions but rather on the overarching term 'governance' itself which is consensus among all definitions. The search algorithm included 'governance' in combination with (i) 'degradation' and 'forest', (ii) 'deforestation' or (iii) 'reforestation' in title, abstract and keywords. This resulted in 810 publications including duplicates (Tab. 1). Within each of the years and search term combinations, those publications were selected that had more citations than the average of the selected publications of the same year and search term combination in order to keep the large number of publications manageable. This resulted in a total of 286 papers. After removing duplicates, there remained 198 potential publications for the review.

\begin{tabular}{|l|l|l|}
\hline & N all publications & $\begin{array}{l}\text { N publications with } \\
\text { above average citations }\end{array}$ \\
\hline governance AND degradation AND forest & 266 & 94 \\
\hline governance AND reforestation & 67 & 28 \\
\hline governance AND deforestation & 477 & 164 \\
\hline subtotal & $\mathbf{8 1 0}$ & $\mathbf{2 8 6}$ \\
\hline after removing duplicates & & 198 \\
\hline $\begin{array}{l}\text { studies with empirical relations on governance } \\
\text { and deforestation including global reviews }\end{array}$ & & 32 \\
\hline Total after removing global reviews & & $\mathbf{2 8}$ \\
\hline
\end{tabular}

Table 1: Results of the literature search on governance relations to deforestation, reforestation and forest degradation. 
From these, only articles were selected for which the abstracts indicated research on effects of one or more governance components on deforestation, reforestation or degradation. Only studies that aimed to establish empirical links between these two were considered, irrespective whether they finally found or did not find such links. Empirical links either could be quantitative statistical or qualitatively descriptive based on defined scientific methods. Only research from countries with notable territories in the tropical climatic zone were selected. Four studies that were based on global reviews were excluded in order to focus the scope. The final selection yielded 28 articles (Tab. 1).

\subsubsection{Content analysis}

Content analysis was used as an approach for the systematic analysis of the published articles. The framework for governance indicators presented by the World Resource Institute (WRI) (Davis et al., 2013b) was used to classify the governance contents. This framework provides a comprehensive set of thematic areas and elements (subthemes) but leaves leeway to adjust the system to the respective context. The specific WRI governance elements (Davis et al., 2013b) tackled in each of the studies were identified.

Governance elements were assigned to either the agency or structure approach based on own interpretation in order to provide a basis for evaluating functional relationships between elements at a later stage (Tab. 2). Forest ownership, tenure dispute resolution, private sector, civil society, public participation in decision making and all elements related to revenues were interpreted as being decisive in the context of an agency related approach because these elements reflect individual decisions, personal motivations - including financial interests - and the possibilities of single actors to implement own interests. The WRI elements of land use planning, land use plan implementation, sectoral land use, forest strategies and plans, legal/policy framework, law enforcement and legislature were interpreted as being related to a structural policy approach, because they emphasize creation, existence and implementations of structures, rules and frames. A number of elements either could not be assigned exclusively to one of the approaches or contained aspects of both.

\begin{tabular}{|c|c|c|}
\hline 1 Forest tenure & 2 Land use & 3 Forest management \\
\hline \multirow{2}{*}{$\begin{array}{l}\text { Forest ownership and use rights } \\
\text { Tenure dispute resolution }\end{array}$} & Land use planning & Forest legal and policy framework \\
\hline & Land use plan implementation & Forest strategies and plans \\
\hline State forest ownership & \begin{tabular}{|l|} 
Sectoral land use \\
\end{tabular} & Forest law enforcement \\
\hline \multirow[t]{2}{*}{ Concession allocation } & Forest classification & Forest management practices \\
\hline & & Forest monitoring \\
\hline 4 Forest revenues & 5 Institutions & 6 Cross cutting issues \\
\hline \multirow{2}{*}{$\begin{array}{l}\text { Forest charge administration } \\
\text { Forest revenue distribution }\end{array}$} & Legislature & Public participation in decision-making \\
\hline & Judiciary & Public access to information \\
\hline \multirow{3}{*}{$\begin{array}{l}\text { Benefit sharing } \\
\text { Budgeting }\end{array}$} & Executive agencies & Financial transparency and accountability \\
\hline & Private sector & Anticorruption measures \\
\hline & Civil society & \\
\hline
\end{tabular}

Table 2: Six thematic areas and 26 elements for governance assessments based on (Davis et al., 2013b). Black: elements that were interpreted as agency related; grey: elements interpreted as structure related. A number of elements could not be assigned to either of these two mechanisms.

Qualitative content analysis required a thorough reading of the articles and assigning of governance information to 26 elements as provided by the framework of the World Resource Institute. The 26 elements were thus subcomponents for classification within the content analysis (Mayring, 2000, 2014). On average, only 4.9 elements out of possible 26 possible elements were identified per study. 
Therefore, the 26 original elements were grouped to 11 aggregated elements by pooling less frequently mentioned elements within thematic areas.

Many studies in addition contained information about the wider socio-economic and political context of deforestation. In a second step, all additional factors related to deforestation were therefore classified as context factors that included drivers and interventions. Content analysis was as well used to analyze such context factors. The study relied on a classification of deforestation drivers by (Hosonuma et al., 2012) and on categories for interventions used by (Agrawal et al., 2014). Factors that directly or indirectly increase deforestation were classified as deforestation drivers. Actions explicitly undertaken to counter land use changes were classified as interventions. The original classification was adapted using qualitative content analysis as an iterative method. This implies that during reading, categories for all context factors were partly newly created, rearranged or successively adapted based on the contents of the material (Mayring, 2000, 2014). A final reading was then conducted based on the final categories for governance elements and context factors. The texts were coded using MAXQDA (version 11). Each result or conclusion related to one of the categories was marked and coded; the coding system in MAXQDA consisted of the classification described above.

Within the 28 studies, 596 key sentences or text pieces were coded: 338 codings were related to governance elements, 154 to drivers and 104 to interventions (column a in Tab. 3). Text related to forest law enforcement was most frequently encoded (58 codings in 20 documents). The most frequently identified context factors were population growth or density and economic development ( 30 codings in 9 documents). The fact that the number of codings for governance elements was higher as compared to codings for context factors was to be expected as governance was the search criterion for the studies.

The number of original governance WRI elements that were coded in all documents was highly variable (column b in Tab. 3). Out of the 26 elements, 12 were only coded in 2 or less studies. None of the studies considered governance issues in the context of forest concessions, legislative institutions, budgeting or forest classification. Also, the number of coded text parts between the WRI thematic governance areas was unequal. Forest management elements were identified in 54 cases, which is mainly due to the importance of policy framework, monitoring and law enforcement. Elements related to the thematic area of forest revenues only occurred in 7 cases. The sum of all coded text pieces for agency related elements (48) and the number of all coded text pieces for structure related elements (47) was almost identical. 


\begin{tabular}{|c|c|c|c|c|c|c|}
\hline & & & & $\begin{array}{c}\text { (a) } \\
\mathrm{N} \text { codings } \\
\text { (MAXQDA) }\end{array}$ & $\begin{array}{c}\text { (b) } \\
\mathbf{N} \\
\text { documents } \\
\text { scored }\end{array}$ & $\begin{array}{c}\text { (c) } \\
\mathbf{N} \text { documents } \\
\text { scored } \\
\text { (aggregated } \\
\text { categories) }\end{array}$ \\
\hline \multicolumn{7}{|l|}{ Governance elements } \\
\hline & Element name & Abbreviation & Aggregated elements & & & \\
\hline \multirow[t]{4}{*}{1 FOREST TENURE } & Forest ownership and use rights & Ownership & Tenure/Ownership & 45 & 13 & 13 \\
\hline & Tenure dispute resolution & Dispute & \multirow{2}{*}{ Dispute resolution } & 4 & 4 & \multirow{2}{*}{4} \\
\hline & State forest ownership & State forest & & 0 & 0 & \\
\hline & Concession allocation & Concession & Concession allocation & 0 & 0 & 0 \\
\hline \multirow[t]{4}{*}{2 LAND USE } & Land use planning & LUplanning & \multirow{3}{*}{ Land use plan. } & 6 & 6 & \multirow{3}{*}{8} \\
\hline & Land use plan implementation & LUimplement & & 3 & 4 & \\
\hline & Sectoral land use & SectoralLU & & 2 & 2 & \\
\hline & Forest classification & Classification & Forest classification & 0 & 0 & 0 \\
\hline \multirow{5}{*}{3 FOREST MANAGEM. } & Forest legal and policy framework & Framework & Legal/Policy framework & 35 & 11 & 11 \\
\hline & Forest strategies and plans & Strategies & \multirow{3}{*}{ Planning/Monit./Manag. } & 4 & 4 & \multirow{3}{*}{13} \\
\hline & Forest monitoring & Monitoring & & 23 & 9 & \\
\hline & Forest management practices & Management & & 10 & 3 & \\
\hline & Forest law enforcement & Enforcement & Law enforcement & 58 & 20 & 20 \\
\hline \multirow[t]{4}{*}{4 FOREST REVENUES } & Forest charge administration & Charges & \multirow{3}{*}{ Revenues } & 2 & 1 & \multirow{3}{*}{4} \\
\hline & Forest revenue distribution & Revenues & & 1 & 1 & \\
\hline & Benefit sharing & Benefit & & 4 & 3 & \\
\hline & Budgeting & Budgeting & Budgeting & 0 & 0 & 0 \\
\hline \multirow[t]{5}{*}{ 5 INSTITUTIONS } & Legislature & Legislature & Legislature & 0 & 0 & 0 \\
\hline & Judiciary & Judiciary & \multirow{2}{*}{ Executive agencies } & 2 & 1 & \multirow{2}{*}{16} \\
\hline & Executive agencies & Executive & & 37 & 16 & \\
\hline & Private sector & Private & \multirow{2}{*}{ Civil society } & 3 & 1 & \multirow{2}{*}{12} \\
\hline & Civil society & Civil & & 32 & 12 & \\
\hline \multirow[t]{4}{*}{6 CROSS-CUT. ISSUES } & Public particip. decision-making & Participation & Participation & 55 & 18 & 18 \\
\hline & Public access to information & Information & \multirow{3}{*}{ Transparency } & 2 & 1 & \multirow{3}{*}{7} \\
\hline & Financial transpar. and accountab. & Transparency & & 3 & 2 & \\
\hline & Anticorruption measures & Anticorruption & & 7 & 4 & \\
\hline \multicolumn{7}{|l|}{ Context factors } \\
\hline \multirow[t]{8}{*}{ DRIVERS } & Corruption, Illegal logging & & & 17 & 8 & \\
\hline & Population growth/density & & & 30 & 9 & \\
\hline & Roads length/density & & & 19 & 10 & \\
\hline & Land speculation, Opportunuity costs & & & 18 & 6 & \\
\hline & Economic development, Forest income & & & 30 & 9 & \\
\hline & Cash crops & & & 15 & 7 & \\
\hline & Agricultural intensification/expansion & & & 16 & 9 & \\
\hline & Timber, Firewood use & & & 9 & 6 & \\
\hline INTERVENTIONS & Subsidies, Credits, Donor aid & & & 24 & 8 & \\
\hline & PES, Certification & & & 8 & 4 & \\
\hline & Protected areas & & & 15 & 7 & \\
\hline & Community forestry/Decentralization & & & 20 & 14 & \\
\hline & Tourism & & & 6 & 2 & \\
\hline & (improved) Technology & & & 11 & 4 & \\
\hline & Public relations, Education, Research & & & 20 & 9 & \\
\hline & total & & & 596 & & \\
\hline
\end{tabular}

Table 3: Assessed governance elements and context factors, number of MAXQDA codings and number of documents scored. Aggregations of elements due to low abundances. Black: agency related governance elements, grey: structure related governance elements. Governance elements as specified by (Davis et al., 2013b). Categories for drivers and interventions adapted from (Hosonuma et al., 2012) and (Agrawal et al., 2014).

\subsubsection{Quantitative scoring}

Based on all coded text parts in a specific document, Likert scores (Likert, 1932) were applied to quantify effects of governance elements and context factors (Tab. 4). Identifying governance components and assigning scales meant interpreting the meaning of the texts. In case that negative governance was reported in the studies, the deforestation effect was inverted to make it comparable to studies reporting on positive governance: when e.g. negative governance within executive agencies was linked to higher deforestation (negative effect of negative governance) the effect of improved governance within executive agencies was assumed to be positive and high scores were given (equal to positive effects of positive governance). The scores for individual governance elements and context factors per study are presented in Table 5. These scores were input for further quantitative statistics (see sections 4.2 and 4.3 ). 


\begin{tabular}{|l|l|}
\hline Governance element or context factor is .... & $\begin{array}{l}\text { Likert } \\
\text { score }\end{array}$ \\
\hline $\begin{array}{l}\text {...strongly linked to increased deforestation (degradation) or decreased reforestation; strong essential } \\
\text { factor, and/or mentioned in abstract or conclusion as a main factor }\end{array}$ & 1 \\
\hline ...linked to increased deforestation (degradation) or decreased reforestation; clear and substantial effect & 2 \\
\hline $\begin{array}{l}\text {... slightly linked to increased deforestation (degradation) or decreased reforestation; small documented } \\
\text { effect }\end{array}$ & 3 \\
\hline ...not linked to deforestation, no effect, or both: positive and negative effects & 4 \\
\hline $\begin{array}{l}\text {...slightly linked to reduced deforestation (degradation) or increased reforestation; small documented } \\
\text { effect }\end{array}$ & 5 \\
\hline ...linked to reduced deforestation (degradation) or increased reforestation; clear and substantial effects & 6 \\
\hline $\begin{array}{l}\text {...strongly linked to reduced deforestation (degradation) or increased reforestation; strong essential } \\
\text { factor, and/or mentioned in abstract or conclusion as a main factor }\end{array}$ & 7 \\
\hline
\end{tabular}

Table 4: Likert scale for de-/reforestation effect of governance elements and context factors. 


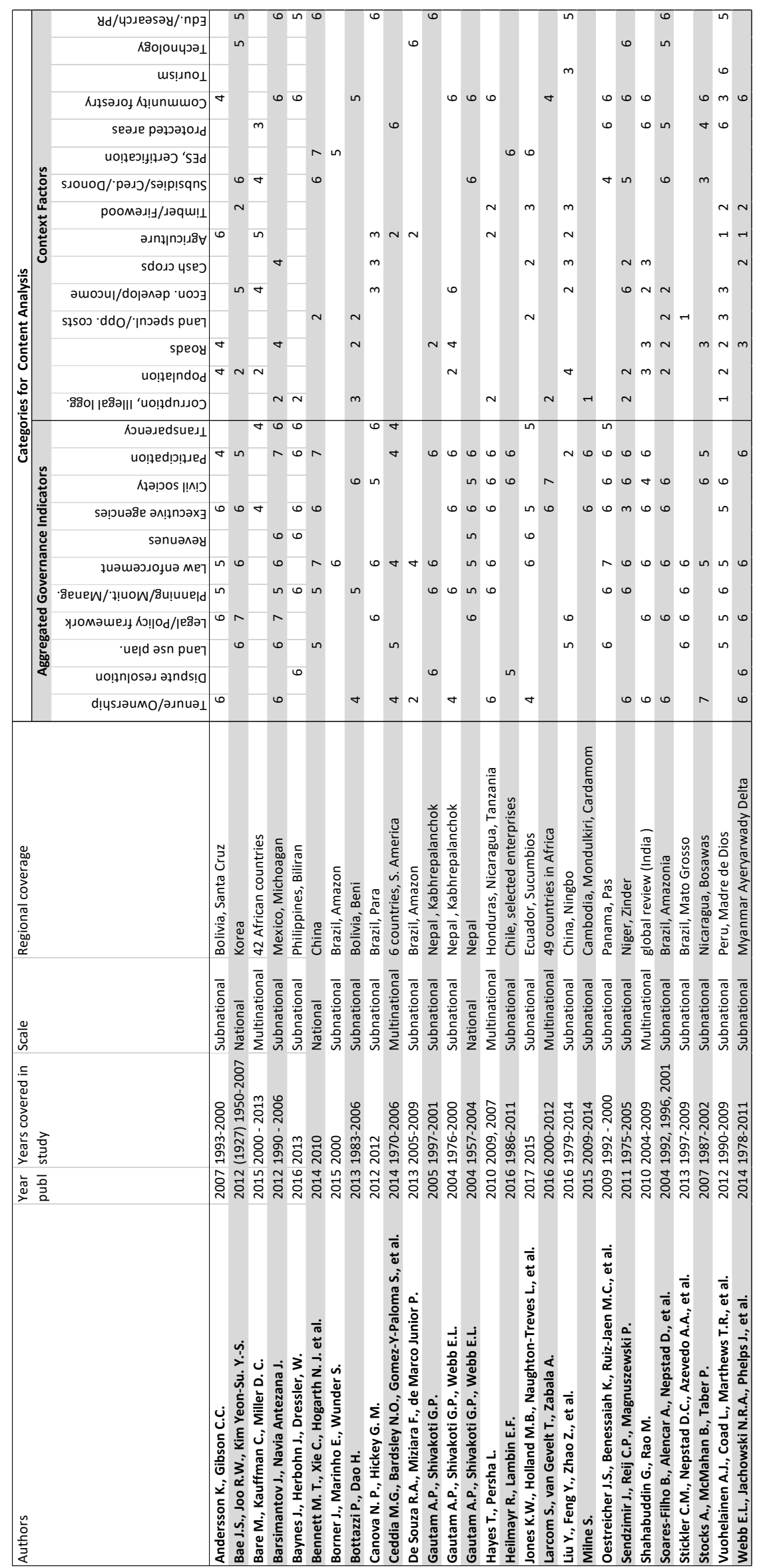

Table 5: Publications selected for the content analysis with scores for governance elements and context factors; blanks indicate "not assessed". 


\subsubsection{Harmonized landscape level governance assessments (Nansikombi et al., 2020; Fischer et al., submitted)}

Numerous forest governance field studies have been conducted and published. Given the wide range of governance definitions (see section 2.1.3) and research aims there is a corresponding range of field assessment methods. A landscape level approach for assessing governance at the field level that is applicable across different context situations and that provides quantitative data for integrated assessments with other components of socio ecological systems like livelihoods, inventory data and satellite information has been missing. Such an approach is presented in this section, because a landscape has been identified as the appropriate scale to examine the various entities that interact with effects on deforestation(Sayer et al., 2013) (see section 2.3). Taking into account specific locally different contexts and peculiarities, the method consists of a frame that needs to be adapted to specific cases on one hand, but allows for comparing results across landscapes and/or countries. It builds on the existing governance definition of (Giessen and Buttoud, 2014) and the assessment framework of the World Resource Institute (Davis et al., 2013b). The method combines qualitative as well as quantitative elements, and requires the participation of the people in the landscapes in participatory mapping exercises and focus group discussions. The main components comprise:

1. Definition of governance arrangements

2. Selection and local adaptation of governance elements

3. Focus group discussions for governance quality scoring by Likert scores

The governance assessment method has been tested and applied between 2016 and 2018 in the context of the LaForeT project (www.la-foret.org). The project is based on 36 research landscapes in Ecuador, Zambia and the Philippines. Together, the landscapes cover approximately 500,000 hectares of land.

\subsubsection{Governance arrangements}

Within a landscape, varying governance mechanisms can be in place. Therefore, governance arrangements need to be determined and assigned as homogenous governance units for the assessment of governance quality on finer scales within landscapes. The term "governance arrangement" is used widely but inhomogenously in current literature. It can e.g. mean the constellation of international forest policies and mechanisms (Rayner et al., 2010) or resources and mechanisms needed to tackle the challenges of sustainable forest management in general (Weiland and Dedeurwaerdere, 2010). In most cases, it is used without specific definition. In this study, governance arrangements are defined as spatial units with homogeneous governance concerning ownership and management objectives including conservation status. Governance arrangements are determined in a way that variation of governance structures within arrangements is minimized whereas variation between governance arrangements in a landscape is maximized. Governance arrangements can be classified and adapted during scoping visits. Locally occurring arrangements can be assigned to general categories by applying a coding system (Tab. 6) which enables cross country analysis based on comparable categories. The system is organized hierarchically in order to enable grouping and aggregation. The first hierarchy level refers to the ownership as defined by (FAO, 2015), whereas 'communal' refers to 'ownership by local, tribal or indigenous communities', 'private' refers to 'private ownership by individuals' and 'state' refers to 'public ownership by the state'. The second hierarchy level refers to land titles, whereas land tiles mean that ownership is formally recognized by 
a cadastral system. The third hierarch level refers to use restrictions, whereas 'restricted land' means 'forest area within protected areas' according to (FAO, 2015). 'Formal' restriction identifies a protection status under state legislation. 'Customary' restriction means protection under traditional and indigenous governance systems.

\begin{tabular}{|c|c|c|c|}
\hline General code system & $\begin{array}{l}\text { Specific arrangements } \\
\text { Ecuador }\end{array}$ & $\begin{array}{l}\text { Specific arrangements } \\
\text { Zambia }\end{array}$ & $\begin{array}{l}\text { Specific arrangements } \\
\text { Philippines }\end{array}$ \\
\hline \multicolumn{4}{|l|}{ 1. communal } \\
\hline \multicolumn{4}{|l|}{1.1 communal, no title } \\
\hline $\begin{array}{l}1.1 .1 \text { individually } \\
\text { managed land }\end{array}$ & communal (2) & $\begin{array}{l}\text { customary individual } \\
\text { (24) }\end{array}$ & \\
\hline $\begin{array}{l}1.1 .2 \text { jointly managed } \\
\text { land }\end{array}$ & & $\begin{array}{l}\text { customary communal } \\
(22)\end{array}$ & \\
\hline $\begin{array}{l}1.1 .3 \text { customary } \\
\text { restricted land }\end{array}$ & & culturally restricted (8) & \\
\hline \multicolumn{4}{|l|}{$\begin{array}{l}\text { 1.1.4 formally restricted } \\
\text { land }\end{array}$} \\
\hline 1.2 communal with title & & & $\begin{array}{l}\text { PACBRMA * } \\
\text { CADT * } \\
\text { CBFM * }\end{array}$ \\
\hline $\begin{array}{l}1.2 .1 \text { individually } \\
\text { managed land }\end{array}$ & communal (29) & $\begin{array}{l}\text { customary individual } \\
\text { (2) }\end{array}$ & \\
\hline \multicolumn{4}{|l|}{$\begin{array}{l}1.2 .2 \text { jointly managed } \\
\text { land }\end{array}$} \\
\hline $\begin{array}{l}1.2 .3 \text { customary } \\
\text { restricted land }\end{array}$ & $\begin{array}{l}\text { indigenous reserves } \\
\text { (7) }\end{array}$ & & \\
\hline $\begin{array}{l}\text { 1.2.4 formally restricted } \\
\text { land }\end{array}$ & Socio Bosque (6) & & \\
\hline 2. private & & private (8) & ISF*, IPR * (3) \\
\hline \multicolumn{4}{|l|}{2.1 private, no title } \\
\hline $\begin{array}{l}2.1 .1 \text { managed } \\
\text { unrestricted land }\end{array}$ & individual (7) & & \\
\hline \multicolumn{4}{|l|}{ 2.1.2 restricted land } \\
\hline \multicolumn{4}{|l|}{2.2 private with title } \\
\hline $\begin{array}{l}\text { 2.2.1 managed } \\
\text { unrestricted land }\end{array}$ & individual (26) & & \\
\hline \multicolumn{4}{|l|}{ 2.2.2 restricted land } \\
\hline \multicolumn{4}{|l|}{ 3. state } \\
\hline 3.0.1 restricted & PANE* (3) & $\begin{array}{l}\text { state forests with } \\
\text { restrictions (6) }\end{array}$ & $\begin{array}{l}\text { state forest with } \\
\text { logging ban (10) }\end{array}$ \\
\hline \multicolumn{4}{|l|}{ 3.0.2 unrestricted } \\
\hline $\begin{array}{l}\text { 4. overlapping claims, } \\
\text { unclarified tenure }\end{array}$ & & $\begin{array}{l}\text { overlapping claims } \\
\text { (21) }\end{array}$ & \\
\hline
\end{tabular}

Table 6: Governance arrangements with general code system and specific arrangements as applied in landscapes of Ecuador (ECU), Zambia (ZMB) and the Philippines (PHI) within the LaForeT project. In the country columns names of the locally determined arrangements are indicated. Single subcategories were grouped in a number of cases in order to enable meaningful statistical evaluations. (in brackets: number of cases evaluated within the LaForeT project).

* CADT - Certificate of Ancestral Domain Title

CBFM - Community Based Forest Management Agreement

IPR - Individual Property Rights

ISF - Integrated Social Forestry

PACBRMA - Protected Area Community Based Resource Management Agreement PANE - Heritage of Natural Areas (Patrimonio de Áreas Naturales del Estado)

Country specific governance arrangements were designated and mapped (Tab. 6). They take into account and are based on the specific forest ownership and tenure situation of the respective 
countries as described in (Fischer et al., submitted) as well as in Annex 1. Seven different governance arrangement types were designated in Ecuador during scoping visits in the LaForeT project area and mapped during the participatory exercises. For further statistical evaluations, the seven arrangements in the project landscapes of Ecuador were grouped into four categories, namely communal, individual, indigenous reserves together with Socio Bosque and state protected areas (PANE). In Zambia, seven types of governance arrangements were designated. For further statistical evaluations these seven arrangements in the project landscapes of Zambia were grouped into six categories, namely customary communal, customary individual, culturally restricted, state restricted, overlapping claims and private land. For private land, however, governance quality could not be assessed, even though they were delineated and mapped. In the Philippines, 5 types of governance arrangements were designated. For further statistical evaluations these five arrangements in the project landscapes of the Philippines were grouped into three categories, namely CBFM (Community Based Forest Management Agreement), other systems with assigned tenure (including PACBRMA, CADT, ISF, IPR), and state forests. In the Philippines, the grouping into categories did not strictly follow the hierarchy of the general governance arrangement systems (see Tab. 6), as within the 'other systems' communal and individual arrangements are grouped. This is due to the specific research focus on CBFM and the low number of cases that did not allow to assign more single categories. The governance arrangements in the three countries of Ecuador, Zambia and the Philippines are examples that show that they are in all cases country specific and their designation requires local governance understanding. Yet, based on the code table (see Tab. 6) they can, if necessary, be aggregated and compared.

\subsubsection{Selection, local adaptation and assessment of governance elements}

Within specified governance arrangements the quality of de facto governance on the ground was assessed by adapting the Governance of Forests Initiatives Framework of the World Resource Institute (WRI) to the specific context. The framework offers a comprehensive diagnostic tool that covers six thematic areas, including (i) forest tenure, (ii) land use planning, (iii) forest management, (iv) forest revenues, (v) institutions and (vi) crosscutting issues (Davis et al., 2013a). The framework assesses these thematic areas through a set of governance elements, each specified by elements of quality (indicators) that are rated on a scale of pre-coded statements, which are understood to range from poor performance to good practice. The assessment tool postulates that elements should be contextualized in order to better fit local needs and it is not foreseen that all elements are assessed, which would be beyond the scope of research relying on input from local communities. Therefore, the selection of elements to be assessed is a crucial step in the design of governance studies. Selected elements need to capture factors that most strongly determine and differentiate local governance in a sense that they are related to deforestation, reforestation or sustainable forest management. The selection of governance elements within the study took into account a number of criteria and aimed to

(i) cover several thematic areas of the WRI framework (Davis et al., 2013b)

(ii) comprise agency and structure related elements (see Tab. 2) (Fischer et al., 2020)

(iii) include elements that are among the most frequently assessed elements as these obviously are perceived to be the most relevant ones (Fischer et al., 2020)

(iv) exclude elements aiming at national de jure governance (e.g. legislative institutions, policy framework)

(v) exclude elements not relevant and applicable in the specific context (e.g. performance of civil society organizations if no NGOs were present in the area) 
(vi) be assessable with the given project resources

The selection was carried out after scoping trips and relied on secondary information about the study area.

Within LaForeT, 8 elements were assessed in Ecuador for 25 specific governance arrangement patches. 19 elements were assessed and evaluated for 80 patches in Zambia and in the Philippines 16 elements were assessed for 22 patches (Tab. 7). The full list of elements with indicators is presented in Annex 2.

\begin{tabular}{|l|l|l|l|l|}
\hline $\begin{array}{l}\text { Thematic Area } \\
\text { (WRI) }\end{array}$ & Governance element & ECU & ZMB & PHI \\
\hline Forest tenure & Forest tenure & $\mathrm{X}$ & $\mathrm{X}$ & $\mathrm{X}$ \\
\hline Land use & Land use decision making. & & $\mathrm{X}$ \\
\hline $\begin{array}{l}\text { Forest } \\
\text { Management }\end{array}$ & Implementation of strategies and plans. & $\mathrm{X}$ \\
\hline & Protection of natural forest (logging moratorium). & $\mathrm{X}$ \\
\hline & Formal law enforcement & & $\mathrm{X}$ \\
\hline & Customary law enforcement & $\mathrm{X}$ & $\mathrm{X}$ \\
\hline & Implementation of National Greening Programme (NGP) & \\
\hline & Reforestation (not for NGP reforestation areas) & $\mathrm{X}$ & $\mathrm{X}$ \\
\hline & Protection and conservation & & $\mathrm{X}$ \\
\hline & Timber harvesting licenses and permits & $\mathrm{X}$ \\
\hline & Non-timber forest product harvesting licenses and permits. & $\mathrm{X}$ & $\mathrm{X}$ \\
\hline & Charcoal licenses and permits & $\mathrm{X}$ & $\mathrm{X}$ \\
\hline & Programmes for supporting of forest-based sustainable livelihoods. & $\mathrm{X}$ & $\mathrm{X}$ \\
\hline & Payment for Ecosystem Services (PES) & $\mathrm{X}$ & \\
\hline & Revenues & $\mathrm{X}$ & $\mathrm{X}$ \\
\hline & Benefit sharing mechanisms & $\mathrm{X}$ & $\mathrm{X}$ \\
\hline Revenues & $\mathrm{X}$ & $\mathrm{X}$ & $\mathrm{X}$ & \\
\hline & Central government institutions. & $\mathrm{X}$ & \\
\hline Institutions & Local government institutions. & $\mathrm{X}$ & \\
\hline & Non-governmental institutions. & $\mathrm{X}$ & $\mathrm{X}$ \\
\hline & Customary institutions. & $\mathrm{X}$ & $\mathrm{X}$ \\
\hline $\begin{array}{l}\text { Cross cutting } \\
\text { issues }\end{array}$ & Public participation in policy making & $\mathrm{X}$ & $\mathrm{X}$ \\
\hline Number of elements evaluated & $\mathrm{X}$ & $\mathrm{X}$ & $\mathrm{X}$ & $\mathrm{X}$ \\
\hline & & $\mathbf{8}$ & $\mathbf{1 9}$ & $\mathbf{1 6}$ \\
\hline
\end{tabular}

Table 7: Governance elements evaluated in Ecuador (ECU), Zambia (ZMB) and the Philippines (PHI) within the LaForeT Project.

\subsubsection{Governance quality assessments with Likert scores in focus group discussions}

Within the presented methodology, governance elements were assessed within focus group discussions through specific indicators. Each indicator was scored on a five point Likert score (Likert, 1932) on a scale from 0 (not existing), 1 (very low) to 5 (very high). Scores of the indicators were aggregated by averaging them to a mean per governance element. In many cases, several governance arrangements could be discussed and scored by the same focus group, if e.g. within a given landscape the same community members were responsible for communal lands, restricted lands and individually managed patches of land. Prior to scoring the quality, mapping was carried out and created awareness for the different governance arrangements.

\subsubsection{Results of governance measurements in Ecuador, Zambia and the Philippines}

The country specific analysis of governance effects on deforestation as a basis for policy recommendations in the countries needs a deeper understanding and interpretation of governance 
quality in the specific landscapes and governance arrangements. Such an analysis is beyond the scope of this study that aims to determine functional relationships between governance elements in general. It is presented in (Fischer et al., submitted) and (Nansikombi et al., submitted). In this section, the quantitative results of governance assessments are thus summarized in order to present the data that are then further analyzed by quantitative statistics (see section 4.2).

In the assessed landscapes of Ecuador (Tab. 8), Socio Bosque and indigenous reserves showed highest mean governance scores. Scores for Socio Bosque and indigenous reserves were almost consistently the highest for all single governance elements as compared to other arrangements. Specifically for tenure, the mean almost reached the maximum. The difference in mean governance scores between communal and individual properties was not significant. PANE areas could not be compared statistically, as only two of them occurred in the analyzed landscapes.

\begin{tabular}{|c|c|c|c|c|c|c|c|c|c|}
\hline \multirow{3}{*}{$\begin{array}{l}\text { Thematic } \\
\text { area }\end{array}$} & \multirow{3}{*}{ Element } & \multicolumn{8}{|c|}{ Governance arrangements } \\
\hline & & \multicolumn{2}{|c|}{$\begin{array}{l}\text { Communal } \\
\text { indigenous } \\
\text { reserves / } \\
\text { Socio } \\
\text { Bosque }\end{array}$} & \multicolumn{2}{|c|}{ Communal } & \multicolumn{2}{|c|}{ Individual } & \multicolumn{2}{|c|}{$\begin{array}{l}\text { State } \\
\text { protected } \\
\text { (PANE) }\end{array}$} \\
\hline & & $\mathbf{N}$ & Mean & $\mathbf{N}$ & Mean & $\mathbf{N}$ & Mean & $\mathbf{N}$ & Mean \\
\hline Forest tenure & Tenure & 7 & $4.5^{\mathrm{A}}$ & 10 & $3.3^{\mathrm{B}}$ & 6 & $3.0^{\mathrm{B}}$ & 2 & $3.2^{-}$ \\
\hline \multirow{2}{*}{$\begin{array}{l}\text { Forest } \\
\text { management }\end{array}$} & Forest management practices* & 7 & $3.8^{\mathrm{A}}$ & 10 & $3.5^{\mathrm{A}}$ & 6 & $3.4^{\mathrm{A}}$ & 2 & $2.7^{-}$ \\
\hline & Law enforcement & 7 & $3.9^{\mathrm{A}}$ & 10 & $3.6^{\mathrm{A}}$ & 6 & $3.0^{\mathrm{A}}$ & 2 & $3.1^{-}$ \\
\hline Institutions & Institutions & 7 & $2.1^{\mathrm{A}}$ & 10 & $2.2^{\mathrm{A}}$ & 6 & $1.8^{\mathrm{A}}$ & 2 & $1.3^{-}$ \\
\hline Cross cutting & Participation & 7 & $3.6^{\mathrm{A}}$ & 10 & $1.8^{\mathrm{B}}$ & 6 & $1.9^{\mathrm{B}}$ & 2 & $1.7^{-}$ \\
\hline \multicolumn{2}{|c|}{ Mean governance } & 7 & $3.6^{\mathrm{A}}$ & 10 & $2.8^{A B}$ & 6 & $2.7^{B}$ & 2 & 2.4 \\
\hline
\end{tabular}

Table 8: Mean governance scores by thematic area, elements and governance arrangement for LaForeT landscapes in Ecuador. Arrangements that do not share similar capital letters are significantly different $(p<0.05)$ as result of the Wilcoxon Test (WIcx); N: number of patches; Mean: mean governance. For PANE areas, only the mean is reported; they are excluded from the test due to the low sample size of 2.

*composite governance element composed of different elements per governance arrangement based on timber licenses, protection/conservation and payments for ecosystem services.

In Zambia (Nansikombi et al., 2020), more elements were assessed than in Ecuador, as a number of elements were included that were applicable only on some governance arrangement patches. The mean scores of the nine governance elements applicable for all sites was very low, with values between 1.23 and 1.51 per governance arrangement. The mean scores did not differ significantly between governance arrangements (Tab. 9). When site-specific elements were added, the final mean governance score remained low, with values between 1.47 and 1.98 and the final mean governance scores did as well not differ significantly between governance arrangements. As regards single elements, only the element of tenure rights recognition scored consistently above a mean Likert score of 3 in all arrangements. This element scored significantly higher in the customary than in state arrangements. Scores for conservation and use restrictions were significantly high on culturally restricted lands. These areas are mostly graveyards where the customary rules were strictly respected. 


\begin{tabular}{|c|c|c|c|c|c|c|c|c|c|c|c|}
\hline \multirow{3}{*}{$\begin{array}{l}\text { Thematic } \\
\text { area }\end{array}$} & \multirow{3}{*}{ Element } & \multicolumn{10}{|c|}{ Governance arrangements } \\
\hline & & \multicolumn{2}{|c|}{$\begin{array}{l}\text { State, } \\
\text { restricted }\end{array}$} & \multicolumn{2}{|c|}{$\begin{array}{l}\text { Culturally } \\
\text { restricted }\end{array}$} & \multicolumn{2}{|c|}{$\begin{array}{l}\text { Customary } \\
\text { communal }\end{array}$} & \multicolumn{2}{|c|}{$\begin{array}{l}\text { Customary } \\
\text { individual }\end{array}$} & \multicolumn{2}{|c|}{$\begin{array}{l}\text { Over-lapping } \\
\text { claims }\end{array}$} \\
\hline & & $\mathbf{N}$ & Mean & $\mathbf{N}$ & Mean & $\mathbf{N}$ & Mean & $\mathbf{N}$ & Mean & $\mathbf{N}$ & Mean \\
\hline Forest tenure & Tenure & 6 & $3.28^{\mathrm{B}}$ & 8 & $4.08^{\mathrm{A}}$ & 22 & $3.85^{\mathrm{AB}}$ & 24 & $4.08^{\mathrm{A}}$ & 20 & $3.91^{\mathrm{AB}}$ \\
\hline Land use plan & Land use planning & 6 & $0.58^{\mathrm{A}}$ & 8 & $0.00^{\mathrm{B}}$ & 22 & $0.23^{\mathrm{B}}$ & 24 & $0.21^{B}$ & 20 & $0.50^{\mathrm{AB}}$ \\
\hline \multirow{8}{*}{$\begin{array}{l}\text { Forest } \\
\text { management }\end{array}$} & Land use plans and strategies & 3 & 1.79 & - & NA & - & NA & - & NA & - & NA \\
\hline & $\begin{array}{l}\text { Conservation and use } \\
\text { restrictions* }\end{array}$ & 6 & $1.63^{B}$ & 8 & $4.23^{A}$ & 22 & $1.28^{\mathrm{B}}$ & 24 & $1.43^{B}$ & 20 & $1.43^{\mathrm{B}}$ \\
\hline & $\begin{array}{l}\text { Non-timber forest products } \\
\text { license }\end{array}$ & 1 & $2.17^{\mathrm{A}}$ & - & NA & 1 & $2.17^{\mathrm{A}}$ & 1 & $2.17^{\mathrm{A}}$ & 1 & $2.17^{A}$ \\
\hline & Reforestation & 2 & $2.20^{\mathrm{A}}$ & - & NA & - & NA & 2 & $2.90^{\mathrm{A}}$ & - & NA \\
\hline & Forest based livelihood programs & 1 & $3.00^{\mathrm{A}}$ & - & NA & 3 & $2.28^{\mathrm{A}}$ & 6 & $3.14^{\mathrm{A}}$ & 5 & $2.48^{\mathrm{A}}$ \\
\hline & $\begin{array}{l}\text { Payment of ecosystem service } \\
\text { program }\end{array}$ & - & NA & - & NA & - & NA & - & NA & - & NA \\
\hline & Formal law enforcement & 6 & $2.03^{\mathrm{A}}$ & 8 & $0.50^{\mathrm{BC}}$ & 22 & $1.0^{\mathrm{ABC}}$ & 24 & $0.49^{c}$ & 20 & $0.79^{\mathrm{B}}$ \\
\hline & Customary law enforcement & 6 & $0.58^{\mathrm{A}}$ & 8 & $1.98^{\mathrm{A}}$ & 22 & $1.59^{\mathrm{A}}$ & 24 & $1.41^{\mathrm{A}}$ & 20 & $1.49^{\mathrm{A}}$ \\
\hline \multirow[t]{2}{*}{ Revenues } & Benefit sharing mechanisms & - & NA & - & NA & - & NA & - & NA & - & NA \\
\hline & Forest revenue & 3 & $2.28^{\mathrm{A}}$ & - & NA & 9 & $1.67^{\mathrm{A}}$ & 10 & $2.08^{\mathrm{A}}$ & 8 & $1.84^{\mathrm{A}}$ \\
\hline \multirow[t]{4}{*}{ Institutions } & Central government & 6 & $1.92^{\mathrm{A}}$ & 8 & $1.34^{\mathrm{A}}$ & 22 & $1.65^{\mathrm{A}}$ & 24 & $1.66^{\mathrm{A}}$ & 20 & $1.57^{\mathrm{A}}$ \\
\hline & Local government & 6 & $0.02^{\mathrm{AB}}$ & 8 & $0.06^{\mathrm{AB}}$ & 22 & $0.07^{\mathrm{B}}$ & 24 & $0.07^{B}$ & 20 & $0.16^{A}$ \\
\hline & Customary institutions & 6 & $1.54^{\mathrm{A}}$ & 8 & $1.39^{\mathrm{A}}$ & 22 & $2.20^{\mathrm{A}}$ & 24 & $1.76^{\mathrm{A}}$ & 20 & $1.69^{A}$ \\
\hline & Non-government organizations & 2 & $3.30^{\mathrm{A}}$ & - & NA & 3 & $3.53^{\mathrm{A}}$ & 3 & $3.53^{\mathrm{A}}$ & 4 & $4.00^{A}$ \\
\hline Crosscutting & Public policy participation & 6 & $0.00^{\mathrm{A}}$ & 8 & $0.00^{\mathrm{A}}$ & 22 & $0.00^{\mathrm{A}}$ & 24 & $0.00^{\mathrm{A}}$ & 20 & $0.00^{\mathrm{A}}$ \\
\hline \multicolumn{2}{|c|}{$\begin{array}{l}\text { Mean Governance score ( } 9 \text { elements applicable in } \\
\text { all sites) }\end{array}$} & 6 & $1.29^{\mathrm{A}}$ & 8 & $1.51^{\mathrm{A}}$ & 22 & $1.32^{\mathrm{A}}$ & 24 & $1.23^{\mathrm{A}}$ & 20 & $1.28^{\mathrm{A}}$ \\
\hline \multicolumn{2}{|c|}{$\begin{array}{l}\text { Mean Governance score (aggregated for all } 19 \\
\text { elements) }\end{array}$} & 6 & $1.98^{\mathrm{A}}$ & 8 & $1.53^{\mathrm{A}}$ & 22 & $1.47^{\mathrm{A}}$ & 24 & $1.68^{\mathrm{A}}$ & 20 & $1.68^{\mathrm{A}}$ \\
\hline
\end{tabular}

Table 9: Mean governance scores by thematic area, elements and governance arrangement for LaForeT landscapes in Zambia. Arrangements not connected by the same letter are significantly different at $p<0.05$ with non-parametric Wilcoxon test. $N=80$. Elements highlighted in orange are applicable in all sites.

*composite element composed of different element per governance arrangement based on timber licenses, charcoal licenses and protection/conservation. Adapted from: (Nansikombi et al., 2020)

In the Philippines, 9 governance elements were assessed that were applicable in each of the patches (Tab. 10). In addition, 6 elements were assessed that were not always applicable. State forest governance was compared to CBFM and other tenure types (CADT, PACBRMA and ISF/IPR). The scores of the other tenure types were summarized due to their low sample size in order to enable meaningful statistics. The results did not show a significant difference in the overall governance mean of CBFMA and other tenures, irrespective whether all elements are evaluated or only those applicable in all cases. However, a significant difference was observed between CBFM and other tenures as compared to state forests. Communities with formalized tenure systems had higher governance scores as compared to land in state forests. 


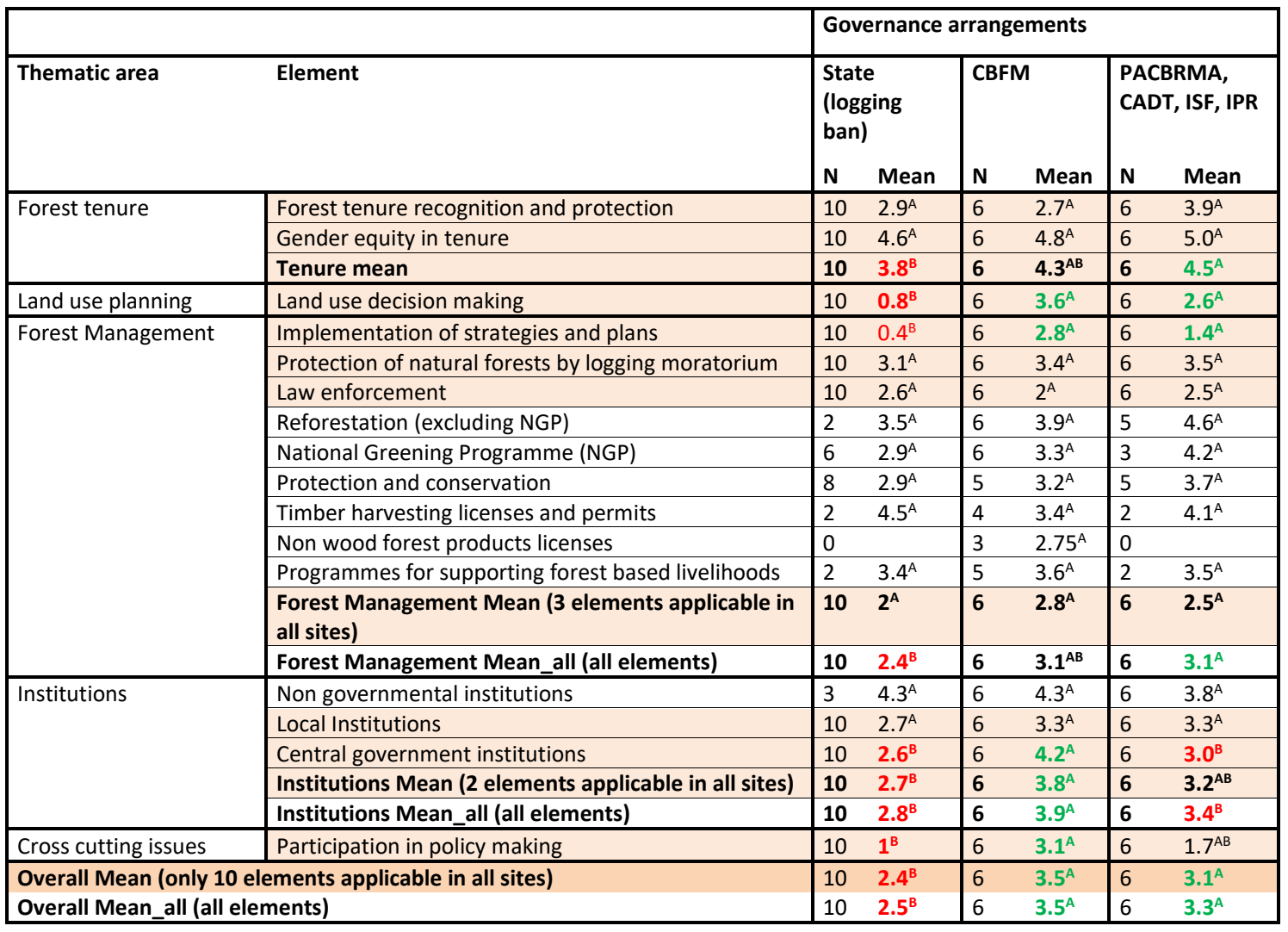

Table 10: Mean governance scores by thematic area, elements and governance arrangement for LaForeT landscapes in the Philippines. Arrangements not connected by the same letter are significantly different at $p<0.05$ with non-parametric Wilcoxon test. $N=22$. Elements highlighted in orange are applicable in all sites.

\subsection{Functional relationships between governance elements}

\subsubsection{Underlying governance factors explained by agency and structure elements}

Irrespective of specific elements, the main theoretical basis of forest governance has been claimed to consist of two mainstream models: rational choice and neo-institutionalism, otherwise described as agency - structure concept, which thus provides a theoretical basis to better understand and describe governance approaches (Arts et al., 2014) (see section 2.1.2). The data sets of this study as derived in a global review through quantitative content analysis (see section 4.1.1) as well as from landscape level field assessments (see section 4.1.2) were thus analyzed under this agency - structure perspective in order to substantiate and evaluate the general assumption.

\subsubsection{Agency and structure mechanisms in global review data (Fischer et al., 2020)}

Principal component analysis (PCA) was applied in order to identify independent gradients within the governance elements tackled in the studies of the review (see section 3.3.2) (Peres-Neto et al., 2003). The results reveal nine components with eigenvalues above 1.0. The first four components explained nearly half of the total variance (Tab. 11). On the first component, nearly all elements for both, agency and structure elements, showed positive loadings. On the second component, structure elements on the negative end were separated from agency elements grouped towards the positive end. Also on the first and third component a certain, yet less distinct separation of agency and structure elements could be observed. On the first three components, that together describe $38 \%$ of the variance in governance elements, agency related elements thus could be distinguished from 
structure elements. On the fourth and the other remaining components (not depicted) there was no distinct pattern of agency and structure related elements. The biplot of the first and the second component summarizes these findings and depicts that structure elements were rather grouped and separated from agency elements mainly along component 2 (Fig. 1).

The results show that within the 28 studies evaluated, part of the variation in governance can be explained by a pattern of structural versus agency elements. A structural functioning of forest governance becomes visible, which can be separated from an agency related mechanism, even though that agency elements were not grouped so distinctively.

\begin{tabular}{|c|c|c|c|c|c|c|c|}
\hline \multicolumn{2}{|c|}{ Component1 } & \multicolumn{2}{|c|}{ Component2 } & \multicolumn{2}{|c|}{ Component3 } & \multicolumn{2}{|c|}{ Component4 } \\
\hline $16.46 \%$ & & $12.18 \%$ & & $9.39 \%$ & & 8.92 & \\
\hline 3.46 & & 2.56 & & 1.97 & & 1.87 & \\
\hline LUimplement & 0.82 & Revenues & 0.76 & Monitoring & 0.67 & Dispute & 0.57 \\
\hline Transparency & 0.64 & Benefit & 0.63 & Charges & 0.56 & Private & 0.52 \\
\hline Fra me work & 0.60 & Transparency & 0.58 & Civil & 0.49 & Executive & 0.50 \\
\hline LUplanning & 0.59 & Dispute & 0.53 & Enforcement & 0.43 & Information & 0.43 \\
\hline Participation & 0.58 & Management & 0.36 & Management & 0.37 & Management & 0.42 \\
\hline Benefit & 0.58 & Private & 0.28 & Strategies & 0.34 & Strategies & 0.40 \\
\hline Enforcement & 0.53 & Monitoring & 0.17 & Ownership & 0.27 & SectoraILU & 0.26 \\
\hline Anticorruption & 0.42 & Charges & 0.10 & SectoraILU & 0.22 & Revenues & 0.19 \\
\hline Revenues & 0.34 & Judiciary & 0.06 & Participation & 0.17 & Ownership & 0.11 \\
\hline Ownership & 0.30 & Civil & -0.01 & Dispute & 0.16 & Enforcement & 0.09 \\
\hline SectoraILU & 0.29 & Participation & -0.10 & LUplanning & 0.11 & LUplanning & 0.07 \\
\hline Dispute & 0.28 & Executive & -0.11 & Revenues & 0.07 & Anticorruption & 0.04 \\
\hline Executive & 0.20 & Anticorruption & -0.13 & LUimplement & 0.06 & Framework & 0.02 \\
\hline Strategies & 0.13 & Ownership & -0.18 & Information & 0.02 & Judiciary & -0.05 \\
\hline Private & 0.11 & Information & -0.24 & Judiciary & -0.01 & Transparency & -0.15 \\
\hline Judiciary & 0.01 & Strategies & -0.25 & Private & -0.03 & Participation & -0.17 \\
\hline Monitoring & -0.01 & Enforcement & -0.28 & Anticorruption & -0.05 & LUimplement & -0.17 \\
\hline Charges & -0.01 & Fra mework & -0.28 & Benefit & -0.14 & Charges & -0.20 \\
\hline Information & -0.08 & LUimplement & -0.31 & Transparency & -0.15 & Monitoring & -0.22 \\
\hline Civil & -0.15 & LUplanning & -0.33 & Executive & -0.36 & Civil & -0.24 \\
\hline Management & -0.23 & SectoraILU & -0.40 & Framework & -0.42 & Benefit & -0.38 \\
\hline
\end{tabular}

Table 11: Loading matrix for the first four principal components of a PCA for governance elements with percentage of explained variance and eigenvalues (in italic). Elements sorted according to the loadings on the respective component; black: agency elements; grey: structure elements. On the first component, nearly all elements load positively. Especially on the second component structure and agency elements are separated with rather antagonistic effects. For abbreviations see Tab. 3. 


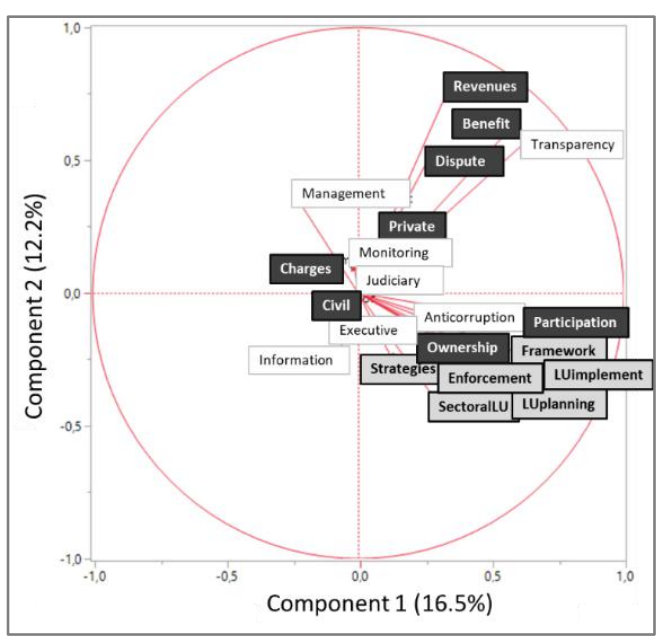

Figure 1: Principal component analysis for governance elements, biplot for $1^{\text {st }}$ and $2^{\text {nd }}$ component. Black: agency elements; grey: structure elements (in brackets: explained variance). For abbreviations see Tab. 3.

\subsubsection{Agency and structure mechanisms on the landscape level}

In the review data, agency and structure could be identified as rather independent underlying mechanisms. Therefore, governance elements from landscape assessments were analyzed in order to substantiate if such a mechanism is effective at the landscape level as well. For this, the field data for governance elements from Ecuador, Zambia and the Philippines (see section 4.1.2) were also classified as either agency related, or structure related or as indifferent (see Tab. 2) following (Fischer et al., 2020). This enabled to analyze them by PCAs in the same way as the review data.

In contrast to the above presented findings, in the three country data sets there was no clear pattern with agency or structure related elements being grouped or differentiated against the others. On none of the principal components with eigenvalues above 1 there was a clear separation or sorting of agency and structure related governance elements (Figs. 2-9). In the data set from Ecuador (Fischer et al., submitted) there was one component with an eigenvalue above one which was most strongly determined by the management and conservation element. Participation had the lowest loading on this component (Tab. 12). Two elements that were not assigned to either structure or agency were loading highest and the agency related elements had the lowest loadings. Also on the second component there was no distinct pattern. Accordingly, the biplot did not show a clear separation (Fig. 3). In the landscape level data set from Zambia there were three components with eigenvalues above 1 (Fig. 4). On none of them there was a distinct differentiation between agency and structure related elements (Tab. 13). Tenure was the only agency related element evaluated in the PCA, as public participation was constantly scored with zero in the focus group discussions and did thus not appear in the PCA. Also for the Philippine data set there were three components with eigenvalues above one (Fig. 6). Land use planning had highest and law enforcement had lowest loadings on the first component (Tab. 14). Agency related elements had an intermediate position. Also on the second and third components there was no differentiation between agency and structure related loadings. In the merged data set that contained elements assessed in all three countries, law enforcement was the only structure related element. It loaded highest on the first component, whereas the agency related elements had lower loadings (Tab. 15). This shows a certain differentiation. On the second component and thus on the biplot there was no clear pattern that separated the two mechanisms (Fig. 9). 
In summary, an agency and structure mechanism could not be substantiated in the data from landscapes in single countries. Instead, specific landscape level dynamics might need to be considered. At a higher scale, i.e. in the merged data set, there were indications for a certain grouping, however there were only five elements present, a generalization thus needs a careful discussion.

\begin{tabular}{|c|c|c|c|}
\hline \multirow{2}{*}{\multicolumn{2}{|c|}{$\begin{array}{llll}20 & 40 & 60 & 80\end{array}$}} & \multirow[b]{2}{*}{ Managem_Cons } & \multirow{2}{*}{$\begin{array}{l}\text { PC1 } \\
0.89\end{array}$} \\
\hline & & & \\
\hline 2,7601 & & Institutions & 0.80 \\
\hline 0,7256 & & Enforcement & 0.78 \\
\hline 0,4880 & & Tenure & 0.67 \\
\hline 0,2069 & & Participation & 0.52 \\
\hline
\end{tabular}

Figure 2: Eigenvalues and cumulated variance explained for five principal components of a PCA for field data from Ecuador. Only components with eigenvalues above 1.0 explain more variation than single variables and are basis for further interpretation.
Table 12: Loading matrix for first principal component (PC) calculated for field data from Ecuador. Loadings above 0.4 in brown. Elements are sorted according to loadings on PC1. Black: elements that are interpreted as agency related; grey: elements interpreted as structure related; white: elements assigned to neither of the two mechanisms. For abbreviations see Tab. 3, partly aggregated elements, following (Fischer et al., submitted).

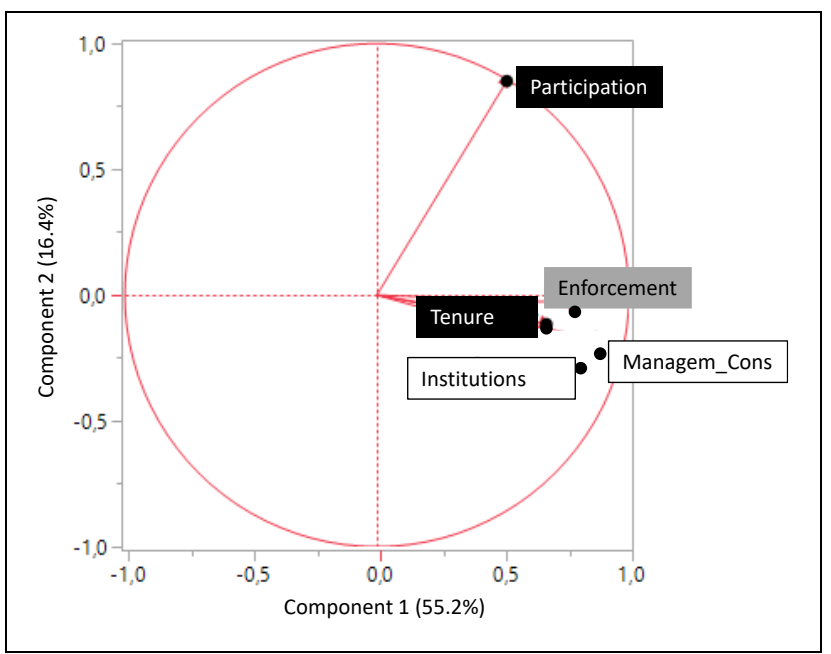

Figure 3: Biplot of first and second principal component calculated for field data from Ecuador. Black: elements that are interpreted as agency related; grey: elements interpreted as structure related; white: elements assigned to neither of the two mechanisms. For abbreviations see Tab. 3, partly aggregated elements, following (Fischer et al., submitted). 


\begin{tabular}{|c|c|c|c|c|c|}
\hline & & & PC1 & PC2 & PC3 \\
\hline \multirow{8}{*}{$\begin{array}{l}2,1514 \\
1,4459 \\
1,2385 \\
0,9853 \\
0,7408 \\
0,5581 \\
0,5197 \\
0,3602\end{array}$} & $\begin{array}{llll}20 & 40 & 60 & 80\end{array}$ & Enforcement_customary & 0.69 & 0.29 & 0.30 \\
\hline & & Executive_national & 0.65 & 0.02 & -0.35 \\
\hline & & Tenure & 0.63 & 0.00 & 0.34 \\
\hline & & Enforcement_formal & 0.56 & -0.36 & -0.37 \\
\hline & & Managem_Cons & 0.52 & -0.66 & 0.19 \\
\hline & & Civil & 0.48 & 0.34 & -0.25 \\
\hline & & LUplanning & 0.21 & 0.76 & 0.32 \\
\hline & & Executive_local & -0.03 & -0.34 & 0.75 \\
\hline
\end{tabular}

Figure 4: Eigenvalues and cumulated variance explained for eight principal components of a PCA for field data from Zambia. Only components with eigenvalues above 1.0 explain more variation than single variables and are basis for further interpretation.
Table 13: Loading matrix for three first principal components (PC) calculated for field data from Zambia. Loadings above 0.4 in brown and below -0.4 in blue. Elements are sorted according to loadings on PC1. Black: elements that are interpreted as agency related; grey: elements interpreted as structure related; white: elements assigned to neither of the two mechanisms. For abbreviations see Tab. 3, "Managem_Cons" is an aggregated element, following (Nansikombi et al., 2020).

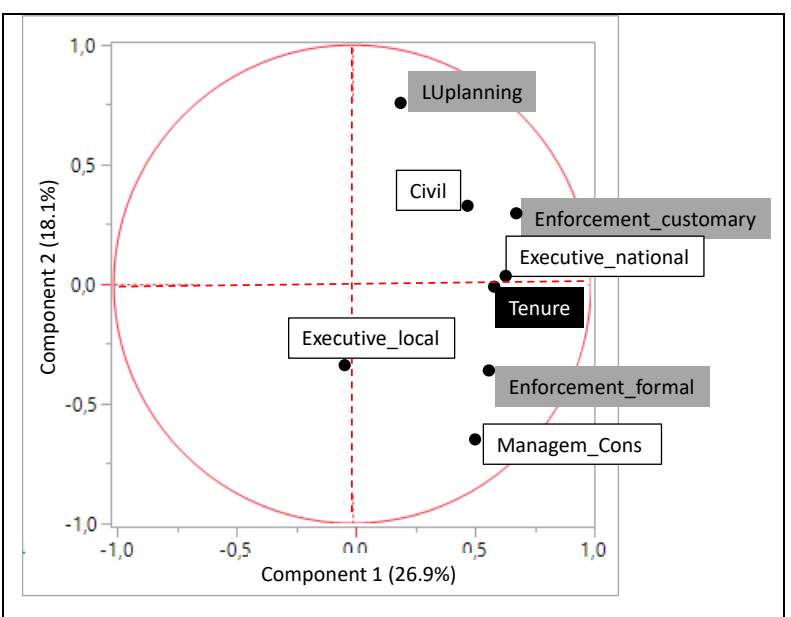

Figure 5: Biplot of first and second principal component calculated for field data from Zambia. Black: elements that are interpreted as agency related; grey: elements interpreted as structure related; white: elements assigned to neither of the two mechanisms. For abbreviations see Tab. 3, "Managem_Cons" aggregated, following (Nansikombi et al., 2020). 


\begin{tabular}{|c|c|c|c|c|c|}
\hline & & & PC1 & PC2 & PC3 \\
\hline & $\begin{array}{llll}20 & 40 & 60 & 80\end{array}$ & LUplanning & 0.87 & -0.31 & 0.04 \\
\hline 3,0219 & & Strategies & 0.78 & -0.28 & -0.19 \\
\hline 2,0150 & & Participation & 0.75 & -0.34 & -0.12 \\
\hline 1,2638 & & Executive_national & 0.73 & 0.18 & -0.10 \\
\hline 0,8793 & 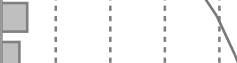 & Tenure & 0.54 & 0.36 & 0.49 \\
\hline $\begin{array}{l}0,6112 \\
0,5115\end{array}$ & & Executive_local & 0.45 & 0.67 & -0.32 \\
\hline 0,4281 & & Managem_Cons & 0.21 & 0.81 & 0.08 \\
\hline 0,1643 & & Tenure_gender & 0.15 & -0.60 & 0.53 \\
\hline 0,1047 & & Enforcement & 0.09 & 0.30 & 0.76 \\
\hline
\end{tabular}

Figure 6: Eigenvalues and cumulated variance explained for nine principal components of a PCA for field data from the Philippines. Only components with eigenvalues above 1.0 explain more variation than single variables and are basis for interpretation.
Table 14: Loading matrix for three first principal components (PC) calculated for field data from the Philippines. Loadings above 0.4 in brown and below -0.4 in blue. Elements are sorted according to loadings on PC1. Black: elements that are interpreted as agency related; grey: elements interpreted as structure related; white: elements assigned to neither of the two mechanisms. For abbreviations see Tab. 3.

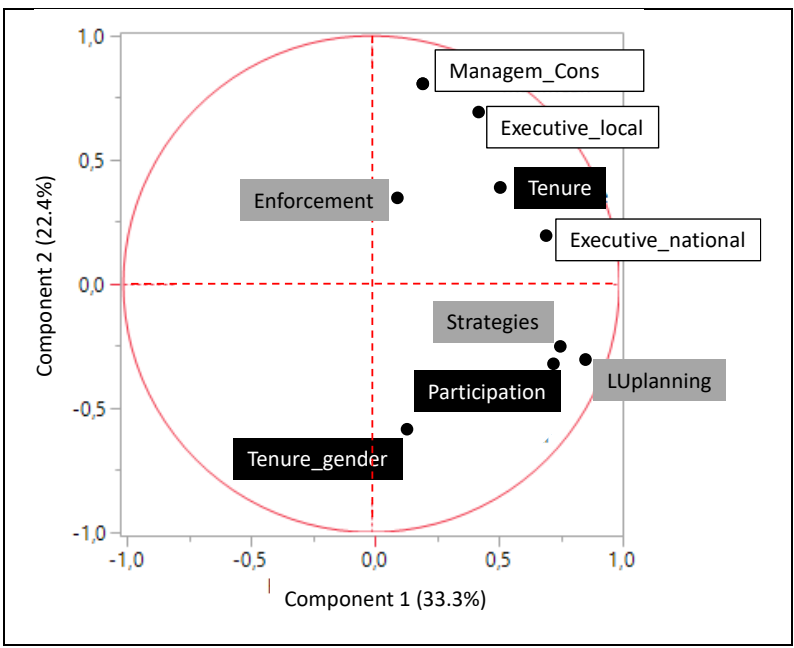

Figure 7: Biplot of first and second principal component calculated for field data from the Philippines. Black: elements that are interpreted as agency related; grey: elements interpreted as structure related; white: elements assigned to neither of the two mechanisms. For abbreviations see Tab. 3. 


\begin{tabular}{|c|c|c|c|c|}
\hline & co to vo uo & & PC1 & PC2 \\
\hline טגנדות & & Enforcement & 0.81 & -0.18 \\
\hline 1,0219 & & Institutions & 0.78 & 0.06 \\
\hline 0,6496 & & Participation & 0.78 & -0.26 \\
\hline 0,4413 & & Managem_Cons & 0.75 & 0.11 \\
\hline 0,3922 & 1 & Tenure & 0.23 & 0.95 \\
\hline
\end{tabular}

Figure 8: Eigenvalues and cumulated variance explained for five principal components of a PCA for merged field data from all three countries. Only components with eigenvalues above 1.0 explain more variation than single variables and are basis for interpretation.
Table 15: Loading matrix for three first principal components (PC) calculated for merged field data from all three countries. Loadings above 0.4 in brown. Elements are sorted according to loadings on PC1. Black: elements that are interpreted as agency related; grey: elements interpreted as structure related; white: elements assigned to neither of the two mechanisms. For abbreviations see Tab. 3.

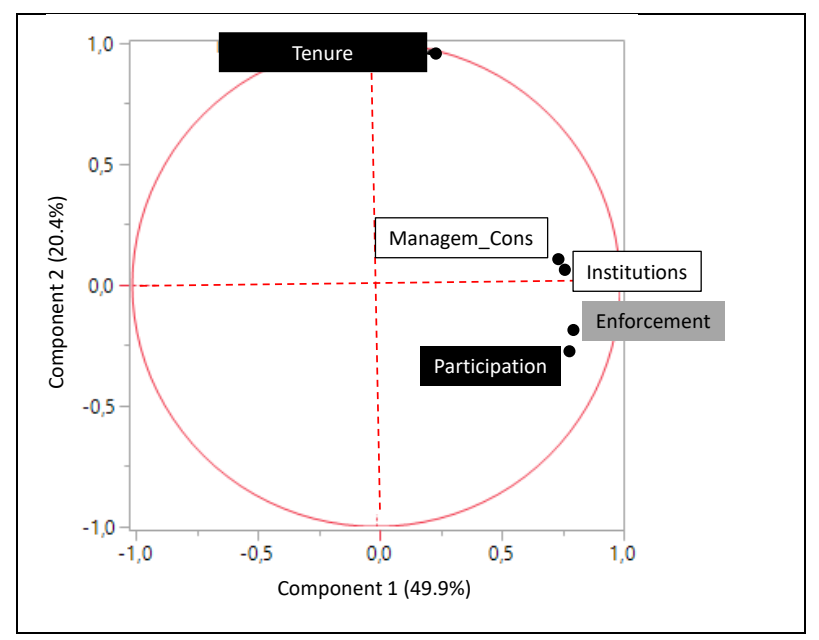

Figure 9: Biplot of first and second principal component calculated for merged field data from all three countries. Black: elements that are interpreted as agency related; grey: elements interpreted as structure related; white: elements assigned to neither of the two mechanisms. For abbreviations see Tab. 3.

\subsubsection{Other independent factors and governance elements explaining them}

The first PCA components were characterized by almost consistently positive loadings of single elements (Tabs. 12 - 15). In the review data set, only 5 out of 21 elements had negative loadings on the first component (Tab. 11). For Zambia only one out of 8 elements, namely local government, loaded negatively on the first component (Tab. 13). In all other country cases the loadings on the first component were (partly strongly) positive. On all first components the governance elements were thus not antagonistic; the elements were solely differentiated by either stronger or weaker positive loadings. Positive bi-variate correlations between single elements confirmed the close relation between element scorings (not depicted). For the data set from Ecuador, 5 out of 10 (50\%) possible correlations between the 5 elements had error probabilities lower than 0.05 . For Zambia, 10 out of 28 possible correlations (38\%) were significant. In the case of the Philippines the share was 5 out of 36 correlations (14\%) and for the merged data set from all three countries it was 8 out of 10 (80\%). 
This finding is closely related to the fact that loadings on the first axis were correlating with mean governance for all data sets (Fig. 10).

Even though their loadings were mainly positive, the order of the single elements on the first components varied strongly. There was no consistent order of the elements in a sense that mostly the same element would have had the highest loading, indicating the strongest influence on mean governance.

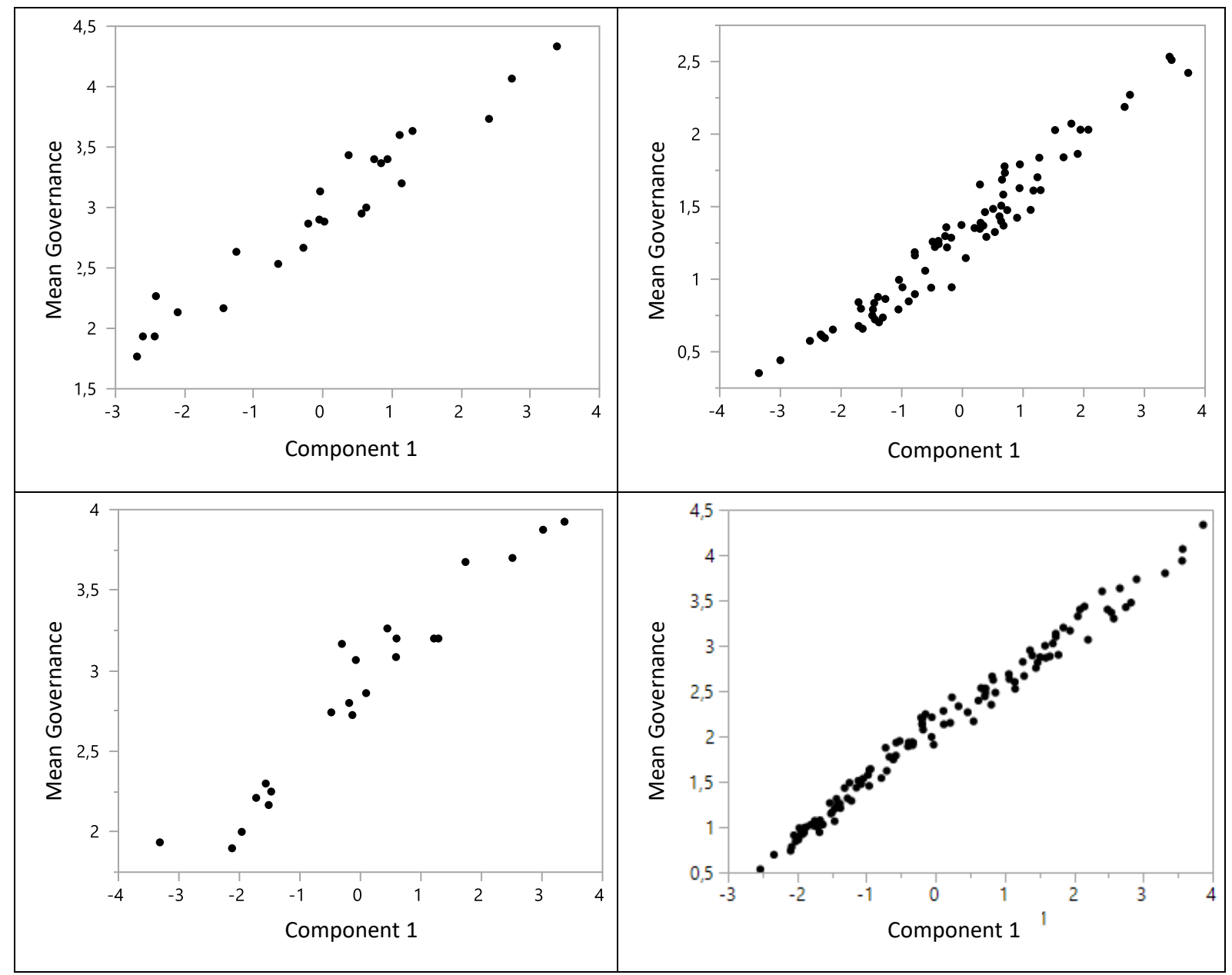

Figure 10: Loadings on first principal components regressed against mean governance for 25 governance arrangements in Ecuador (top left), 80 governance arrangements in Zambia (top right), 22 governance arrangements in the Philippines (bottom left), and 127 governance arrangements in all three countries (bottom right).

In all PCAs, with exception of Ecuador, there were additional second and third components with eigenvalues above 1 . On these components, single elements were partly antagonistic. But also for these components there was no single element or general set of elements that predominantly explained them, but instead country wise different elements that characterized the components (Tabs. 11; 13-15).

The results show that in their relation to a main underlying process (represented by the first component) which closely correlates to mean governance, elements in general act conjointly. However, the importance of single elements for explaining this process varies between the local contexts. Also, additional general mechanisms (expressed by additional components) differ between countries, they are characterized by differing elements. 


\subsection{Effects on tropical deforestation}

\subsubsection{Governance effects on deforestation and most decisive governance elements}

The effects of governance elements on deforestation were of interest in order to substantiate if governance was linked to reduced deforestation. The scores as derived from the quantitative content analysis within the review contained information on deforestation as they explicitly scored effects of governance elements on deforestation. The governance data from field assessments in Ecuador and Zambia were regressed against deforestation rates that were calculated for the respective areas based on satellite data.

For the review data (Fischer et al., 2020), the number of studies with empirical relations of specific governance elements to deforestation was counted and provided quantitative information on governance - deforestation relations. The results show that all governance elements were predominately linked to decreasing deforestation or degradation or to increased reforestation (Fig. 11). Tenure/ownership showed the largest share of controversial results: in five cases it was scored as positive and negative or with no effect and in one study it was related to increased deforestation, whereas in eight studies it was linked to deforestation decrease. It is notable that "not assessed" was the most frequently occurring category, showing that most studies only tackled a small subset of governance elements. Only law enforcement, executive agencies and participation were mentioned in more than half of the studies. A number of elements was not assessed at all in the reviewed studies (Tab. 3).

In order to evaluate if structure or agency indictors had stronger effects on deforestation, the reviewed studies were classified into more agency or more structure related studies by calculating the share of assessed agency to assessed structure elements per study. Neither the share of assessed agency elements, nor the share of assessed structure elements nor the share agency vs. structure elements correlated with the mean governance effects on deforestation (not depicted).

Thus, as all single governance elements showed relations to reduced deforestation, the general hypothesis of high governance scores being generally linked to lower deforestation could not be falsified. But neither a general focus on agency, nor a more pronounced focus on structure elements in the studies resulted in stronger or weaker effects on deforestation. The governance elements that were studied were highly variable and most studies focused on a limited number of elements only. 


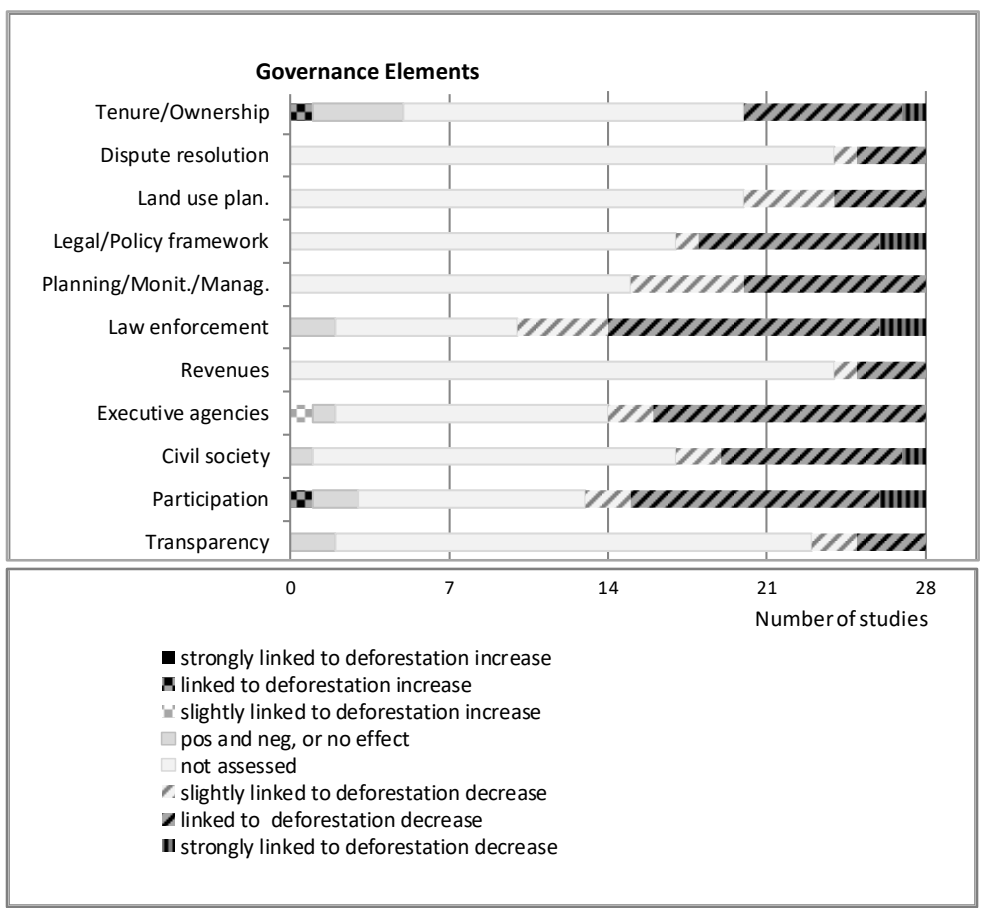

Figure 11: Distribution of Likert scores for relations between aggregated governance elements and deforestation over 28 studies.

For the data sets from the landscapes in Ecuador and Zambia (see section 4.1.2) satellite data on deforestation were available (Fischer et al., submitted; Nansikombi et al., submitted). This allowed to analyze deforestation effects of single governance elements based on harmonized field level data. In addition, it allowed to quantify governance effects in relation to other context factors influencing deforestation. Context factors were assessed in key informant interviews and focus group discussions during field assessments (Fischer et al., submitted; Nansikombi et al., submitted). Multivariate regression analysis with backward elimination was applied in order to check for potential relationships between deforestation (target variable) and several context factors as well as governance elements as predictor variables. Infrastructure, socio-economic factors and land use were included as context factors representing direct drivers of deforestation. In a first run, models were implemented that explain deforestation with direct drivers only. In further steps, governance data were added to evaluate if this would improve the models.

Based on the data from Ecuador, the first model (Tab. 16, column a) explained 34\% of deforestation by electrification, literacy and the percentage of land covered by crops. These variables represent infrastructure, development and agricultural intensification as direct drivers of deforestation. Adding governance arrangements in the second model (Tab. 16, column b) increased the $r^{2}$ by additional 13 percent points. Distance to markets became significant in this model. A detailed interpretation of the context factors' effects on deforestation is presented by (Fischer et al., submitted). In the third model (Tab. 16, column c), mean governance added to the explanation of deforestation independently from other explanatory variables. The additional effect was, however, comparatively small. In the third model, also relative income from forests was negatively related to deforestation. In the fourth model, mean governance was replaced by specific governance elements. This model provided more explanatory power than the model with mean governance and increased $r^{2}$ to 0.54 . In this model, tenure and participation were significant with negative coefficients, supporting the hypothesis that high governance scores are related to lower deforestation. Institutions were positively related to 
deforestation, even though in a bivariate analysis it had a negative correlation coefficient as well (not depicted, (Fischer et al., submitted)). Law enforcement had to be excluded from the model due to a high variance inflation factor (VIF) of 5. VIFs for tenure and participation were moderately high but below 5 ( 4.6 and 3.4 respectively). Governance arrangements were no longer significant in the fourth model.

In general, these results show that governance elements either as specific elements or as overall mean had a negative effect on deforestation which is independent from other variables: when governance performance was high, deforestation was significantly lower. Single selected governance elements explained deforestation better than governance arrangements as explanatory variable. However, cropland percentage and electrification were significant in all four models and explained larger parts of the variation. Agricultural land use and intensification as well as infrastructure development were the most predominant direct deforestation drivers in the analyzed landscapes in Ecuador.

\begin{tabular}{|c|c|c|c|c|}
\hline & a & b & c & d \\
\hline r2 corr & 0.34 & 0.47 & 0.50 & 0.54 \\
\hline Prob $>F$ & $* * *$ & $* * *$ & $* * *$ & $* * *$ \\
\hline $\mathrm{N}$ & 80 & 80 & 80 & 80 \\
\hline \multicolumn{5}{|l|}{ Infrastructure } \\
\hline electrification & $(+)^{*}$ & $(+)^{* * *}$ & $(+)^{* * *}$ & $(+)^{* *}$ \\
\hline \multicolumn{5}{|l|}{$\mathrm{km}$ roads / ha } \\
\hline km_to_general market & & $(+)^{* *}$ & $(+)^{* * *}$ & $(+)^{* *}$ \\
\hline km_to_agrimarket & ns & ns & ns & $(+) * *$ \\
\hline \multicolumn{5}{|l|}{ Land use } \\
\hline$\%$ area covered by crops & $(+)^{* * *}$ & $(+)^{* *}$ & $(+) * *$ & $(+)^{* * *}$ \\
\hline \multicolumn{5}{|l|}{ Socio economics } \\
\hline literacy & $(+)^{* * *}$ & $(+)^{* * *}$ & $(+)^{* * *}$ & ns \\
\hline \multicolumn{5}{|l|}{ \$ wage employment } \\
\hline$\%$ income from forests & & ns & $(-)^{* *}$ & $(-)^{* * *}$ \\
\hline$\%$ income from agricult & & & & ns \\
\hline \multicolumn{5}{|l|}{ Governance arrangement } \\
\hline Communal & & $(+)^{* *}$ & $(+)^{* * *}$ & ns \\
\hline Individual & & $(+)^{* *}$ & ns & ns \\
\hline $\begin{array}{l}\text { Socio Bosque / } \\
\text { indigenous reserves }\end{array}$ & & reference & reference & reference \\
\hline PANE & & ns & ns & ns \\
\hline \multicolumn{5}{|l|}{ Governance elements } \\
\hline Mean governance & & & $(-)^{* *}$ & \\
\hline Participation & & & & $(-)^{* * *}$ \\
\hline Institutions & & & & $(+)^{*}$ \\
\hline \multicolumn{5}{|l|}{ Enforcement } \\
\hline Managem_Cons & & & & ns \\
\hline Tenure & & & & $(-)^{* * *}$ \\
\hline
\end{tabular}

Table 16: Multilinear regression models explaining mean annual deforestation per patch in the years 2008 2016 in Ecuador. a: model disregarding governance information; b: model in addition including categories of governance arrangements, $c$ : model in addition including mean governance performance; $d$ : model with single governance elements instead of mean governance. From: (Fischer et al., submitted)

+ - : positive/negative estimator

ns: not significant

significance levels: *0.1; **0.05; ***0.01

shaded cells: variable excluded during backward selection

hatched cells: variable not considered in the model 
The first model based on data from Zambia (Nansikombi et al., submitted) explained $43 \%$ of deforestation with distance to roads, percentage of crop area and the intensity of charcoal production, as direct drivers, as well as by region (Tab. 17, column a). The Eastern region had lower deforestation rates as compared to Copperbelt. In contrast to the data set from Ecuador, the inclusion of governance arrangement information did not substantially change the model, it even increased the $p$ value (Tab. 17, column b). The inclusion of governance elements, however, increased the $r^{2}$ value and thus the percentage of explained variance to $50 \%$ (Tab. 17, column c). Only one governance element, namely local government capacity and effectiveness, showed a significant negative relation to the rate of deforestation i.e. better capacitated and more effective local government institutions were associated with lower rates of deforestation. Other governance variables (elements and arrangements) were not statistically significant. Three drivers, distance to road, percentage of area under crop cultivation and charcoal production and two regional dummies (Eastern and North Western) were statistically significant. Distance to road was associated with lower rates of deforestation; Eastern and North Western regions, as compared to the reference regional dummy of Copperbelt, were associated with lower rates of deforestation. On the other hand, percentages of area under crop cultivation and charcoal production were positively related to the rate of deforestation i.e. the higher the percentage of area under crop cultivation and the higher the production of charcoal, the higher the rate of deforestation.

The comparison between the first and third model indicates that with the introduction of governance attributes in the analysis the $r^{2}$ value increased by 7 percent points. In this model, governance can contribute to the explanation of deforestation. However, the direct drivers had the stronger direct explanatory power and effects. The error probabilities ( $p$-values) of 0.13 and 0.12 were higher as compared to Ecuador, i.e. the complete models hardly significant. Governance scores in Zambia in general were much lower and hardly varying between governance arrangements (see Tab. 9) which made it difficult to show statistical effects. 


\begin{tabular}{|c|c|c|c|}
\hline & $\mathbf{a}$ & b & c \\
\hline$r^{2}$ corr & 0.43 & 0.44 & 0.50 \\
\hline Shapiro-Wilk p-values & 0.13 & 0.25 & 0.12 \\
\hline Number of observations & 80 & 80 & 80 \\
\hline Intercept & $0.536 *(0.037)$ & $0.507 *(0.042)$ & $0.475 *(0.041)$ \\
\hline \multicolumn{4}{|l|}{ Proximate drivers } \\
\hline Distance to road & $-0.131 *(0.036)$ & $-0.117 *(0.037)$ & $-0.112 *(0.035)$ \\
\hline Percentage of crop area & $0.168 *(0.039)$ & $0.144 *(0.042)$ & $0.155 *(0.040)$ \\
\hline Charcoal production & $0.152 *(0.036)$ & $0.135 *(0.038)$ & $0.146 *(0.037)$ \\
\hline \multicolumn{4}{|l|}{ Timber extraction } \\
\hline \multicolumn{4}{|l|}{ Pole extraction } \\
\hline \multicolumn{4}{|l|}{ Firewood extraction } \\
\hline \multicolumn{4}{|l|}{ Livestock grazing } \\
\hline \multicolumn{4}{|l|}{ Percentage of built-up area } \\
\hline \multicolumn{4}{|l|}{ Other factors } \\
\hline \multicolumn{4}{|l|}{ Slope } \\
\hline \multicolumn{4}{|l|}{ Area of arrangement } \\
\hline Eastern region (Yes) & $-0.270 *(0.041)$ & $-0.302 *(0.046)$ & $-0.322 *(0.049)$ \\
\hline North Western region (Yes) & & $-0.083(0.055)$ & $-0.167 *(0.059)$ \\
\hline Copperbelt region (Yes) & reference & reference & reference \\
\hline \multicolumn{4}{|l|}{ Governance arrangements } \\
\hline \multicolumn{4}{|l|}{ State forests restricted } \\
\hline Traditionally restricted & & reference & reference \\
\hline \multicolumn{4}{|l|}{ Customary communal } \\
\hline \multicolumn{4}{|l|}{ Customary individual } \\
\hline \multicolumn{4}{|l|}{$\begin{array}{l}\text { Overlapping community } \\
\text { claims }\end{array}$} \\
\hline \multicolumn{4}{|l|}{ Governance elements } \\
\hline \multicolumn{4}{|l|}{ Mean governance } \\
\hline Local government & & & $-0.087 *(0.038)$ \\
\hline Customary government & & & $0.092(0.046)$ \\
\hline \multicolumn{4}{|l|}{ Central government } \\
\hline \multicolumn{4}{|l|}{ Tenure rights } \\
\hline \multicolumn{4}{|l|}{ Land use planning } \\
\hline \multicolumn{4}{|l|}{$\begin{array}{l}\text { Conservation, use } \\
\text { restrictions }\end{array}$} \\
\hline \multicolumn{4}{|l|}{ Formal law enforcement } \\
\hline \multicolumn{4}{|l|}{ Customary law enforcement } \\
\hline Public policy participation & & & \\
\hline
\end{tabular}

Table 17: Stepwise multiple regression results showing linkages between annual rates deforestation, de-facto forest governance elements and arrangements, proximate and other factors for Zambia. Coefficients (with standard error); * Implies parameter estimates are significant at 95\% confidence interval using standardized variables; adapted from: (Nansikombi et al., submitted). shaded cells: variable excluded during backward selection hatched cells: variable not considered in the model

\subsubsection{The role of context factors for governance effects on deforestation}

The socio-economic and infrastructure context plays an important role in differentiating the specific effects of governance on deforestation. Studies focusing on governance effects need to take specific context into account as governance measures depend on them and do not act independently (Wehkamp et al., 2018). Effects of governance elements as well as of socio-economic and political context variables on deforestation were quantified within quantitative content analysis (see section 4.1.1). Context factors were determined based on a classification of deforestation drivers by (Hosonuma et al., 2012). Actions explicitly undertaken to counter land use changes were classified as 
interventions. These were classified according to (Agrawal et al., 2014). Multiple regression analysis with backward selection was then applied with governance effects on deforestation as target and effects of context factors on deforestation as explanatory variables. The resulting model could explain $38 \%$ of the variation of governance effects $\left(r^{2}=0.38\right)$ by the socio-economic and political context (Tab. 18). Based on the review data, corruption and illegal logging were negatively related to governance effects. Population growth/density correlated positively with governance effects on deforestation, showing that the stronger population effects on deforestation are, the less effects governance has on deforestation (population growth/density in general had Likert scores below 4, decreasing Likert scores for population thus show stronger relations to deforestation). Also economic development, tourism and technology were significant explanatory variables.

In summary and applying the theoretical framework of (Fischer et al., 2020), these results show that beyond their direct effects on deforestation, context factors obviously moderate the effects of governance.

\begin{tabular}{|l|l|l|}
\hline & \multicolumn{1}{|c|}{$\mathbf{a}$} & \multicolumn{1}{c|}{ b } \\
\hline$r^{2}$ adjusted & 0.18 & 0.38 \\
\hline probability > F & 0.2872 & 0.029 \\
\hline N studies & 28 & 28 \\
\hline Context factors & & \\
\hline Corruption/IllegalLog & $0.055 /-$ & $\mathbf{0 . 0 3 8} /-$ \\
\hline Population growth/density & $0.262 /+$ & $\mathbf{0 . 0 2 6} /+$ \\
\hline Roads & $0.646 /-$ & \\
\hline LandSpeculation/OpportCosts & $0.381 /-$ & $0.300 /-$ \\
\hline EconDevelop/Income & $0.255 /+$ & $0.057 /+$ \\
\hline CashCrop & $0.688 /-$ & \\
\hline Agriculture & $0.567 /-$ & $0.119 /-$ \\
\hline Timber/Firewood & $0.950 /-$ & \\
\hline Nat.subsidies/Credits/Donor aid & $0.436 /-$ & \\
\hline PES/Certification & $0.819 /-$ & \\
\hline Protected Areas & $0.696 /+$ & \\
\hline CommForestry & $0.224 /+$ & $0.148 /+$ \\
\hline Tourism & $0.373 /+$ & $\mathbf{0 . 0 4 2} /+$ \\
\hline Technology & $\mathbf{0 . 0 1 1 * * / -}$ & $\mathbf{0 . 0 0 1 * * * / -}$ \\
\hline Education/Research/PR/Awareness & $0.105 /+$ & $0.104 /+$ \\
\hline
\end{tabular}

Table 18: Multiple linear regression explaining mean governance effects on deforestation by context factors; $p$ values for single factors. +/- : positive/negative effect; shaded cells: variables not included in optimized model; significance levels: *0.05; **0.01; ** 0.001; a: full model with all context factors; $b$ : optimized model with selected factors; optimization by backward selection. 


\section{Discussion}

\subsection{Methodological considerations}

The presented research develops and applies qualitative forest governance assessment methods within a review and within field assessments. It further transforms the findings into quantitative scores that are then the basis for a number of statistical applications. Such mixed methods approaches have until now not been applied in forest governance research. Even though, it has been acknowledged that the complexity of a modern governance understanding requires both, quantitative and qualitative methods (Krott et al., 2014; Kleinschmit et al., 2016), a combination has rarely been implemented. Methodological details of the mixed methods approach are discussed in the following sections.

\subsubsection{Quantitative content analysis with standardized scores}

Given the multitude of scientific studies and results related to forest governance and deforestation, interest is growing in deriving generalized knowledge from the multitude of case studies. The presented method of a quantitative content analysis with standardized scores presents a new approach to deal with such requirements. Whereas content analysis (Mayring, 2014) and Likert scoring (Likert, 1932) have frequently been applied, their combination in a new methodology provides new perspectives on forest governance. Generalization, which is the main aim of this method, means extending an empirical or conceptual relationship deduced from a set of case study observations beyond the specific contexts in which the relationship was observed (Steinberg, 2015). (Magliocca et al., 2018) reflect on general requirements for producing so called generalized knowledge claims consisting of three so-called dimensions, namely

1. the existing knowledge base

2. the generalization approach

3. the methodology for producing so-called knowledge claims.

The first dimension entails being explicit about the existing knowledge base of empirical evidence. In the study presented, the existing knowledge base was very comprehensive. The varying definitions of 'governance' in applied research (Broekhoven et al., 2012; Facility, 2013; Giessen and Buttoud, 2014) and the large amount of studies covering varying scales and local conditions were major challenges. Nevertheless, this study applied a broad search term of 'governance' because pre-selection based on more specific governance components from sometimes dissenting definitions could have biased the results or excluded relevant literature. In order to derive a still manageable number of publications and to specifically focus on most remarkable scientific contributions, the research concentrated on more frequently cited papers, because citation indices are a widespread proxy for scientific quality. Sample size is a core methodological issue, specifically taking into account the broad and heterogeneous knowledge base related to governance effects on deforestation. A larger number of studies as a basis for the review might have produced more detailed results. However, many authors confirm that the number of observations in the review presented can be adequate as 198 articles were screened and 28 were evaluated. (Shahabuddin and Rao, 2010) base their global review on 34 studies. (Porter-Bolland et al., 2012) publish a review across the tropics based on 27 studies. (Magliocca et al., 2018) suggest "a general rule of thumb is a sample size of 30". (Wehkamp et al., 
2018) present a meta-analysis based on 32 empirical cross-country studies. However, due to the still limited sample size, this does not necessarily mean that non-significant variables do not play a role. In a statistical terminology this refers to 'type one errors' that have to be taken into account, expressing the probability that true null hypotheses (significant governance studies and variables) were rejected (Dekking, 2005).

The second dimension of the generalization approach refers to the type of inference presented in a study. This has implications on the extent to which an analysis can establish causality between the outcomes of interest and hypothesized related factors. The logic of the generalization (Magliocca et al., 2018) within the presented governance analysis is based on causal effects in the sense of a frequency analysis. The existence of frequent effects can be regarded as basis for claiming general causal effects (Magliocca et al., 2018). Given that all governance elements were predominately linked to decreasing deforestation, the assumption of a universal trend cannot be falsified based on the reviewed studies.

As concerns the third dimension, which refers to the methodology for producing the knowledge claim the governance review relied on and further extended content analysis (Mayring, 2014). Such content analysis already takes into account the existing divide between a purely hermeneutical (qualitative) position, which tries to understand the meaning of the text as interaction between the preconceptions of the reader and the intentions of the text producer, and a positivistic (quantitative) position that tries to measure, to record and to quantify aspects of the text. (Mayring, 2014) specifies the approach as a "mixed method" that includes quantitative components. These quantitative components are however mainly confined to counting frequencies of text passages within the predefined categories. The novelty of the here presented method is that within these categories Likert scores were applied to standardize the information and thus to increase comparability and statistical power. This is an adequate methodology specifically when regarding large and heterogeneous data sets (Magliocca et al., 2018). Converting thematic analysis into quantitative Likert scales constitutes a data transformation based on an intensity scale (Castro et al., 2010). This is needed because scientific approaches in the underlying studies may not be consistent across observers and/or contexts, which requires standardization or harmonization in the form of coding before comparisons can be made (Coe and Scacco, 2017; Magliocca et al., 2018). The quantitative content analysis with standardized scores is therefore as well a mixed method in which qualitative results of reading the text are coded and thus transformed.

\subsubsection{Field governance measurements}

In the last decade the world has seen an "explosion" of empirical research aimed at measuring governance (Worldbank, 2006). This is the consequence of the attention governance has received in the context of endeavors aiming to reduce deforestation and improving development in general. Governance measurements are needed to identify policy strengths and weaknesses, initiate progress and monitor development (Kishor and Kenneth, 2012). Nevertheless, reliable information on functioning and effects of various forest governance elements across developing countries is lacking, even though it is very much needed also for guiding forest policy (Barbier and Tesfaw, 2015). Many case studies are existing (Wehkamp et al., 2018; Fischer et al., 2020). They employ a wide variety of specific methodologies that are rarely comparable. There are only a few harmonized field assessment methods. These are, however, mostly qualitatively descriptive (CIFOR, 2015; Ravikumar et al., 2015) or mainly focus on selected local forest patches (IFRI, 2011). To overcome this, a new 
quantitative methodology for forest governance assessments at landscape level has been presented in section 4.1.2, comprising:

1. Definition of governance arrangements

2. Selection and local adaptation of governance elements

3. Focus group discussions for governance quality scoring by Likert scores

\subsubsection{Governance arrangements}

Governance arrangements are a new approach. They define basic spatial units for the field level assessments within the presented landscape level assessment methodology. Mere governance assessments on landscape level (e.g.(de Graaf et al., 2017)) can provide means but would blur the underlying mechanisms, because within landscapes governance mechanisms can differ substantially as has been shown (see section 4.1.2). Governance arrangement delineation therefore is indispensable if mechanisms, functioning and effects of governance, e.g. on deforestation, are to be studied not only between but also within landscapes. They enable a more detailed and precise assessment. The proposed methodology based on governance arrangements is more laborious and expensive than only producing results per landscape; however focus group discussions are an efficient way to collect the data. The hierarchical code list for governance arrangements (Tab. 6) provides the basis for aggregation and cross country harmonization and thus comparison. On the highest level it takes into account actors (i.e. communal, individual and communal owners). On the lower levels it accounts for main structural features (land titling and management rules including use restrictions). It is thus applicable under the presented governance understanding (see section 2.1.3).

\subsubsection{Selection of governance elements to be assessed}

The selection and adaptation of governance elements builds on an existing framework (Davis et al., 2013a) but provides new theory based considerations on the selection process. Existing measurement tools are all based on the separate assessment of different governance subcomponents that are called indicators, variables, elements or thematic areas depending on the assessment tool (see section 2.1.4). The long lists, different structures of governance assessment frameworks and hardly manageable compilations of elements, variables and indicators are due to the broad and complex nature of the recent governance understanding (Larson and Petkova, 2011; Broekhoven et al., 2012; Davis et al., 2013b; Giessen and Buttoud, 2014; de Graaf et al., 2017; Mansourian, 2017). Indeed it seems that "everything matters" (Brass, 2016). But because governance is complex and any indicator is subject to a degree of imprecision, no single indicator can be used mechanically for governance assessments (Worldbank, 2006). The multitude of elements and indicators pose a challenge and the only way for operational assessments is selection of specific elements and adaptation of existing frameworks to the regional or local context and to the research aim as proposed by (Davis et al., 2013a) or (Kishor and Kenneth, 2012) and as conducted in this study.

Based on these considerations the open question remains whether a universal governance assessment tool with a manageable set of elements for de facto forest governance on the landscape level can be proposed. The answer is probably: no; because governance is on one side too broad and at the same time context specific. Thus, forest governance needs a deeper understanding before a selection can be made. Instead of defining a fixed set of elements, a functional understanding can help designing operational assessments. In any case, a selection of elements implies reduced assessments instead of a comprehensive approach covering full indicator frameworks. The economic 
concept of marginal utilities can steer the reflection on justifying a reduced number of elements. Assuming that the "marginal utility of each (homogenous) unit decreases as the supply of units increases" (Rothbard, 2009), the marginal utility of additional governance elements assessed would be of interest. An economic assessment is beyond the limits of this study and would call for extended research. But the PCA and the correlation results of the presented governance research (see section 4.2) point to the fact that the marginal utility of each additional governance information is rather quickly decreasing, which means that reliable (mean) information will mostly be available based on reduced stets of assessed governance elements. Synchronous functioning, probably even synergies between different governance elements - also as concerns effects on deforestation (see section 4.3) are encouraging and support an approach that has a focus on a few selected core issues, covering main mechanisms instead of trying to cover all elements. Together with additional selection criteria (see section 4.1.2.2), the agency - structure approach can help to select indicators as it captures important governance functions. At the same time, elements that characterize local governance conditions need to be taken into account.

\subsubsection{Participatory mapping and focus group discussions}

Focus group discussions are a well-defined and already existing tool. However, they are mostly focused on qualitative statements and rarely used in combination with quantitative scoring. Participatory mapping and focus groups are classical tools of participatory rural appraisals (PRA). A large body of literature supports the application of the tools within the landscape level assessments presented. PRA tools were originally used for involvement of local people into planning processes of development projects. They have been further developed as research methods including modern tools like GIS (Chambers, 1994). Focus groups are discussions among a predetermined group of people in an interactive environment (Adhikari et al., 2018). The method has become a prominent component of field level research and practical guidelines have been prepared to support scientifically sound implementation (IFAD, 2009). Participatory mapping is a process of using local perceptions and knowledge to build maps of a shared geographical location (Beaudoin et al., 2016). Participatory mapping and focus group discussions are, like in the presented research, frequently used in combination with remote sensing analysis. This combination of methods has a number of mutual benefits. Participatory mapping provides an advanced and very comprehensive method for ground truthing of remote sensing data on one side and a basis for subsequent focus group discussions on the other, which then are the basis for the collection of quantitative and qualitative georeferenced data (Mapedza et al., 2003; Nackoney et al., 2013; Beaudoin et al., 2016). The combination of mapping and focus groups is also recommended because during the joint mapping problem understanding is created and an open trustful atmosphere can be created in the group (Freund et al., 2016). On the other side, findings from participatory rural appraisals can be affected by the composition of participant groups and group discussions can be influenced by one or two dominant individuals. To overcome these inherent weaknesses, it has been suggested that PRA techniques should best be deployed in conjunction with other methods, so that findings from technical and social research methods may subsequently be triangulated. One such complementary technology is GIS based remote sensing analysis (Mapedza et al., 2003), as applied in the presented research.

In a few cases, mapping has been based on blanc sheets of white paper in order to capture the subjective perception of participants related to their physical environment (Lingel, 2011). However, following (Beaudoin et al., 2016; Freund et al., 2016) this study used predefined base maps and 
satellite images that helped to identify basic features and were a basis for digitizing and subsequent georeferencing. Base maps are reported to save time and to provide a more efficient assessment (Nackoney et al., 2013).

Like other PRA methods, participatory mapping and focus group discussions not only provide data input to research projects but have an important feedback side effect: PRA exercises can facilitate social learning and provide the foundation for the creation of social capital within the communities (Damastuti and de Groot, 2019). It is a key component of the interactive participation process that communities and villages take control over their own decisions. Village ownership of the mapping process needs to be promoted. Therefore, it has been emphasized that participatory maps and focus group results will belong to the village community, not to the research program (Nackoney et al., 2013). Within the field campaigns of the LaForeT project which provided data input to the above presented research, feedback workshops were therefore conducted in the villages. During these workshops professionally prepared maps were handed over to the communities in order to demonstrate such ownership.

\subsubsection{Principal component analysis as tool for evaluating the inherent governance structure}

Principal component analyses (PCA) based on quantified review data or field governance assessments have to date not been applied. They can be regarded as a methodological contribution to the further development of forest governance research. PCA is a technique for reducing the dimensionality of the governance datasets (Dunteman, 1989; Jolliffe, 2002 ). In multidimensional data sets, each variable can be considered as a different dimension (Kassambara, 2017). Dimensionality in this study therefore relates to a high number of governance elements, the interrelation of which was not known and which was to be explored according to the research questions. Any reduction of the dimensionality of a dataset needs to ensure that as much variability as possible is preserved in order to not loose essential information. In contrast to "feature elimination" (Brems, 2017) which would imply eliminating governance elements from the analysis that are regarded less important, PCA solves this by "feature extraction". This means determining new features (principal components) that are linear functions of the variables in the original dataset, that successively maximize variance and that are uncorrelated with each other (Jolliffe, 2002 ; Kassambara, 2017). In that sense, PCA is an adaptive descriptive open data analysis tool, as the new components depend on the dataset, rather than being pre-defined functions. In the presented study two basic features of forest governance could be extracted: the general positive loadings on the first components that signify the conjoint and synchronous functioning as well as the agency-structure dualism that became visible at least within the large scale governance data set. These results are based on a data set that fulfilled the assumptions for applying the method and they reveal new functional features that were not visible in the raw data set. PCA was thus a suitable and adequate method for identifying functional relationships between governance elements.

A number of technical issues need to be considered with respect to the PCAs applied to the specific data sets. Due to the formal violation of the assumption of sampling adequacy (see section 3.3.2) data interpretation had to take into account that results had a comparatively small number of structured components, and very many noise dimensions, i.e. components with very low eigenvalues (Jolliffe, 2002 ). Therefore, only the first four components of the PCA related to the reviewed studies were interpreted. They explained nearly $50 \%$ of the variation and all showed eigenvalues above 1 . The PCAs for country wise analysis had a higher number of elements per sampling unit which means that sampling adequacy in the above mentioned sense was given; however, at the expense of a 
limited number of elements that were included in these analyses. Given the large number of possible governance elements, a full assessment of their statistical relations would require a higher number of assessed governance arrangements.

Usually standardization of data is recommended before conducting PCAs, especially if data is measured on different scales. In the PCAs presented, however, all data were measured on identical Likert scales. After standardization the new covariance matrix would merely be a scalar multiple of the old one, hence with the same eigenvectors and the same proportion of total variance explained by each component (Jolliffe, 2002 ). Standardization was thus not required.

\subsubsection{Evaluating governance effects with multiple regression analysis}

The study analyzed governance effects and those of proximate drivers on deforestation by multiple regression analysis. Regression analyses have already been applied in forest governance research (Vuohelainen et al., 2012; de Souza et al., 2013; Larcom et al., 2016; Liu et al., 2016). The method has a focus on causal inference. This means it describes the process of drawing a conclusion about a causal connection between cause and effect variables; it analyzes the response of the effect variable when the cause is changed (Pearl, 2009). In the case of the presented study the aim was to analyze the response of deforestation when governance is changed. The fundamental problem of causal inference studies is that effects of a changing predictor cannot be directly measured. It is not possible to observe both: what happens to an individual after taking the treatment and what happens to that same individual after not taking the treatment. In statistical words: the unobserved counterfactual outcome for each treatment cannot be observed (Dunning, 2008). But a linear model, such as multiple linear regression - which estimates the average effect on a target variable for each additional unit of explanatory variables - is seen as a natural starting point and appropriate method for causal inference evaluation (Gelman and Hill, 2006) given that the respective formal assumptions are met (see section 3.3.4). Thus multiple regression analysis can be regarded as the appropriate tool for evaluating the data of this study under the given objectives.

\subsection{Functional relationships between governance elements}

\subsubsection{The agency and structure concept as theoretical foundation}

The agency - structure concept has been described as a theoretical basis of forest governance and is based on two mainstream models: rational choice and neo-institutionalism (Arts et al., 2014). The PCA results (see section 4.2.1) show that for the review data, specifically on the second component, agency and structure indictors were clearly differentiated. The grouping of structure and agency elements on the PCA components shows that forest governance functioning is indeed characterized by a mechanism that differentiates between agency and structure. Even though theoretically formulated, such a mechanism has to date not been shown based on empirical governance data.

Even though that the agency - structure dualism became visible, it is undebated that agency and structure are idealized poles. There is consensus that actors' decisions will not purely follow one or the other logic and context-specific combinations with different shares of agency and structure components need to be taken into account (Giddens, 1984a; March and Olsen, 1998). There was no statistically significant stronger effect of either of the two aspects on deforestation. Both aspects seem equally important and even though that structural elements were loading stronger on the PCA axes. This is supported e.g. by the institutional economics theory (Ostrom, 2009) claiming that rational choice is mediated by rules, norms and beliefs. In this respect also the practice based 
approach (Arts et al., 2014) gains relevance. This approach emphasizes the constant and mutual feedback between structure aspects and agency.

The application of this approach to landscape data from the three case study countries did, however, not reveal agency - structure patters for the single countries. For the country wise analyses based on data from single landscapes, agency and structure elements showed no distinct sorting on PCA components with eigenvalues above 1.0. The landscape approach has been advocated by (Sayer et al., 2013) as a basis for assessing field data (see section 2.3). Related to governance, however, it may be assumed that the landscapes still were too small to capture the full functioning of forest governance, as agency and structure mechanisms were not visible at this level. Multilevel governance approaches as advocated by (Korhonen-Kurki et al., 2013; Rantala et al., 2014; Piketty et al., 2015) may thus be needed, which spatially exceed landscapes. In the ongoing forest policy debate, this implies the need to create nested REDD+ designs (Kashwan and Holahan, 2014) that take into account and relate international, national regional and local scales.

The existence of agency and structure mechanisms connected through dynamic and interactive feed backs may help to design and steer governance research and development work. An example for practical implications of the theoretical governance research is the debate on whether existing governance results generally support agency based approaches to counteract tropical deforestation in contrast to structural approaches. Results based payments under the REDD+ ("Reducing Emissions from Deforestation and Degradation") approach of the United Nations Framework Convention on Climate Change (UNFCCC 2007a; FCCC/CP/2010/7/Add.1) would be a prominent example for an agency based tool in international forest policy. Such payments build on the financial motivation of recipients. In contrast, traditional input based development aid often aims to improve structures, rules and their implementation. Results based payments under REDD+ have been promoted as an innovative tool. Still today, they are seen as a "main innovation to REDD+" (Angelsen et al., 2018). However, the disbursement of such finance is far below expectations and a controversial discussion on success and the future of REDD+ and the applicability of results based payments in international forest policy is ongoing (Fischer et al., 2016; Fletcher et al., 2016; Angelsen et al., 2017; Arts et al., 2020). The findings support that structural components which are as well foreseen under REDD+ aiming to install legal and institutional structures, so-called readiness measures, need to be implemented first. They need to be perceived and communicated as independently functioning components. Expectations to tackle the tropical deforestation challenge with purely agency related measures are obviously hard to fulfil.

\subsubsection{Other independent factors and single elements explaining forest governance}

Nearly all elements loaded positively on the first principal components of the PCAs conducted (Tabs. 11-14). This shows that there is in general a consistent functioning of the single elements.

Governance elements obviously act conjointly; they are expressions of a similar underlying process. Such a joint functioning of different governance elements, independently from scale or context, has not been documented so far.

However, none of the governance elements consistently had the highest loadings on the first component. This shows that the importance of single elements for a general characterization of governance depends on the respective context. For example, law enforcement had the lowest loadings on the first component in the Philippines, an intermediate position in Ecuador and the highest loadings in Zambia. 
There were between none (Ecuador) and eight (review data) additional components with eigenvalues above 1 . The interpretation of each of these components requires expert knowledge related to the underlying dataset in order to interpret specific processes or functions that are expressed by these independent components (Jolliffe, 2002 ). However, whereas the first component could in general be explained as expressing mean governance (see Fig. 10), there was no consistent explanation of element loadings on additional components. Overall, the importance and function of single elements on additional components was case specific. Also (Wehkamp et al., 2018) point to the fact that governance effects are context specific which means that in each area or country it might be other elements that more specifically characterize governance functioning beyond the general positive interrelation of single elements. It is be necessary to focus on specific governance elements in each context.

Elements of the same thematic areas as defined by the framework of the World Resource Institute (Davis et al., 2013b) did not turn out to determine independent factors (components) in any of the PCAs. However, sample size was mostly too low to elaborate on such a complex and multidimensional framework in detail. Nevertheless, based on the results presented, the framework can be understood as an operational list of different aspects, not as a functional explanation of governance.

\subsection{Effects on tropical deforestation}

\subsubsection{Governance effects on deforestation}

There is substantial knowledge on relations between single governance elements and deforestation (Kanninen et al., 2007; Korhonen-Kurki et al., 2014; Stickler et al., 2017). Many authors claim positive effects of forest governance (Bhatterai and Hammig, 2001; Bhattarai and Hammig, 2004) or state that governance is a "precondition for achieving a sustainable landscape" (de Graaf et al., 2017) or vital for "successful REDD+ implementation"(Korhonen-Kurki et al., 2014). But a comparison of deforestation effects of single governance elements based on a consistent empirical field data set is a novelty and has not been available until now. (Barbier and Tesfaw, 2015) apply multiple regression analysis based on a panel data set that includes three structural governance variables. (KorhonenKurki et al., 2014) use qualitative comparative analysis (QCA) to evaluate combinations of governance and context factors on REDD+ implementation. However, they do not study effects on deforestation.

The qualitative parts for studying governance effects on deforestation allow a deeper interpretation of relations between single governance elements and deforestation. The content analysis showed that high governance scores were predominately linked to decreasing deforestation. Between the elements, there were hardly differences in effects on deforestation or degradation (Fig. 11).

Participation and tenure/ownership were the most frequently studied agency elements and the only two that, even though only in limited cases, were linked to increasing deforestation. Many authors base the importance of tenure security on the assumption that more secure land and resource tenure motivates land users to manage resources more efficiently (Ostrom, 1999; Angelsen and Kaimowitz, 2001; Andersson and Gibson, 2007; Ceddia et al., 2014). However, tenure security and participation alone can have divergent impacts by motivating agricultural expansion (de Souza et al., 2013; Agrawal et al., 2014; Ceddia et al., 2014; Jones et al., 2017) or by fostering forest clearing to demonstrate property rights (Soares-Filho et al., 2004; Bottazzi and Dao, 2013). Granting of tenure 
and enabling of participation obviously need to be controlled by a frame of structural governance mechanisms in order to be effective.

Structural elements were most frequently represented by policy framework and law enforcement. The review showed both: negative effects of policies that do not care for deforestation (Soares-Filho et al., 2004; Porter-Bolland et al., 2012; Webb et al., 2014) and positive effects of laws aiming at forest conservation (Shahabuddin and Rao, 2010; Bae et al., 2012; Canova and Hickey, 2012). Policy framework and law enforcement are classical government related elements that remain important and need continued support even though the governance concept has been widened into a much broader concept. Structural elements like land use plan implementation, legal/policy framework and related law enforcement loaded stronger on the first component of the review based PCA as compared to agency elements that loaded less on the first axis. This might suggest a more uniform effect of these structural elements that are more strongly determining mean governance as compared to other elements, specifically as compared to agency related elements.

Executive agencies were the most frequently studied example of an element that could not be assigned to either agency or structure and it also had an intermediate position between structure and agency related elements on the respective PCA axes. Executive agencies comprise both: structure and agency aspects (Giessen et al., 2014; Rahman and Giessen, 2017). On one side forest services are guards that are tasked with enforcing laws, structures and rules (Hayes and Persha, 2010; Baynes et al., 2016; Mansourian, 2016). Often they even originate from police-like organizations (Hutchins, 1916). But on the other side they are service providers that need to locally moderate interests of stakeholders and multiple demands of society (Bennett et al., 2014; Mansourian, 2016). This can be interpreted as serving the agency aspect. Installing such executive institutions that fulfil both aspects, therefore, is a challenge that needs support and capacities. Most studies, however, did not differentiate between different aspects of executive agencies' work (Bhattarai and Hammig, 2004; Gautam et al., 2004; Andersson and Gibson, 2007; Bae et al., 2012; Porter-Bolland et al., 2012).

Multiple regression analysis helped to quantify effects of governance elements on deforestation. It was applied based on the data sets from Ecuador and Zambia in order to study the combined effects of several governance elements, to compare them against each other and against the effects of direct drivers. (Barbier and Tesfaw, 2015) followed the same approach, however with only three structural governance variables. The now presented study relies on two country wise and harmonized data sets and uses a larger number of governance elements. In both countries there were significant effects of a number of governance elements. The regression coefficients and significance levels of governance elements were, however, lower as for direct drivers (Geist and Lambin, 2002) such as e.g. agricultural land use. All models consistently revealed stronger effects of direct drivers on deforestation. However, the $r^{2}$ of the models increased when governance variables were included. This supports the underlying theoretical understanding whereas governance has an effect on deforestation which however always has to be seen in relation to the context of direct drivers. 
Among the governance elements analyzed in Zambia (Nansikombi et al., submitted), only local government was significant. It had an isolated function on reduced deforestation (see Tab. 17) in relation to other elements like law enforcement, central government and tenure which were not significant and from which it was clearly differentiated on the first component of the PCA (see Tab. 13). The results from Zambia specifically suggest that improvement of forest governance alone does not exclusively guarantee successful deforestation abatement. However, governance scores in Zambia were very low and with little variation, which in general makes it statistically hard to explain any target variable.

The governance data underlying the multiple regression analysis from Ecuador (Fischer et al., submitted) showed more variation. Specifically tenure and public participation were elements that jointly contribute to reduced deforestation (see Tab. 16). These two elements were grouped on the first component of the PCA (see Tab. 12) and also both of them explained reduced deforestation in the multiple regression. They were separated from institutions in the PCA and the multiple regression analysis. Both, the cases of Zambia and Ecuador show that those governance elements which are differentiated form others within the PCA also function jointly in their effects on deforestation. The joint functioning, however, can make it statistically difficult to substantiate isolated effects of single elements due to their multicollinearity. The exclusion of law enforcement as explanatory variable due to high VIFs is an example for this.

For examining specific relations between direct drivers and governance, the multiple regressions presented are an indirect approach, because these relations between governance and direct drivers are not quantified in the models. For such quantification, interaction terms would need to be included. However, given the large number of governance elements and deforestation drivers, the resulting number of possible combinations would be too big for meaningful statistical analyses. For meta-analysis, (Rudel, 2008) points to the fact that when "cases drop below 60, the creation of interaction terms creates so many variables that the quantitative analysis begins to lose its power".

\subsubsection{The role of context factors for governance effects on deforestation}

The target of this study with respect to context factors was to contribute understanding how context factors influence governance effects on deforestation (Fischer et al., 2020). Governance effects on deforestation as derived from the review study were used as target variable in a multiple regression analysis. Context factors were included as independent variables (see Tab. 18). This application bears the advantage that context factors can directly be linked to governance effects. Such an approach has until now not been presented. The constraint of this approach is however, that only mean governance effects are used as target variable. This is a simplification as not individual governance elements can be considered. The results show that corruption and illegal logging can negatively affect governance effects. Results also show that, the stronger population effects on deforestation are, the less effects governance has on deforestation. This supports (Wehkamp et al., 2018) who found that a governance effect was more likely to become significant when accounting for population in the models and suggest that political institutions are more important when demographic pressures are high. The now presented study also supports that agriculture and timber harvest did not moderate governance effects. Governance thus seems important irrespective of high or low pressures through agriculture and timber extraction. Technology was the strongest 
explanatory variable and negatively related, suggesting that were a focus is on technological improvements, the effects of improved governance are less pronounced. 


\section{Conclusions}

\subsection{Mixed governance assessment methods serving the science policy interface}

Two new methods for collection of forest governance data have been developed and implemented: Quantitative content analysis with standardized scores relies on existing results to derive generalized knowledge, whereas harmonized landscape level governance assessments produce new standardized field data. Both methodological approaches have been shown to be fully operational and applicable. Quantitative content analysis benefits from already existing studies but on the other hand has to deal with differing approaches, methods and not directly comparable studies. Harmonized landscape level governance assessments, in contrast, collect new standardized field data which provides the advantage of being directly comparable, however on the expense of not integrating existing data and knowledge. Based on the experience and results of this study, quantitative content analysis of existing research is advocated due to the fact that it will hardly be possible to produce new harmonized forest governance results to an extent comparable to existing scientific work. Before adding new case studies, governance researchers are required to clarify if it is not more efficient to re-analyze and generalize from existing work. The quantitative content analysis with standardized scores is a valuable methodological contribution in this respect. This does not mean that new field studies are not needed. On the contrary, new aspects and questions are arising that require new field research. Such new field research is recommended to follow standardized procedures as e.g. presented in this study. In this respect, research networks and scientific cooperation should gain importance, as standardization requires methodological integration and compromises between approaches. The presented standardized landscape level approach can stimulate the application of harmonized methods by a larger number of governance projects and researchers.

Both methodological approaches presented are mixed method approaches that benefit from the strengths of qualitative and the quantitative components. Whereas qualitative understanding enables to capture more complexity and inquire more deeply, quantification is needed to apply statistical tools as a basis for generalizing results. Application of mixed methods in forest governance research needs to be strengthened in order to provide policy relevant information that makes full use of available knowledge and results. This requires a dialogue between researcher communities that have traditionally specialized on one or the other methodological domain. It as well requires a respective qualification of individual scientists. Principal component analysis and multiple regression analysis have been shown as viable quantitative approaches for the specific research questions in this study. Additional multivariate statistical tools need to be explored within forest governance research.

\subsection{Synchronous governance elements can encourage development policies}

To date there has been no comprehensive study analyzing functional interrelations of single forest governance elements based on empirical data. The presented results offer first insights in this respect. Governance elements such as e.g. tenure, law enforcement, participation, institutional performance act conjointly and into the same direction, they are features of the same underlying process that is highly correlated to overall mean governance. On one side, this is an important theoretical finding that helps understand and explain governance functioning. On the other side, this has as well practical consequences. The fact that the complexity of a modern forest governance 
concept probably leads to more demanding development concepts must, with these results in mind, not refrain from timely implementation of governance measures. On the contrary: the fact that there might even be synergies between governance elements and clear indications that these reinforce each other is encouraging. Rather than remaining in an "analysis paralysis" (Ranadive, 2020) and struggling to disentangle ever more details of governance functioning in all cases, these findings can justify and motivate politicians, scientists and practitioners to analyze governance core features that are relevant in the specific context and then take action. Actors in the forest governance arena can rely on the justified assumption that work on a few, however well selected, core elements will certainly not be in conflict with other governance elements, probably even have positive effects on the wider forest governance settings.

\subsection{An agency - structure based understanding provides a changed perspective for e.g. REDD+ implementation}

The agency and structure related forest governance understanding is not only a theoretical basis. Results of this study show that these two aspects are effective governance mechanisms. In view of complex indicator frameworks and different definitions this can help to focus research, development work and policy. Governance elements selected for specific action should at least cover these two aspects. Additional research might uncover additional underlying mechanisms that can help to still better understand governance functioning.

An agency and structure related perspective provides the basis for understanding the current debate on the delayed success of REDD+. This debate builds on the fact that disbursement of carbon related results based payments is far below expectations. Results based payments focus on the agency of the recipients and may certainly be an effective measure. But a pure agency related focus will hardly work. Structural components like readiness measures have been implemented under REDD+ from the beginning and need to be perceived as independent and self-standing measures that are not only needed to prepare the ground for the payments. Readiness activities are themselves equally important governance measures and need to be considered in the discussion on the success of REDD+. The funds that have been spend for them may have a justification independent from results based payments.

Forest governance requires a multilevel understanding in which international, national, regional and local measures and activities need to be integrated. Agency and structure mechanisms of governance only became visible at higher scales, i.e. when combining cross country data or analyzing review data from a larger number of cases. This supports that local and regional scales are not sufficient to tackle governance issues.

\section{4 "Good governance" to reduce deforestation}

The results of this study support the notion of a number of governance elements as being "good" for low deforestation. The findings thus imply that present "good governance" based approaches are applicable and can help reduce deforestation. However, when applying such frameworks, development work and policy needs to continuously reflect on the underlying goals and inherent values, as specifically informal values can differ between actors. Compared to such a normative approach, the principal difference of the presented analytical approach is that it explores causalities. It is outcome oriented. Based on this approach measures can rely on jointly agreed aims instead of value oriented principles. This can facilitate targeted policy and its implementation. 
As improved performance of a number of governance elements is linked to reduced deforestation, the focus on governance as observed in all major international and many national forest policy initiatives is justified. On the other hand, numerous indicators were hardly or not at all covered in the reviewed studies. Thus, when talking and publishing about forest governance, at least a specification of the applied elements is needed in order to avoid governance to become a meaningless buzzword. The results further suggest that an improvement of forest governance alone will not exclusively guarantee successful deforestation abatement. The stronger statistical power of factors like intensified agriculture and infrastructure measures justifies their perception as direct deforestation drivers and shows the need to directly tackle these challenges. However, without taking into account governance elements, such measures will most probably not be effective. Also here the REDD+ readiness measures are a prominent example. It shows that basic governance measures are needed before additional action is implemented. 


\section{References}

Adhikari, S., Baral, H., Nitschke, C., 2018. Identification, Prioritization and Mapping of Ecosystem Services in the Panchase Mountain Ecological Region of Western Nepal. Forests 9.

Agrawal, A., Wollenberg, E., Persha, L., 2014. Governing agriculture-forest landscapes to achieve climate change mitigation. Global Environmental Change 29, 270-280.

Andersson, K., Benavides, J.P., León, R., 2014. Institutional diversity and local forest governance. Environmental Science \& Policy 36, 61-72.

Andersson, K., Gibson, C.C., 2007. Decentralized governance and environmental change: Local institutional moderation of deforestation in Bolivia. Journal of Policy Analysis and Management 26, 99-123.

Angelsen, A., Brockhaus, M., Duchelle, A.E., Larson, A., Martius, C., Sunderlin, W.D., Verchot, L., Wong, G., Wunder, S., 2017. Learning from REDD+: a response to Fletcher et al. Conserv Biol $31,718-720$.

Angelsen, A., Hermansen, E.A., Rajão , R., van der Hoff, R., 2018. Results-based payments. In: Arngelsen, A., Martius, C., De Sy, V., Duchelle, A.E., Larson, A., Thu Thuy, P. (Eds.), Transforming REDD+: Lessons and new directions. CIFOR, Bogor, Indonesia.

Angelsen, A., Kaimowitz, D., 2001. Agricultural Technologies and Tropical Deforestation. CABI Publishing, Oxon, UK.

Ansell, C., Torfing, J., 2016. Handbook on Theories of Governance. Edward Elgar, Cheltenham, UK

Northhampton, MA, USA

Archer, M.S., 2003. Structure, agency and the internal conversation. Cambridge University Press.

Arts, B., 2014. Assessing forest governance from a 'Triple G' perspective: Government, governance, governmentality. Forest Policy and Economics 49, 17-22.

Arts, B., Behagel, J., Turnhout, E., de Koning, J., van Bommel, S., 2014. A practice based approach to forest governance. Forest Policy and Economics 49, 4-11.

Arts, B., Ingram, V., Brockhaus, M., 2020. The Performance of REDD From Global Governance to Local Practices. MDPI books, Basel.

Arts, B., Visseren-Hamakers, I.J., 2012. Forest governance: mainstream and critical views. In, Moving Forward with Forest Governance. Tropenbos International, ETFRN, Wageningen, NL.

Austin, Z., Sutton, J., 2014. Qualitative Research: Getting Started. The Canadian Journal of Hospital Pharmacy 67.

Bae, J.S., Joo, R.W., Kim Yeon-Su, Y.S., 2012. Forest transition in South Korea: Reality, path and drivers. Land Use Policy 29, 198-207.

Barbier, E.B., Tesfaw, A., 2015. Explaining forest transitions: The role of governance. Ecological Economics 119, 252-261.

Baynes, J., Herbohn, J., Dressler, W., 2016. Power relationships: Their effect on the governance of community forestry in the Philippines. Land Use Policy 54, 169-176.

Beaudoin, G., Rafanoharana, S., Boissiere, M., Wijaya, A., Wardhana, W., 2016. Completing the Picture: Importance of Considering Participatory Mapping for REDD+ Measurement, Reporting and Verification (MRV). PLoS One 11, e0166592. 
Bennett, M., Xie, C., Hogarth, N., Peng, D., Putzel, L., 2014. China's Conversion of Cropland to Forest Program for Household Delivery of Ecosystem Services: How Important is a Local Implementation Regime to Survival Rate Outcomes? Forests 5, 2345-2376.

Bhagwat, S.A., Humphreys, D., Jones, N., 2017. Forest governance in the Anthropocene: Challenges for theory and practice. Forest Policy and Economics 79, 1-7.

Bhattarai, M., Hammig, M., 2004. Governance, economic policy, and the environmental Kuznets curve for natural tropical forests. Environment and Development Economics 9, 367-382.

Bhatterai, M., Hammig, M., 2001. Institutions and the Environmental Kuznets Curve for Deforestation: A Crosscountry Analysis for Latin America, Africa and Asia. World Development 29, 995 - 1010.

Bottazzi, P., Dao, H., 2013. On the road through the Bolivian Amazon: A multi-level land governance analysis of deforestation. Land Use Policy 30, 137-146.

Brass, J.N., 2016. Chapter 8: Development theory In: Ansell, C., Torfing, J. (Eds.), Handbook on Theories of Governance. Edward Elgar Publishing, Glos, UK.

Brems, M., 2017. A One-Stop Shop for Principal Component Analysis. In. Medium.com.

Brennan, G., Buchanan, J.M., 1985. The Reason of Rules. Cambridge University Press, Cambridge.

Broekhoven, G., Savenije, H., von Scheliha, S., 2012. Moving Forward with Forest Governance. In: Tropenbos International, W.t.N. (Ed.), ETFRN News. ETFRN, Wageningen, NL.

Busch, J., Ferretti-Gallon, K., 2017. What Drives Deforestation and What Stops It? A Meta-Analysis. Review of Environmental Economics and Policy 11, 3-23.

Canova, N.P., Hickey, G.M., 2012. Understanding the impacts of the 2007-08 Global Financial Crisis on sustainable forest management in the Brazilian Amazon: A case study. Ecological Economics 83, 19-31.

Castro, F.G., Kellison, J.G., Boyd, S.J., Kopak, A., 2010. A Methodology for Conducting Integrative Mixed Methods Research and Data Analyses. Journal of mixed methods research 4, 342-360.

Ceddia, M.G., Bardsley, N.O., Gomez-Y-Paloma, S., Sedlacek, S., 2014. Governance, agricultural intensification, and land sparing in tropical South America. Proceedings of the National Academy of Sciences of the United States of America 111, 7242-7247.

Chambers, R., 1994. The origins and practice of participatory rural appraisal. World Development 22, 953-969.

CIFOR, 2015. Interview Questions Guide. In. CIFOR, Bogor, Indonesia.

Coe, K., Scacco, J., M., 2017. Content Analysis, Quantitative. In, The International Encyclopedia of Communication Research Methods, pp. 1-11.

Damastuti, E., de Groot, R., 2019. Participatory ecosystem service mapping to enhance communitybased mangrove rehabilitation and management in Demak, Indonesia. Reg Environ Change $19,65-78$.

Davis, C., Williams, L., Lupberger, S., Daviet, F., 2013a. Assessing forest governance: the governance of forests initiative indicator framework. World Resources Institute, Washington D. C., USA.

Davis, C., Williams, L., Lupberger, S., Daviet, F., 2013b. Assessing Forest Governance: The Governance of Forests Initiative Indicator Framework. In. WRI, Washington, D.C., USA.

de Graaf, M., Buck, L., Shames, S., Zagt, R., 2017. Assessing Landscape Governance, A Participatory Approach. In. Tropenbos, EcoAgriculture, Wageningen, Washington. 
de Souza, R.A., Miziara, F., de Marco Junior, P., 2013. Spatial variation of deforestation rates in the Brazilian Amazon: A complex theater for agrarian technology, agrarian structure and governance by surveillance. Land Use Policy 30, 915-924.

Dekking, M., 2005. A modern introduction to probability and statistics : understanding why and how. Springer, London.

Dray, S., Josse, J., 2014. Principal component analysis with missing values: a comparative survey of methods. Plant Ecology 216, 657-667.

Dunning, T., 2008. Improving Causal Inference: Strengths and Limitations of Natural Experiments. Political Research Quarterly 61, 282-293.

Dunteman, G.H., 1989. Principal Component Analysis. Sage Publications, Newsbury Park, CA.

Dytham, C., 2011. Choosing and using statistics: a biologist's guide. John Wiley \& Sons.

Elwood, S., Ghose, R., 2011. PPGIS in Community Development Planning: Framing the Organizational Context. In, pp. 83-105.

Facility, E.F., 2013. Governance Research Agenda for FLEGT: Towards global forest governance research and action. In. EFI, Tropenbos International, EU.

FAO, 2015. FRA 2015 Terms and Definitions. In. Food and Agriculture Oragnisation (FAO), Rome, Italy.

FAO, 2020. Global Forest Resources Assessment 2020, Rome, Italy.

Farina, A., 2000. The Cultural Landscape as a Model for the Integration of Ecology and Economics. BioScience 50.

Fischer, R., Giessen, L., Günter, S., 2020. Governance effects on deforestation in the tropics: A review of the evidence. Environmental Science and Policy 105, 84 - 101.

Fischer, R., Hargita, Y., Günter, S., 2016. Insights from the ground level? A content analysis review of multi-national REDD+ studies since 2010. Forest Policy and Economics 66, 47-58.

Fischer, R., Tamayo, F., Ojeda Luna, T., Ferrer Velasco, R., DeDecker, M., Torres, B., Giessen, L., Günter, S., submitted. Effects of governance elements and their interplay on deforestation in tropical landscapes: Quantitative insights from Ecuador. World Development.

Fletcher, R., Dressler, W., Buscher, B., Anderson, Z.R., 2016. Questioning REDD+ and the future of market-based conservation. Conserv Biol 30, 673-675.

Freeman, M.F., Tukey, J.W., 1950. Transformations related to the angular and the square root. The Annals of Mathematical Statistics, 607-611.

Freund, L., Hawkins, B., Saewyc, E., 2016. Reflections on the use of Participatory Mapping to study Everyday Health Information Seeking by LGBTQ Youth. Proceedings of the Association for Information Science and Technology 53, 1-4.

Gautam, A.P., Shivakoti, G.P., Webb, E.L., 2004. A review of forest policies, institutions, and changes in the resource condition in Nepal. International Forestry Review 6, 136-148.

Geist, H.J., Lambin, E.F., 2002. Proximate Causes and Underlying Driving Forces of Tropical DeforestationTropical forests are disappearing as the result of many pressures, both local and regional, acting in various combinations in different geographical locations. BioScience 52, 143-150. 
Gelman, A., Hill, J., 2006. Causal inference using regression on the treatment variable. In, Data Analysis Using Regression and Multilevel/Hierarchical Models. Cambridge University Press, Cambridge, pp. 167-198.

Giddens, A., 1984a. The Constitution of Society. Outline of the Theory of Structuration. Polity Press, Cambridge.

Giddens, A., 1984b. The constitution of society: Outline of the theory of structuration. Polity Press, Cambridge.

Giessen, L., Buttoud, G., 2014. Defining and assessing forest governance. Forest Policy and Economics 49, 1-3.

Giessen, L., Krott, M., Möllmann, T., 2014. Increasing representation of states by utilitarian as compared to environmental bureaucracies in international forest and forest-environmental policy negotiations. Forest Policy and Economics 38, 97-104.

Given, L.M., 2008. The SAGE Encyclopedia of Qualitative Research Methods. SAGE Publications, Los Angeles.

Glesne, C., 2011. Becoming Qualitative Researchers: An Introduction (4th ed.). Pearson, Boston.

Hayes, T., Persha, L., 2010. Nesting local forestry initiatives: Revisiting community forest management in a REDD+ world. Forest Policy and Economics 12, 545-553.

Hocking, R.R., 1976. A Biometrics invited paper. The analysis and selection of variables in linear regression. Biometrics 32, 1-49.

Hosonuma, N., Herold, M., Sy, V., De Fries, R.S., Brockhaus, M., Verchot, L., Angelsen, A., Romijn, E., 2012. An assessment of deforestation and forest degradation drivers in developing countries. Environmental Research Letters 7, 044009.

Hutchins, D.E., 1916. A Discussion of Australian Forestry. Publisher Perth, Government Printer.

IFAD, 2009. Good practices in participatory mapping - a review prepared for the International Fund of Agricultural Development (IFAD). In.

IFRI, 2011. Field Manual, Version 14. In: Elinor, O. (Ed.). International Forestry Resources and Institutions (IFRI) Research Program, Michigan.

Jolliffe, I.T., 2002 Principal component analysis, 2nd edn. Springer, New York.

Jones, K.W., Holland, M.B., Naughton-Treves, L., Morales, M., Suarez, L., Keenan, K., 2017. Forest conservation incentives and deforestation in the Ecuadorian Amazon. Environmental Conservation 44, 56-65.

Kanninen, M., Murdiyarso, D., Seymour, F., Angelsen, A., Wunder, S., German, L., 2007. Do Trees Grow on Money? The implications of deforestation research for policies to promote REDD. In. CIFOR, Bogor, Indonesia.

Kashwan, P., Holahan, R., 2014. Nested governance for effective REDD+: Institutional and political arguments. International Journal of the Commons 8, 554-575.

Kassambara, A., 2017. Practical Guide To Principal Component Methods in R, 1st Edition. sthda.com.

Kenney, J.F., Keeping, E.S., 1962. Ch. 15 .Linear Regression and Correlationin In, Mathematics of Statistics, . Van Nostrand, Princeton, NJ, pp. 252-285.

Kishor, N., Kenneth, R., 2012. Assessing and Monitoring Forest Governance:: A user's guide to a diagnostic tool. In, Program on Forests. PROFOR, Washington, D.C., USA. 
Kleinschmit, D., Böcher, M., Giessen, L., 2016. Forest Policy Analysis: Advancing the analytical approach. Forest Policy and Economics 68, 1-6.

Korhonen-Kurki, K., Brockhaus, M., Duchelle, A.E., Atmadja, S., Thuy, P.T., Schofield, L., 2013. Multiple levels and multiple challenges for measurement, reporting and verification of REDD+. International Journal of the Commons 7, 344-366.

Korhonen-Kurki, K., Sehring, J., Brockhaus, M., Di Gregorio, M., 2014. Enabling factors for establishing REDD+ in a context of weak governance. Climate Policy 14, 167-186.

Krott, M., Bader, A., Schusser, C., Devkota, R., Maryudi, A., Giessen, L., Aurenhammer, H., 2014. Actor-centred power: The driving force in decentralised community based forest governance. Forest Policy and Economics 49, 34-42.

Laraswati, D., Rahayu, S., Pratama, A.A., Soraya, E., Sahide, M.A.K., Maryudi, A., 2020. Problemmethod fit in forest policy analysis: Empirical pre-orientation for selecting tested or innovative social-qualitative methods. MethodsX 7, 100794.

Larcom, S., van Gevelt, T., Zabala, A., 2016. Precolonial institutions and deforestation in Africa. Land Use Policy 51, 150-161.

Larson, A.M., 2011. Forest tenure reform in the age of climate change: Lessons for REDD+. Global Environmental Change 21, 540-549.

Larson, A.M., Petkova, E., 2011. An introduction to forest governance, people and REDD+ in latin america: Obstacles and opportunities. Forests 2, 86-111.

Leard, 2020. Principal Components Analysis (PCA) using SPSS Statistics. In. Lund Research, Nottingham, U.K. .

Likert, R., 1932. A technique for the measurement of attitudes. Archives of Psychology 22 140, 55-55.

Lingel, J., 2011. Information tactics of immigrants in an urban environment. Information Research 16.

Liu, Y., Feng, Y., Zhao, Z., Zhang, Q., Su, S., 2016. Socioeconomic drivers of forest loss and fragmentation: A comparison between different land use planning schemes and policy implications. Land Use Policy 54, 58-68.

Magliocca, N.R., Ellis, E.C., Allington, G.R.H., de Bremond, A., Dell'Angelo, J., Mertz, O., Messerli, P., Meyfroidt, P., Seppelt, R., Verburg, P.H., 2018. Closing global knowledge gaps: Producing generalized knowledge from case studies of social-ecological systems. Global Environmental Change 50, 1-14.

Manley, B.F.J., 2005. Multivariate Statistical Methods. A Primer. Third Edition. Chapman and Hall.

Mansourian, S., 2016. Understanding the Relationship between Governance and Forest Landscape Restoration. Conservation and Society 14, 267-278.

Mansourian, S., 2017. Governance and forest landscape restoration: A framework to support decision-making. Journal for Nature Conservation 37, 21-30.

Mapedza, E., Wright, J., Fawcett, R., 2003. An investigation of land cover change in Mafungautsi Forest, Zimbabwe, using GIS and participatory mapping. Applied Geography 23, 1-21.

March, J.G., Olsen, J.P., 2004. The logic of appropriateness. . In: Moran, M., Rein, M., Goodin, R.E. (Eds.), The Oxford handbook of political science. Oxford University Press, Oxford.

March, J.P., Olsen, J.P., 1998. The institutional dynamics of international political orders. International Organization 52, 943-969. 
Martin, M., Peters, B., Corbett, J., 2012. Participatory Asset Mapping in the lake victoria basin of Kenya. Journal of the Urban and Regional Information Systems Association 25, 45-56.

Maryudi, A., Nurrochmat, D.R., Giessen, L., 2018. Research trend: Forest policy and governance Future analyses in multiple social science disciplines. Forest Policy and Economics 91, 1-4.

Mayring, P., 2000. Qualitative Content Analysis. Forum: Qualitative Social Research 1, Art 25.

Mayring, P., 2014. Qualitative content analysis: theoretical foundation, basic procedures and software solution. Open Access Repository, Klagenfurt.

Nackoney, J., Rybock, D., Dupain, J., Facheux, C., 2013. Coupling participatory mapping and GIS to inform village-level agricultural zoning in the Democratic Republic of the Congo. Landscape and Urban Planning 110, 164-174.

Nansikombi, H., Fischer, R., Ferrer Velasco, R., Kabwe, G., Lippe, M., Kanungwe Kalaba, F., Günter, S., submitted. Can de facto governance influence deforestation drivers in the Zambian Miombo? Forest Policy and Economics.

Nansikombi, H., Fischer, R., Kabwe, G., Günter, S., 2020. Exploring patterns of forest governance quality: Insights from forest frontier communities in Zambia's Miombo ecoregion. Land Use Policy 99, 104866.

Nansikombi , H., Fischer, R., Kabwe, G., Günter, S., 2020. Exploring patterns of forest governance quality: insights from forest frontier communities in Zambia's Miombo ecoregion. Land Use Policy (accepted).

Nyumba, T.O., Wilson, K., Derrick, C.J., Mukherjee, N., Geneletti, D., 2018. The use of focus group discussion methodology: Insights from two decades of application in conservation. Methods in Ecology and Evolution 9, 20-32.

Ostrom, E., 1999. Governing the commons: the evolution of institutions for collective action. Cambridge University Press, New York.

Ostrom, E., 2009. A general framework for analyzing sustainability of social-ecological systems. Science 325, 419-422.

Pallant, J., 2010. SPSS Survival Manual. Open University Press.

Pearl, J., 2009. Causal inference in statistics: An overview. Statistics Surveys 3, 96-146.

PennState, 2019. Detecting Multicollinearity Using Variance Inflation Factors. In, STAT 462. The Pennsylvania State University.

Peres-Neto, P.R., Jackson, D.A., Somers, K.M., 2003. Giving Meaningful Interpretation to Ordination Axes: Assessing Loading Significance in Principal Component Analysis. Ecology 84, 2347-2363.

Piketty, M.G., Poccard-Chapuis, R., Drigo, I., Coudel, E., Plassin, S., Laurent, F., Thâles, M., 2015. Multi-level Governance of land use changes in the Brazilian Amazon: Lessons from Paragominas, State of Pará. Forests 6, 1516-1536.

Porter-Bolland, L., Ellis, E.A., Guariguata, M.R., Ruiz-Mallén, I., Negrete-Yankelevich, S., Reyes-García, V., 2012. Community managed forests and forest protected areas: An assessment of their conservation effectiveness across the tropics. Forest Ecology and Management 268, 6-17.

QGIS, 2018. QGIS Geographic Information System. Open Source Geospatial Foundation Project, QGIS version 2.18. In.

Rahman, M.S., Giessen, L., 2017. Formal and Informal Interests of Donors to Allocate Aid: Spending Patterns of USAID, GIZ, and EU Forest Development Policy in Bangladesh. World Development 94, 250-267. 
Ranadive, A., 2020. Making Decisions Under Uncertainty or, How to Decide with Incomplete Data. In. Medium.com.

Rantala, S., Hajjar, R., Skutsch, M., 2014. Multilevel governance for forests and climate change: Learning from Southern Mexico. Forests 5, 3147-3168.

Ratner, C., 2002. Subjectivity and Objectivity in Qualitative Methodology. Forum Qualitative Sozialforschung 3.

Ravikumar, A., Kijazi, M., Larson, A.M., Kowler, L., 2015. Multilevel Governance and Carbon Management at the Landscape Scale. Project Guide and Methods Training Manual. In. CIFOR, Bogor, Indonesia.

Rayner, J., Buck, A., Katila, P., 2010. Embracing complexity in internationa forest governance: a way forward. Policy Brief. In: IUFRO (Ed.).

Rencher, A.C., Christensen, W.F., 2012. Multivariate Regression. Methods of Multivariate Analysis, 339-383.

Rothbard, M., 2009. Man, Economy, and State with Power and Market. Ludwig von Mises Institute., Auburn, USA.

Rudel, T.K., 2008. Meta-analyses of case studies: A method for studying regional and global environmental change. Global Environmental Change 18, 18-25.

SAS, 2015. JMP 12. Basic Analysis. SAS Institute, Carry, N.C.

Sayer, J., Sunderland, T., Ghazoul, J., Pfund, J.L., Sheil, D., Meijaard, E., Venter, M., Boedhihartono, A.K., Day, M., Garcia, C., van Oosten, C., Buck, L.E., 2013. Ten principles for a landscape approach to reconciling agriculture, conservation, and other competing land uses. Proc Natl Acad Sci U S A 110, 8349-8356.

Schusser, C., Krott, M., Devkota, R., Maryudi, A., Salla, M., Movuh, M.C.Y., 2012. Sequence design of quantitative and qualitative surveys for increasing efficiency in forest policy researc. Allgemeine Forst- und Jagdzeitung 183, 75-83.

Schusser, C., Krott, M., Yufanyi Movuh, M.C., Logmani, J., Devkota, R.R., Maryudi, A., Salla, M., Bach, N.D., 2015. Powerful stakeholders as drivers of community forestry - Results of an international study. Forest Policy and Economics 58, 92-101.

Secco, L., Pettenella, D., Gatto, P., 2011. Forestry governance and collective learning process in Italy: Likelihood or utopia? Forest Policy and Economics 13, 104-112.

Shahabuddin, G., Rao, M., 2010. Do community-conserved areas effectively conserve biological diversity? Global insights and the Indian context. Biological Conservation 143, 2926-2936.

Siegel, S., 1988. Nonparametric statistics for the behavioral sciences., McGraw-Hill, New York

Singer, B., Giessen, L., 2017. Towards a donut regime? Domestic actors, climatization, and the hollowing-out of the international forests regime in the Anthropocene. Forest Policy and Economics 79, 69-79.

Soares-Filho, B., Alencar, A., Nepstad, D., Cerqueira, G., Del Carmen Vera Diaz, M., Rivero, S., Solórzano, L., Voll, E., 2004. Simulating the response of land-cover changes to road paving and governance along a major Amazon highway: The Santarém-Cuiabá corridor. Global Change Biology 10, 745-764.

Steinberg, P.F., 2015. Can We Generalize from Case Studies? Global Environmental Politics 15, 152175. 
Stevanov, M., Dobšinska, Z., Surový, P., 2016. Assessing survey-based research in forest science: Turning lemons into lemonade? Forest Policy and Economics 68, 105-117.

Stickler, M.M., Huntington, H., Haflett, A., Petrova, S., Bouvier, I., 2017. Does de facto forest tenure affect forest condition? Community perceptions from Zambia. Forest Policy and Economics $85,32-45$.

Subhan Mollick, A., Khalilur Rahman, M., Nabiul Islam Khan, M., Nazmus Sadath, M., 2018. Evaluation of good governance in a participatory forestry program: A case study in Madhupur Sal forests of Bangladesh. Forest Policy and Economics 95, 123-137.

Thacker, N.A., Bromiley, P.A., 2001. The effects of a square root transform on a Poisson distributed quantity. Tina memo 10, 2001.

Umemiya, C., Rametsteiner, E., Kraxner, F., 2010a. Quantifying the impacts of the quality of governance on deforestation. Environmental Science and Policy 13, 695-701.

Umemiya, C., Rametsteiner, E., Kraxner, F., 2010b. Quantifying the impacts of the quality of governance on deforestation. Environmental Science \& Policy 13, 695-701.

UN, 2019. Global Forest Goals and Targets of the UN Strategic Plan of Forests 2030. In. Unite Nations, New York.

UN, 2020. Global Hub on the Governance for the SDGs. In. United Nations, New York.

Vuohelainen, A.J., Coad, L., Marthews, T.R., Malhi, Y., Killeen, T.J., 2012. The effectiveness of contrasting protected areas in preventing deforestation in Madre de Dios, Peru. Environmental Management 50, 645-663.

Watts, J.D., Colfer, C.J.P., 2011. The governance of Tropical forest Landscapes. In: Colfer, C.J.P., Pfund, J.-L. (Eds.), Collaborate Governance of Tropical Landscapes. Earthscan, New York, pp. 35-54.

Webb, E.L., Jachowski, N.R.A., Phelps, J., Friess, D.A., Than, M.M., Ziegler, A.D., 2014. Deforestation in the Ayeyarwady Delta and the conservation implications of an internationally-engaged Myanmar. Global Environmental Change 24, 321-333.

Wehkamp, J., Aquino, A., Fuss, S., Reed, E.W., 2015. Analyzing the perception of deforestation drivers by African policy makers in light of possible REDD+ policy responses. Forest Policy and Economics 59, 7-18.

Wehkamp, J., Koch, N., Lübbers, S., Fuss, S., 2018. Governance and deforestation - a meta-analysis in economics. Ecological Economics 144, 214-227.

Weiland, S., Dedeurwaerdere, T., 2010. Change in forest governance in developing countries. In search of sustainable governance arrangements. International Journal of the Commons 4 , 683-686.

Worldbank, 2006. A Decade of Measuring the Quality of Governance. Governance matters 2006. Worldwide Governance Indicators. In, Washington, D.C. 
Annex 


\section{Annex 1: Forest ownership and tenure in Ecuador, Zambia and The Philippines}

\section{Forest ownership and tenure in Ecuador}

In Ecuador, the constitution of 2008 recognizes the right of communities, nationalities and indigenous territories to preserve the imprescriptible tenure over their ancestral territories with an inalienable and indivisible character (Art. 57). This includes the guarantee of collective rights for agricultural organizations and ancestral domains. Nowadays the two biggest owners of native forest are the Ecuadorian State and indigenous groups (Morales et al., 2010). Indigenous groups occupy territories corresponding to $65 \%$ of the Ecuadorian forests (Palacios, 2005). A significant portion of the indigenous groups, specifically in the Ecuadorian Amazon is still in the process of claiming the legal recognition of their lands. Within communal lands, with or without title, indigenous communities usually follow traditional governance mechanisms, including rules of land use planning, with significant portions of the land assigned to single families for individual management. Private individuals or organizations can obtain land titles if possession and production is documented over a minimum period of five years. But based on customary rights, private farms also exist on nontitled lands. With the agrarian reforms in 1964 and 1973, the state government of Ecuador had awarded farms with on average 50 ha to enhance colonization (Pan et al., 2004). After colonists had settled, their claims on the land were respected if at least $50 \%$ of the forest was cleared (Richards, 1997) and evidence of agricultural use was provided (Murphy et al., 1997). To a smaller extent, also indigenous families colonize land outside communal territories and claim the ownership under the same mechanism as non-indigenous settlers. Land use systems and governance mechanisms specifically of individual indigenous farmers more and more match those of colonizing settlers. Traditionally indigenous communities leave parts of their lands unmanaged as reserve after having assigned portions of individual land to each of the members. In the Amazon Basin, these indigenous reserves are mainly covered by forests, the ultimate goal is to reserve land for future generations and future production (Holt and Bilsborrow, 2004; Izurieta et al., 2014).

Article 261 (11) of the constitution of Ecuador foresees that forest resources are under the principal competence of the state (ACE, 2008). The largest share of Ecuadorian state forest is constituted by the the 'Patrimonio de Áreas Naturales del Estado' (patrimony of natural areas - PANE) which is part of the system of protected areas 'Sistema Nacional de Areas Protegidas' (SNAP) (MAE, 2016). SNAP covers approximately $20 \%$ of the Ecuadorian surface in 56 natural reserves, ranging from National Parks (the highest level of protection) to ecological municipal areas. Forest use in PANE areas is not allowed, however, there is an overlap with ancestral domain areas inhabited by indigenous people, who are allowed to use forest products for subsistence use.

\section{Forest ownership and tenure in Zambia}

The forest governance arrangements of Zambia are grounded in the land reform in 1924, which dates back to the colonial period. At that time, land in Zambia was demarcated into crown land and native reserve land (Van Loenen, 1999, Brown, 2005). Following Zambia's independence in 1964, crown land was converted to state land. The differentiation into customary and state land persists until today, but customary land administration was sub-ordinated to the formal law, which previously only applied to crown land. However, the method of customary land alienation continued to be under the 
customary law. Today, the majority of Zambia's forest occurs on customary land. In parallel to the political state administration within each district there is a strong customary administrative structure that is guaranteed by the Constitution of the Republic of Zambia (Mason-Case, 2011) and that build on tribes headed by their chiefs who can delegate rights and responsibilities to headpersons and subchiefs within their jurisdictions (Mason-Case, 2011). Today only selected customary lands are formally titled. Traditional leaders determine land use, access and user rights on customary land based on local traditions. The political administration must engage in consultations with traditional institutions before undertaking any activities on customary lands. Under the formal law, commercial use of forest products without a license on customary lands is restricted although access and subsistence use are not (GRZ, 2015a). The local government's involvement in governance of customary forests is constrained by contradicting land tenure policies (Chikulo, 2009). While the Local Government Act of 1991 gives the district council mandate to plan and lead the management of customary forests, the Land Act of 1995 places the administration of these lands under customary authority. Besides, customary authorities sometimes challenge the authority of the sub-district governance structures (Mfune, 2013). Following traditional rules, local chiefs can designate customary land either for individual use by single families or keep it as communal forests to meet the social, cultural and economic needs of local communities. For specific communal forests there are cultural use restrictions, e.g. in graveyards.

Other forests in Zambia are located on state lands. State forests include National and Local Forest Reserves, administered by the Forest Department (GRZ, 2015a, Kalinda et al., 2008) as well as National Parks and Game Management Areas, administered by the Department of National Parks and Wildlife (GRZ, 2015b). The primary objective of the state forests is protection and enhancement of wildlife, ecosystems, biological diversity and natural beauty. Under the formal law, access and use of forest resources on state forests is restricted except with special permits. There also exist private forests on state lands, which constitute $10.6 \%$ of the total forest area. Registered individuals or companies through leasehold tenure own these.

\section{Forest ownership and tenure in the Philippines}

The Revised Forestry Code of the Philippines (PD 705) provides a system of land classification based on topography to distinguish "alienable and disposable" lands and "forest lands". It defines forestlands as all land within or above the so-called 18 percent slope line. These forestlands are inalienable and are owned by the state, because as adopted by the Philippine Constitution, "all lands of the public domain belong to the state, and those lands not appearing to be clearly within private ownership are presumed to belong to the state." An individual can only utilize, exploit, occupy, possess or conduct any activity within a forest upon the issuance of a license agreement, license, lease or permit issued by the Department of Environment and Natural Resources (DENR). The state forests fall under a "moratorium on the cutting and harvesting of timber in the natural forest" (Executive Order No. 23), commonly known as logging ban. However, the small scale use of timber in state forests is hard to control (Carandang et al., 2012). Since there is limited manpower to guard and patrol these areas, people can easily get in and out of these areas resulting in uncontrolled use of the forest. Therefore, these forests have been occupied by upland dwellers who have cultivated the area for subsistence farming, claiming stake in the forest land informally. The informal claims are often respected by the community. 
In 1995, Executive Order 263 was enacted to adopt Community Based Forest Management (CBFM) as a national strategy for sustainable forest management. The strategy regards the people as partners in forest management through the integration of people-oriented forestry projects, provision of land tenure security, promotion of livelihood projects, and decentralization of forest resource governance. With this instrument, communities are encouraged to establish livelihoods using forest resources since the program aims to provide an enabling environment where people can manage their forest resources. CBFM enables people organizations to apply for timber and NTFP licenses and resource use permits to legally acquire forest resources based on management plans. Protected Area Community Based Resource Management Agreements (PACBRMA) are comparable instruments, however they are issued to communities living in buffer zones of the National Integrated Protected Area System (NIPAS) or other types of protected areas. Both tenure instruments provide 25 years contracts (renewable for another 25 years) for tenure holders to develop, manage, protect, and use specified areas of the forest land (Executive Order 263, DENR Administrative Order No. 2004-32). The main incentive of the community-based agreements is tenure security.

Certificate of Ancestral Domain Titles (CADT) provides the rights to ancestral domains and lands to indigenous communities. With the provision of Rights to Ancestral Domains and Lands, the Republic Act 8371 recognizes communal land tenure of indigenous peoples as a legitimate right and offers the right to use and develop lands and natural resources in accordance with indigenous knowledge systems and practices and customary laws and traditions.

The Integrated Social Forestry Program was launched in 1982. Integrated Social Forestry (ISF) with Individual Property Rights (IPR) provide individual forest tenure and land use rights for a period of 25 years and is renewable for an additional 25 years to upland dwellers participating in the program With the implementation of the CBFM in 1995, ISF and other people-oriented forestry programs were integrated in the CBFM program. Nevertheless, the previous designated ISF areas are until today managed by individuals in contrast to the remaining CBFM area which is under community management. The rules and obligations of ISF are comparable to the remaining CBFM areas. 


\section{Annex 2: Governance elements with indicators as implemented in assessments in Ecuador (ECU), Zambia (ZMB) and the Philippines (PHI)}

(x: assessed)

Thematic Area

Elements (in bold) with indicators and description

ECU

ZMB

PHI

Forest tenure

\begin{tabular}{|c|c|c|c|}
\hline \multicolumn{4}{|l|}{$\begin{array}{l}\text { Forest tenure recognition and protection in practice. } \\
\text { To what extent are tenure rights widely recognized } \\
\text { and protected in practice? }\end{array}$} \\
\hline $\begin{array}{l}\text { Recognition. Individual and communal rights-holders } \\
\text { have their rights formally recognized and recorded. }\end{array}$ & $x$ & $x$ & $x$ \\
\hline $\begin{array}{l}\text { Demarcation. Individual and communal forest lands } \\
\text { have boundaries demarcated and surveyed }\end{array}$ & $x$ & $x$ & $x$ \\
\hline $\begin{array}{l}\text { Enforcement. Infringements of rights are quickly and } \\
\text { fairly addressed. }\end{array}$ & & $x$ & $x$ \\
\hline $\begin{array}{l}\text { Customary tenure. Minimal conflict exists between } \\
\text { customary forest tenure systems and statutory } \\
\text { systems on the ground. }\end{array}$ & & $x$ & $x$ \\
\hline $\begin{array}{l}\text { Gender equity. Rights registered to individuals or } \\
\text { households are registered in the names of women, } \\
\text { either jointly or individually }\end{array}$ & $x$ & $x$ & $x$ \\
\hline
\end{tabular}

Land use decision making. To what extent are legal users involved in land use decision making?

Procedure. Land use decisions are taken in a formally established process

Transparency. Planning process is transparent and procedures are clearly defined

Opportunities for participation. Communities or

entitled individuals have the possibility for

participation in land use planning processes.

Coordination. Implementing

agencies/persons/enterprise effectively coordinate in carrying out their roles and responsibilities.

Representation. Representatives to land use-planning processes reflect a range of community perspectives, including women and different socioeconomic classes Capacity to engage. Representatives in land-use planning have information and skills to effectively engage and participate in land use planning processes

Forest

Management

Implementation of strategies and plans. To what extent are land use/forest/protected area strategies and plans effectively implemented in practice?

Coordination. Implementing

agencies/persons/enterprise effectively coordinate in carrying out their roles and responsibilities

Timeliness. Implementation happens according to the timeline specified by the plan/strategy.

Monitoring. Implementation is subject to regular monitoring of impacts and effectiveness.

Transparency. Land use plans and monitoring reports are publicly disclosed on a regular basis.

Review. Plans and strategies are reviewed and updated regularly

Protection of natural forest (logging moratorium) . To what extent are natural forests protected? Use restrictions. Stakeholders clearly understand the timeframe and what activities are allowed and not allowed within the natural forests Transparency. Implementing agencies are aware and effectively coordinate to carry out their roles and responsibilities in enforcing the logging moratorium 
Apprehension. Violators are apprehended and brought to trial by concerned authorities Consistency. Assigned penalties are generally consistent with the law and appropriate given the nature of the offense

Compliance. Penalties are served or are paid in full in a timely manner

Monitoring of compliance. Compliance with penalties is monitored and further legal action is taken in cases of non-compliance

Transparency. Information about penalties and their state of compliance is publicly disclosed

$\begin{array}{lll}x & x & x \\ & x & x \\ & x & \\ & x & \\ & x & \\ & x & \end{array}$

Customary law enforcement. To what extent is customary law enforced?

Apprehension. Violators are apprehended and brought to trial by concerned authorities Consistency. Assigned penalties are generally consistent with the law and appropriate given the nature of the offense

Compliance. Penalties are served or are paid in full in a timely manner

Monitoring of compliance. Compliance with penalties is monitored and further legal action is taken in cases of non-compliance

Transparency. Information about penalties and their state of compliance is publicly disclosed

$\mathrm{x}$
$\mathrm{x}$
$\mathrm{x}$
$\mathrm{x}$

Reforestation. To what extent are available forest lands replanted and rehabilitated not for NGP reforestation areas)?

Coordination. The implementing agency coordinates implementation by establishing clear agreements with people and organizations

Procedures. Stakeholders understand the procedures and terms of the program, including planting sites and species, duration, and associated benefits and responsibilities

Capacities. Communities have been capacitated to implement the program

Benefits. Participants have received compensation as agreed.

Monitoring. Implementation is subject to regular monitoring to ensure compliance and effectivity.

Implementation of National Greening Programme. To what extent are available forest lands under the NGP Programme replanted and rehabilitated? Procedures. Stakeholders understand the procedures and terms of the program, including planting sites and species, duration, and associated benefits and responsibilities

Coordination. The implementing agency coordinates

implementation by establishing clear agreements with people and organizations

Benefits. Participants have received compensation as agreed.

Monitoring. Implementation is subject to regular monitoring to ensure compliance and effectivity.

Protection and conservation. To what extent is forestland protected or allocated to the conservation of soil, water, biodiversity or culture? Demarcation. Boundaries of protected or conservation forests areas are clearly demarcated. Use restrictions. Stakeholders clearly understand the timeframe and what activities are allowed and not allowed within the protection or conservation area Enforcement. Implementing agencies are aware and effectively coordinate to carry out their roles and responsibilities 
Penalties. Stakeholders understand penalties for failing to comply with the rules of the arrangement Monitoring. Implementation is subject to regular monitoring of impacts and effectiveness

Administration of timber harvesting licenses and permits. To what extent can tenure holders obtain necessary licenses and permits for harvesting timber?

To what extent can tenure holders obtain necessary licenses and permits for harvesting timber forest products?

Procedural clarity. Clear administrative procedures $\quad x \quad x \quad x$ regulate the obtaining of licenses and permits Transparency. Application status can be tracked Accessibility. The process for acquiring a license or permit is not prohibitively complicated and expensive Timeliness. Licenses and permits can be obtained in a reasonable time and within the time prescribed Implementation. Licenses and permits are honoured during harvesting and transport of forest products

Administration of non-timber forest product harvesting licenses and permits. To what extent can tenure holders obtain necessary licenses and permits for harvesting non-timber forest products? Procedural clarity. Clear administrative procedures regulate the obtaining of licenses and permits Transparency. Application status can be tracked Accessibility. The process for acquiring a license or permit is not prohibitively complicated and expensive Timeliness. Licenses and permits can be obtained in a reasonable time and within the time prescribed Implementation. Licenses and permits are honoured during harvesting and transport of forest products

Administration of charcoal licenses and permits. To what extent can tenure holders obtain necessary licenses and permits for harvesting charcoal products?

Procedural clarity. Clear administrative procedures regulate the obtaining of licenses and permits Transparency. Application status can be tracked Accessibility. The process for acquiring a license or permit is not prohibitively complicated and expensive Timeliness. Licenses and permits can be obtained in a reasonable time and within the time prescribed Implementation. Licenses and permits are honoured during harvesting and transport of forest products

Implementation of programme/project for supporting of forest-based sustainable livelihoods. To what extent are forest-based sustainable livelihood programmes/projects implemented? Procedures. Stakeholders clearly understand the procedures for setting up sustainable livelihood projects.

Coordination. Government agencies coordinate and provide support in implementing and sustaining projects

Resources. Forest resources are adequate to sustain livelihoods

Facilities. Credit facilities and capacity building were made available to local communities Benefits. Community members receive shares and benefits equitably

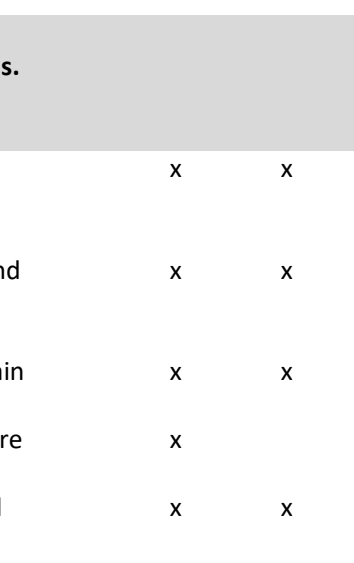


Transparency. Field staff generate comprehensive and accurate records of all fees collected and are made available to public.

Awareness. The government takes action to ensure that non-governmental "payers" are aware of their obligations.

Timeliness. Fees are collected in a timely manner. Monitoring. Regular monitoring evaluates whether appropriate fees are collected as agreed

Benefit sharing mechanisms.

Participation. Community has participated in the design of local benefit sharing arrangements.

Compliance. Benefits are delivered in accordance with the agreed terms set out in relevant legal or project documents

Awareness. Community members are aware of benefits received and obligations associated with those benefits

Fairness. The type and magnitude of benefits are fair and appropriate

Monitoring. Regular monitoring evaluates whether

benefits as agreed have reached intended recipients

Capacities and effectiveness of central government institutions.

Knowledge and skills. Institutions capacitated with up to date knowledge and skills to take active role in forest management

Human resources. Institutions capacitated with adequate number of staff to take active role in forest management

Financial resources. Institutions capacitated with sufficient financial resources to take active role in forest management

Scientific and technical information. Institutions capacitated with relevant scientific and technical information to take active role in forest management Effectiveness. Institutions are effective in implementing forest management objectives

$\mathrm{x}$

\section{Capacities and effectiveness of local government} institutions.

Knowledge and skills. Institutions capacitated with up to date knowledge and skills to take active role in forest management

Human resources. Institutions capacitated with adequate number of staff to take active role in forest management

Financial resources. Institutions capacitated with sufficient financial resources to take active role in forest management

Scientific and technical information. Institutions capacitated with relevant scientific and technical information to take active role in forest management Effectiveness. Institutions are effective in implementing forest management objectives Government capacities. Government agencies have adequate number of staff with up-to-date knowledge and skills, technology and equipment, and budget to perform its roles and duties.

\section{Capacities and effectiveness of non government} institutions.

Knowledge and skills. Institutions capacitated with up to date knowledge and skills to take active role in forest management Human resources. Institutions capacitated with adequate number of staff to take active role in forest management

Financial resources. Institutions capacitated with sufficient financial resources to take active role in forest management 
Scientific and technical information. Institutions

$x$ capacitated with relevant scientific and technical information to take active role in forest management Effectiveness Institutions are effective in implementing forest management objectives NGO capacities. NGOs have adequate number of staff $\quad x$ with up-to-date knowledge and skills, technology and equipment, and budget to provide services.
Cross cutting

issues

\section{Capacities and effectiveness of customary} institutions.

Knowledge and skills. Institutions capacitated with up to date knowledge and skills to take active role in forest management

Human resources. Institutions capacitated with $x$ adequate number of staff to take active role in forest management

Financial resources. Institutions capacitated with sufficient financial resources to take active role in forest management

Scientific and technical information. Institutions capacitated with relevant scientific and technical information to take active role in forest management Effectiveness. Institutions are effective in implementing forest management objectives Local community capacities. Local communities have adequate number of staff with up-to-date knowledge and skills, technology and equipment, and budget to perform its roles and duties. 


\section{References}

ACE, 2008. Constitución de la República del Ecuador. In: Ecuador, A.C.d. (Ed.).

Carandang , A.P., Bugayong, L.A., Dolom, P.C., Garcia, L.N., Villanueva, M.B., Espiritu, N.O., 2012. Analysis of Key Drivers of Deforestation andForest Degradation in the Philippines. In. GIZ, BMZ, DENR, Manila.

Chikulo, B., 2009. Local governance reforms in Zambia: a review. Commonwealth Journal of Local Governance, 98.

Holt, F.L., Bilsborrow, R.E., 2004. Demography, household economics, and land and resource use of five indigenous populations in the Northern Ecuadorian Amazon: a summary of ethnographic research. In, Occasional Paper, Carolina Population Center. University of North Carolina, Chapel Hill, NC.

Izurieta, J.C., Erazo, G., Larson, A.M., Cronkleton, P., 2014. Desde nuestros ojos: La historia de los pueblos y bosques de Napo. In, Bogor, Indonesia, p. 48.

MAE, 2016. Proyecto de sostenibilidad financiera para el Sistema Nacional de Áreas Protegidas. Una visión a su historia. In. Ministerio del Ambiente del Ecuador, Quito - Ecuador.

Mfune, O., 2013. Has decentralisation of forest resources to local governments really taken off on the ground? Experiences from Chongwe District in central Zambia. Journal of Sustainable Development 6, 57.

Morales, M., Naughton-Treves, L., Suárez, L., 2010. Seguridad en la Tenencia de la Tierra e Incentivos para la Conservación de Bosques. In. ECOLEX, Quito.

Murphy, L., R., B., F., P., 1997. Poverty and prosperity among migrant settlers in the Amazon rainforest frontier of Ecuador. The Journal of Development Studies 34, 35-66.

Palacios, W., 2005. Potencial etnobotánico de los territorios indígenas en el Ecuador. In, Revista Bosques Latitud Cero, Loja, Ecuador, pp. 3-9.

Pan, W.K.Y., Walsh, S.J., Bilsborrow, R.E., Frizzelle, B.G., Erlien, C.M., Baquero, F., 2004. Farm-level models of spatial patterns of land use and land cover dynamics in the Ecuadorian Amazon. Agriculture, Ecosystems \& Environment 101, 117-134.

Richards, M., 1997. Common Property Resource Institutions and Forest Management in Latin America. Development and Change 28, 95-117. 
Annex 3: Publications of the cumulative dissertation 


\title{
Governance effects on deforestation in the tropics: A review of the evidence
}

\author{
Richard Fischer ${ }^{\mathrm{a}, *}$, Lukas Giessen ${ }^{\mathrm{b}}$, Sven Günter ${ }^{\mathrm{c}}$ \\ a Thünen Institute for Interatnional Forestry and Forest Economics, Hamburg 21033, Germany \\ ${ }^{\mathrm{b}}$ European Forest Insitute, Bonn, Germany and IPB Bogor Agricultural University, Indonesia \\ ${ }^{\mathrm{c}}$ Thünen Institute for International Forestry and Forest Economics, Hamburg, Germany
}

\section{A R T I C L E I N F O}

\section{Keywords:}

Governance

Deforestation

Agency

Structure

Tropics

Principal component analysis

\begin{abstract}
A B S T R A C T
In view of a continuing global decrease of forest cover, many authors mention forest governance as a basic concept contributing to reduced deforestation, specifically in the tropics. There are numerous definitions for forest governance. The concept is commonly understood as a broad approach and assessment tools comprise dozens of indicators. However, there is no information about relations between single indicators, their individual importance and whether contextual factors modify their effects. This article aims to analyze if the hypothesized relation between governance leading to reduced tropical deforestation in general holds true, to identify the most decisive governance components and to explore if the wider socio-economic and political context influences potential governance effects. The structure - agency concept is used as theoretical basis to identify underlying mechanisms and as conceptual basis for discussing individual indicators. We employ a quantitative literature review based on scientific articles on governance and deforestation. From a total of 810 articles we select the most frequently cited publications related to the subject. From the resulting 198 papers only those are studied that contain empirical relations between governance and deforestation. The remaining 28 studies are analyzed by applying the governance indicators of the World Resource Institute as categories for content analysis. Likert scores are used to quantify governance effects as input for subsequent principal component analysis and multiple linear regressions. Results show that indeed high governance scores frequently relate to lower rates of deforestation and we thus recommend continued political support for the concept. But the reviewed studies mostly focus on a smaller number of classical governance indicators, which suggests that the governance concept might benefit from streamlining into a more targeted approach. In this respect, several indicators were related to underlying principal components reflecting the agency and structure concept. Even though we cannot claim a statistically significant stronger effect of one or the other component, single structural indicators were more strongly and more consistently linked to reduced deforestation in comparison to agency related indicators. The concept can thus be helpful to guide policy design and implementation. We show this by applying it to the ongoing discussion on results based payments under REDD + as a prominent example for agency related measures. The reviewed literature in addition suggests that governance effects are moderated by deforestation drivers such as corruption, illegal logging and population growth and by interventions like technology transfer.
\end{abstract}

\section{Introduction}

\subsection{Background}

Even though the pace of net forest loss has slowed, the area of the world's forests continues to decrease with a net annual forest loss of 3.3 mio ha (FAO, 2015). The largest loss of forest area still occurs in the tropics. Research on causes of deforestation in the tropics has a long tradition and numerous publications name and identify possible drivers (Geist and Lambin, 2002; Hosonuma et al., 2012; Wehkamp et al.,
2015; Busch and Ferretti-Gallon, 2017). Governance has come into the focus as a general approach to reverse the deforestation trend and in international forest policy governance is increasingly taken into account (Singer and Giessen, 2017).

Numerous definitions have been proposed for forest governance (Larson and Petkova, 2011; Broekhoven et al., 2012; Davis et al., 2013; Giessen and Buttoud, 2014; de Graaf et al., 2017; Mansourian, 2017). The recent definitions all understand governance as a broad and comprehensive concept that goes far beyond governments. For (Larson and Petkova, 2011) and (Broekhoven et al., 2012) forest governance is

\footnotetext{
* Corresponding author.

E-mail address: richard.fischer@thuenen.de (R. Fischer).
} 
centered around decisions on forest management. de Graaf et al. (2017) emphasize rules and decisions. Wehkamp et al. (2018) and Davis et al. (2013) focus on different dimensions by introducing levels and horizontal dimensions or components and principles. Scholars have produced an increasing number of (i) case studies analyzing governance effects on the ground (Andersson et al., 2014; Schusser et al., 2015; Subhan Mollick et al., 2018) (ii) statistical evaluations of governance effects using regional or global panel data sets (Umemiya et al., 2010) and (iii) reviews of existing research results (Bhagwat et al., 2017; Wehkamp et al., 2018). Whatever concept applied, the prevailing conclusion is that improved forest governance will at least contribute to reduced deforestation (Kanninen et al., 2007; Korhonen-Kurki et al., 2014; Stickler et al., 2017). However, such a general conclusion needs to be questioned or at least analyzed in detail, as governance comprises a multitude of different components. Handbooks and toolboxes list governance indicators but without substantiation of effects for each of the multiple elements and components. The (Worldbank, 2006) specifies six dimensions of governance. Kishor and Kenneth (2012) list 130 governance indicators. Davis et al. (2013) provide 122 indicators in six thematic areas and (Worldbank, 2006; Kishor and Kenneth, 2012; Davis et al., 2013; de Graaf et al., 2017) defines four criteria with 18 indicators. Previous studies rely on such indicator descriptions and analyze effects of single governance components on deforestation, but an understanding of the inherent structure of different governance components and how they interact is missing until today. It is also not clear which of the multiple components are the most decisive ones with regards to effects on deforestation. This, however, would be important for the scientific understanding of governance functioning. It would also have practical implications, as policy requires information on which of the multiple components to concentrate and practitioners need to know if additional governance components are affected when they are working on one specific element. Additionally and above all, there are indications that governance effects also depend on the specific context (Wehkamp et al., 2018). Thus, context factors like local deforestation drivers and other policy interventions on the ground need to be considered as well.

Irrespective of specific indicators, the main theoretical basis of forest governance has been claimed to consist of two mainstream models: rational choice and neo-institutionalism, otherwise described as agency -structure concept, which thus provides a theoretical basis to better understand and describe governance approaches (Arts et al., 2014). An agency line of reasoning predominantly builds on local actors' rational choice and e.g. financial motivation for increased economic benefit of forest conservation. Structural approaches are based on command and control interventions, with a focus on setting and improving institutions, frames and rules enforcing them. Analyzing current governance elements and results under this perspective could thus provide a starting point for understanding the relation and impact of different governance components.

An example for practical implications of such governance research is whether existing governance results generally support agency based approaches to counteract tropical deforestation in contrast to structural approaches. Results based payments under the REDD+ ("Reducing Emissions from Deforestation and Degradation") approach of the United Nations Framework Convention on Climate Change (UNFCCC 2007a; FCCC/CP/2010/7/Add.1) would be a prominent example for an agent based tool in international forest policy as they build on the financial motivation of recipients, in contrast to traditional input based development aid, often aiming to improve structures, rules and their implementation. Results based payments under REDD + have been promoted as an innovative tool. Still today, they are seen as a "main innovation to REDD +" (Angelsen et al., 2018). However, the disbursement of such finance is far below expectations and a controversial discussion on success and the future of REDD + and the applicability of results based payments in international forest policy is ongoing (Fischer et al., 2016; Fletcher et al., 2016; Angelsen et al., 2017).

\subsection{Aim and objectives}

This article aims to study the effects of governance on tropical forests taking into account the specific local policy and deforestation context. The particular objectives are to analyze (a) if the hypothesized relation between quality of governance and deforestation in general holds true and whether it applies to all governance elements. It (b) further explores if general and independent structure or agency mechanisms are underlying applied governance research in order to conclude whether aspects of rational choice or institutional settings have stronger explanatory power as determinant governance factors for deforestation in the tropics. In this respect, the study aims to (c) identify the most decisive governance indicators and (d) further analyzes effects of context factors on forests to find out if governance effects depend on these.

\section{Methods}

The study firstly develops a theoretical framework for analyzing governance effects on deforestation. It then applies a mixed method approach, including systematic literature search and a review of peer reviewed articles based on quantitative as well as qualitative content analysis. This provides the basis for a principal component analysis (PCA) and multiple regression analysis to evaluate the effects of governance components, their interrelation and the wider socio-economic and political context on deforestation, forest degradation or reforestation.

\subsection{Development of governance concept and theoretical framework}

The agency approach postulates that it is mainly self-interested actors, with their specific motivations, intentions, goals, actions and resources, that take active agency (Archer, 2003) and, hence, drive land use decisions. Land users are assumed to take rational choices in order to maximize their economic or political benefits. Broadly, this school of thought assumes that "man's natural proclivity is to pursue his own interests" (Brennan and Buchanan, 1985) and follows the logic of consequences of behavior (March and Olsen, 2004). On the other side, laws, regulations, plans, cultural conventions and norms shape land use decisions providing a structural frame. Hence, this approach broadly follows the logic of appropriate behavior (March and Olsen, 2004). It has to be taken into account that usually neither structure nor agency alone drive human behavior. March and Olsen (1998) consider the need to study "which settings in practice enable the dominance of one logic over all others" and (Giddens, 1984) formulates that agents - groups or individuals - draw upon structures to perform social actions but at the same time structure is the result of these social practices. This "feedback-feedforward" system has been adapted to forest governance by Arts et al. (2014) in a so-called practice based approach described by the metaphor of a dance or theatre performance in which actors are on one side driven by scripts (structures) which they on the other hand constantly re-interpret.

Taking into account the numerous definitions that have been proposed for governance, a review needs a wide governance perspective (Mansourian, 2016), because it should not exclude specific results only because of different definitions. We thus base our study on the broad definition of (Giessen and Buttoud, 2014) according to which "forest governance comprises a) all formal and informal, public and private regulatory structures, i.e. institutions consisting of rules, norms, principles, decision procedures, concerning forests, their utilization and their conservation, b) the interactions between public and private actors therein and c) the effects of either on forests". This definition inherently reflects structure and agency components as it explicitly mentions structural aspects in its first part and describes agency related aspects as interactions of different actors in the second part. It further relates governance to effects on forests, which is in line with the aims of our study. 
Table 1

Six thematic areas and 26 indicators for governance assessments based on (Davis et al., 2013). Black: indicators that we interpreted as agency related; grey: indicators interpreted as structure related. A number of indicators cannot be assigned to either of these two mechanisms.

\begin{tabular}{|c|c|c|}
\hline 1 Forest tenure & 2 Land use & 3 Forest management \\
\hline \multirow{2}{*}{$\begin{array}{l}\text { Forest ownership and use rights } \\
\text { Tenure dispute resolution }\end{array}$} & Land use planning & Forest legal and policy framework \\
\hline & Land use plan implementation & Forest strategies and plans \\
\hline State forest ownership & Sectoral land use & Forest law enforcement \\
\hline \multirow[t]{2}{*}{ Concession allocation } & Forest classification & Forest management practices \\
\hline & & Forest monitoring \\
\hline 4 Forest revenues & 5 Institutions & 6 Cross cutting issues \\
\hline Forest charge administration & Legislature & Public participation in decision-making \\
\hline Forest revenue distribution & Judiciary & Public access to information \\
\hline Benefit sharing & Executive agencies & Financial transparency and accountability \\
\hline Budgeting & Private sector & Anticorruption measures \\
\hline & Civil society & \\
\hline
\end{tabular}

From the different tools that are available to assess governance we apply the framework presented by the World Resource Institute (WRI) (Davis et al., 2013) because it provides a comprehensive set of operationally defined indicators but leaves leeway to adjust the system to the respective context. The assessment tool is structured along six thematic areas comprising all together 26 subthemes which we refer to as indicators (Table 1). The assignment of indicators and thematic areas to either the agency or structure approach allows applying the framework under our definition. We interpret forest ownership, tenure dispute resolution, private sector, civil society, public participation in decision making and all indicators related to revenues as being decisive in the context of an agency related approach because these indicators reflect individual decisions, personal motivations - including financial interests - and the possibilities of single actors to implement own interests. We interpret the WRI indicators of land use planning, land use plan implementation, sectoral land use, forest strategies and plans, legal/policy framework, law enforcement and legislature as indicators related to a structural policy approach, because they emphasize creation, existence and implementations of structures, rules and frames. A number of indicators either cannot be assigned exclusively to one of the approaches or contains elements of both.

When analyzing relations between governance and deforestation, single indicators, including their interactions. In our theoretical framework, we consider governance indicators of the WRI framework. However, it is not these indicators but always actors that exercise influence on forests because deforestation processes depend on human behavior. Governance indicators affect actors but are as well affected by these. Actors, in addition, are influenced by other actors' behavior (Kickert et al., 1997; Hanneman and Riddle, 2005). Additionally we take into account context factors like deforestation drivers and interventions, that interact with governance indicators as well as with actors (Fig. 1). Finally, actors are influencing forests but are as well influenced by these.

The actor-governance interactions are highly complex and case specific and their study needs qualitative, individual and interpretative approaches and "thick descriptions" (Arts et al., 2014). This is not applicable in a review study aiming to generalize results (see Section 2.3). We therefore do not explore governance-actor interrelations but focus directly on governance effects on deforestation because these are of ultimate political interest. Information on governance-forest interrelations is available in multiple studies and can thus be analyzed (Fig. 2). In this respect, a governance effect means that within a specific study qualitative or quantitative evidence is described for a specific WRI governance indicator as independent variable causing changes on deforestation, reforestation or degradation as dependent variables.

Our framework also describes interrelations between governance indicators because this has important practical implications for designing forest governance measures in the field (Fig. 3). In addition, we analyze effects of context factors on governance and forests (Fig. 4).

\subsection{Selection of articles}

The study relies on peer reviewed articles or reviews containing empirical results from forest governance studies. We identified studies through a literature search in Scopus in March 2017. In order to determine the period of the analysis we checked the number of publications in Scopus per year using 'forest' and 'governance'. After 2000, there was a nearly constant increase in number of publications with 7 publications in 2000, 20 publications in 2001 and 297 publications in 2016. Thus, we focused the search on studies published after 2000 . We only selected English journal research articles. Given the wide range of applied forest governance definitions we did not focus the study on search terms that are elements of different definitions but rather focused on the overarching term "governance" itself which is consensus among all definitions. We thus searched in title, abstract and keywords for 'governance' in combination with (i) 'degradation' and 'forest', (ii) 'deforestation' and (iii) 'reforestation', resulting in 810 publications including duplicates (Table 2). Within each of the years and search term combinations, we selected those publications that had more citations than the average of the selected publications of the same year and search term combination in order to keep the large number of publications manageable. This resulted in a total of 286 papers. After removing duplicates, we ended with 198 review publications.

From these, we only selected articles for which the abstracts indicated research on effects of one or more governance components on deforestation, reforestation or degradation. We searched for studies that aimed to establish empirical links between these two, irrespective whether they finally found or did not find such links. Empirical links either could be quantitative statistical or qualitatively descriptive based on defined scientific methods. We left aside studies focusing on urban forestry and only focused on rural areas. We only selected research from countries with notable territories in the tropical climatic zone or in the case of reviews including more than $50 \%$ of tropical countries. We excluded four studies that were based on global reviews in order to focus the scope. The final selection yielded 28 articles (Table 2).

\subsection{Content analysis for governance indicators and context factors}

We used content analysis as an approach for the systematic analysis of the published articles. We firstly identified which of the specific WRI governance indicators (Davis et al., 2013) were tackled in each of the studies. In a second step, all additional factors related to deforestation were classified as context factors. Qualitative content analysis required a thorough reading of the articles and assigning of governance information to indicators as provided by the framework of the World Resource Institute (see Tables 1 and 3). The 26 indicators were thus 


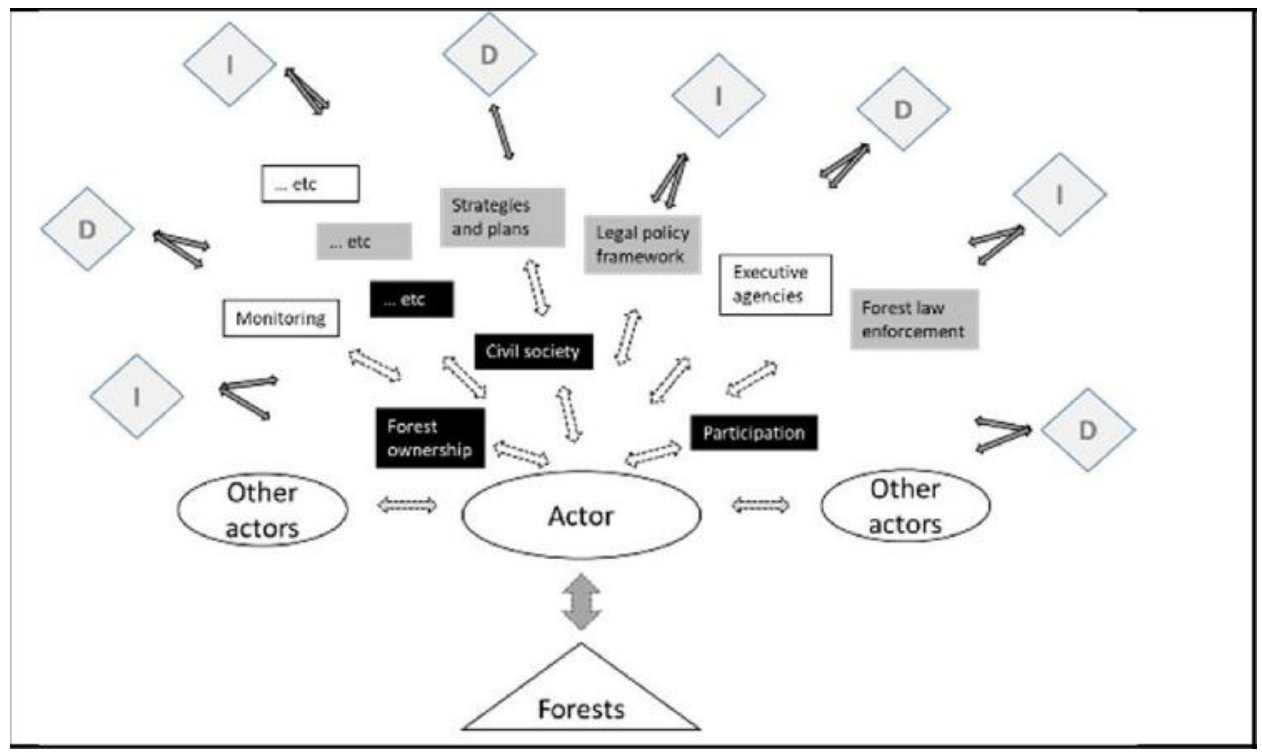

Fig. 1. Theoretical framework for analyzing forest governance effects on deforestation taking into account governance indicators that are agency related (black rectangles) or structure related (grey rectangles), or related to neither of them (white rectangles). Context factors are deforestation drivers ("D" rhombs) or interventions ("I" rhombs). Full grey arrows: interactions of context factors with governance and actors; dashed arrows: actor-governance, actor-actor and actor-forest interactions; more explanations in the text.

subcomponents for classification within our content analysis (Mayring, $2000,2014)$. On average, only 4.9 indicators out of possible 26 possible indicators were considered per study. For a more focused descriptive presentation and qualitative discussion we thus merged the 26 original indicators to 11 aggregated indicators by pooling less frequently mentioned indicators within thematic areas.

Many studies in addition contained information about the wider socio-economic and political context of deforestation. We also used content analysis to analyze such context factors. We relied on a classification of deforestation drivers by (Hosonuma et al., 2012) and on categories for interventions used by (Agrawal et al., 2014). Factors that directly or indirectly increase deforestation were classified as deforestation drivers. Actions explicitly undertaken to counter land use changes were classified as interventions. We adjusted the original classifications using qualitative content analysis as an iterative method. This implies that during reading, categories for all context factors were partly newly created, rearranged or successively adapted based on the contents of the material (Mayring, 2000, 2014). A final reading was then conducted based on the final categories for governance indicators and context factors. We coded our texts using MAXQDA (version 11). Each result or conclusion related to one of our categories was marked and coded; the coding system in MAXQDA consisted of the classification described above. Based on the summary of all coded text parts in a specific document we then applied Likert scores for effects of governance indicators and context factors (Tables 4 and 5). Identifying governance components and assigning scales meant interpreting the meaning of the texts. An example is given in Appendix A. Based on this list of marked key statements the co-authors routinely checked codes for plausibility in order to guarantee reliability. Taking into account a still manageable amount of 28 studies we refrained from working with multiple analyzers also taking into considering the challenges of calibrating multiple scientists (Bryman, 2003).

Converting thematic analysis into quantitative Likert scales constitutes a data transformation based on an intensity scale (Castro et al., 2010).This is needed because qualitative data descriptions as well as quantitative approaches in the underlying studies may not be consistent across observers and/or contexts, which requires standardization or harmonization in the form of coding before comparisons can be made (Coe and Scacco, 2017; Magliocca et al., 2018). Our content analysis is therefore a mixed method in which qualitative results of reading the text are coded and thus transformed. Quantitative components gain particular importance when generalization of the results is required (Mayring, 2014).

In case that negative governance was reported in the studies we

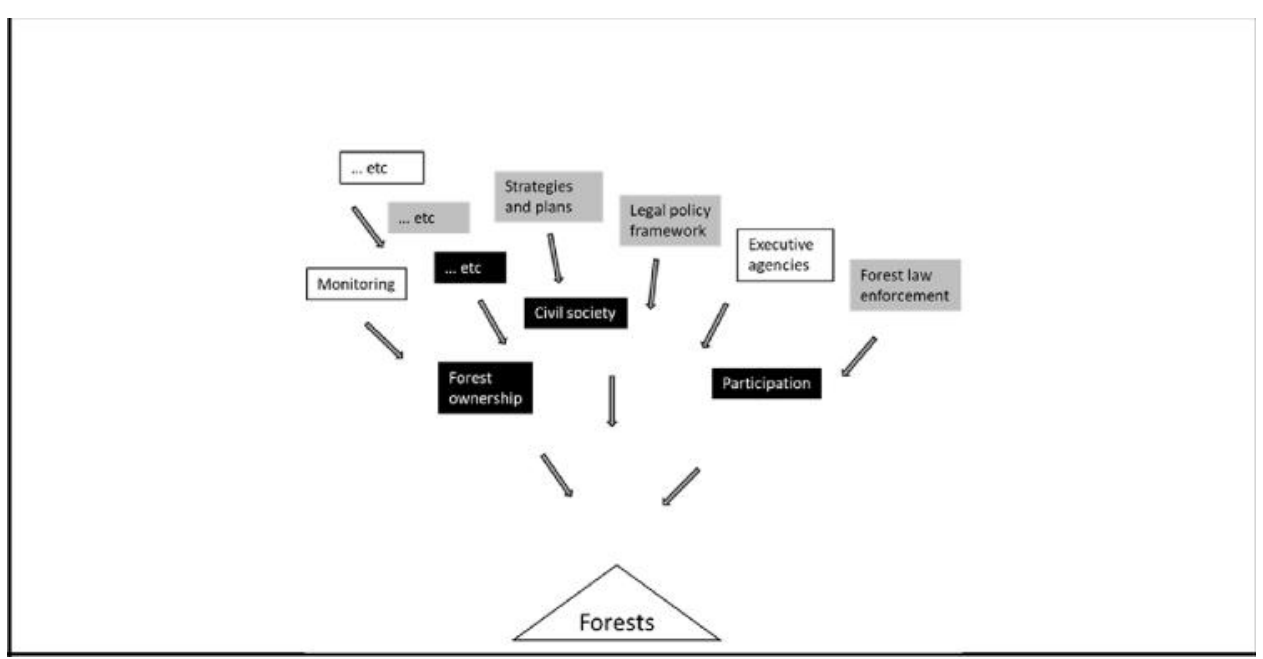

Fig. 2. Simplified model of governance effects on deforestation, as studied following objective (a) in order to analyze if the hypothesized relation between quality of governance and deforestation in general holds true. 


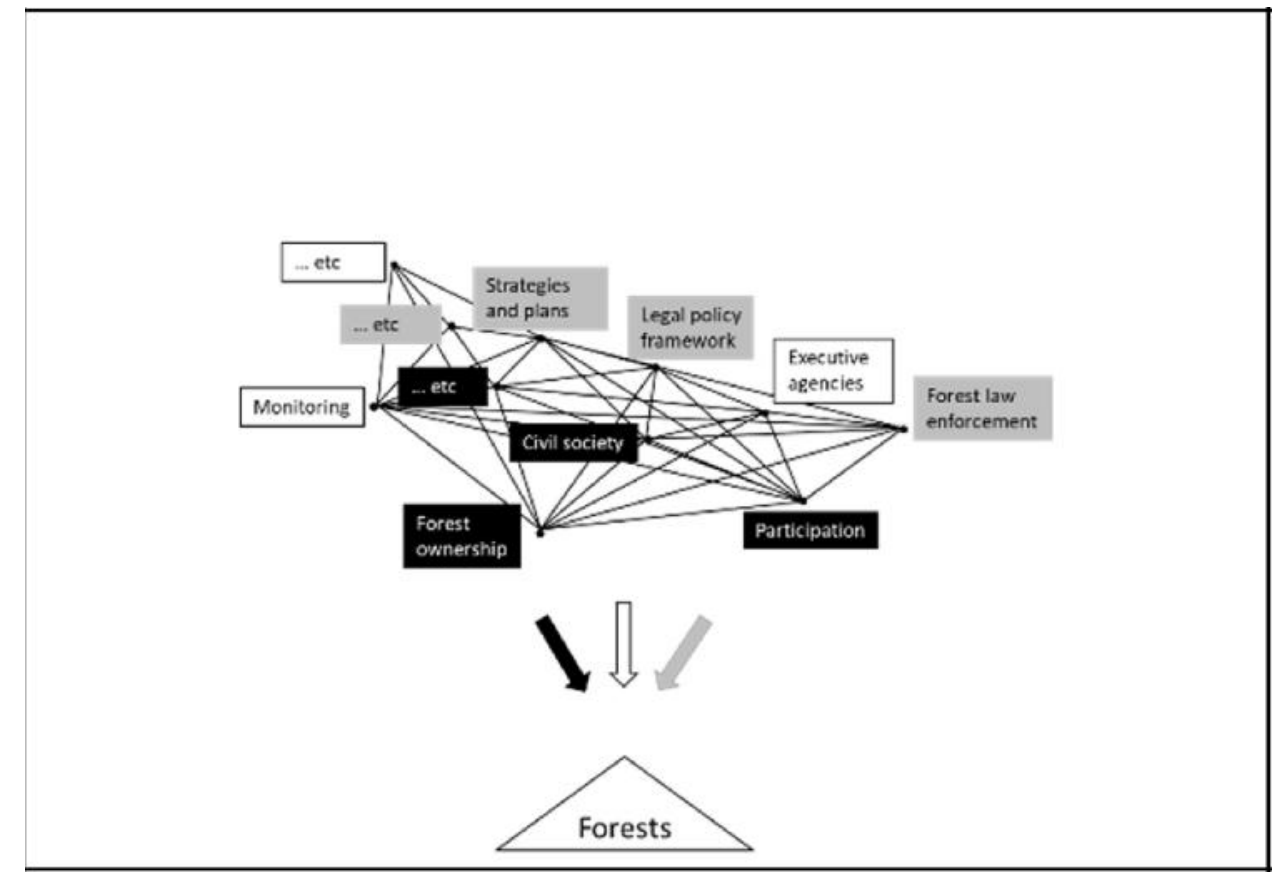

Fig. 3. Relations between governance indicators in order to further explore if general and independent structure or agency mechanisms are underlying applied governance and to identify the most decisive governance indicators following objectives (b) and (c).

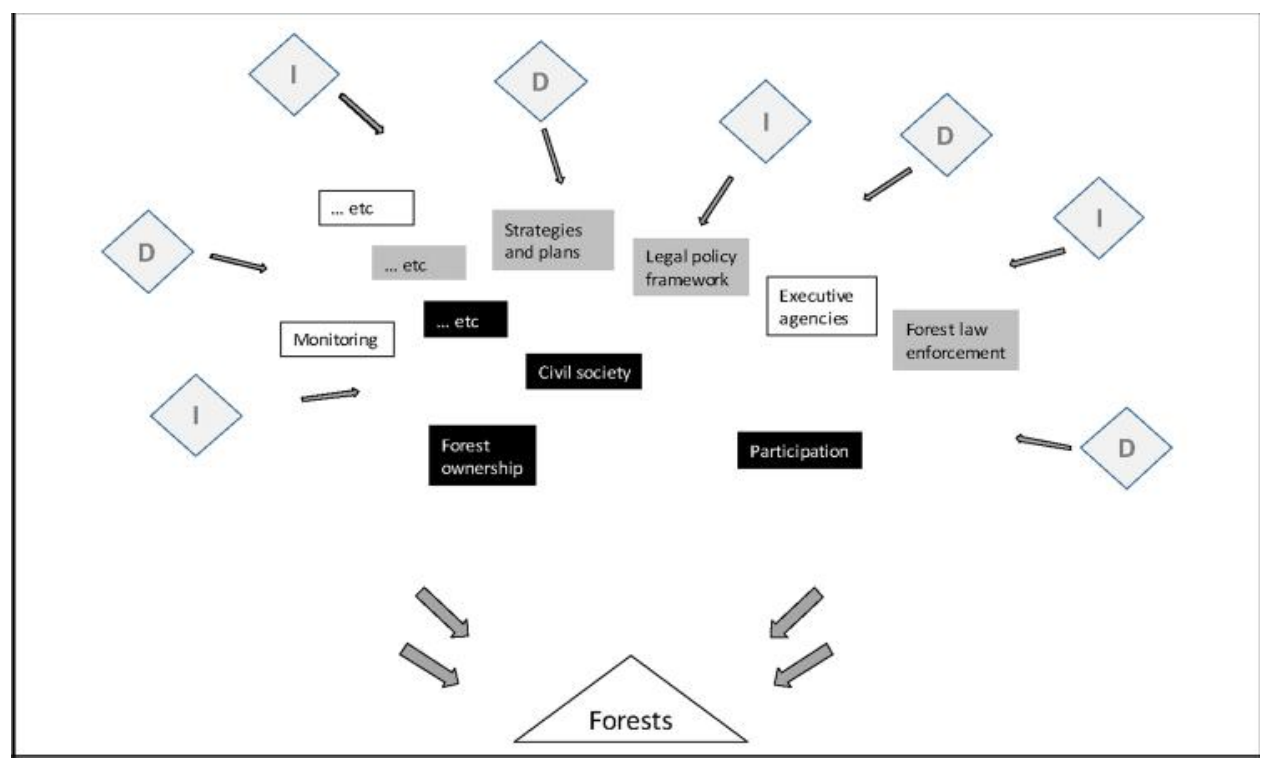

Fig. 4. Effects of context factors on forests and on governance indicators, as studied following objective (d).

Table 2

Results of the literature search on governance relations to deforestation, reforestation and forest degradation.

\begin{tabular}{|c|c|c|}
\hline & $\mathrm{N}$ all publications & $\mathrm{N}$ publications with above average citations \\
\hline governance AND degradation AND forest & 266 & 94 \\
\hline governance AND reforestation & 67 & 28 \\
\hline governance AND deforestation & 477 & 164 \\
\hline subtotal & 810 & 286 \\
\hline after removing duplicates & & 198 \\
\hline studies with empirical relations on governance and deforestation including global reviews & & 32 \\
\hline Total after removing global reviews & & 28 \\
\hline
\end{tabular}


Table 3

Assessed governance indicators and context factors, number of MAXQDA codings and number of documents scored. Aggregations for qualitative analysis due to low abundances. Black: agency related governance indicators, grey: structure related governance indicators. Governance indicators as specified by (Davis et al., 2013). Categories for drivers and interventions adapted from (Hosonuma et al., 2012) and (Agrawal et al., 2014).

\begin{tabular}{|c|c|c|c|c|c|c|}
\hline & & & & $\begin{array}{c}\text { (a) } \\
N \text { codings } \\
\text { (MAXQDA) }\end{array}$ & $\begin{array}{c}\text { (b) } \\
\mathrm{N} \\
\text { documents } \\
\text { scored }\end{array}$ & $\begin{array}{c}\text { (c) } \\
\text { N documents } \\
\text { scored } \\
\text { (aggregated } \\
\text { categories) }\end{array}$ \\
\hline \multicolumn{7}{|c|}{ Governance Indicators } \\
\hline & Indicator Name & Abbreviation & Aggregated indicators & & & \\
\hline \multirow[t]{4}{*}{1 FOREST TENURE } & Forest ownership and use rights & Ownership & Tenure/Ownership & 45 & 13 & 13 \\
\hline & Tenure dispute resolution & Dispute & \multirow{2}{*}{ Dispute resolution } & 4 & 4 & \multirow{2}{*}{4} \\
\hline & State forest ownership & State forest & & 0 & 0 & \\
\hline & Concession allocation & Concession & Concession allocation & 0 & 0 & 0 \\
\hline \multirow[t]{4}{*}{ 2 LAND USE } & Land use planning & LUplanning & \multirow{3}{*}{ Land use plan. } & 6 & 6 & \multirow{3}{*}{8} \\
\hline & Land use plan implementation & LUimplement & & 3 & 4 & \\
\hline & Sectoral land use & SectoralLU & & 2 & 2 & \\
\hline & Forest classification & Classification & Forest classification & 0 & 0 & 0 \\
\hline \multirow[t]{5}{*}{ 3FOREST MANAGEM. } & Forest legal and policy framework & Framework & Legal/Policy framework & 35 & 11 & 11 \\
\hline & Forest strategies and plans & Strategies & \multirow{3}{*}{ Planning/Monit./Manag. } & 4 & 4 & \multirow{3}{*}{13} \\
\hline & Forest monitoring & Monitoring & & 23 & 9 & \\
\hline & Forest management practices & Management & & 10 & 3 & \\
\hline & Forest law enforcement & Enforcement & Law enforcement & 58 & 20 & 20 \\
\hline \multirow[t]{4}{*}{4 FOREST REVENUES } & Forest charge administration & Charges & \multirow{3}{*}{ Revenues } & 2 & 1 & \multirow{3}{*}{4} \\
\hline & Forest revenue distribution & Revenues & & 1 & 1 & \\
\hline & Benefit sharing & Benefit & & 4 & 3 & \\
\hline & Budgeting & Budgeting & Budgeting & 0 & 0 & 0 \\
\hline \multirow[t]{5}{*}{ 5INSTITUTIONS } & Legislature & Legislature & Legislature & 0 & 0 & 0 \\
\hline & Judiciary & Judiciary & \multirow{2}{*}{ Executive agencies } & 2 & 1 & \multirow{2}{*}{16} \\
\hline & Executive agencies & Executive & & 37 & 16 & \\
\hline & Private sector & Private & \multirow{2}{*}{ Civil society } & 3 & 1 & \multirow{2}{*}{12} \\
\hline & Civil society & Civil & & 32 & 12 & \\
\hline \multirow[t]{4}{*}{ 6CROSS-CUT. ISSUES } & Public particip. decision-making & Participation & Participation & 55 & 18 & 18 \\
\hline & Public access to information & Information & \multirow{3}{*}{ Transparency } & 2 & 1 & \multirow{3}{*}{7} \\
\hline & Financial transpar. and accountab. & Transparency & & 3 & 2 & \\
\hline & Anticorruption measures & Anticorruption & & 7 & 4 & \\
\hline \multicolumn{7}{|l|}{ Context Factors } \\
\hline \multirow[t]{8}{*}{ DRIVERS } & Corruption, Illegal logging & & & 17 & 8 & \\
\hline & Population growth/density & & & 30 & 9 & \\
\hline & Roads length/density & & & 19 & 10 & \\
\hline & Land speculation, Opportunuity costs & & & 18 & 6 & \\
\hline & Economic development, Forest income & & & 30 & 9 & \\
\hline & Cash crops & & & 15 & 7 & \\
\hline & Agricultural intensification/expansion & & & 16 & 9 & \\
\hline & Timber, Firewood use & & & 9 & 6 & \\
\hline INTERVENTIONS & Subsidies, Credits, Donor aid & & & 24 & 8 & \\
\hline & PES, Certification & & & 8 & 4 & \\
\hline & Protected areas & & & 15 & 7 & \\
\hline & Community forestry/Decentralization & & & 20 & 14 & \\
\hline & Tourism & & & 6 & 2 & \\
\hline & (improved) Technology & & & 11 & 4 & \\
\hline & Public relations, Education, Research & & & 20 & 9 & \\
\hline & total & & & 596 & & \\
\hline
\end{tabular}

Table 4

Likert scale for de-/reforestation effect of governance indicators and context factors.

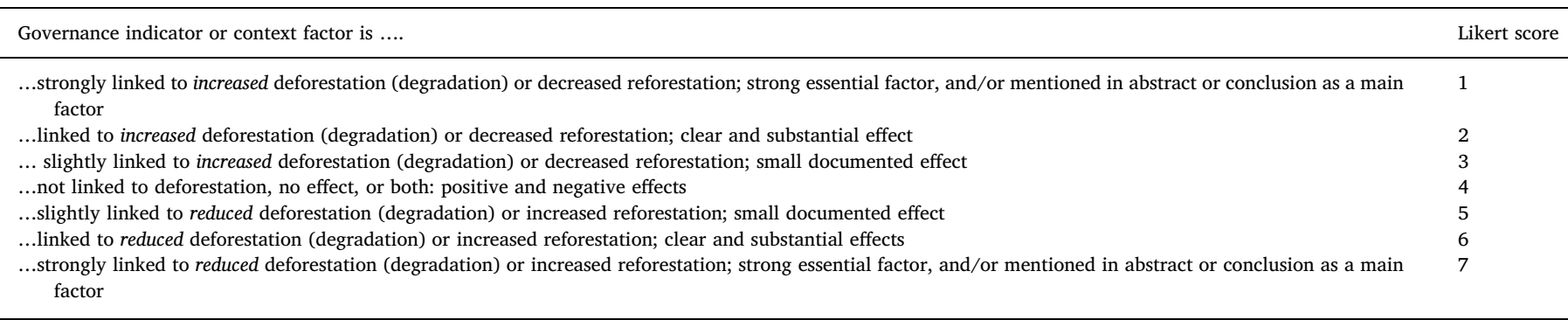

inverted the deforestation effect to make it comparable to studies reporting on positive governance: when e.g. negative governance within executive agencies was linked to higher deforestation (negative effect of negative governance) we assumed the effect of improved governance within executive agencies to be positive and gave high scores (equal to positive effects of positive governance).

\subsection{Additional information}

We coded supplementary information. Supplementary information included four categories for scale. Subnational studies were those that focused on specific regions within a country only. National studies included one single country. Global studies related to at least 10 countries distributed across the three major tropical forest regions (Central/South 


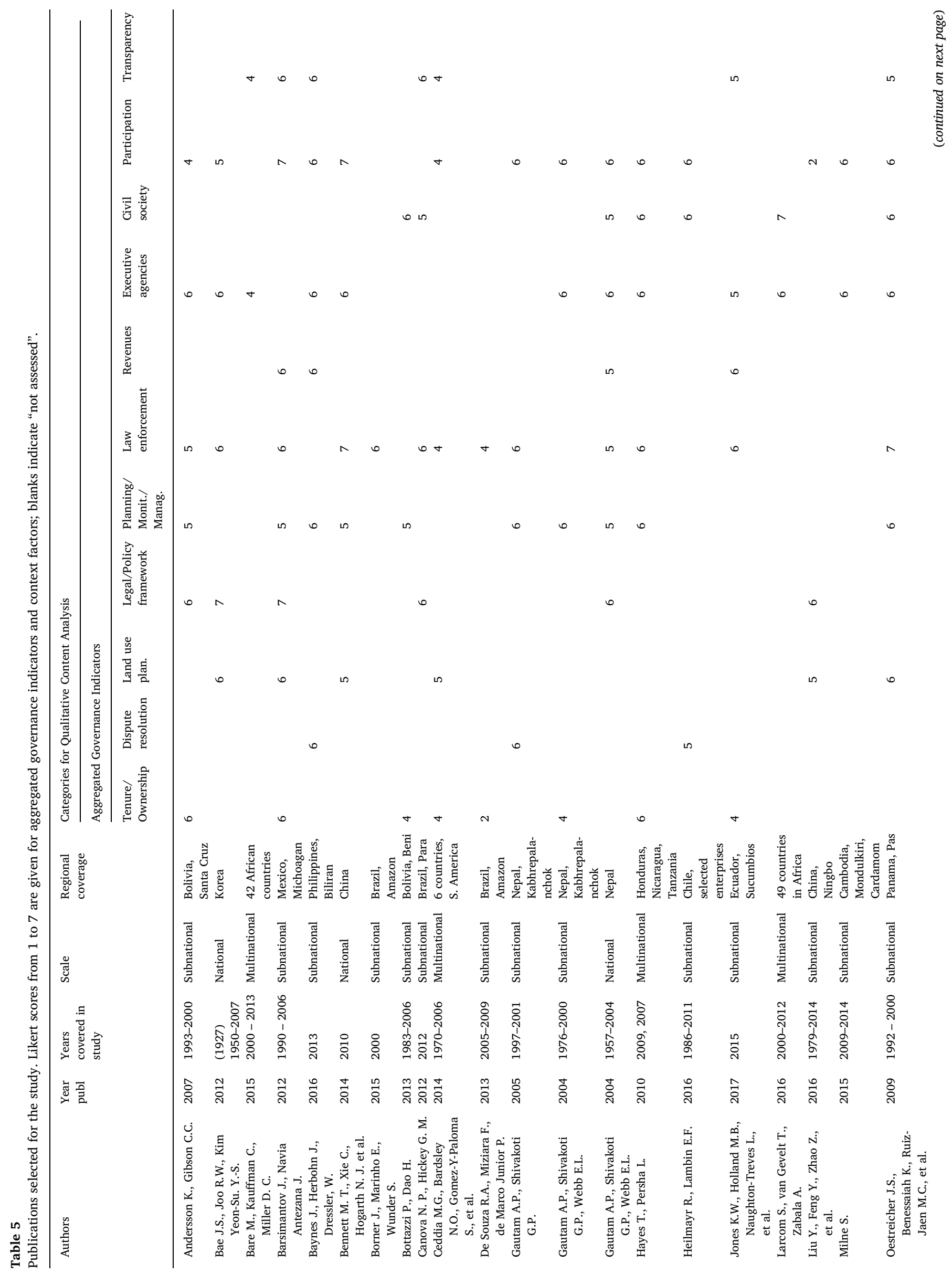




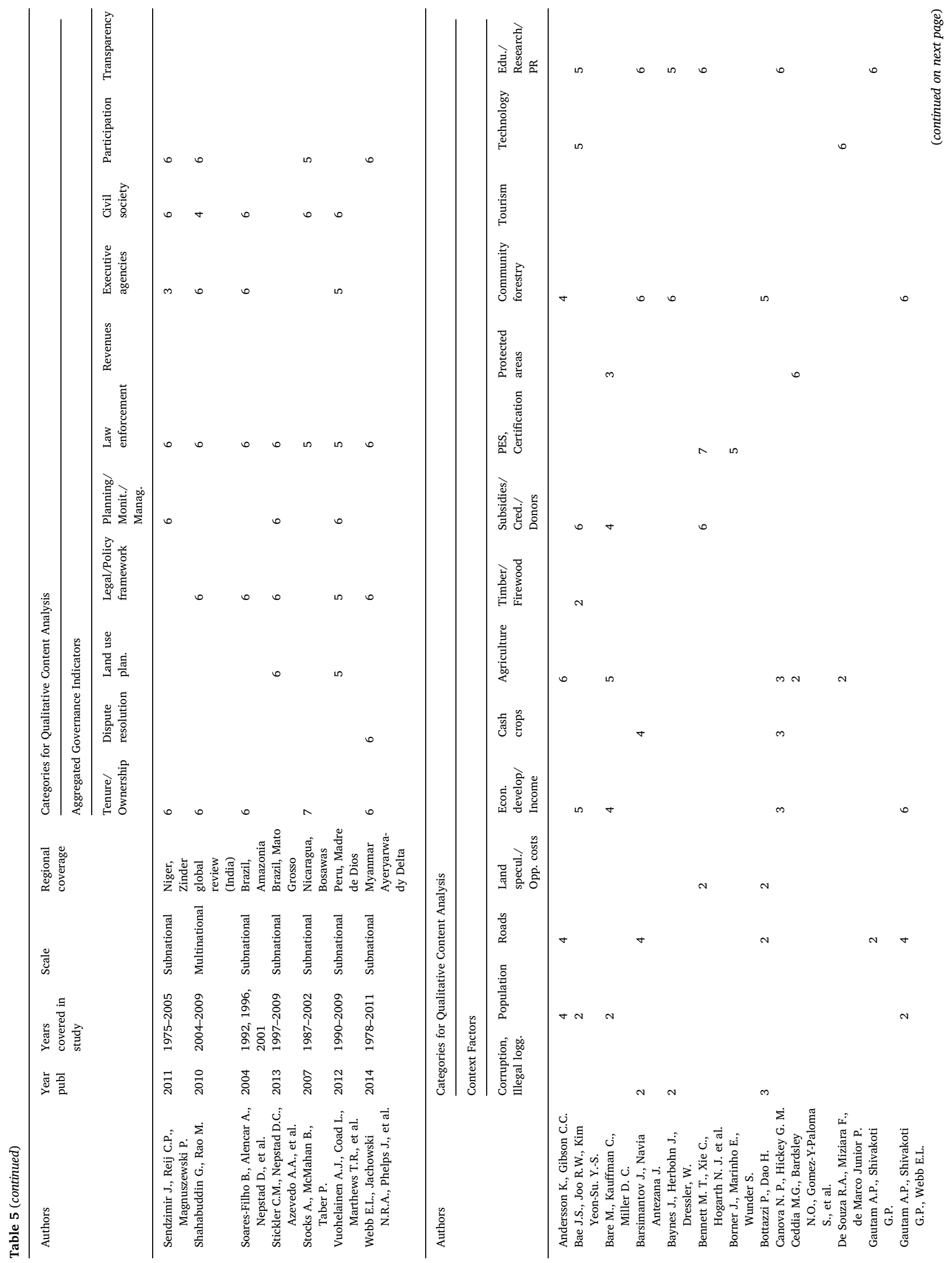




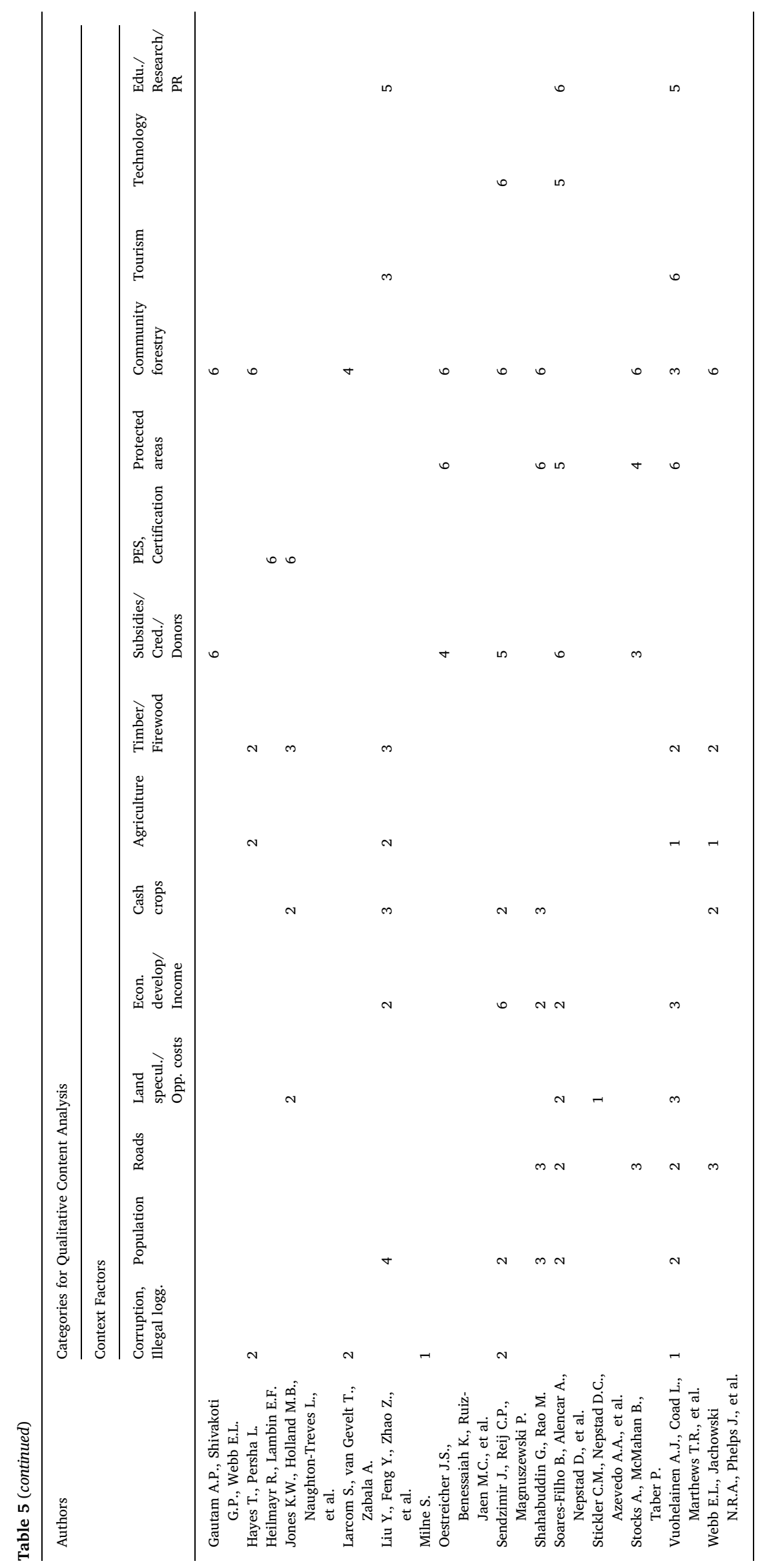


America, Africa, South-East Asia). Multinational studies comprised all other studies.

In order to identify explanatory theoretical concepts in the reviewed studies, we noted whether studies explicitly mentioned any social science theory and, if yes, whether the agency or structure theory were mentioned in the related study.

We coded the methodology applied in the different studies depending on whether governance data within the studies was assessed in the field or was taken from existing literature or databases. Forest and deforestation information was either measured in the field, e.g. through inventories, or could be derived from satellite data or literature. For linking governance (explanatory) with deforestation (target) information, studies were rated as either applying descriptive methods or quantitative statistical approaches. Reviews summarizing results from multiple studies were treated separately.

\subsection{Statistical analyses}

We applied Likert scores to quantify results of the qualitative content analysis. Mean governance effects on deforestation as well as mean effect of context factors per study were calculated as the arithmetic mean of the Likert scores of all original governance indicators and context factors for each study. We also used Likert scores in principal component analysis and multiple regression analysis following (Manley, 2005). Gaps in the data sets occurred because not all indicators and context factors, occurred in each of the studies. For conducting principal component analysis and multiple regression analysis, we filled the gaps with the mean Likert scores for indicators, drivers and interventions respectively following (Dray and Josse, 2014).

In order to structure the complex data set of governance indicators and to identify a smaller number of independent gradients (components) we applied principal component analysis (Dunteman, 1989). We used multivariate regression analysis with backward elimination in order to check for potential relationships between single context factors (predictors) and governance (target variable). Multicollinearity refers to the condition in which two or more predictors are highly correlated with one another which can make it difficult to determine the effect of each predictor on the response. We checked for multicollinearity of predictors by calculating variance inflation factors (VIF) for each of the predictors. VIFs quantify the severity of multicollinearity in an ordinary least squares regression analysis providing an index that measures how much the variance of an estimated regression coefficient is increased because of collinearity. VIFs were in all cases below 2 and we thus excluded multicollinearity which is a precondition to run a valid multiple regression analysis. We checked normal distribution of the residuals by plotting and comparing the distribution against a standardized normal distribution. Plotting residuals against predicted values helped identifying possible relationships between these. However, in none of the cases we identified statistical significant linear relationships between the residuals and the predicted values.

All statistical evaluations were carried out using the statistical software package of JMP 12 (SAS, 2015).

\section{Results}

\subsection{Regional, methodological and theory context of the studies}

Out of the 28 studies analyzed, 20 were local studies (Fig. 5). Case studies from South America dominated the review, Africa was underrepresented. 13 studies were from South or Central America. Only three studies were from Africa and out of these, only one was a field study, the other two represented multinational ones, relying on existing databases. Mean governance effects in the three African studies were lowest (5.3). Mean governance effects in the Asian studies were highest (5.7), but in an analysis of variance (not depicted) differences between regions were not significant.
Remote sensing data provided the basis for evaluating governance effects on deforestation in most studies. Deforestation information was based on satellite data in 17 studies, some studies used field inventories (7 studies) or literature (4 studies). Quantitative and qualitative methods were applied to similar extents. 14 studies used quantitative statistics to examine relationships between governance indicators and deforestation and 13 studies used qualitative descriptive tools. There was one review among the studies. With a mean governance effect of 5.8 qualitative studies showed stronger effects of high governance scores on deforestation as compared to quantitative studies that had a mean of 5.2. However, differences were not statistically significant. Social or policy theory considerations did not play a major role in the reviewed sample of governance research. 23 studies did not mention any social or policy theory as background for the research. Five studies mentioned a theory context, namely concepts developed by (Bourdieu, 1991), (Becker, 1968), (Ostrom, 1990), or (Fraser, 2007). Oestreicher et al. (2009) did not explicitly mention a theory concept but explicitly called for a command and control structure. None of the studies explicitly mentioned agency or structure based theories.

\subsection{Effects of governance indicators, deforestation drivers and interventions on deforestation}

Within the 28 studies, we coded 596 key sentences or text pieces: 338 codings were related to governance indicators, 154 to drivers and 104 to interventions (column a in Table 3). Text related to forest law enforcement was most frequently encoded (58 codings in 20 documents). The most frequently identified context factors were population growth or density and economic development (30 codings in 9 documents). The fact that the number of codings for governance indicators was higher as compared to codings for context factors was to be expected as governance was the search criterion for the studies.

The number of original governance WRI indicators that we scored in all documents was highly variable (column $\mathrm{b}$ in Table 3 ). Out of the 26 indicators, 12 were only scored in 2 or less studies. Even though that governance today is defined and conceptualized as a broad and comprehensive approach comprising many different aspects, none of the studies considered governance issues in the context of forest concessions, legislative institutions, budgeting or forest classification. Also, the distribution of scores between the WRI thematic governance areas was unequal. Forest management indicators were scored in 54 cases, which is mainly due to the importance of policy framework, monitoring and law enforcement. Indicators related to the thematic area of forest revenues only occurred in 7 cases. The sum of all scores for agency indicators (48) and the number of all scores for structure indicators (47) was almost identical.

All governance indicators were predominately linked to decreasing deforestation, degradation or to increased reforestation (Fig. 6). Only tenure/ownership showed a larger share of controversial results as it did

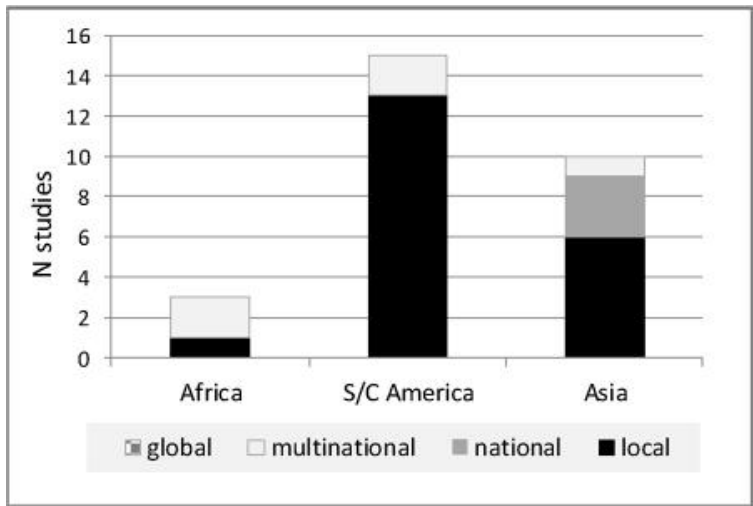

Fig. 5. Number of reviewed studies covering specific regions and scales. 


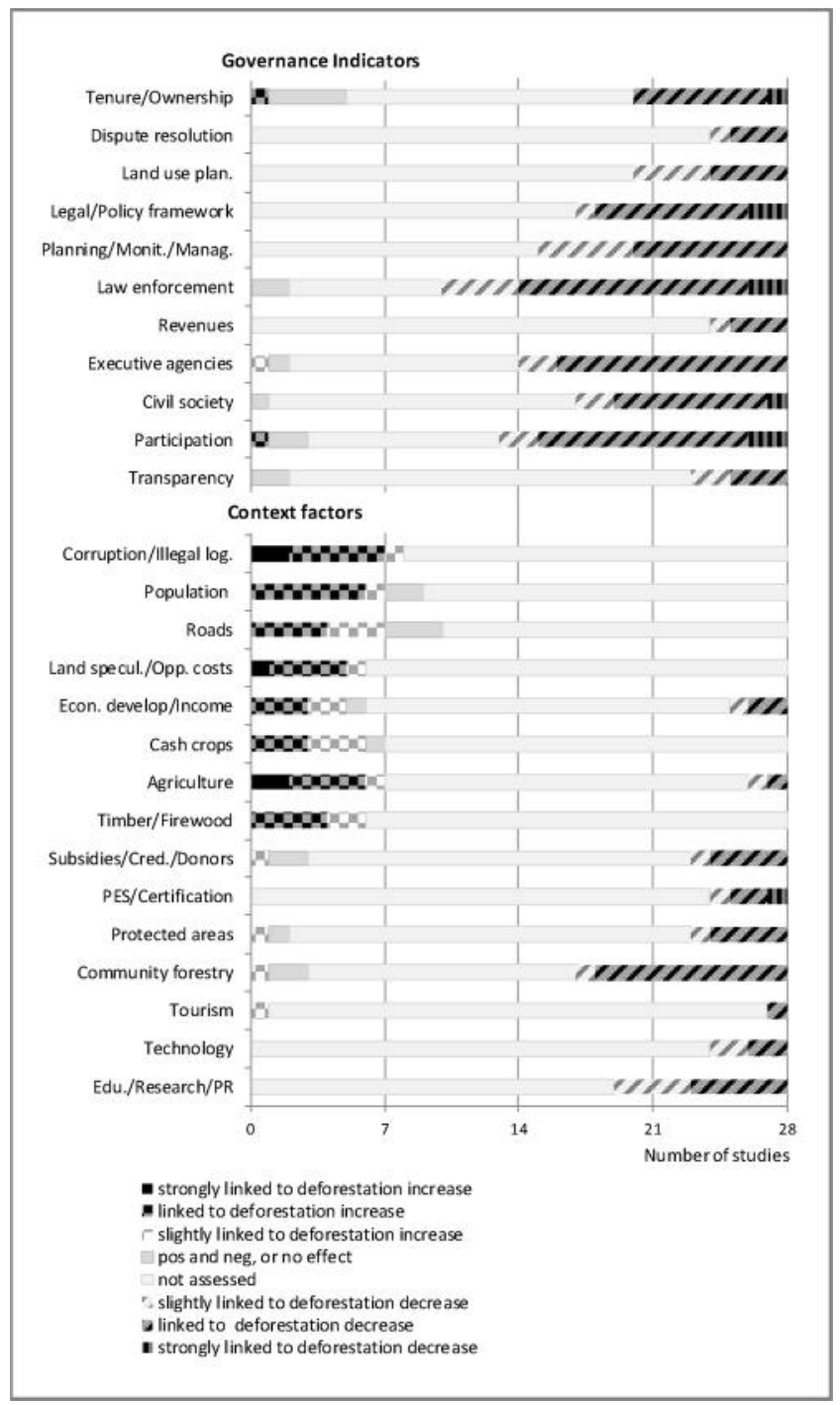

Fig. 6. Distribution of Likert scores for aggregated governance indicators and context factors over the 28 studies.

not only yield positive results. In five cases it was scored as positive and negative or with no effect and in one study it was related to increased deforestation. Among context factors, deforestation drivers were mostly related to increased deforestation which is implied in the definition of a deforestation driver. However, economic development/income and agriculture in some cases also had positive effects, i.e. they were linked to decreasing deforestation. Interventions mostly decreased deforestation. It is notable that "not assessed" was the most frequently occurring category, showing that most studies only tackled a small subset of governance indicators and context factors. Only law enforcement, executive agencies and participation were mentioned in more than half of the studies.

\subsection{Reducing the complexity of governance indicators}

Principal component analysis (PCA) reduces the dimensionality of a multivariate data set by producing linear combinations (principal components) of the original variables (e.g. governance indicators) that summarize the predominant patterns in the data (Peres-Neto et al., 2003). In other words, we applied PCA in order to identify independent gradients within the complex data set of those 22 governance indicators that were tackled in the studies. The results reveal nine components
Table 6

Eigenvalues for each principal component in order from largest to smallest. The eigenvalues represent a partition of the total variation in the multivariate sample. An eigenvalue of 1.0 (2.0 or 3.0) indicates that the respective component explains as much variation as one (two or three) single variables. The first nine components explain $78 \%$ of the total variance of the model.

\begin{tabular}{llll}
\hline Component & Eigenvalue & \% Expl. variance & Cumulative \% \\
\hline 1 & 3.46 & 16.46 & 16.46 \\
2 & 2.56 & 12.18 & 28.64 \\
3 & 1.97 & 9.39 & 38.03 \\
4 & 1.87 & 8.92 & 46.95 \\
5 & 1.56 & 7.44 & 54.39 \\
6 & 1.45 & 6.89 & 61.28 \\
7 & 1.29 & 6.15 & 67.43 \\
8 & 1.08 & 5.14 & 72.58 \\
9 & 1.05 & 5.02 & 77.60 \\
10 & 1.00 & 4.78 & 82.38 \\
11 & 0.88 & 4.18 & 86.56 \\
12 & 0.79 & 3.74 & 90.29 \\
13 & 0.62 & 2.94 & 93.23 \\
14 & 0.51 & 2.44 & 95.67 \\
15 & 0.37 & 1.76 & 97.43 \\
16 & 0.22 & 1.04 & 98.47 \\
17 & 0.19 & 0.90 & 99.38 \\
18 & 0.07 & 0.34 & 99.71 \\
19 & 0.04 & 0.17 & 99.89 \\
20 & 0.02 & 0.11 & 100.00 \\
\hline
\end{tabular}

with eigenvalues above 1.0, i.e. components explaining more variation than a single indicator. Those nine components together explained 78 $\%$ of the variation (Table 6). On the first component, nearly all indicators showed positive loadings. They together were linked to decreasing deforestation. This component was most strongly determined by land use plan implementation, transparency and legal and policy frameworks. On the second component, structure indicators on the negative end were separated from agency indicators grouped more towards the positive end. Also on the third component a certain, yet less distinct separation of agency and structure indicators could be observed. On the first three components that together explained $38 \%$ of the variation agency thus had rather antagonistic effects to structure indicators; structure and agency indicators were determining these components (Table 7). The biplot of the first and the second component summarizes these findings and depicts that structure indicators were clearly grouped and separated from agency indicators (Fig. 7). In summary, the results show that within the 28 studies evaluated there is a clear pattern of structural indicators, which means that even though not explicitly named in the studies, a structural approach of forest governance research can be distinguished, whereas agency indicators show a rather diffuse relationship with underlying deforestation-governance components.

\subsection{Comparing agency and structure-related governance studies}

In order to classify the studies into more agency or more structure related ones we counted how many agency and how many structure related indicators had been assessed in each study. Then we related the number of assessed agency indicators to maximum possible agency indicators and called this relation the share of assessed agency indicators per study. The same we did for the structure indicators. We also calculated the share of assessed agency to assessed structure indicators. Neither the share of assessed agency indicators, nor the share of assessed structure indicators nor the share agency vs. structure indicators correlated with the mean governance effects on deforestation. Thus, neither a stronger focus on agency, nor a more pronounced focus on structure indicators in the studies resulted in stronger or weaker effects on deforestation. 
Table 7

Loading matrix for the first four principal components of a PCA for governance indicators. For full names of indicators see Table 3. Indicators sorted according to the loadings on the respective component. Components aggregate information from several governance indicators. By definition, loadings can range between -1 and 1 . High positive or negative loadings indicate strong explanatory power of the indicators for the respective component; black: agency indicators; grey: structure indicators. Especially on the second component structure and agency indicators are aggregated. On the first component structure parameters are loading higher, on the second the agency parameters.

\begin{tabular}{|c|c|c|c|c|c|c|c|}
\hline \multicolumn{2}{|c|}{ Component1 } & \multicolumn{2}{|c|}{ Component2 } & \multicolumn{2}{|c|}{ Component3 } & \multicolumn{2}{|c|}{ Component4 } \\
\hline LUimplement & 0.82 & Revenues & 0.76 & Monitoring & 0.67 & Dispute & 0.57 \\
\hline Transparency & 0.64 & Benefit & 0.63 & Charges & 0.56 & Private & 0.52 \\
\hline Framework & 0.60 & Transparency & 0.58 & Civil & 0.49 & Executive & 0.50 \\
\hline LUplanning & 0.59 & Dispute & 0.53 & Enforcement & 0.43 & Information & 0.43 \\
\hline Participation & 0.58 & Management & 0.36 & Management & 0.37 & Management & 0.42 \\
\hline Benefit & 0.58 & Private & 0.28 & Strategies & 0.34 & Strategies & 0.40 \\
\hline Enforcement & 0.53 & Monitoring & 0.17 & Ownership & 0.27 & Sectoraltu & 0.26 \\
\hline Anticorruption & 0.42 & Charges & 0.10 & Sectoraltu & 0.22 & Revenues & 0.19 \\
\hline Revenues & 0.34 & Judiciary & 0.06 & Participation & 0.17 & Ownership & 0.11 \\
\hline Ownership & 0.30 & Civil & -0.01 & Dispute & 0.16 & Enforcement & 0.09 \\
\hline Sectoraltu & 0.29 & Participation & -0.10 & LUplanning & 0.11 & LUplanning & 0.07 \\
\hline Dispute & 0.28 & Executive & -0.11 & Revenues & 0.07 & Anticorruption & 0.04 \\
\hline Executive & 0.20 & Anticorruption & -0.13 & LUimplement & 0.06 & Framework & 0.02 \\
\hline Strategies & 0.13 & Ownership & -0.18 & Information & 0.02 & Judiciary & -0.05 \\
\hline Private & 0.11 & Information & .0 .24 & Judiciary & -0.01 & Transparency & -0.15 \\
\hline Judiciary & 0.01 & Strategies & -0.25 & Private & -0.03 & Participation & -0.17 \\
\hline Monitoring & -0.01 & Enforcement & -0.28 & Anticorruption & -0.05 & LUimplement & -0.17 \\
\hline Charges & -0.01 & Framework & -0.28 & Benefit & -0.14 & Charges & -0.20 \\
\hline Information & -0.08 & LUimplement & -0.31 & Transparency & -0.15 & Monitoring & -0.22 \\
\hline Givil & -0.15 & LUplanning & -0.33 & Executive & -0.36 & Civil & -0.24 \\
\hline Management & -0.23 & Sectoraltu & -0.40 & Framework & -0.42 & Benefit & -0.38 \\
\hline
\end{tabular}

\subsection{Multiple linear regressions explaining mean governance effects}

In Section 3.2 we showed that governance indicators are in general linked to decreasing deforestation. In order to analyze this effect in more detail and to examine if this effect is moderated by context factors, we applied multiple linear regression analyses. We used mean governance effects on deforestation as dependent variable and

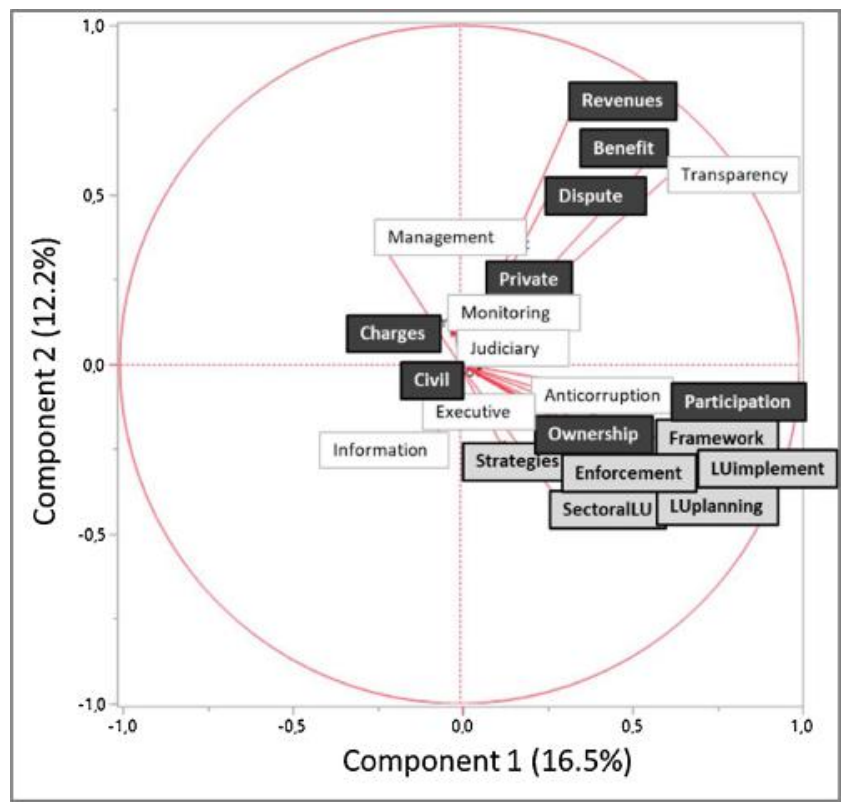

Fig. 7. Principal component analysis for governance indicators, biplot for $1^{\text {st }}$ and $2^{\text {nd }}$ component. For full names of indicators see Table 3. Black: agency indicators; grey: structure indicators. The grouped occurrence of structure indicators suggests that there are inherent structural approaches in governance research whereas agency aspects are separated from them and more dispersed throughout the studies.
Table 8

Multiple linear regression explaining mean governance effects on deforestation by context factors; $\mathrm{p}$ values for single factors. +/- : positive/negative effect; shaded cells: variables not included in optimized model; significance levels: $* 0.05 ; * * 0.01 ; * * * 0.001$; a: full model with all context factors; b: optimized model with selected factors; optimization by backward selection.

\begin{tabular}{|l|l|l|}
\hline & a & b \\
\hline$r^{2}$ adjusted & 0.18 & 0.38 \\
\hline probability $>\mathrm{F}$ & 0.2872 & 0.029 \\
\hline N studies & 28 & 28 \\
\hline Context factors & & \\
\hline Corruption/IllegalLog & $0.055 /-$ & $\mathbf{0 . 0 3 8} /-$ \\
\hline Population growth/density & $0.262 /+$ & $\mathbf{0 . 0 2 6} /+$ \\
\hline Roads & $0.646 /-$ & \\
\hline LandSpeculation/OpportCosts & $0.381 /-$ & $0.300 /-$ \\
\hline EconDevelop/Income & $0.255 /+$ & $0.057 /+$ \\
\hline CashCrop & $0.688 /-$ & \\
\hline Agriculture & $0.567 /-$ & $0.119 /-$ \\
\hline Timber/Firewood & $0.950 /-$ & \\
\hline Nat.subsidies/Credits/Donor aid & $0.436 /-$ & \\
\hline PES/Certification & $0.819 /-$ & \\
\hline Protected Areas & $0.696 /+$ & \\
\hline CommForestry & $0.224 /+$ & $0.148 /+$ \\
\hline Tourism & $0.373 /+$ & $\mathbf{0 . 0 4 2} /+$ \\
\hline Technology & $\mathbf{0 . 0 1 1 * * / -}$ & $\mathbf{0 . 0 0 1 * * * / -}$ \\
\hline Education/Research/PR/Awareness & $0.105 /+$ & $0.104 /+$ \\
\hline
\end{tabular}

explained it by context factors. Full models included all available explanatory driver and intervention data. In the backward selected/optimized model we removed non-significant variables that did not increase the $r^{2}$ (Table 8). The full model with all context factors (column a) had a low $\mathrm{r}^{2}$ of 0.18 and was not significant. The improved model could explain $38 \%$ of the variation of governance effects on deforestation $\left(r^{2}=0.38\right)$. Thus, in the dataset based on 28 studies, over one third of the variation in governance effects was explained by the socioeconomic and political context. Corruption/illegal logging was negatively related to governance effects, i.e. acting in the opposite direction as governance. We interpret that corruption can counteract governance effects. Population growth/density was positively correlated with governance effects on deforestation, showing that the stronger population effects on deforestation are, the less effects governance has on deforestation (population in general has Likert scores below 4, decreasing Likert scores for population thus show stronger relations to deforestation). The same holds true for economic development. Tourism was positively correlated, showing that where tourism is related to decreasing deforestation, the effects of governance are reinforced and vice versa. Technology was the strongest explanatory variable and negatively related. We interpret that technological improvements and governance effects are antagonistic.

\section{Discussion}

\subsection{Relation between quality of governance and deforestation}

High scores for governance indicators analyzed across the 28 selected studies, were predominately linked to decreasing deforestation. Between the indicators, there were hardly differences in effects on forests (Fig. 6). In addition, nearly all indicators loaded jointly and positively on the first PCA component (Table 6). This confirms the finding of in general consistent effects and suggests that the governance indicators act conjointly and together have predominantly positive effects on reduced deforestation. Seemingly, the hypothesized relation between quality of governance and deforestation holds true and the findings are thus in line with many authors claiming positive effects of forest governance (Bhatterai and Hammig, 2001; Bhattarai and Hammig, 2004) or stating that governance is a "precondition for 
achieving a sustainable landscape" (de Graaf et al., 2017) or vital for "successful REDD + implementation" (Korhonen-Kurki et al., 2014). Angelsen et al. (2017) even refer to missing governance as a reason for unsatisfactory results of REDD + globally.

\subsection{Structure or agency mechanisms underlying applied governance research}

The reviewed studies examine effects of one or several governance indicators on deforestation, but they hardly consider relations between them. Our PCA shows specific relations between single governance indicators across the studies. Specifically on the second axis agency and structure indictors are clearly differentiated, and also on the first and third axis there is a certain, yet less distinct sorting (Table 6). The grouping of structure and agency indicators on the first three components shows that beyond a general trend of positive effects, independent governance mechanisms are in place that are characterized by varying contributions of single indicators. Agency and structure can be interpreted as such general and underlying governance mechanisms. This supports (Arts et al., 2014) claiming them to be two mainstream models that can help to understand governance functioning.

It is, however, undebated that agency and structure are idealized poles. As shown in our conceptual considerations (Section 2.1), there is consensus that actors' decisions will not purely follow one or the other logic and context-specific combinations with different shares of agency and structure components need to be taken into account (Giddens, 1984; March and Olsen, 1998). Both aspects are important and our results show that none of the two has stronger effects on deforestation. This is supported e.g. by the institutional economics theory (Ostrom, 2009) claiming that rational choice is mediated by rules, norms and beliefs. In this respect also the practice based approach (Arts et al., 2014) gains relevance, even though that in our evaluated studies such a dynamic dualism is hardly mentioned. Only (Andersson and Gibson, 2007) formulate such an understanding as "local ... moderation of national policy ... that researchers and policymakers need to understand". The perception of individual agency and structure mechanisms connected through dynamic and interactive feed backs may help to design and steer governance research and development work.

\subsection{Most decisive governance indicators}

Governance can only be assessed through individual indicators that represent specific governance aspects and that contribute to differing extends to structural or agency mechanisms. This necessitates a more detailed discussion of single indictors in the structure-agency context, taking also into account that a number of indicators represent aspects of both or cannot be assigned to either of the mechanisms.

Structural indicators like land use plan implementation, legal/policy framework and related law enforcement load stronger on the first PCA component as compared to agency indicators that load less on the first axis. In addition, agency indicators of tenure/ownership and participation show controversial results with some studies also reporting negative effects on deforestation (Fig. 6). This might suggest a more uniform and positive effect of structural indicators which might be interpreted as more strongly determining deforestation reduction. However, neither the share of agency nor the share of structural indicators per study correlated with mean deforestation effects (Section 3.4). It thus seems that even though we cannot claim a statistically significant stronger effect of one or the other mechanism, single structure indicators are more strongly and more consistently linked to reduced deforestation. This is an important finding in the context of the ongoing discussion on results based payments under REDD + . Such payments aim to utilize the financial motivation of recipient countries for reducing deforestation; they are an agency related governance component. The ongoing discussions on its implementations (Fischer et al., 2016; Fletcher et al., 2016; Angelsen et al., 2017, 2018) already show that a pure agency focus will hardly work. Our findings support that structural components which are as well foreseen under REDD + aiming to install legal and institutional structures, so-called readiness measures, need to be implemented first. They need to be perceived and communicated as independently functioning components. Expectations to tackle the tropical deforestation challenge with purely agency related measures are obviously hard to fulfil.

In our review, structural indicators were most frequently represented by policy framework and law enforcement. The legal policy framework and its enforcement are very closely intertwined in the PCA results (Fig. 7). Both of them are linked to reduced deforestation and in many studies they were evaluated conjointly. Our studies show both: negative effects of policies that do not care for deforestation (SoaresFilho et al., 2004; Porter-Bolland et al., 2012; Webb et al., 2014) and positive effects of laws aiming at forest conservation (Shahabuddin and Rao, 2010; Bae et al., 2012; Canova and Hickey, 2012). Policy framework and law enforcement are classical government related components that remain important and need continued support even though the governance concept has been widened into a much broader concept.

Participation and tenure/ownership were the most frequently studied agency indicators. Public participation aims to ensure that stakeholders' interests are reflected in final decisions. The reviewed studies provide strong support for the general positive notion of participatory approaches (Hayes, 2006; Chhatre and Agrawal, 2009) and provide rich evidence for positive effects of many aspects of participation including among others cooperative management (Gautam and Shivakoti, 2005; Oestreicher et al., 2009), respect of customary law (Webb et al., 2014) and autonomy of communities and indigenous people (Gautam et al., 2004a; Shahabuddin and Rao, 2010). In contrast, top down policy approaches (Baynes et al., 2016) and industry dominated activities without civil society participation (Heilmayr and Lambin, 2016) seem to lead to increased deforestation. Tenure/ownership which was the second most frequently studied agency indicator refers to the entire bundle of property and user rights that might be held individually or by an organization such as community, a state entity or a private company. In general, many authors base its importance on the assumption that more secure land and resource tenure motivates land users to manage resources more efficiently (Ostrom, 1999; Angelsen and Kaimowitz, 2001; Andersson and Gibson, 2007; Ceddia et al., 2014). Indeed, we find prevailing positive effects in most of the studies. However, participation and tenure/ownership also show some ambivalent results (Fig. 6). Tenure security alone can have divergent impacts by motivating agricultural expansion (de Souza et al., 2013; Agrawal et al., 2014; Ceddia et al., 2014; Jones et al., 2017) or by fostering forest clearing to demonstrate property rights (Soares-Filho et al., 2004; Bottazzi and Dao, 2013). Increased participation and decentralization was linked to higher forest clearing specifically in urban areas (Liu et al., 2016). Such divergent impacts of participation and tenure/ownership show that on one hand the motivation of single agents is a helpful mechanism to be built upon in deforestation abatement policies. On the other hand, it needs to be controlled by a frame of structural governance mechanisms in order to be effective.

The first three PCA axes, which we interpret as depicting agency and structure mechanisms, only explain $38 \%$ of the variation of governance effects (Table 6). In addition, there are indicators that could not exclusively be assigned to either of the two mechanisms. Executive agencies is the most frequently studied example of such an indicator and it consequently has an intermediate position independent from structure or agency related indicators on the first two PCA axes (Table 7). We interpret that executive agencies comprise both: structure and agency aspects (Giessen et al., 2014; Rahman and Giessen, 2017). On one side forest services are guards that are tasked with enforcing laws, and structures rules (Hayes and Persha, 2010; Baynes et al., 2016; Mansourian, 2016). Often they even originate from police-like organizations (Hutchins, 1916). But on the other side they are service providers that need to locally moderate interests of 
stakeholders and multiple demands of society (Bennett et al., 2014; Mansourian, 2016). This we interpret as serving the agency aspect. To set up such executive institutions that fulfil both aspects is a challenge that needs support and capacities. Most studies, however, did not differentiate between different aspects of executive agencies' work (Bhattarai and Hammig, 2004; Gautam et al., 2004b; Andersson and Gibson, 2007; Bae et al., 2012; Porter-Bolland et al., 2012). The example of executive agencies and the remaining unexplained variance are indications that the agency-structure concept is not the only mechanism underlying forest governance and further research is required to explain more variation.

The assessment frequency of the indictors in the articles varied much stronger than the effects of governance indicators on forests. Law enforcement, executive agencies and participation were scored in more than every second study. But in contrast, 12 indicators were of (very) minor importance in current research, occurring in only two or less studies. None of the studies even considered governance issues in the context of forest concessions, legislative institutions, budgeting or forest classification. It remains open if these indicators are indeed not studied or if they are simply not perceived as governance indicators by authors thus making them undetectable for our search algorithm. In any case, it shows the limitation of a too wide concept. Hence, it is questionable whether large sets of e.g. 130 governance indicators (Kishor and Kenneth, 2012) do not pose the risk of making it inapplicable. The importance of a number of governance factors should not result in subsuming "everything" under governance. At least, research as well as development work needs to specify what aspects of governance they cover.

\subsection{Effects of context factors}

As expected by definition, deforestation drivers in our review were linked to increasing deforestation and interventions were mostly linked to decreasing deforestation (see Fig. 6). For in-depth conclusions related to single drivers or interventions we refer to specified literature (Geist and Lambin, 2002; Hosonuma et al., 2012; Agrawal et al., 2014; Busch and Ferretti-Gallon, 2017). But beyond their direct effects on deforestation, context factors obviously moderate the effects of governance (Table 8). We show that governance is specifically linked to reduced deforestation in the context of corruption and illegal logging and can thus obviously counteract negative effects. In addition, the stronger the deforestation effects of population are, the less effective governance measures become. We thus support (Wehkamp et al., 2018) who found that a governance effect was more likely to become significant when accounting for population in the models and suggest that political institutions are more important when demographic pressures are high. In line with our study, agriculture and timber harvest did not moderate governance effects. Governance thus seems important irrespective of high or low pressures through agriculture and timber extraction. Wehkamp et al. (2018) included forest area and could show that forest policy gains importance if forest area becomes smaller. We, in addition, show an effect of economic development. In general, the understanding of governance effects certainly requires consideration of the socio-economic and biophysical context. Given the large number of context factors reported, a larger number of reviewed studies would certainly improve the statistical power of our results.

A discussion of all context factors would be beyond the scope of our review. Instead, we discuss two deforestation drivers - economy and agriculture - and two interventions - community forests and protected areas. These issues were most frequently mentioned and most controversially discussed in the reviewed studies. We consider them of specific political relevance and worth a specific discussion.

Economic development/income and agricultural intensification are context factors with positive and negative effects reported. On one hand, both do have the potential to reduce pressure on forests (Ashraf et al., 2017; Liu et al., 2017; Andoh and Lee, 2018). On the other hand, leading to increased opportunity costs, they can also increase the demand for forestland. They are an example showing that not only context factors affect governance but that governance structures are needed to moderate economic activities; or as (Ceddia et al., 2014) summarizes: economic development and "agricultural intensification need to be accompanied by policies that specifically focus on the environmental aspects of governance".

Community forests and protected areas are often regarded as competing, focusing rather on utilization versus conservation. Community forests emphasize participation and agency of local stakeholders whereas strictly protected areas are a structural approach often based on top down rules and bans (Ribot et al., 2010; Porter-Bolland et al., 2012; Agrawal et al., 2014). For both approaches we find supporters. For community forestry (Porter-Bolland et al., 2012) conclude that "tropical forest protected areas may not always represent the best way to conserve forests vis à vis tropical forests locally managed for production of goods and services". Protected areas do often not avoid clearing within the boundaries (Stocks et al., 2007; Porter-Bolland et al., 2012), highly depend on monitoring and law enforcement (Oestreicher et al., 2009) and displacement of deforestation from protected areas is a permanent risk (Bare et al., 2015). Positive outcomes for community forestry are reported in 12 of the studies (see Fig. 6). On the other side (Shahabuddin and Rao, 2010) argue that communityconserved areas "fall short of the needs of comprehensive biological conservation" and community forests may tend to conserve an altered species composition and tend to loose species, often those of the highest conservation value (Shahabuddin and Rao, 2010; Ceddia et al., 2014). Five studies find positive evidence for protected areas. A closer look reveals that such generalizing "either - or" discussions do not lead further because (i) the landscape context is of huge importance and (ii) both approaches often contain elements of the other one anyhow. To improve their effectiveness it might be an alternative to include protected areas as parts of community managed forests as long as indigenous demarcation works (Stocks et al., 2007).

\subsection{Methodological considerations}

The regional distribution of our studies was highly uneven with studies mainly based on the Asian and central/south American context. This has to be taken into account when generalizing the results and points to a regional challenge for forest governance research. Also in the review of (Porter-Bolland et al., 2012) eleven out of 16 countries were located in Latin America and the Caribbean and only two of them were from in Africa. Our results confirm (Stickler et al., 2013) who complain about a heavy regional bias with very limited evidence from governance research in Africa. Substantiating our findings specifically for Africa would be a next step that would require more samples, e.g. derived from a stratified random sampling method.

In our review, quantitative studies yielded weaker effects of governance indicators on deforestation as compared to qualitative studies. There is a long ongoing discussion on objectivity or subjectivity of qualitative research e.g. Ratner (2002) and Austin and Sutton (2014). Even though that the difference was not significant, our results might be based on the fact that the paradigm of good governance leading to less deforestation is omnipresent in the research community. This may challenge unprejudiced research and imply some danger for subjectivity in qualitative methods. We thus recommend using quantitative statistical methods as much as possible as being the obviously more critical ones.

Producing generalized knowledge based on reviews requires a discussion on the validity, transparency and accuracy of the results, specifically as our studies cover a wide variety of scales and are based on multiple different methods. Pathways to generalize review results are proposed by (Magliocca et al., 2018) providing typology based on (i) the existing knowledge base, (ii) the generalization approach and (iii) 
the methodology for producing the knowledge claim. In our case, the existing knowledge base was very comprehensive. The varying definitions of 'governance' in applied research (Broekhoven et al., 2012; Facility, 2013; Giessen and Buttoud, 2014) and the large amount of studies were major challenges. Nevertheless we stuck to the broad search term of 'governance' because pre-selection based on more specific governance components from sometimes dissenting definitions could have biased the results or excluded relevant literature. We concentrated on more frequently cited papers because citation indices are a widespread proxy for scientific quality. Our generalization approach is based on quantifying effects of governance indictors on deforestation (see Figs. 1 and 6). The existence of frequent effects is the basis for claiming general causal effects (Magliocca et al., 2018). Given that all governance indicators were predominately linked to decreasing deforestation, we cannot falsify the assumption of a universal trend. As concerns the methodology for producing the knowledge claim we standardized the mixed data through coding in order to increase comparability and statistical power. This is an adequate methodology specifically when regarding large and heterogeneous data sets (Magliocca et al., 2018). Reviews and meta analysis will gain importance taking into account the increasing number of governance publications. Related methodological guidelines are available (Petrokofsky et al., 2013; Livoreil et al., 2017; Pullin et al., 2018) and we support that investing existing resources in condensing and concluding from existing field studies is more efficient than adding new case studies with specified regional scope.

Sample size is a core methodological issue. Many authors confirm that our number of observations (198 articles screened and 28 evaluated) can be adequate. Shahabuddin and Rao (2010) base their global review on 34 studies. Porter-Bolland et al. (2012) publish a review across the tropics based on 27 studies. Magliocca et al. (2018) suggest "a general rule of thumb is a sample size of 30". However, due to the still limited sample size, this does not necessarily mean that non-significant variables do not play a role.

Our target variable "effects on deforestation, degradation or reforestation" needs some critical reflection, because deforestation in the tropics is not per se a negative event. It would have been desirable to differentiate between authorized deforestation under the sovereign discretion of tropical countries and illegal land use change. However, only (Andersson and Gibson, 2007) provided for such a differentiation which we could thus not take into account.

\section{Conclusions}

Our results show that successful implementation of different governance components mostly fosters reduced deforestation in the tropics, even across different regional and context situations. We thus confirm governance as an important instrument for reducing tropical deforestation or increasing reforestation. In consequence, the governance focus of current deforestation policies needs continued support. But governance is a very comprehensive concept and there are assessment tools that specify more than 100 different aspects and indicators (Davis et al., 2013). Our analysis shows that single indicators act conjointly towards reduced deforestation. We hardly found conflicting elements. This is encouraging for policy applications. On the other hand, numerous indicators were hardly or not at all covered in the reviewed studies. Thus, when talking and publishing about forest governance, at least a specification of the applied components is needed in order to avoid governance to become a meaningless buzzword (Giessen and Buttoud, 2014). The importance of a number of governance elements should not result in subsuming "everything" under governance.

In view of the broad concept with numerous synergistic elements, the question arises as to which elements applied policy should focus. Our analysis shows that previously defined agency and structure components (Arts et al., 2014) are visible as underlying factors and allow to structure the multitude of elements. Agency relies on the selfinterest of actors, with their specific motivations, whereas the structure concept has a focus on social norms, political conventions and frames as well as on agreed rules. Even though that the structural component was more clearly distinguishable in our principal component analysis, neither of the two approaches revealed statistically stronger effects on reduced deforestation. Both general aspects therefore need to be taken into account when selecting specific indicators. The selection and application of specific indicators needs to be locally adapted and we follow (Davis et al., 2013) recommending to adjust the system to the respective context. From the multitude of indicators, the structural indicators of land use planning, policy framework and law enforcement were scoring highest on the first axis of the PCA and we interpret that they have strongest effects on deforestation (Table 7); also in single studies they were consistently related to decreasing deforestation (Fig. 6). Among agency related indicators tenure/ownership and participation were most frequently studied and together with indicators related to financial interests had the highest scores on the first PCA axis. However, tenure/ownership and participation also show a small number of cases with negative effects (Fig. 6), suggesting that agency needs to be framed by legal and political structures. Results based payments under REDD+ are a prominent example to which we apply these findings. The current debate on applicability and limited implementation of such payments shows that agency related measures need to be accompanied by structural work, which is e.g. tackled in so-called readiness measures under REDD + . Structural development on one side is a precondition for agency based payments and on the other side results based payments function as an agency driven motivation for basic structural development.

In our PCA, only $38 \%$ of the variation in effects of governance indicators could be explained by the first three components related to a structure or agency mechanism. Governance is thus still more complex. Targeted development work and forest conservation measures still need a better understanding of interactions and relations between single governance indicators. More work is required to clarify and to describe specific correlations between single indicators. This would further clarify governance functioning and would show if additional indicators are directly affected by the work on one specific indicator.

Deforestation drivers and development interventions need to be taken into account as they can moderate governance effects. We could explain approximately one third of the governance effects by context factors. Population growth and corruption are prominent examples. We interpret that population density and corruption can counteract governance effects. On the other hand, agricultural development and timber extraction were not significant in our regression analysis suggesting that high governance scores have effects on reduced deforestation independently from high or low direct land use pressure.

Methodological literature for review studies is available (Petrokofsky et al., 2013; Livoreil et al., 2017; Magliocca et al., 2018; Pullin et al., 2018). Given the increasing number of governance publications, reviews should gain importance and should rely on still lager samples as we only focused on most frequently cited papers. Gaps in governance studies still need to be filled. In this respect, we draw the attention to the limited number of governance studies from Africa.

\section{Declaration of Competing Interest}

Authors declare that there are no conflicts of interest

\section{Acknowledgement}

This research did not receive any specific grant from funding agencies in the public, commercial, or not-for-profit sectors. 


\section{Appendix A. Key statements for scouring the governance indicator "Forest ownership and use rights"}

Example for illustrating the scoring process referring to column "Tenure/Ownership" in Table 4 of the main document Description of "Tenure/Ownership" indicator

"Forest ownership and use rights (hereafter called "forest tenure rights") refers to the entire bundle of forest-related property rights that may be held individually or communally in a country, including rights of land ownership and secondary rights to access, use, and manage forest resources."

Summarized key statements that were the basis for governance scores related to tenure/ownership (Note: in many cases statements were included in several parts of the publication, e.g. in results, conclusions and abstract. Here we present key statements only.)

\begin{tabular}{|c|c|c|c|}
\hline Study authors & Year & Key statements & $\begin{array}{l}\text { Resulting gov- } \\
\text { ernance score }\end{array}$ \\
\hline Andersson K., Gibson C.C. & 2007 & $\begin{array}{l}\text { municipal governance systems can mitigate pressures to deforest ... municipal moderation of deforestation is related } \\
\text { to ... facilitation of improved forest property rights for local forest users. And forest users who have more secure forest } \\
\text { property rights are more likely to engage in forest management activities and are less likely to convert forest }\end{array}$ & 6 \\
\hline Barsimantov J., Navia Antezana J. & 2012 & $\begin{array}{l}\text { communities that have maintained forest cover have stronger local governance institutions, } \ldots \text { and choose to maintain } \\
\text { the common property regime. .... Local governance in non-forestry communities is nearly non-functioning. Non- } \\
\text { forestry communities did not initiate the official process of certification of communal lands ... in this official process, } \\
\text { rules stating that forested lands cannot be divided are explained and usually enforced. }\end{array}$ & 6 \\
\hline Bottazzi P., Dao H. & 2013 & $\begin{array}{l}\text { It is obvious that the inherent characteristics of individual property rights pave the way for an extreme fragmentation } \\
\text { of this space, which entails a linear evolution of deforestation under the pressure of cattle-rearing ... On individual } \\
\text { parcels, each user directly affects himself ... to sell or rent his parcel for pastoral use (which) is not an incentive to limit } \\
\text { overexploitation... This means that the more land is fragmented by individual ownership, the higher the deforestation } \\
\text { rate. Land rights are thus a secondary factor of forest cover change (note: we interpret that it is not ownership per se that } \\
\text { has an effect on deforestation but fragmentation) }\end{array}$ & 4 \\
\hline $\begin{array}{l}\text { Ceddia M.G., Bardsley N.O., Go- } \\
\text { mez-Y-Paloma S., et al. }\end{array}$ & 2014 & $\begin{array}{l}\text { With respect to the conventional dimensions of governance, we use three indicators developed by the Worldbank ... } \\
\text { ROL reflects the ability to enforce contracts and the security of property rights ... (note: the indicator was obviously } \\
\text { included but no results reported) }\end{array}$ & 4 \\
\hline $\begin{array}{l}\text { De Souza R.A., Miziara F., de Ma- } \\
\text { rco Junior P }\end{array}$ & 2013 & $\begin{array}{l}\text { A significant and positive relationship }(p<0.050) \text { was found between the percentage of titled lands in the } \\
\text { municipalities (per } 1000 \text { ha) and the deforestation rates for all years between } 2005 \text { and } 2009 \ldots \text { This finding supports } \\
\text { the claim that deforestation is still significantly related to the presence of land under the regime of private property. }\end{array}$ & 2 \\
\hline $\begin{array}{l}\text { Gautam A.P., Shivakoti G.P., We- } \\
\text { bb E.L. }\end{array}$ & 2004 & $\begin{array}{l}\text { Legal transfer of resource ownership is not an important precondition for successful forest conservation at the local } \\
\text { level ... The finding that semigovernment forests managed by self-organized informal user groups improved and } \\
\text { gained forest more rapidly than formal community forests suggests that a formal handover of forest ownership is not } \\
\text { necessarily a strong determinant of successful forest conservation }\end{array}$ & 4 \\
\hline Hayes T., Persha L. & 2010 & $\begin{array}{l}\text { since the Ministry of Forestry technically owned the reserve lands, there was no reason for the local residents to } \\
\text { comply with land-use rules as the lands were no longer their responsibility (note: In case that negative governance was } \\
\text { reported in the studies we inverted the deforestation effect i.e. negative effect of no ownership was scored equally to positive } \\
\text { effects of ownership, see explanation in Section } 2.3 \text { of main document) }\end{array}$ & 6 \\
\hline $\begin{array}{l}\text { Jones K.W., Holland M.B., Naug- } \\
\text { hton-Treves L., et al. }\end{array}$ & 2017 & $\begin{array}{l}\text { Overall, the responses were mixed in terms of actual changes in land use following titling: about half the groups stated } \\
\text { no major differences were occurring and the other half mentioned that they were starting to increase agricultural } \\
\text { production. }\end{array}$ & 4 \\
\hline $\begin{array}{l}\text { Sendzimir J., Reij C.P., Magnusz- } \\
\text { ewski P. }\end{array}$ & 2011 & $\begin{array}{l}\text { In an atmosphere free of oversight by colonial or national authorities, farmers and communities took ownership of } \\
\text { trees and the ways in which they farmed. In the regreened area of the Maradi/Zinder region ... tree density increased } \\
\ldots \text { when farmers became free to experiment with techniques rediscovered with NGO help. The resulting tree growth } \\
\text { increased tree density and further reinforced the sense of ownership and other variables in the chain of feedbacks. }\end{array}$ & 6 \\
\hline Shahabuddin G., Rao M. & 2010 & $\begin{array}{l}\text { factors related to institutions, governance and tenure are likely very significant in influencing trends in biological } \\
\text { indicators. Well-defined user groups, high social capital and strong governance were associated with higher basal area } \\
\text { and species diversity... } \\
\text { factors underlying good ecosystem management in include .... autonomy that allows local communities to craft locally } \\
\text { relevant institutional arrangements, well-defined boundaries and tenurial security. }\end{array}$ & 6 \\
\hline $\begin{array}{l}\text { Soares-Filho B., Alencar A., Neps- } \\
\text { tad D., et al. }\end{array}$ & 2004 & Landholders clear their forest less if they have strong claims on their property (legal titles). & 6 \\
\hline Stocks A., McMahan B., Taber P. & 2007 & $\begin{array}{l}\text { all differences between indigenous and colonist controlled regions were statistically significant... Indigenous } \\
\text { communities, even with relatively high populations, maintain large areas of intact forest .... They have held the belief, } \\
\text { even from the beginning of their mapping project that they would somehow be able to legalize their territorial claims } \\
\ldots \text { This belief or hope, we argue, has been a significant factor that has kept a measure of protection for the land even } \\
\text { when funding for supporting voluntary forest rangers was irregular. }\end{array}$ & 7 \\
\hline $\begin{array}{l}\text { Webb E.L., Jachowski N.R.A., Ph- } \\
\text { elps J., et al. }\end{array}$ & 2014 & $\begin{array}{l}\text { Emerging policies are likely to tip the scales towards ... potentially greater rates of deforestation due to the } \\
\text { introduction of wellfunded investors, insufficient land tenure agreements, and low governance effectiveness. }\end{array}$ & 6 \\
\hline
\end{tabular}

\section{Appendix B. Supplementary data}

Supplementary material related to this article can be found, in the online version, at doi:https://doi.org/10.1016/j.envsci.2019.12.007.

\section{References}

Agrawal, A., Wollenberg, E., Persha, L., 2014. Governing agriculture-forest landscapes to achieve climate change mitigation. Glob. Environ. Change 29, 270-280.

Andersson, K., Benavides, J.P., León, R., 2014. Institutional diversity and local forest governance. Environ. Sci. Policy 36, 61-72.
Andersson, K., Gibson, C.C., 2007. Decentralized governance and environmental change: local institutional moderation of deforestation in Bolivia. J. Policy Anal. Manag. 26, 99-123.

Andoh, J., Lee, Y., 2018. Forest transition through reforestation policy integration: a comparative study between Ghana and the Republic of Korea. For. Policy Econ. 90, $12-21$.

Angelsen, A., Brockhaus, M., Duchelle, A.E., Larson, A., Martius, C., Sunderlin, W.D., 
Verchot, L., Wong, G., Wunder, S., 2017. Learning from REDD + : a response to Fletcher et al. Conserv. Biol. 31, 718-720.

Angelsen, A., Hermansen, E.A., Rajão, R., van der Hoff, R., 2018. Results-based payments. In: Arngelsen, A., Martius, C., De Sy, V., Duchelle, A.E., Larson, A., Thu Thuy, P. (Eds.), Transforming REDD + : Lessons and New Directions. CIFOR, Bogor, Indonesia.

Angelsen, A., Kaimowitz, D., 2001. Agricultural Technologies and Tropical Deforestation. CABI Publishing, Oxon, UK.

Archer, M.S., 2003. Structure, Agency and the Internal Conversation. Cambridge University Press.

Arts, B., Behagel, J., Turnhout, E., de Koning, J., van Bommel, S., 2014. A practice based approach to forest governance. For. Policy Econ. 49, 4-11.

Ashraf, J., Pandey, R., de Jong, W., 2017. Assessment of bio-physical, social and economic drivers for forest transition in Asia-Pacific region. For. Policy Econ. 76, 35-44.

Austin, Z., Sutton, J., 2014. Qualitative research: getting started. Can. J. Hosp. Pharm. 67.

Bae, J.S., Joo, R.W., Kim, Y.S., 2012. Forest transition in South Korea: reality, path and drivers. Land Use Policy 29, 198-207.

Bare, M., Kauffman, C., Miller, D.C., 2015. Assessing the impact of international conservation aid on deforestation in sub-Saharan Africa. Environ. Res. Lett. 10.

Baynes, J., Herbohn, J., Dressler, W., 2016. Power relationships: their effect on the governance of community forestry in the Philippines. Land Use Policy 54, 169-176.

Becker, G., 1968. Crime and punishment: an economic approach. J. Polit. Econ. 76, 169-217.

Bennett, M., Xie, C., Hogarth, N., Peng, D., Putzel, L., 2014. China's conversion of cropland to forest program for household delivery of ecosystem services: how important is a local implementation regime to survival rate outcomes? Forests 5, 2345-2376.

Bhagwat, S.A., Humphreys, D., Jones, N., 2017. Forest governance in the Anthropocene: challenges for theory and practice. For. Policy Econ. 79, 1-7.

Bhattarai, M., Hammig, M., 2004. Governance, economic policy, and the environmental Kuznets curve for natural tropical forests. Environ. Dev. Econ. 9, 367-382.

Bhatterai, M., Hammig, M., 2001. Institutions and the environmental Kuznets curve for deforestation: a crosscountry analysis for Latin America, Africa and Asia. World Dev. 29, 995-1010.

Bottazzi, P., Dao, H., 2013. On the road through the Bolivian Amazon: a multi-level land governance analysis of deforestation. Land Use Policy 30, 137-146.

Bourdieu, P., 1991. Language and Symbolic Power. Polity Press, Padstow, Cornwall.

Brennan, G., Buchanan, J.M., 1985. The Reason of Rules. Cambridge University Press, Cambridge.

Broekhoven, G., Savenije, H., von Scheliha, S., 2012. Moving forward with forest governance. In: Tropenbos International, W. (Ed.), ETFRN News. ETFRN, Wageningen, NL.

Bryman, A., 2003. Quantity and Quality in Social Research. Taylor \& Francis.

Busch, J., Ferretti-Gallon, K., 2017. What drives deforestation and what stops it? A metaanalysis. Rev. Environ. Econ. Policy 11, 3-23.

Canova, N.P., Hickey, G.M., 2012. Understanding the impacts of the 2007-08 Global Financial Crisis on sustainable forest management in the Brazilian Amazon: a case study. Ecol. Econ. 83, 19-31.

Castro, F.G., Kellison, J.G., Boyd, S.J., Kopak, A., 2010. A methodology for conducting integrative mixed methods research and data analyses. J. Mix. Methods Res. 4, 342-360.

Ceddia, M.G., Bardsley, N.O., Gomez-Y-Paloma, S., Sedlacek, S., 2014. Governance, agricultural intensification, and land sparing in tropical South America. Proc. Natl. Acad. Sci. U. S. A. 111, 7242-7247.

Chhatre, A., Agrawal, A., 2009. Trade-offs and synergies between carbon storage and livelihood benefits from forest commons. Proc. Natl. Acad. Sci. U. S. A. 106 17667-17670.

Coe, K., Scacco, J.M., 2017. Content analysis, quantitative. The International Encyclopedia of Communication Research Methods. pp. 1-11.

Davis, C., Williams, L., Lupberger, S., Daviet, F., 2013. Assessing Forest Governance: The Governance of Forests Initiative Indicator Framework. WRI, Washington, D.C., USA.

de Graaf, M., Buck, L., Shames, S., Zagt, R., 2017. Assessing Landscape Governance: A Participatory Approach. Tropenbos, EcoAgriculture, Wageningen, Washington.

de Souza, R.A., Miziara, F., de Marco Junior, P., 2013. Spatial variation of deforestation rates in the Brazilian Amazon: a complex theater for agrarian technology, agrarian structure and governance by surveillance. Land Use Policy 30, 915-924.

Dray, S., Josse, J., 2014. Principal component analysis with missing values: a comparative survey of methods. Plant Ecol. 216, 657-667.

Dunteman, G.H., 1989. Principal Component Analysis. Sage Publications, Newsbury Park, CA.

Facility, E.F., 2013. Governance Research Agenda for FLEGT: Towards Global Forest Governance Research and Action. EFI, Tropenbos International, EU.

FAO, 2015. Global Forest Resources Assessment 2015, Desk Reference. Food and Agriculture Organization of the United Nations, Rome.

Fischer, R., Hargita, Y., Günter, S., 2016. Insights from the ground level? A content analysis review of multi-national REDD + studies since 2010. For. Policy Econ. 66, $47-58$.

Fletcher, R., Dressler, W., Buscher, B., Anderson, Z.R., 2016. Questioning REDD + and the future of market-based conservation. Conserv. Biol. 30, 673-675.

Fraser, E.D.G., 2007. Travelling in antique lands: using past famines to develop an adaptability/resilience framework to identify food systems vulnerable to climate change. Clim. Change 83, 495-514.

Gautam, A.P., Shivakoti, G.P., 2005. Conditions for successful local collective action in forestry: some evidence from the Hills of Nepal. Soc. Nat. Resour. 18, 153-171.

Gautam, A.P., Shivakoti, G.P., Webb, E.L., 2004a. Forest cover change, physiography, local economy, and institutions in a mountain watershed in Nepal. Environ. Manage. $33,48-61$.

Gautam, A.P., Shivakoti, G.P., Webb, E.L., 2004b. A review of forest policies, institutions, and changes in the resource condition in Nepal. Int. For. Rev. 6, 136-148.

Geist, H.J., Lambin, E.F., 2002. Proximate causes and underlying driving forces of tropical deforestation tropical forests are disappearing as the result of many pressures, both local and regional, acting in various combinations in different geographical locations. BioScience 52, 143-150.

Giddens, A., 1984. The Constitution of Society. Outline of the Theory of Structuration. Polity Press, Cambridge.

Giessen, L., Buttoud, G., 2014. Defining and assessing forest governance. For. Policy Econ. 49, $1-3$

Giessen, L., Krott, M., Möllmann, T., 2014. Increasing representation of states by utilitarian as compared to environmental bureaucracies in international forest and forest-environmental policy negotiations. For. Policy Econ. 38, 97-104.

Hanneman, R., Riddle, M., 2005. Introduction to Social Network Methods: Free Online Textbook. Riverside.

Hayes, T., Persha, L., 2010. Nesting local forestry initiatives: revisiting community forest management in a REDD + world. For. Policy Econ. 12, 545-553.

Hayes, T.M., 2006. Parks, people, and forest protection: an institutional assessment of the effectiveness of protected areas. World Dev. 34, 2064-2075.

Heilmayr, R., Lambin, E.F., 2016. Impacts of nonstate, market-driven governance on Chilean forests. Proc. Natl. Acad. Sci. U. S. A. 113, 2910-2915.

Hosonuma, N., Herold, M., Sy, V., De Fries, R.S., Brockhaus, M., Verchot, L., Angelsen, A., Romijn, E., 2012. An assessment of deforestation and forest degradation drivers in developing countries. Environ. Res. Lett. 7044009.

Hutchins, D.E., 1916. A Discussion of Australian Forestry. Publisher Perth, Government Printer.

Jones, K.W., Holland, M.B., Naughton-Treves, L., Morales, M., Suarez, L., Keenan, K., 2017. Forest conservation incentives and deforestation in the Ecuadorian Amazon. Environ. Conserv. 44, 56-65.

Kanninen, M., Murdiyarso, D., Seymour, F., Angelsen, A., Wunder, S., German, L., 2007. Do Trees Grow on Money? The Implications of Deforestation Research for Policies to Promote REDD. CIFOR, Bogor, Indonesia.

Kickert, W., Klijn, E., Koppejan, J., 1997. Managing Complex Networks Strategies for the Public Sector. SAGE, London.

Kishor, N., Kenneth, R., 2012. Assessing and monitoring forest governance: a user's guide to a diagnostic tool. Program on Forests. PROFOR, Washington, D.C., USA.

Korhonen-Kurki, K., Sehring, J., Brockhaus, M., Di Gregorio, M., 2014. Enabling factors for establishing REDD + in a context of weak governance. Clim. Policy 14, 167-186.

Larson, A.M., Petkova, E., 2011. An introduction to forest governance, people and REDD + in Latin America: obstacles and opportunities. Forests 2, 86-111.

Liu, J., Liang, M., Li, L., Long, H., De Jong, W., 2017. Comparative study of the forest transition pathways of nine Asia-Pacific countries. For. Policy Econ. 76, 25-34.

Liu, Y., Feng, Y., Zhao, Z., Zhang, Q., Su, S., 2016. Socioeconomic drivers of forest loss and fragmentation: a comparison between different land use planning schemes and policy implications. Land Use Policy 54, 58-68.

Livoreil, B., Glanville, J., Haddaway, N.R., Bayliss, H., Bethel, A., de Lachapelle, F.F., Robalino, S., Savilaakso, S., Zhou, W., Petrokofsky, G., Frampton, G., 2017. Systematic searching for environmental evidence using multiple tools and sources. Environ. Evid. 6.

Magliocca, N.R., Ellis, E.C., Allington, G.R.H., de Bremond, A., Dell'Angelo, J., Mertz, O., Messerli, P., Meyfroidt, P., Seppelt, R., Verburg, P.H., 2018. Closing global knowledge gaps: producing generalized knowledge from case studies of social-ecological systems. Glob. Environ. Change 50, 1-14.

Manley, B.F.J., 2005. Multivariate Statistical Methods. A Primer, Third edition. Chapman and Hall.

Mansourian, S., 2016. Understanding the relationship between governance and forest landscape restoration. Conserv. Soc. 14, 267-278.

Mansourian, S., 2017. Governance and forest landscape restoration: a framework to support decision-making. J. Nat. Conserv. 37, 21-30.

March, J.G., Olsen, J.P., 2004. The logic of appropriateness. In: Moran, M., Rein, M., Goodin, R.E. (Eds.), The Oxford Handbook of Political Science. Oxford University Press, Oxford.

March, J.P., Olsen, J.P., 1998. The institutional dynamics of international political orders Int. Organ. 52, 943-969.

Mayring, P., 2000. Qualitative content analysis. Forum Qual. Soc. Res. 1 Art 25.

Mayring, P., 2014. Qualitative Content Analysis: Theoretical Foundation, Basic Procedures and Software Solution. Open Access Repository, Klagenfurt.

Oestreicher, J.S., Benessaiah, K., Ruiz-Jaen, M.C., Sloan, S., Turner, K., Pelletier, J., Guay, B., Clark, K.E., Roche, D.G., Meiners, M., Potvin, C., 2009. Avoiding deforestation in Panamanian protected areas: an analysis of protection effectiveness and implications for reducing emissions from deforestation and forest degradation. Glob. Environ. Change 19, 279-291.

Ostrom, E., 1990. Governing the Commons: The Evolution of Institutions for Collective Action. Cambridge University Press, New York.

Ostrom, E., 1999. Governing the Commons: The Evolution of Institutions for Collective Action. Cambridge University Press, New York.

Ostrom, E., 2009. A general framework for analyzing sustainability of social-ecological systems. Science 325, 419-422.

Peres-Neto, P.R., Jackson, D.A., Somers, K.M., 2003. Giving meaningful interpretation to ordination axes: assessing loading significance in principal component analysis. Ecology 84, 2347-2363.

Petrokofsky, G., Brown, N.D., Hemery, G.E., 2013. Matching a scientific knowledge base with stakeholders' needs. For. Policy Econ. 37, 29-36.

Porter-Bolland, L., Ellis, E.A., Guariguata, M.R., Ruiz-Mallén, I., Negrete-Yankelevich, S., Reyes-García, V., 2012. Community managed forests and forest protected areas: an assessment of their conservation effectiveness across the tropics. For. Ecol. Manage. $268,6-17$. 
Pullin, A.S., Frampton, G.K., Livoreil, B., Petrokofsky, G., 2018. Guidelines and Standards for Evidence Synthesis in Environmental Management (Version 5.0).

Rahman, M.S., Giessen, L., 2017. Formal and informal interests of donors to allocate aid: spending patterns of USAID, GIZ, and EU forest development policy in Bangladesh. World Dev. 94, 250-267.

Ratner, C., 2002. Subjectivity and Objectivity in Qualitative Methodology. Forum Qual. Social Res. 3 (3). www.qualitative-research.net.

Ribot, J.C., Lund, J.F., Treue, T., 2010. Democratic decentralization in sub-Saharan Africa: its contribution to forest management, livelihoods, and enfranchisement. Environ. Conserv. 37, 35-44.

SAS, 2015. JMP 12. Basic Analysis. SAS Institute, Carry, N.C.

Schusser, C., Krott, M., Yufanyi Movuh, M.C., Logmani, J., Devkota, R.R., Maryudi, A., Salla, M., Bach, N.D., 2015. Powerful stakeholders as drivers of community forestry-results of an international study. For. Policy Econ. 58, 92-101.

Shahabuddin, G., Rao, M., 2010. Do community-conserved areas effectively conserve biological diversity? Global insights and the Indian context. Biol. Conserv. 143, $2926-2936$.

Singer, B., Giessen, L., 2017. Towards a donut regime? Domestic actors, climatization, and the hollowing-out of the international forests regime in the Anthropocene. For Policy Econ. 79, 69-79.

Soares-Filho, B., Alencar, A., Nepstad, D., Cerqueira, G., Del Carmen, V., Diaz, M., Rivero, S., Solórzano, L., Voll, E., 2004. Simulating the response of land-cover changes to road paving and governance along a major Amazon highway: the Santarém-Cuiabá corridor. Glob. Change Biol. 10, 745-764.
Stickler, C.M., Nepstad, D.C., Azevedo, A.A., McGrath, D.G., 2013. Defending public interests in private lands: compliance, costs and potential environmental consequences of the Brazilian Forest Code in Mato Grosso. Philos. Trans. Biol. Sci. 368.

Stickler, M.M., Huntington, H., Haflett, A., Petrova, S., Bouvier, I., 2017. Does de facto forest tenure affect forest condition? Community perceptions from Zambia. For. Policy Econ. 85, 32-45.

Stocks, A., McMahan, B., Taber, P., 2007. Indigenous, colonist, and government impacts on Nicaragua's Bosawas reserve. Conserv. Biol. 21, 1495-1505.

Subhan Mollick, A., Khalilur Rahman, M., Nabiul Islam Khan, M., Nazmus Sadath, M., 2018. Evaluation of good governance in a participatory forestry program: a case study in Madhupur Sal forests of Bangladesh. For. Policy Econ. 95, 123-137.

Umemiya, C., Rametsteiner, E., Kraxner, F., 2010. Quantifying the impacts of the quality of governance on deforestation. Environ. Sci. Policy 13, 695-701.

Webb, E.L., Jachowski, N.R.A., Phelps, J., Friess, D.A., Than, M.M., Ziegler, A.D., 2014. Deforestation in the Ayeyarwady Delta and the conservation implications of an internationally-engaged Myanmar. Glob. Environ. Change Part A 24, 321-333.

Wehkamp, J., Aquino, A., Fuss, S., Reed, E.W., 2015. Analyzing the perception of deforestation drivers by African policy makers in light of possible REDD + policy responses. For. Policy Econ. 59, 7-18.

Wehkamp, J., Koch, N., Lübbers, S., Fuss, S., 2018. Governance and deforestation-a meta-analysis in economics. Ecol. Econ. 144, 214-227.

Worldbank, 2006. A Decade of Measuring the Quality of Governance. Governance Matters 2006. Worldwide Governance Indicators. Inc., Washington, D.C. 
Development

Elsevier Editorial System(tm) for World

Manuscript Draft

Manuscript Number:

Title: Interplay of governance elements and their effects on

deforestation in tropical landscapes: Quantitative insights from Ecuador

Article Type: Manuscript

Keywords: Governance; Deforestation; Principal Component Analysis; Multiple Regression Analysis; Ecuador; South America

Corresponding Author: Mr. Richard Fischer,

Corresponding Author's Institution:

First Author: Richard Fischer

Order of Authors: Richard Fischer; Fabian Tamayo; Tatiana Ojeda Luna; Rubén Ferrer Velasco; Maria DeDecker; Bolier Torres; Lukas Giessen; Sven Günter

Abstract: After state-centered and market-centered approaches have driven international development cooperation activities in previous decades, improved governance has now come into the focus as a means to help reversing global trends of tropical deforestation. Yet, "good governance" remains a normative, broad and often underspecified concept consisting of a wide range of elements and implicit value judgements. Specific knowledge is missing on the relative importance of single elements, on their interdependencies and their specific effects. Following an analytical approach, we aimed to investigate if single governance elements affect each other and whether they relate to decreasing deforestation. We conducted a quantitative field study in twelve selected landscapes across 160,000 ha of tropical lowland forest in Ecuador. We mapped governance arrangements and land use in participatory exercises. The performance of single governance elements including tenure, forest management practices, law enforcement, institutions, and participation was quantified based on the governance assessment framework of the World Resource Institute. We assessed context information and used satellite based deforestation data. Principal component analysis showed that all governance elements loaded positively on the first axis. Specific governance elements thus acted conjointly. They interact positively and might reinforce each other. Policy and development work may therefore focus on a smaller number of well-selected governance elements. High performance of specific governance elements, in particular tenure and participation was linked to reduced deforestation. This supports the notion of a number of governance elements as being indeed "good" for low deforestation. This functional understanding draws a more differentiated picture for single governance elements and supports outcome oriented decisions instead of value-oriented principles that underlie "good governance". Direct deforestation drivers such as agriculture and infrastructure explained larger shares of deforestation as compared to governance. A number of conclusions and recommendations for the specific governance situation in tropical lowland forests of Ecuador are given. 

Thünen Institute (IW) · Leuschnerstraße $91 \cdot 21031$ Hamburg/Germany

Editor

World Development

your References

Dear Dr. Agrawal,
Institute of International Forestry and Forest Economics

Richard Fischer

Leuschnerstraße 91

21031 Hamburg/Germany

Phone +49 $4073962-129$

Fax +4940 38905-399

richard.fischer@thuenen.de

Date

07 June 2020

attached please find our manuscript "Interplay of governance elements and their effects on deforestation in tropical landscapes: Quantitative insights from Ecuador " that we submit for publication in "World Development".

Please observe that we had already submitted a first version of this work to "World Development" which was rejected (WD-15498). The reviewer's final statement, whereas ... "a comprehensive revision would allow the rest of the world the innovative and careful research that is buried in this paper" motivated us to comprehensively re-work this manuscript, also taking into account the valuable comments of the reviewer. We are still convinced that your journal would be the ideal platform to publish our research and hope for a re-consideration.

I declare on behalf of all co-authors that we do not have any interests to declare and that there is no conflict of interests for neither of the authors.

The work has not been published previously it is not under consideration for publication elsewhere. The publication is approved by all authors and, if accepted, it will not be published elsewhere in the same form, in English or in any other language, including electronically without the written consent of the copyrightholder.

With kind regards

Richard Fischer

The Johann Heinrich von Thünen Institute, Federal Research Institute for Rural Areas, Forestry and Fisheries - Thünen Institute in brief consists of 14 specialized institutes that carry out research and provide policy advice in the fields of economy, ecology and technology. President: Prof. Dr. Folkhard Isermeyer 
Interplay of governance elements and their effects on deforestation in tropical landscapes: Quantitative insights from Ecuador

\begin{abstract}
After state-centered and market-centered approaches have driven international development cooperation activities in previous decades, improved governance has now come into the focus as a means to help reversing global trends of tropical deforestation. Yet, "good governance" remains a normative, broad and often underspecified concept consisting of a wide range of elements and implicit value judgements. Specific knowledge is missing on the relative importance of single elements, on their interdependencies and their specific effects. Following an analytical approach, we aimed to investigate if single governance elements affect each other and whether they relate to decreasing deforestation. We conducted a quantitative field study in twelve selected landscapes across 160,000 ha of tropical lowland forest in Ecuador. We mapped governance arrangements and land use in participatory exercises. The performance of single governance elements including tenure, forest management practices, law enforcement, institutions, and participation was quantified based on the governance assessment framework of the World Resource Institute. We assessed context information and used satellite based deforestation data. Principal component analysis showed that all governance elements loaded positively on the first axis. Specific governance elements thus acted conjointly. They interact positively and might reinforce each other. Policy and development work may therefore focus on a smaller number of well-selected governance elements. High performance of specific governance elements, in particular tenure and participation was linked to reduced deforestation. This supports the notion of a number of governance elements as being indeed "good" for low deforestation. This functional understanding draws a more differentiated picture for single governance elements and supports outcome oriented decisions instead of value-oriented principles that underlie "good governance". Direct deforestation drivers such as agriculture and infrastructure explained larger shares of deforestation as compared to governance. A number of conclusions and recommendations for the specific governance situation in tropical lowland forests of Ecuador are given.
\end{abstract}


Interplay of governance elements and their effects on deforestation in tropical landscapes:

Quantitative insights from Ecuador

Highlights

- Specific governance elements act conjointly, interact positively and probably reinforce each other.

- Tenure and participation were related to decreasing deforestation.

- A differentiated view on single governance components is needed for development work and research.

- Direct drivers such as agriculture and infrastructure had higher explanatory power for deforestation as compared to governance elements.

- Results are based on a comprehensive, empirical field study in Ecuadorian lowland forests covering 160,000 ha. 
Interplay of governance elements and their effects on deforestation in tropical landscapes: Quantitative insights from Ecuador

\author{
Richard Fischer ${ }^{1,3}$, Fabian TAmayo ${ }^{2}$, Tatiana Ojeda LunA ${ }^{1,3}$, Rubén FerRer Velasco ${ }^{1,4}$, Maria DeDeCKer ${ }^{2}$, \\ Bolier TORRES ${ }^{2}$, Lukas GIESSEN ${ }^{5,6}$, Sven GÜNTER ${ }^{1,4}$ \\ ${ }^{1}$ Thünen Institute for International Forestry and Forest Economics, Hamburg/Germany; ${ }^{2}$ Universidad \\ Estatal Amazonica, Puyo/Ecuador; ${ }^{3}$ Graduate School Forest and Agricultural Sciences, University of \\ Goettingen, Goettingen/Germany; ${ }^{4}$ School of Life Sciences Weihenstephan, Technical University of \\ Munich, Freising/Germany; ${ }^{5}$ European Forest Institute, Bonn/Germany; ${ }^{6}$ IPB Bogor Agricultural \\ University, Indonesia
}

$\begin{array}{ll}\text { Richard Fischer } & \text { richard.fischer@thuenen.de } \\ \text { Fabian Tamayo } & \text { tamayocordero@hotmail.com } \\ \text { Tatiana Ojeda Luna } & \begin{array}{l}\text { tatiana.ojeda@thuenen.de } \\ \text { Rubén Ferrer Velasco }\end{array} \\ \text { Maria de Decker } & \text { mariadedecker@hotmail.de } \\ \text { Bolier Torres } & \text { bolier.torres@gmail.com } \\ \text { Lukas Giessen } & \text { lukas.giessen@efi.int } \\ \text { Sven Günter } & \text { sven.guenter@thuenen.de }\end{array}$

\title{
Acknowledgements
}

The study is part of the project Landscape Forestry in the Tropics (LaForeT) conducted in Ecuador by the Thünen Institute of International Forestry and Forest Economics, Hamburg, Germany and the Universidad Estatal Amazónica of Ecuador. It was funded by the conducting institutions as well as by the German Federal Ministry of Food and Agriculture and the German Federal Office of Agriculture and Food (BLE) due to a decision of the Deutscher Bundestag, Project number 281-006-01. We acknowledge the support of the Universidad Luis Vargas Torres, Esmeraldas for facilitating logistics for the field campaign and opening the doors to the local communities. 


\section{${ }^{*}$ Conflict of Interest Statement}

Thünen Institute (IW) · Leuschnerstraße $91 \cdot 21031$ Hamburg/Germany

Editor

World Development

your References

Dear Sir or Madam, our References
Institute of International Forestry and Forest Economics

Richard Fischer

Leuschnerstraße 91

21031 Hamburg/Germany

Phone +49 $4073962-129$

Fax +4940 38905-399

richard.fischer@thuenen.de

Date

7 Jun 2020-0ع 
Interplay of governance elements and their effects on deforestation in tropical landscapes: Quantitative insights from Ecuador

\section{Introduction}

\subsection{Background}

Even though the pace of net forest loss has slowed, the area of the world's forests continues to decrease. The rate of annual net loss of forest has slowed from 7.8 mio hectares in the 1990s to 4.7 mio hectares between 2015 and 2020 (FAO, 2020). The largest loss of forest area still occurs in the tropics particularly in Africa and South America. Improved governance has come into the focus as a promising mechanism to globally reverse this trend. In international forest policy, governance is increasingly taken into account (Singer and Giessen, 2017), even though it is clear that forest governance alone is certainly not sufficient to address drivers of deforestation and degradation (Larson, 2011; Busch and Ferretti-Gallon, 2017). Governance is one out of six UN Forest Goals (UN, 2019) and plays a core role in international forest programs, such as REDD+ ("Reducing Emissions from Deforestation and Forest Degradation") and FLEGT ("Forest Law Enforcement, Governance and Trade") to which it even lends its name.

The concept of governance has, in part, evolved from a fundamental problematization of the role and function of the state, starting in the 1970s (Ansell and Torfing, 2016). This resulted in a transition from state-driven governments to multi-actor governance (Arts, 2014). Such governance is understood to steer society and the economy through collective action (Torfing et al., 2012). In contrast to a normative "good governance" concept (Arts, 2012; Ansell and Torfing, 2016), analytical governance approaches rely on the mere reflection of the processes and their explanation (Giessen and Buttoud, 2014). But as forest governance comprises a multitude of different elements, an analytical governance approach needs an understanding of how different governance elements are related, how they affect each other and which of them are of specific relevance for achieving predefined aims. In practice, governance elements and numerous forest governance indicators are specified by handbooks, frameworks and toolboxes (Kishor and Rosenbaum, 2012; Davis et al., 2013b; de Graaf et al., 2017). Analytical governance understanding is challenging due to the large number of governance elements and the decisive role of the local contexts (Wehkamp et al., 2018). First insights into governance functioning have been provided by (Fischer et al., 2020) based on review data. Further substantiation based on empirical field data is now required.

In order to value the importance and relevance of different governance elements, it is necessary to relate them to outcomes, such as reduced deforestation in the tropics. (Geist and Lambin, 2002) conceptualize that proximate drivers have effects on deforestation and are themselves affected by governance which is understood as an underlying cause. There are numerous case studies that analyze effects of single governance elements on deforestation. Reviews based on such case studies have been published (Wehkamp et al., 2018; Fischer et al., 2020). However, a comprehensive analysis based on empirical field data is hardly available until today. Specific analyses on landscape level are needed in order to research larger areas where agriculture, forestry, and other productive land uses compete with environmental and biodiversity goals (Sayer et al., 2013).

\subsection{Aims}


This study aims to empirically analyze forest governance functioning and to quantify governance

\section{Theoretical foundations}

\subsection{Governance theory and definition}

The main theoretical basis of forest governance has been claimed to consist of two mainstream models: rational choice and neo-institutionalism, otherwise described as agency - structure concept, which provides a theoretical basis to better understand and describe governance approaches (Arts et al., 2014). The agency approach postulates that it is mainly self-interested actors with their specific motivations, intentions, goals, actions and resources, which take active agency and, hence, drive land use decisions. On the other side, structural elements like laws, regulations, plans, cultural conventions and norms provide a frame for land use decisions (Archer, 2003). Specifically (Ostrom, 1990) points to the fact that institutions impact behavior through rules, norms and incentives in order to prevent a tragedy of the commons. (North, 1991) emphasizes the importance of informal institutions vis a vis the formal ones. It has to be taken into account that usually neither structure nor agency alone drive human behavior. (Giddens, 1984) formulates that agents - groups or individuals draw upon structures to perform social actions but at the same time structure is the result of these social practices.

Numerous definitions have been proposed for forest governance (Larson and Petkova, 2011; Broekhoven et al., 2012; Davis et al., 2013b; Giessen and Buttoud, 2014; de Graaf et al., 2017; Mansourian, 2017). The recent definitions all understand governance as a broad and comprehensive concept that goes far beyond governments and that is centered around decisions on forest management (Larson and Petkova, 2011; Broekhoven et al., 2012). Following (Giessen and Buttoud, 2014) "forest governance comprises a) all formal and informal, public and private regulatory structures, i.e. institutions consisting of rules, norms, principles, decision procedures, concerning forests, their utilization and their conservation, b) the interactions between public and private actors therein and c) the effects of either on forests". This definition explicitly mentions structural aspects in its first part and describes agency related aspects as interactions of different actors in the second part. It further relates governance to effects on forests, which is in line with the aims of this study. This definition thus provides the basis for the present study.

\subsection{Interlinkages of governance elements and their effects on forests}

Whatever definition applied, governance comprises a multitude of different elements specified by numerous indicators. Handbooks and toolboxes list governance indicators but without substantiation 
of functional links or effects for each of them (Worldbank, 2006; Kishor and Rosenbaum, 2012; Davis et al., 2013a; de Graaf et al., 2017). (IFRI, 2011) provides conceptualizations of governance element interactions and a methodology for field assessments based on (Ostrom, 1999) but is mainly based on qualitative descriptions. Also (CIFOR, 2015; Ravikumar et al., 2015) aim at a descriptive approach. Systematic studies that quantify functional relations based on these approaches are missing. First quantitative insights into governance functioning have been provided by (Fischer et al., 2020) based on review data. Our study relies on the forest governance assessment framework of the World Resource Institute (Davis et al., 2013a). It extends the methodological approach of (Fischer et al., 2020) to the field level.

Existing results on governance effects show positive relations between improved governance and reduced deforestation. Scholars have produced an increasing number of (i) case studies analyzing governance effects on deforestation in field studies (Andersson et al., 2014; Schusser et al., 2015; Subhan Mollick et al., 2018) (ii) statistical evaluations of governance effects using regional or global panel data sets (Umemiya et al., 2010) and (iii) reviews of existing research results (Bhagwat et al., 2017; Wehkamp et al., 2018; Fischer et al., 2020). The prevailing conclusion in such studies is that improved forest governance at least contributes to reduced deforestation. However, quantitative relations of governance indicators to proximate drivers remain open and effects are reported for individual governance elements only. It is not clear, which are the most decisive governance elements with respect to deforestation outcomes and how elements are functionally related in their effects.

\subsection{Conceptual Framework}

Taking into account the definition of (Giessen and Buttoud, 2014) we conceptualize governance as being based on (A) multiple actors and (B) structures including formal and informal rules of forestrelated decisions and their implementation (Fig. 1). These two main governance components reflect the agency - structure concept, which provides a theoretical basis to better understand and describe governance approaches (Arts et al., 2014; Fischer et al., 2020). In addition to these two components we take into account (C) interactions between actors, (D) interactions between actors and structures and $(E)$ the effects of either on forests in order to compose a comprehensive governance framework. In order to specify actors, structures and interactions we use a set of governance elements as described by the World Resource Institute (Davis et al., 2013a). We relate governance elements either to one specific component (e.g. institutions represent an actor) or in other cases to several governance components (e.g. tenure refers to actors and rules, participation refers to interactions between actors and to interactions between actors and structures).

Like socio-economic factors, forest governance is an underlying cause i.e. a fundamental force that underpins the proximate drivers of deforestation and forest degradation (Turner et al., 1993; Geist and Lambin, 2001; Geist and Lambin, 2002; Hosonuma et al., 2012a). Therefore, we incorporate selected proximate drivers of deforestation (Fig. 1). The proximate drivers are human activities that directly affect the environment or forest. In our study we consider agricultural expansion, wood extraction and extension of infrastructure. 


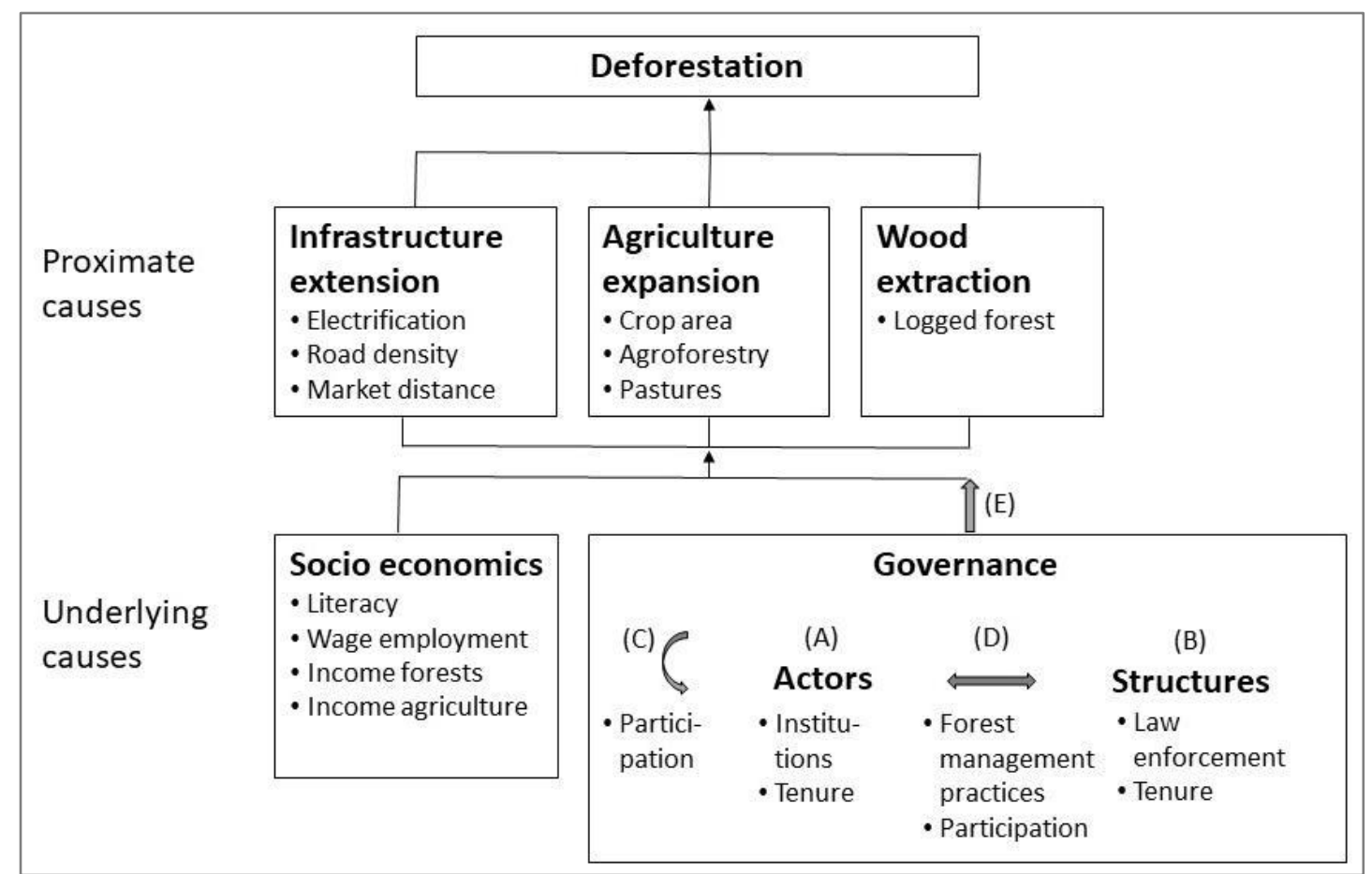

Figure 1: Conceptual framework underpinning the study. Adapted from (Geist and Lambin, 2002) and amended by the governance components: $(A)$ actors, $(B)$ structures $(C)$, interactions between actors, (D) interactions between actors and structures, $(E)$ the effects on forests. Bullet points represent governance elements and other variables assessed within the study.

\section{Methods}

\subsection{Deforestation, forest governance and study area in Ecuador}

With an annual forest loss rate of 0.6\% calculated for the period 1990 - 2015 (FAO, 2015), Ecuadorian forests are among those with highest deforestation rates in South America. The main drivers of deforestation in Ecuador are agricultural expansion with crops produced for subsistence use, domestic and international markets as well as land demand for pastures. Road infrastructure provides access to remote areas and is frequently provided by logging operations, oil mining industries as well as governmental investments. Commercial crop plantations play a regionally important role, like e.g. palm oil plantations in the province of Esmeraldas (Castro et al., 2013; Sierra, 2013).

Forest resources of Ecuador are under the principal competence of the state (ACE, 2008). The largest share of state forests falls under the patrimony of natural areas (PANE). This is part of the national system of protected areas 'Sistema Nacional de Areas Protegidas' (SNAP) which covers approximately $20 \%$ of the Ecuadorian territorial surface. Private individuals or organizations can obtain land titles if possession and production is documented over a minimum period of five years. But based on customary rights, private farms and communal settlements also exist on non-titled lands (Holland et al., 2014). Settlers introduced intensified agricultural practices including cattle ranching (Pichón, 1997; Rudel et al., 2002) and until today often benefit from road infrastructure created by logging and mining enterprises as well as public and non-public oil roads (Baynard et al., 2013). Indigenous populations occupy territories corresponding to $65 \%$ of the Ecuadorian forests (Palacios, 2005) (Morales et al., 2010), with large parts located in SNAP areas. Traditionally indigenous communities leave parts of their forests unmanaged as reserve after having assigned 
portions of individual land to each of the members. The ultimate goal is to reserve land for future generations and future production (Holt and Bilsborrow, 2004; Izurieta et al., 2014). In 2008, the Ecuadorian government launched the Socio Bosque program, which applies to private and communal forest owners and gives direct monetary incentives for the conservation of vulnerable ecosystems. The program is based on 20-year legally binding conservation contracts including biannual payments as partial compensation for restrictions from altering the forests. 1.6 mio ha are currently under Socio Bosque, annual payments for 2018 amounted to 10.5 mio USD and were distributed to 175.000 beneficiaries (MAE, 2018b).

The study was conducted in the provinces of Esmeraldas (Northwestern Coast), Napo, Pastaza and Orellana (Central Amazon). These provinces accounted for $27 \%$ of the net deforestation of Ecuador in the years 2014-2016 (MAE, 2018a). For our research, we selected twelve landscapes within the larger LaForeT project (www.la-foret.org). Each landscape covered approximately $100 \mathrm{~km}^{2}$ and was situated within one parish ('parroquia') to ensure homogeneous formal administration. Each landscape was placed to cover a gradient of typical forest cover development and to include different phases of forest transition (Mather, 1992; Grainger, 1995; Hosonuma 2012). Half of the landscapes included conservation areas of PANE or Socio Bosque as two prominent forest conservation schemes in Ecuador, whereas the other half did not include such restricted areas. All landscapes were located at elevations of below $1100 \mathrm{~m}$ asl. within the natural vegetation zones of evergreen lowlands or evergreen foothill forests (MAE, 2013) (Tab. 1).

\begin{tabular}{|l|l|l|}
\hline Landscape name & $\begin{array}{l}\text { Total landscape } \\
\text { area [ha] }\end{array}$ & FC2016 (AFCC)* \\
\hline San Francisco Ónzole & 10.615 & $62,16 \%(-0,50 \%)$ \\
\hline Santo Domingo Ónzole & 10.010 & $88,48 \%(-0,34 \%)$ \\
\hline Tabiazo & 8.800 & $31,07 \%(+0,96 \%)$ \\
\hline Cube & 11.937 & $23,92 \%(-3,46 \%)$ \\
\hline Chontapunta & 16.407 & $50,17 \%(-1,27 \%)$ \\
\hline Ahuano & 18.919 & $65,03 \%(-0,17 \%)$ \\
\hline Carlos Julio Arosemena & 13.458 & $57,60 \%(-0,99 \%)$ \\
\hline Rukullakta & 15.878 & $71,52 \%(+2,31 \%)$ \\
\hline San Jose de Dahuano & 13.010 & $49,37 \%(-1,73 \%)$ \\
\hline Avila Huirino & 16.128 & $61,83 \%(-0,87 \%)$ \\
\hline Arajuno & 16.136 & $81,84 \%(-0,71 \%)$ \\
\hline Canelos & 12.148 & $72,62 \%(-0,36 \%)$ \\
\hline
\end{tabular}

Table 1: Key characteristics of landscapes studied ( ${ }^{*} \mathrm{FC} 2016$ is native forest cover $\%$ within the landscape boundaries in 2016, calculated from (MAE, 2017b). AFCC (in brackets) is the mean annual native forest cover change within the landscape for the period 2008-2016 (MAE, 2016, 2017a))

\subsection{Data collection}

Data collection was carried out through participatory exercises (see 3.2.1) and included mapping of governance arrangements (3.2.2) for which governance performance was assessed (see 3.2.3), as well as land use mapping (see 3.2.4). Key informant interviews were conducted for socio economic and infrastructure data (see 3.2.5). Deforestation was calculated based on satellite data and served as target variable in the models (see 3.2.6). Explanatory variable for the multiple linear regression consist of infrastructure, land use, socio-economic variables as well as of governance elements.

\subsubsection{Mapping exercises for governance and land use information}


We carried out participatory mapping (Elwood and Ghose, 2011; Martin et al., 2012; Freund et al.,

\subsubsection{Classification and delineation of governance arrangements}

Governance arrangements were defined as spatial units with a homogeneous constellation of governance components (see 2.3). During scoping visits we identified 6 different governance arrangement types based on an own categorization related to the conditions in the research area. Governance arrangements were determined so that variation of governance within arrangements was minimized whereas variation between governance arrangements in a landscape was maximized. They comprised

1. Communal land, with or without land title, excluding conservation areas. In the research area, communal lands were coinciding with indigenous land ownership.

2. Individually owned land, with or without land title. In the research area, individual land predominantly coincided with farms owned by settlers.

3. Indigenous reserves as traditional form of land conservation on communal indigenous land.

4. Socio Bosque conservation areas on communal indigenous land.

5. State protection areas (PANE).

6. Others (including private enterprises, research areas, land with unidentifiable/unassessable governance and ownership, cities, airports, large infrastructure)

In total, we mapped 139 polygons each one determining the area of one specific governance arrangement patch. These patches covered 163,627 ha. We excluded the category " 6 . Others" from further evaluations. It was not possible to establish contacts to private enterprises engaged with logging activities in the landscapes.

\subsubsection{Governance elements and performance}

During the focus group discussions we assessed governance performance for patches of single governance arrangements by applying the forest governance assessment tool of the World Resource Institute (Davis et al., 2013b). The assessment tool postulates that predefined elements should be contextualized in order to better fit local needs. After scoping trips in the study region we selected five governance elements namely (i) tenure security, (ii) forest management practices, (iii) law enforcement, (iv) institutions, and (v) participation in public decision making. These elements are among the most frequently researched governance elements in global literature (Fischer et al., 2020), represent different governance components (see 2.3) and thematic areas as specified by (Davis et al., 2013b). Each of the five governance elements was assessed by three indicators through Likert scores (Likert, 1932) on a scale from 0 (not existing), 1 (very low) to 5 (very high). Definitions of governance elements and indicators are provided in Annex 1.

Considering available project resources and time that stakeholders were able to make available for the workshops, governance was scored for 25 selected governance arrangement patches covering in total 50,115 ha. We selected all available Socio Bosque and PANE patches for the assessment of governance performance scores as these categories were less frequently occurring. Governance performance of the remaining governance arrangements was assessed on randomly selected patches in the landscapes. We used the 25 patches with governance performance assessments to extrapolate 
governance performance scores to additional 59 patches. We extrapolated within the same or neighboring landscapes where patches were comparable in terms of land use and governance mechanisms. Extrapolation of governance scores increased the number of patches with governance information to 84 covering 99,563 hectares.

\subsubsection{Land use types}

Land use is considered a decisive context factor influencing deforestation. We classified it adapting and simplifying (Di Gregorio and Jansen, 2005). Seven land use types were mapped in all landscapes in participatory exercises during the workshops. They included (i) primary forests (ii) secondary succession forests, (iii) secondary forests after timber harvest, (iv) crop lands, (v) pastures, (vi) agroforestry systems, (vii) others. In all we mapped 1136 land use polygons in the 12 landscapes.

\subsubsection{Socio economic and infrastructure context}

We conducted three key informant interviews per landscape with randomly selected community leaders. Seven key variables were derived from the interviews: (i) percentage households with electricity, (ii) percentage of population that can read/write, (iii) $\mathrm{km}$ from community center to nearest general market, (iv) km from community center to nearest agricultural market, (v) hourly rate for wage employment of an unskilled worker in US Dollars, (vi) mean percent of household income from forests, (vii) mean percent of household income from agriculture.

Road density is associated with economic-infrastructure development and it can be understood as an indicator of accessibility, which is related to a range of pressures on the natural environment and likely to affect forest cover negatively (Reed et al., 1996; Hawbaker et al., 2005). We determined total road length within each governance arrangement patch by summing up all the terrestrial means of transportation, including highways, roads, paths and railways as obtained from shapefiles of public sources (IGM, 2018; OSM, 2018). The road density [km/ha] was then calculated by dividing the total road length $[\mathrm{km}]$ by the total area of each specific governance arrangement patch [ha].

\subsubsection{Deforestation}

The net loss of native forest (deforestation) between years 2008 and 2016 was determined for the area of each of the 139 mapped governance arrangements based on data from the Ecuadorian Ministry of Environment (MAE, 2015, 2017c). Based on automatic classification of LandSat imagery using RapidEye scenes and ground control points as validation sources (MAE-MAGAP, 2015), this data set provides spatially explicit land cover information. We calculated the loss of native forests ('bosque nativo') between 2008 and 2016 in hectares relative to the total area of each delineated governance arrangement patch and divided it by the number of years in order to derive mean annual deforestation rates.

\subsection{Statistical analysis}

In order to compare governance scores we used the non-parametric Wilcoxon test comparing multiple pairs. We applied this non-parametric test because in a number of cases the assumption of normality in the data was not given (Siegel, 1988). We pooled Socio Bosque patches and indigenous reserves because sample sizes of five Socio Bosque and two indigenous reserves polygons were too low for meaningful statistics. In addition, they showed very similar governance which justified 
pooling (mean governance for indigenous reserves was 3.4 and for Socio Bosque 3.8). We excluded governance was calculated as the mean of the five single governance elements per polygon. Principal component analysis (PCA) (Dunteman, 1989) reduces the dimensionality of a multivariate data set by producing linear combinations (principal components) of the original variables (e.g. governance indicators) that summarize the predominant patterns in the data (Peres-Neto et al., 2003). We calculated a PCA for the 25 governance arrangement patches with field governance assessments in order to identify independent gradients within the governance data and their correlations to original governance variables.

We used multivariate regression analysis with backward elimination in order to check for potential relationships between deforestation (target variable) and infrastructure, socio-economic, land use as well as governance variables (predictors) for all 84 patches with assessed or extrapolated governance information. As we could not determine a statistically significant difference in annual deforestation between patches with assessed and extrapolated governance scores, a bias due to the method of determining governance performance can be excluded. From the original 84 patches that we used as basis for regression analysis, we removed four patches with more than three times standard deviation of deforestation. Our models satisfy the assumptions of normality (Shapiro-Wilk-W test, $\mathrm{p}$ values always $>0.5$ ), and no multicollinearity (VIF $<5$, (PennState, 2019)). We assured for homoscedasticity applying the Breusch-Pagan test.

As independent variables were measured at different scales, we conducted $Z$ score standardization to normalize data. Land use variables were all highly intercorrelated as indicated by variance inflation factors (VIF) above 10; we thus only used percentage of crops to characterize land use, which we interpret as indictor for agricultural land use intensity. Within backward selection, we successively removed explanatory variables that were not significant and that did not decrease the $r^{2}$. Within our nested survey design, governance arrangement patches are clustered in 12 landscapes. We therefore checked for the effect of landscapes by including the landscapes as a dummy variable. We also checked for an effect of PANE/Socio Bosque being present or absent in the landscapes. Both effects were not significant.

We used Likert scores and their means as continuous values in quantitative statistical approaches including comparison of means, principal component analysis and multiple regression analysis following (Manley, 2005). All statistical evaluations were carried out using the statistical software package of JMP 12 (SAS, 2015).

\section{Results}

\subsection{Mean governance performance in the landscapes}

Socio Bosque patches and indigenous reserves in general had highest governance scores (Tab. 2). These significantly differed as compared to individually managed patches. This overall difference was based on a significant difference of governance performance for tenure and participation between Socio Bosque/indigenous reserves on one side and communal and individually managed patches on the other side. There were no differences in governance performance for forest management practices, law enforcement and institutions. PANE had lowest scores for mean governance, forest management practices, institutions and participation. 


\begin{tabular}{|c|c|c|c|c|c|c|c|c|c|c|c|c|c|c|c|c|}
\hline \multirow[t]{2}{*}{$\begin{array}{l}\text { Governance } \\
\text { arrangement }\end{array}$} & \multirow[t]{2}{*}{$\mathrm{N}$} & \multicolumn{3}{|c|}{$\begin{array}{c}\text { Mean } \\
\text { governance }\end{array}$} & \multicolumn{3}{|c|}{ Tenure } & \multicolumn{2}{|c|}{$\begin{array}{c}\text { Forest } \\
\text { Management } \\
\text { Practices }\end{array}$} & \multicolumn{2}{|c|}{$\begin{array}{c}\text { Law } \\
\text { Enforcement }\end{array}$} & \multicolumn{2}{|c|}{ Institutions } & \multicolumn{3}{|c|}{ Participation } \\
\hline & & Wlc & & mean & Wlcx & & mean & Wlcx & mean & Wlcx & mean & Wlcx & mean & & Icx & mean \\
\hline SBosque/IndRes & 7 & A & & 3,6 & $A$ & & 4.5 & A & 3.8 & A & 3.9 & $\mathrm{~A}$ & 2.1 & A & & 3.6 \\
\hline Communal & 10 & A & B & 2,8 & & B & 3.3 & A & 3.5 & $\mathrm{~A}$ & 3.6 & $\mathrm{~A}$ & 2.2 & & $B$ & 1.8 \\
\hline Individual & 6 & & B & 2,7 & & $B$ & 3.0 & $A$ & 3.4 & $\mathrm{~A}$ & 3.0 & $\mathrm{~A}$ & 1.8 & & $B$ & 1.9 \\
\hline
\end{tabular}

\begin{tabular}{|l|l|l|l|l|l|l|l|l|l|l|l|l|l|l|l|l|l|l|l|}
\hline PANE & 2 & - & - & $\mathbf{2}, 4$ & - & - & 3.2 & - & - & 2.7 & - & - & 3.1 & - & - & 1.3 & - & - & 1.7 \\
\hline
\end{tabular}

Table 2: Wilcoxon Test for governance differences between governance arrangements. Arrangements that do not share similar capital letters are significantly different $(p<0.05)$ as result of the Wilcoxon Test (Wlcx); $N$ : number of patches; mean: mean governance. For PANE areas, only the mean is reported; they are excluded from the test due to low sample size of 2. SBosque/IndRes - pooled category of Socio Bosque and indigenous reserves.

\subsection{The interrelation of different governance elements}

The PCA showed that all governance elements loaded high on the first component, which already explained 55.2\% of the variance (Fig. 2, Tab. 3). Bivariate correlations corroborate these findings: 7 out of 10 pairwise correlations between these five governance elements were statistically significant (correlation coefficients not depicted, $\mathrm{p}<0.05$ ). Additional components were characterized by single governance elements that loaded high on these. Participation had the strongest individual effect on the second component. The third component differentiated tenure against institutions and the fourth component was strongly determined by law enforcement. The fifth component differentiated (to a weaker extent) forest management practices against institutions (Tab. 3). However, the explanatory power of these latter components low, as only the first component had an eigenvalue above 1.

The loadings on the first axis significantly correlated with mean governance ( $p<0.05)$ (Fig. 3). In other words, governance arrangement patches with high mean governance were characterized by high loadings on the first component.

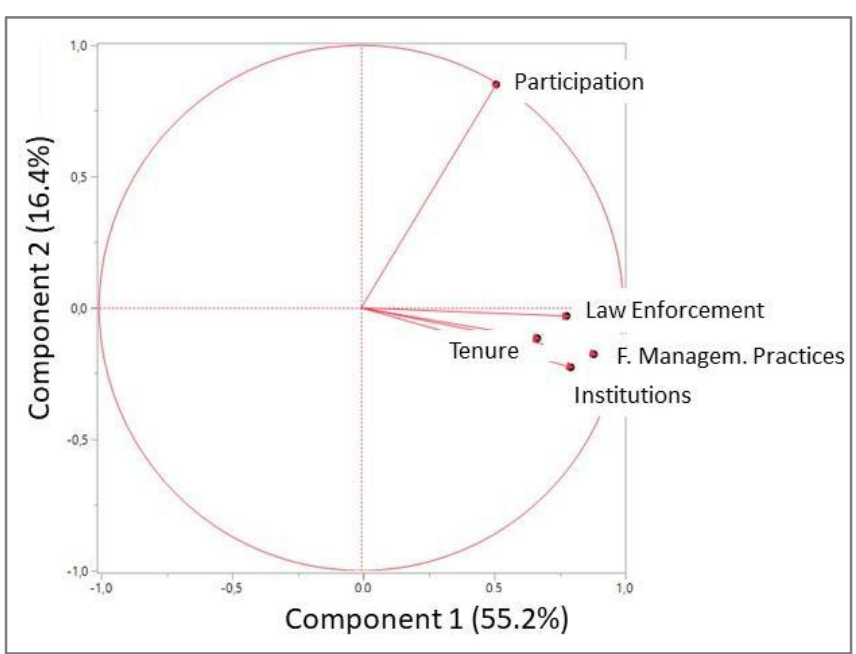

Figure 2: Biplot of a PCA for Likert scores of five governance elements assessed for 25 polygons.

$\begin{array}{lrrrrr} & \text { PC 1 } & \text { PC 2 } & \text { PC 3 } & \text { PC 4 } & \text { PC 5 } \\ & (2.8) & (0.8) & (0.7) & (0.5) & (0.2) \\ \text { Tenure } & \mathbf{0 , 6 7} & -0,11 & \mathbf{0 , 6 8} & 0,26 & 0,11 \\ \text { Forest Management Practices } & \mathbf{0 , 8 9} & -0,18 & -0,17 & 0,18 & -0,34\end{array}$




$\begin{array}{lrrrrr} & \text { PC 1 } & \text { PC 2 } & \text { PC } \mathbf{3} & \text { PC } \mathbf{4} & \text { PC 5 } \\ \text { LawEnf } & \mathbf{0 , 7 8} & -0,03 & 0,13 & -\mathbf{0 , 6 1} & -0,00 \\ \text { Institutions } & \mathbf{0 , 8 0} & -0,23 & -0,46 & 0,12 & 0,28 \\ \text { Participation } & \mathbf{0 , 5 2} & \mathbf{0 , 8 5} & -0,06 & 0,08 & 0,02\end{array}$

Table 3: Loadings on the principal components (PC). Loadings larger/smaller than +/- 0.5 in bold. By definition, loadings of each variable can range between -1 and 1 . High positive or negative loadings indicate strong explanatory power of the indicators for the respective component. Eigenvalues are given in brackets. An eigenvalue of 1.0 ( 2.0 or 3.0 ) indicates that the respective component explains as much variation as one (two or three) single variables.

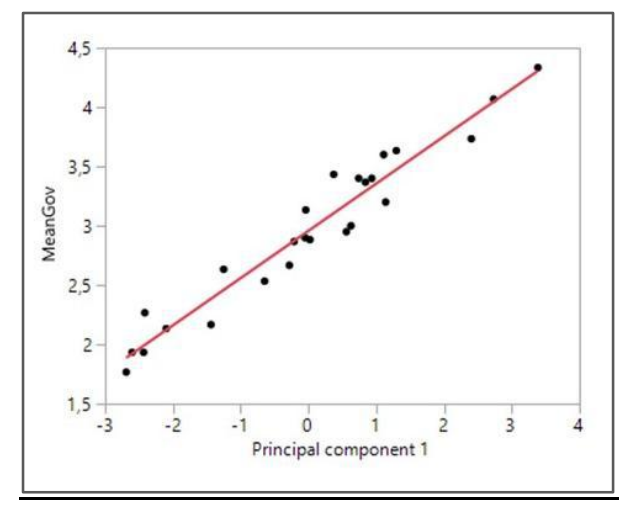

Figure 3: Correlation between loadings on first principal component and mean governance for 25 governance arrangement patches $\left(r^{2}=0.94, p<0.01\right)$. Loadings on the first component are adjusted for the mean and standard deviation (SAS, 2017).

\subsection{Single correlations of potential deforestation drivers with deforestation}

We calculated single bivariate correlations of infrastructure, socio-economic, land use and governance variables with deforestation (see Annex 2). Infrastructure variables did not correlate with deforestation. Among socio economic variables, the literacy rate and income from forests were highly significant. Land use cover variables were mostly related to deforestation. In addition, percentages of specific land use types correlated among themselves which was to be expected as land use percentages per patch always add up to $100 \%$ in a sense that high percentages of the land covered e.g. by forest automatically resulted in lower percentages covered by agriculture. Among governance elements, participation, law enforcement and tenure correlated negatively with deforestation. Also mean governance, which was based on all five governance elements correlated with deforestation.

\subsection{Multiple linear regressions explaining deforestation}

Multiple linear regression allows to analyze effects of multiple predictors (deforestation drivers) on a target variable (deforestation). The first model (Tab. 4, column a) excluded governance and had an $r^{2}$ of 0.34 . In this model, percentage of households with electricity, literacy and the percentage of land covered by crops were significant explanatory variables. In the second model (Tab. 4, column b) governance arrangements were added as explanatory variables which increased the $r^{2}$ to 0.47 . Results show that deforestation was significantly higher on managed communal and individual lands as compared to the reference of Socio Bosque and indigenous reserves. Distance to markets was also significant in this model. In the third model (Tab. 4, column c) mean governance was added as additional variable and significantly contributed to the explanation of deforestation. In the third model, relative income from forests was negatively related to deforestation. In the fourth model (Tab. 4, column d), we replaced mean governance by single governance elements. These explicit governance variables contributed more explanation to deforestation than mean governance as they 
increased the $r^{2}$ to 0.54 . Specifically tenure and participation were highly significant. These two governance elements had also shown significant differences between individually and communally managed land on one side and protected areas on the other side (Tab. 2) and were at the same time most clearly differentiated from the remaining governance variables on the second and third component of the PCA (see Tab. 4). In the fourth model, individual and communal arrangements turned insignificant. Participation and tenure as single selected governance elements thus overruled governance arrangements as explanatory variables. Law enforcement was significant in the multiple linear regression but had to be removed due to a high VIF above 5. VIFs for tenure and participation were moderately high but below 5 (4.6 and 3.4 respectively).

In general, governance either as selected elements or as overall mean had an effect on deforestation which is independent from other variables: when governance performance was high, deforestation was significantly lower. However, cropland percentage and electrification were significant in all four models and explained larger parts of the variation, showing that agricultural land use and intensification as well as infrastructure development are predominant proximate deforestation drivers in the analyzed landscapes.

\begin{tabular}{|c|c|c|c|c|}
\hline & $\mathbf{a}$ & b & c & d \\
\hline r2 corr & 0.34 & 0.47 & 0.50 & 0.54 \\
\hline Prob $>F$ & $* \star *$ & $* \star *$ & $* * *$ & $* * *$ \\
\hline $\mathrm{N}$ & 80 & 80 & 80 & 80 \\
\hline \multicolumn{5}{|l|}{ Infrastructure } \\
\hline \%electricity & $(+)^{*}$ & $(+)^{\star \star \star}$ & $(+)^{\star * \star}$ & $(+)^{* \star}$ \\
\hline \multicolumn{5}{|l|}{$\mathrm{km}$ roads /ha } \\
\hline km_to_market & & $(+)^{\star \star}$ & $(+)^{\star \star \star}$ & $(+)^{\star \star}$ \\
\hline km_to_agrimarket & ns & ns & ns & $(+)^{* \star}$ \\
\hline \multicolumn{5}{|l|}{ Land use } \\
\hline Crops\% & $(+)^{\star \star *}$ & $(+)^{* \star}$ & $(+)^{\star \star}$ & $(+)^{\star \star \star}$ \\
\hline \multicolumn{5}{|l|}{ Socio economics } \\
\hline \%read_write & $(+)^{\star \star \star}$ & $(+)^{\star \star \star}$ & $(+)^{\star * \star}$ & ns \\
\hline \multicolumn{5}{|l|}{$\$$ wage/h } \\
\hline \%income_forests & & ns & $(-)^{\star \star}$ & $(-)^{\star \star \star}$ \\
\hline \%income_agri & & & & ns \\
\hline \multicolumn{5}{|l|}{$\begin{array}{l}\text { Governance } \\
\text { arrangement }\end{array}$} \\
\hline Communal & & $(+)^{* \star}$ & $(+)^{\star \star \star}$ & ns \\
\hline Individual & & $(+)^{\star \star}$ & ns & ns \\
\hline SBosque/ResIndig & & reference & reference & reference \\
\hline PANE & & ns & ns & ns \\
\hline \multicolumn{5}{|l|}{$\begin{array}{l}\text { Governance } \\
\text { performance }\end{array}$} \\
\hline MeanGov & & & & \\
\hline Participation & & & & $(-)^{*}$ \\
\hline Institutions & & & & $(+)^{*}$ \\
\hline LawEnforcement & & & & \\
\hline ForestManPract & & & & ns \\
\hline Tenure & & & & $(-)^{\star \star \star}$ \\
\hline
\end{tabular}

Table 4: Multilinear regression models explaining mean annual deforestation per patch in the years 2008 2016. a: model disregarding governance information; $b$ : model in addition including categories of governance arrangements, c: model in addition including mean governance performance; $\mathrm{d}$ : model with single governance elements instead of mean governance. Abbreviations of variables are explained in Tab. 8.

$+/-$ : positive/negative estimator

ns: not significant

significance levels: $* 0.1 ; * * 0.05 ; * * 0.01$ 
shaded cells: variable excluded during backward selection

hatched cells: variable not considered in the model

\section{Discussion}

\subsection{The interrelation of different governance elements}

The main finding with regard to interrelations between single governance elements is that they all load positively and high on the first PCA axis, which already explains $55 \%$ of the variance of the governance elements (see Fig. 2 and Tab. 3). This finding is based on the fact that correlations between single governance elements were mostly significant. The different governance elements are obviously expressions of a same underlying process. Governance as observed in the field study is a process that is characterized by several governance elements which act conjointly and which are not antagonistic. A predominant importance of single elements as differentiated by the framework of the World Resource Institute could hardly be identified. The general governance trend can be expressed by mean governance (see Fig. 3). As the loadings on the first component of the PCA were closely related to mean governance, the elements with highest loadings on the first component can be interpreted as those most strongly determining mean governance. But as four out of the five elements had loadings between 0.67 and 0.80 it is hard to claim a predominant role of one of them. The results confirm (Fischer et al., 2020) who applied the same methodology to 26 governance elements as derived from 28 reviewed studies and who did not find substantial negative loadings on the first component of a PCA as well. The homogeneous and harmonized data set from the field study shows this trend even more clearly as compared to the heterogeneous review data set. However, the global findings of (Fischer et al., 2020) provide the basis for a generalization of our results.

Our findings have implications for the understanding of governance functioning. We cannot falsify the concept of governance, building on actors and structures and their interactions (Giessen and Buttoud, 2014) (see Fig. 1). We found indications that these governance components as quantified by five governance elements are equally important. At least for the extensive data set from tropical Ecuadorian forests we claim that none of the different components is more strongly determining overall governance.

In view of the large number of governance elements that have been described in different frameworks (Kishor and Rosenbaum, 2012; Davis et al., 2013a), the results are encouraging for policy, applied development work and further research. The positive interrelation of governance elements suggests that work on one element may have positive effects on others and that governance elements behave synergistically. They are not antagonistic. As it is simply impossible to focus on all governance elements in development work, policy or research, it may be promising to select a few of them and concentrate work on these. The conceptual framework can be applied to make sure that actors, structures and interactions are considered in the selection of elements. Beyond the general positive loadings on the first components there are governance element that differentiate governance on additional components depending on the local context. We recommend that such locally important elements, like participation and tenure in the case of our Ecuadorian data set, receive specific attention in the respective implementation.

\subsection{Governance effects on deforestation}


We confirm governance effects on reduced deforestation (Kanninen et al., 2007; Korhonen-Kurki et (Barbier and Tesfaw, 2015) who also carried out a comparison of deforestation effects of different governance elements in addition to proximate drivers, however with a few structural governance variables only. We differentiate this effect for five governance elements and show that the effects are independent from proximate deforestation drivers and have an additional effect on reduced deforestation (Tab. 4). However, the significance level and the explanatory power for governance elements was lower as for the proximate drivers which is rather plausible as governance elements are understood as underlying causes (Geist and Lambin, 2002)(see Fig. 1) in comparison to direct deforestation drivers such as e.g. agricultural land use (Hosonuma et al., 2012b; Ferrer Velasco et al., 2020). The results imply that in development work, policy and research a focus on governance elements alone is not sufficient. Governance needs to be tackled in addition to proximate causes of deforestation.

"Good governance" is based on a number of principals such as effectiveness, efficiency, transparency, accountability, legitimacy, lack of corruption, stability, empowerment, social justice, equity, environmental and social sustainability (Arts and Visseren-Hamakers, 2012; Secco et al., 2014; Ansell and Torfing, 2016). In this normative approach the principal question of "who has the right to define them" remains open (Secco et al., 2011). In practice, the above mentioned principals represent formal rules and norms as formulated in official policies, e.g. (UN, 2019). Our empirical results support the notion of a number of governance elements as indeed being "good" for low deforestation and thus justify the "good governance" approach related to this outcome. But the analytical approach which is based on empirical causalities can make it easier to negotiate and agree upon governance measures independently form implicit value statements, as informal values may substantially differ between e.g. indigenous and government stakeholders (Schweizer, 2017; Gupta and Koontz, 2019; Gustafsson and Scurrah, 2019).

In our analysis, the governance element of "institutions" comprised a mean of government, NGO and community institutions (see Annex 1). It hardly correlated with deforestation in a bivariate correlation (see Annex 2) but was positively related to deforestation in the multiple regression model (see Tab. 4). Such inconsistent behavior points to the need for in-depth evaluations that reflect on formal and informal stakeholders separately in subsequent analyses. (Nansikombi et al., 2020) also point to the need to differentiate between customary and formal institutions.

\subsection{Present land use and deforestation drivers as context for governance effects}

Our results confirm for Ecuador that infrastructure, socio economic and land use variables have predominant effects on deforestation (Geist and Lambin, 2002; Barbier and Tesfaw, 2015). These variables need a specific discussion that relates their effects to governance and which also provides the basis for conclusions related to the specific local context.

Intensified agricultural land use, including ranching and livestock farming has been reported as a main deforestation driver in developing countries in general (Hosonuma et al., 2012b) and specifically for Ecuador (Lerner et al., 2014; MAGAP, 2014). (Castro et al., 2013) report that expansion of crops like cocoa, oil palm, rice, and cassava is the main deforestation driver along the Northwestern coast of Ecuador and in the provinces of Napo, Pastaza, and Orellana. Our findings are fully in line with these results. The development and implementation of improved land use systems, however, might be hampered by the specifically low governance scores for individual land ownership of settlers (see Tab. 3). Specifically performance of institutions and participation in decision making 
need to be improved as a basis for further developing land use systems that save or re-establish forests.

Among the socio-economic variables, literacy rate in the study landscapes related positively to deforestation. Direct positive links between literacy and deforestation would contradict numerous authors reporting that higher education is related to decreasing deforestation (Bhattarai and Hammig, 2004; Soares-Filho et al., 2004; Barsimantov and Navia Antezana, 2012; Baynes et al., 2016). In our study, settlers had highest literacy rates (not depicted, $p<0.05$ ). Therefore, we interpret that it is not literacy itself which is related to increasing deforestation but potentially a more intensive and deforesting land use of the better-educated settlers. At the same time, percentage of income from forests showed negative effects on deforestation. This shows that when forests are a source for income, deforestation might be lower which is in line with (Bae et al., 2012) and (Sendzimir et al., 2011) who report that income sources from forests could even foster reforestation. These findings mean that policy makers should take care that education is accompanied with sustainable management measures like e.g. certification or land use planning and that sustainable forest management is fostered as general safeguard for rural development projects.

Socio Bosque areas showed reduced deforestation as compared to communal and individually managed lands (see Tab. 4) and as well highest governance scores (see Tab. 2). Many authors report success of this incentive program (Loaiza et al., 2017) (Jones and Lewis, 2015; Rosa da Conceição et al., 2015; Jones et al., 2017; Cuenca et al., 2018; Mohebalian and Aguilar, 2018). Lessons from improved governance in these areas can stimulate to specifically work on tenure security and participation in adjacent areas as well. These governance elements scored specifically high in Socio Bosque areas. (Eguiguren et al., 2019) have shown that the mere presence of Socio Bosque areas has positive effects on neighboring areas where logging operations are carried out and interpret this as, among others, governance effects. These results also advocate to extend governance improving measures to other land use forms.

The two PANE areas considered in this study show high governance performance for the ecological reserve of El Pambilar and low scores for Mache-Chindul. The ecological reserve of Mache-Chindul was established and use restrictions were superimposed when already indigenous people were living there. This creates land use conflicts until today as expressed by qualitative statements, low governance scores and higher deforestation rates. El Pambilar, on the other side, was created to solve land use conflicts between a logging company and indigenous people. The use restrictions are respected until today, because the involved stakeholders participated in the process and their own interest in dispute resolution was taken into account. For El Pambilar, governance scores were considerably higher and deforestation is low. These findings support the need to include local communities in decision making in order to sustainably implement conservation areas (Stocks et al., 2007; Oestreicher et al., 2009; Shahabuddin and Rao, 2010). In the specific case of the two PANE areas in Ecuador, institutions' capacities and local participation need to be improved as these elements scored specifically low in both cases.

\section{Conclusions}

Improved governance is today seen as core to approaches aiming to reduce tropical deforestation. Our study provides first insights into interrelations and functioning of different forest governance elements in the field. Such analytical understanding is urgently needed in order to complement a normative "good governance" approach. 
Governance elements such as e.g. tenure, law enforcement, participation, institutional performance act conjointly and into the same direction, they are expressions of a same underlying process that is highly correlated to overall mean governance. This has implications for an analytical understanding of forest governance, which, based on our findings, is characterized by a synchronous functioning of different governance elements. Forest governance can be described by a conceptual framework including actors, structures and their interactions. This framework is now supported by empirical evidence because the results show that these components are equally important and interact positively. Such functional understanding of forest governance can support an efficient implementation of governance measures. From the multitude of governance elements that are described in existing assessment frameworks, the locally relevant ones need to be identified. These are elements that score low in all or in a number of governance arrangements. At the same time the selected elements should consider actors, structures as well as their interactions. Stakeholders in the forest governance arena can then rely on the justified assumption that work on a few, however well selected, core elements will have positive effects on the wider governance settings.

Multiple regression analysis confirmed an effect of specific governance elements on reduced deforestation. In the case of Ecuador mostly tenure and participation had an effect on reduced deforestation, but this may vary depending on the local context. Further studies are needed to analyze which governance elements have effects on deforestation in a differing context. The quantification of governance effects on deforestation is important to specify "good governance" as an approach that is to date mainly based on a number of politically accepted principles. The difference to such a normative approach is that our analytical understanding is outcome oriented. Analytical governance rather highlights cause-effect chains related to a specific outcome of interest. A normative approach rather relies on value-oriented principles without revealing causalities. This may be problematic as informal values of local stakeholders can differ from official principles.

Proximate drivers like infrastructure development and pressure from agricultural land use as well as the socio - economic context had stronger deforestation effects as compared to governance which is seen as an underlying factor. Proximate drivers urgently need to be taken into account and a sectoral emphasis on governance measures alone will not yield the expected results. However, governance measures are needed to ensure success of work related to proximate drivers.

Based on our landscape data from deforestation hotspots in Ecuador there are a number of case specific conclusions. We confirm agricultural land use as prominent direct driver of deforestation. Improved agricultural techniques are needed to reduce the pressure on remaining forests. Land use planning is important in order to ensure that improved techniques will not result in increasing opportunity costs that again accelerate deforestation. Indigenous communities need alternative land use systems and income possibilities as they are in the process of adopting agricultural methods of the settlers. Income from forests can be an alternative, however it is unclear how long such forest based livelihoods are sustainable in view of still ongoing deforestation. We show that Socio Bosque is a functioning incentive based forest conservation program that rightly receives attention. The program can stimulate governance development in neighboring individually (settlers) and communally managed (indigenous) lands as well as in other countries striving to include PES (payment for ecosystem services) programs e.g. under REDD+. With increasing pressure on primary forests specifically to be expected for the Amazon region, it seems to be relevant to install conservation areas like Socio Bosque in time. Forest state conservation areas (PANE) were rated with lower governance quality. Institutional performance and participation of the local population were specifically seen as critical and need to be improved. 


\section{References}

ACE, 2008. Constitución de la República del Ecuador. In: Ecuador, A.C.d. (Ed.).

Andersson, K., Benavides, J.P., León, R., 2014. Institutional diversity and local forest governance. Environmental Science \& Policy 36, 61-72.

Ansell, C., Torfing, J., 2016. Handbook on Theories of Governance. Edward Elgar, Cheltenham, UK Northhampton, MA, USA.

Archer, M.S., 2003. Structure, agency and the internal conversation. Cambridge University Press.

Arts, B., 2012. Forests policy analysis and theory use: Overview and trends. Forest Policy and Economics 16, 7-13.

Arts, B., 2014. Assessing forest governance from a 'Triple G'perspective: Government, governance, governmentality. Forest Policy and Economics 49, 17-22.

Arts, B., Behagel, J., Turnhout, E., de Koning, J., van Bommel, S., 2014. A practice based approach to forest governance. Forest Policy and Economics 49, 4-11.

Arts, B., Visseren-Hamakers, I.J., 2012. Forest governance: mainstream and critical views. In, Moving Forward with Forest Governance. Tropenbos International, ETFRN, Wageningen, NL.

Bae, J.S., Joo, R.W., Kim Yeon-Su, Y.S., 2012. Forest transition in South Korea: Reality, path and drivers. Land Use Policy 29, 198-207.

Barbier, E.B., Tesfaw, A., 2015. Explaining forest transitions: The role of governance. Ecological Economics 119, 252-261.

Barsimantov, J., Navia Antezana, J., 2012. Forest cover change and land tenure change in Mexico's avocado region: Is community forestry related to reduced deforestation for high value crops. Applied Geography 32, 844-853.

Baynard, C.W., Ellis, J.M., Davis, H., 2013. Roads, petroleum and accessibility: the case of eastern Ecuador. GeoJournal 78, 675-695.

Baynes, J., Herbohn, J., Dressler, W., 2016. Power relationships: Their effect on the governance of community forestry in the Philippines. Land Use Policy 54, 169-176.

Bhagwat, S.A., Humphreys, D., Jones, N., 2017. Forest governance in the Anthropocene: Challenges for theory and practice. Forest Policy and Economics 79, 1-7.

Bhattarai, M., Hammig, M., 2004. Governance, economic policy, and the environmental Kuznets curve for natural tropical forests. Environment and Development Economics 9, 367-382.

Broekhoven, G., Savenije, H., von Scheliha, S., 2012. Moving Forward with Forest Governance. In: Tropenbos International, W.t.N. (Ed.), ETFRN News. ETFRN, Wageningen, NL.

Busch, J., Ferretti-Gallon, K., 2017. What Drives Deforestation and What Stops It? A Meta-Analysis. Review of Environmental Economics and Policy 11, 3-23.

Castro, M., Sierra, R., Calva, O., Camacho, J., Lopez, F., 2013. Zonas de Procesos Homogéneos de Deforestación del Ecuador: Factores promotores y tendencias al 2020. In. Programa GESOREN-GIZ y Ministerio de Ambiente del Ecuador, Quito, Ecuador.

CIFOR, 2015. Interview Questions Guide. In. CIFOR, Bogor, Indonesia.

Cuenca, P., Robalino, J., Arriagada, R., Echeverria, C., 2018. Are government incentives effective for avoided deforestation in the tropical Andean forest? PLoS One 13, e0203545.

Davis, C., Williams, L., Lupberger, S., Daviet, F., 2013a. Assessing forest governance: the governance of forests initiative indicator framework. World Resources Institute, Washington D. C., USA.

Davis, C., Williams, L., Lupberger, S., Daviet, F., 2013b. Assessing Forest Governance: The Governance of Forests Initiative Indicator Framework. In. WRI, Washington, D.C., USA. 
de Graaf, M., Buck, L., Shames, S., Zagt, R., 2017. Assessing Landscape Governance, A Participatory Approach. In. Tropenbos, EcoAgriculture, Wageningen, Washington.

Di Gregorio, A., Jansen, L.J.M., 2005. Land Cover Classification System Classification concepts and user manual. In, Rome, Italy.

Dunteman, G.H., 1989. Principal Component Analysis. Sage Publications, Newsbury Park, CA.

Eguiguren, P., Fischer, R., Günter, S., 2019. Degradation of Ecosystem Services and Deforestation in Landscapes With and Without Incentive-Based Forest Conservation in the Ecuadorian Amazon. Forests 10.

Elwood, S., Ghose, R., 2011. PPGIS in Community Development Planning: Framing the Organizational Context. In, pp. 83-105.

FAO, 2015. Global Forest Resources Assessment 2015, Desk Reference. In. Food and Agriculture Organization of the United Nations, Rome.

FAO, 2020. Global Forest Resources Assessment 2020, Rome, Italy.

Ferrer Velasco, R., Kothke, M., Lippe, M., Gunter, S., 2020. Scale and context dependency of deforestation drivers: Insights from spatial econometrics in the tropics. PLoS One 15, e0226830.

Fischer, R., Giessen, L., Günter, S., 2020. Governance effects on deforestation in the tropics: A review of the evidence. Environmental Science and Policy 105, 84 - 101.

Freund, L., Hawkins, B., Saewyc, E., 2016. Reflections on the use of Participatory Mapping to study Everyday Health Information Seeking by LGBTQ Youth. Proceedings of the Association for Information Science and Technology 53, 1-4.

Geist, H.J., Lambin, E.F., 2001. What drives tropical deforestation. LUCC Report series 4, 116.

Geist, H.J., Lambin, E.F., 2002. Proximate Causes and Underlying Driving Forces of Tropical DeforestationTropical forests are disappearing as the result of many pressures, both local and regional, acting in various combinations in different geographical locations. BioScience $52,143-150$.

Giddens, A., 1984. The constitution of society: Outline of the theory of structuration. Polity Press, Cambridge.

Giessen, L., Buttoud, G., 2014. Defining and assessing forest governance. Forest Policy and Economics 49, 1-3.

Gupta, D., Koontz, T.M., 2019. Working together? Synergies in government and NGO roles for community forestry in the Indian Himalayas. World Development 114, 326-340.

Gustafsson, M.-T., Scurrah, M., 2019. Strengthening subnational institutions for sustainable development in resource-rich states: Decentralized land-use planning in Peru. World Development 119, 133-144.

Hawbaker, T., Radeloff, V., Hammer, R., K. Clayton, M., 2005. Road Density and Landscape Pattern in Relation to Housing Density, and Ownership, Land Cover, and Soils.

Holland, M.B., de Koning, F., Morales, M., Naughton-Treves, L., Robinson, B.E., Suárez, L., 2014. Complex Tenure and Deforestation: Implications for Conservation Incentives in the Ecuadorian Amazon. World Development 55, 21-36.

Holt, F.L., Bilsborrow, R.E., 2004. Demography, household economics, and land and resource use of five indigenous populations in the Northern Ecuadorian Amazon: a summary of ethnographic research. In, Occasional Paper, Carolina Population Center. University of North Carolina, Chapel Hill, NC.

Hosonuma, N., Herold, M., De Sy, V., De Fries, R.S., Brockhaus, M., Verchot, L., Angelsen, A., Romijn, E., 2012a. An assessment of deforestation and forest degradation drivers in developing countries. Environmental Research Letters 7, 044009. 
Hosonuma, N., Herold, M., Sy, V., De Fries, R.S., Brockhaus, M., Verchot, L., Angelsen, A., Romijn, E., 2012b. An assessment of deforestation and forest degradation drivers in developing countries. Environmental Research Letters 7, 044009.

IFRI, 2011. Field Manual, Version 14. In: Elinor, O. (Ed.). International Forestry Resources and Institutions (IFRI) Research Program, Michigan.

IGM, 2018. Base Nacional escala 1:50.000. In. Instituto Geográfico Militar, Ecuador.

Izurieta, J.C., Erazo, G., Larson, A.M., Cronkleton, P., 2014. Desde nuestros ojos: La historia de los pueblos y bosques de Napo. In, Bogor, Indonesia, p. 48.

Jones, K.W., Holland, M.B., Naughton-Treves, L., Morales, M., Suarez, L., Keenan, K., 2017. Forest conservation incentives and deforestation in the Ecuadorian Amazon. Environmental Conservation 44, 56-65.

Jones, K.W., Lewis, D.J., 2015. Estimating the Counterfactual Impact of Conservation Programs on Land Cover Outcomes: The Role of Matching and Panel Regression Techniques. PLoS One 10, e0141380.

Kanninen, M., Murdiyarso, D., Seymour, F., Angelsen, A., Wunder, S., German, L., 2007. Do Trees Grow on Money? The implications of deforestation research for policies to promote REDD. In. CIFOR, Bogor, Indonesia.

Kishor, N., Rosenbaum, K., 2012. Assessing and Monitoring Forest Governance: A user's guide to a diagnostic tool.

Korhonen-Kurki, K., Sehring, J., Brockhaus, M., Di Gregorio, M., 2014. Enabling factors for establishing REDD+ in a context of weak governance. Climate Policy 14, 167-186.

Larson, A.M., 2011. Forest tenure reform in the age of climate change: Lessons for REDD+. Global Environmental Change 21, 540-549.

Larson, A.M., Petkova, E., 2011. An introduction to forest governance, people and REDD+ in latin america: Obstacles and opportunities. Forests 2, 86-111.

Lerner, A.M., Rudel, T.K., Schneider, L.C., McGroddy, M., Burbano, D.V., Mena, C.F., 2014. The spontaneous emergence of silvo-pastoral landscapes in the Ecuadorian Amazon: patterns and processes. Reg. Environ. Chang 15, 1421-1431.

Likert, R., 1932. A technique for the measurement of attitudes. Archives of Psychology 22 140, $55-$ 55.

Loaiza, T., Borja, M.O., Nehren, U., Gerold, G., 2017. Analysis of land management and legal arrangements in the Ecuadorian Northeastern Amazon as preconditions for REDD+ implementation. Forest Policy and Economics 83, 19-28.

MAE-MAGAP, 2015. Metodología para la elaboración del mapa de cobertura y uso. In, Quito, Ecuador.

MAE, 2013. Ecostems map of Ecuador. In: Environment, M.o.t. (Ed.), Quito, Ecuador.

MAE, 2015. Mapa de deforestación del Ecuador continental, periodo 2008-2014, escala 1:100.000. In.

MAE, 2016. Análisis de la deforestación en el Ecuador continental 1990-2014. In, Quito, Ecuador.

MAE, 2017a. Deforestación del Ecuador continental periodo 2014-2016. In, Quito, Ecuador.

MAE, 2017b. Mapa de cobertura y uso de la tierra del Ecuador Continental 2016, escala 1:100.000. In, Quito, Ecuador.

MAE, 2017c. Mapa de deforestación del Ecuador continental, periodo 2014-2016, escala 1:100.000. In

MAE, 2018a. Natural Heritage Statistics of Continental Ecuador. In: Ambiente, M.d. (Ed.), Quito.

MAE, 2018b. Resultados de Socio Bosque. In: Ambiente, M.d. (Ed.).

MAGAP, 2014. Agenda de Transformación Productiva en la Amazonia Ecuatoriana. In. MAGAP, Quito, Ecuador. 
Manley, B.F.J., 2005. Multivariate Statistical Methods. A Primer. Third Edition. Chapman and Hall.

Mansourian, S., 2017. Governance and forest landscape restoration: A framework to support decision-making. Journal for Nature Conservation 37, 21-30.

Martin, M., Peters, B., Corbett, J., 2012. Participatory Asset Mapping in the lake victoria basin of Kenya. Journal of the Urban and Regional Information Systems Association 25, 45-56.

Mohebalian, P.M., Aguilar, F.X., 2018. Beneath the Canopy: Tropical Forests Enrolled in Conservation Payments Reveal Evidence of Less Degradation. Ecological Economics 143, 64-73.

Morales, M., Naughton-Treves, L., Suárez, L., 2010. Seguridad en la Tenencia de la Tierra e Incentivos para la Conservación de Bosques. In. ECOLEX, Quito.

Nansikombi , H., Fischer, R., Kabwe, G., Günter, S., 2020. Exploring patterns of forest governance quality: insights from forest frontier communities in Zambia's Miombo ecoregion. Land Use Policy (accepted).

North, D., 1991. Institutions, Institutional Change and Economic Performance. Cambridge University Press, Cambridge.

Nyumba, T.O., Wilson, K., Derrick, C.J., Mukherjee, N., Geneletti, D., 2018. The use of focus group discussion methodology: Insights from two decades of application in conservation. Methods in Ecology and Evolution 9, 20-32.

Oestreicher, J.S., Benessaiah, K., Ruiz-Jaen, M.C., Sloan, S., Turner, K., Pelletier, J., Guay, B., Clark, K.E., Roche, D.G., Meiners, M., Potvin, C., 2009. Avoiding deforestation in Panamanian protected areas: An analysis of protection effectiveness and implications for reducing emissions from deforestation and forest degradation. Global Environmental Change 19, 279-291.

OSM, 2018. OpenStreetMap.

Ostrom, E., 1990. Governing the commons: The evolution of institutions for collective action. Cambridge University Press, New York.

Ostrom, E., 1999. Governing the commons: the evolution of institutions for collective action. Cambridge University Press, New York.

Palacios, W., 2005. Potencial etnobotánico de los territorios indígenas en el Ecuador. In, Revista Bosques Latitud Cero, Loja, Ecuador, pp. 3-9.

PennState, 2019. Detecting Multicollinearity Using Variance Inflation Factors. In, STAT 462. The Pennsylvania State University.

Peres-Neto, P.R., Jackson, D.A., Somers, K.M., 2003. Giving Meaningful Interpretation to Ordination Axes: Assessing Loading Significance in Principal Component Analysis. Ecology 84, 2347-2363.

Pichón, F., 1997. Colonist Land-Allocation Decisions, Land Use, and Deforestation in the Ecuadorian Amazon Frontier. Economic Development and Cultural Change 45, 707-744.

QGIS, 2018. QGIS Geographic Information System. Open Source Geospatial Foundation Project, QGIS version 2.18. In.

Ravikumar, A., Kijazi, M., Larson, A.M., Kowler, L., 2015. Multilevel Governance and Carbon Management at the Landscape Scale. Project Guide and Methods Training Manual. In. CIFOR, Bogor, Indonesia.

Reed, R., Johnson-Barnard, J., Baker, W., 1996. Contribution of Roads to Forest Fragmentation in the Rocky Mountains. Conservation Biology 10, 1098-1106.

Rosa da Conceição, H., Börner, J., Wunder, S., 2015. Why were upscaled incentive programs for forest conservation adopted? Comparing policy choices in Brazil, Ecuador, and Peru. Ecosystem Services 16, 243-252. 
Rudel, T., Bates, D., Machinguiashi, R., 2002. A tropical transitions? Agricultural change outmigration, and secondary forests in the Ecuadorian Amazon. Annals of Association of American Geographers 92, 87-102

SAS, 2015. JMP 12. Basic Analysis. SAS Institute, Carry, N.C.

SAS, 2017. JMP ${ }^{\circledR} 13$ Multivariate Methods, Second Edition. SAS Institute Inc., Cary, NC.

Sayer, J., Sunderland, T., Ghazoul, J., Pfund, J.L., Sheil, D., Meijaard, E., Venter, M., Boedhihartono, A.K., Day, M., Garcia, C., van Oosten, C., Buck, L.E., 2013. Ten principles for a landscape approach to reconciling agriculture, conservation, and other competing land uses. Proc Natl Acad Sci U S A 110, 8349-8356.

Schusser, C., Krott, M., Yufanyi Movuh, M.C., Logmani, J., Devkota, R.R., Maryudi, A., Salla, M., Bach, N.D., 2015. Powerful stakeholders as drivers of community forestry - Results of an international study. Forest Policy and Economics 58, 92-101.

Schweizer, D., 2017. Stakeholder perceptions on governance for the protection and increase of forest cover in the Panama Canal Watershed. World Development Perspectives 6, 11-13.

Secco, L., Da Re, R., Pettenella, D.M., Gatto, P., 2014. Why and how to measure forest governance at local level: A set of indicators. Forest Policy and Economics 49, 57-71.

Secco, L., Pettenella, D., Gatto, P., 2011. Forestry governance and collective learning process in Italy: Likelihood or utopia? Forest Policy and Economics 13, 104-112.

Sendzimir, J., Reij, C.P., Magnuszewski, P., 2011. Rebuilding Resilience in the Sahel: Regreening in the Maradi and Zinder Regions of Niger. Ecology and Society 16, 08.

Shahabuddin, G., Rao, M., 2010. Do community-conserved areas effectively conserve biological diversity? Global insights and the Indian context. Biological Conservation 143, 2926-2936.

Siegel, S., 1988. Nonparametric statistics for the behavioral sciences., McGraw-Hill, New York

Sierra, R., 2013. Patrones y factores de deforestación en el Ecuador continental, 1990-2010. Y un acercamiento a los próximos 10 años. In. Conservación Internacional Ecuador y Forest Trends, Quito, Ecuador.

Singer, B., Giessen, L., 2017. Towards a donut regime? Domestic actors, climatization, and the hollowing-out of the international forests regime in the Anthropocene. Forest Policy and Economics 79, 69-79.

Soares-Filho, B., Alencar, A., Nepstad, D., Cerqueira, G., Del Carmen Vera Diaz, M., Rivero, S., Solórzano, L., Voll, E., 2004. Simulating the response of land-cover changes to road paving and governance along a major Amazon highway: The Santarém-Cuiabá corridor. Global Change Biology 10, 745-764.

Stickler, M.M., Huntington, H., Haflett, A., Petrova, S., Bouvier, I., 2017. Does de facto forest tenure affect forest condition? Community perceptions from Zambia. Forest Policy and Economics 85, 32-45.

Stocks, A., McMahan, B., Taber, P., 2007. Indigenous, colonist, and government impacts on Nicaragua's Bosawas reserve. Conservation Biology 21, 1495-1505.

Subhan Mollick, A., Khalilur Rahman, M., Nabiul Islam Khan, M., Nazmus Sadath, M., 2018. Evaluation of good governance in a participatory forestry program: A case study in Madhupur Sal forests of Bangladesh. Forest Policy and Economics 95, 123-137.

Torfing, J., Peters, B.G., Pierre, J., Sorensen, E., 2012. Interactive Governance: Advancing the Paradigm. Oxford University Press, Oxford.

Turner, B.L., Moss, R.H., Skole, D., 1993. Relating land use and global land-cover change. [No source information available].

Umemiya, C., Rametsteiner, E., Kraxner, F., 2010. Quantifying the impacts of the quality of governance on deforestation. Environmental Science and Policy 13, 695-701. 
UN, 2019. Global Forest Goals and Targets of the UN Strategic Plan of Forests 2030. In. Unite Nations, New York.

Wehkamp, J., Koch, N., Lübbers, S., Fuss, S., 2018. Governance and deforestation - a metaanalysis in economics. Ecological Economics 144, 214-227.

Worldbank, 2006. A Decade of Measuring the Quality of Governance. Governance matters 2006. Worldwide Governance Indicators. In, Washington, D.C. 


\section{Annex 1}

Governance elements with indicators.

\section{Tenure security}

- Recognition. Individual and communal rights-holders have their rights formally recognized and recorded.

- Demarcation. Individual and communal forest lands have boundaries demarcated and surveyed.

- Gender equity. Rights registered to individuals or households are registered in the names of women, either jointly or individually

\section{Forest Management practices}

Administration of timber licenses (for individual and communal land)

- Procedural clarity. Clear administrative procedures regulate the obtaining of licenses and permits.

- Timeliness. Licenses and permits can be obtained in a reasonable time and within the time prescribed

- Implementation. Licenses and permits are honored during harvesting and transport of forest products

Protection and conservation (for indigenous reserves and SNAP)

- Use restrictions. Stakeholders clearly understand the timeframe and what activities are allowed and not allowed within the protection or conservation area.

- Enforcement. Implementing agencies are aware and effectively coordinate to carry out their roles and responsibilities.

- Monitoring. Implementation is subject to regular monitoring of impacts and effectiveness. Implementation of payments for ecosystem services (for Socio Bosque)

- Procedures. The procedures for establishing PES have been made clear to the stakeholders.

- Benefit sharing. The schemes for benefit sharing have been jointly decided, understood and acceptable to the stakeholders.

- Protection. The protection of the forests providing these ecosystem services has been put in place.

\section{Law enforcement}

- Apprehension. Violators are apprehended and brought to trial by concerned authorities.

- Compliance. Penalties are served or are paid in full in a timely manner.

- Transparency. Information about penalties and their state of compliance is publicly disclosed

\section{Institutions}

- Government capacities. Government agencies have adequate number of staff with up-todate knowledge and skills, technology and equipment, and budget to perform its roles and duties.

- NGO capacities. NGOs have adequate number of staff with up-to-date knowledge and skills, technology and equipment, and budget to provide services.

- Local community capacities. Local communities have adequate number of staff with up-todate knowledge and skills, technology and equipment, and budget to perform its roles and duties.

\section{Participation in public policy making}

- Awareness. Nongovernmental stakeholders are aware in a timely manner of policies to be developed, reviewed and revised that are relevant for land use in their community.

- Platforms. Platforms are provided for multistakeholder participation in policy making

- Transparency. The stakeholders are informed of the results of policy engagements 


\section{Annex 2:}

Bivariate correlations between explanatory variables and deforestation

\begin{tabular}{|c|c|c|c|}
\hline Variable & Description & $\begin{array}{r}\text { Pearson } \\
\text { correlation } \\
\text { coefficient }\end{array}$ & $\begin{array}{l}\text { Error } \\
\text { probability }\end{array}$ \\
\hline \multicolumn{4}{|l|}{ Infrastructure } \\
\hline electricity (\%) & $\%$ households with electricity & 0,17 & \\
\hline $\mathrm{km}$ roads /ha & $\mathrm{km}$ roads / ha & 0,1 & \\
\hline km_to_market & $\mathrm{km}$ to nearest market & 0,09 & \\
\hline km_to_agrimarket & $\mathrm{km}$ to nearest agricultural market & 0,07 & \\
\hline \multicolumn{4}{|l|}{ Land use } \\
\hline Agrofor (\%) & $\%$ of patch area agroforestry & 0,3 & *** \\
\hline Crops (\%) & $\%$ of patch area crops & 0,49 & *** \\
\hline Pastures (\%) & $\%$ of patch area pastures & 0,41 & *** \\
\hline PrimForest (\%) & $\%$ of patch area primary forests & $-0,53$ & *** \\
\hline HarvestFoestr (\%) & $\%$ of patch area harvested forests & $-0,1$ & \\
\hline SuccessForest (\%) & $\%$ of patch area succession forests & 0,27 & ** \\
\hline \multicolumn{4}{|l|}{ Socio economics } \\
\hline read_write (\%) & $\%$ of population that can read/write & 0,33 & *** \\
\hline$\$$ wage/h & hourly rate for wage employment & 0,22 & * \\
\hline income_forests (\%) & $\%$ of household income from forests & $-0,3$ & *** \\
\hline income_agri (\%) & $\%$ of household income from agriculture & -0.06 & \\
\hline \multicolumn{4}{|l|}{ Governance } \\
\hline Participation & participation & $-0,36$ & *** \\
\hline Institutions & institutions & $-0,02$ & \\
\hline LawEnforcement & law enforcement & $-0,26$ & ** \\
\hline ForestManPract & forest management practices & $-0,08$ & \\
\hline Tenure & tenure & $-0,18$ & * \\
\hline MeanGov & mean governance & $-0,29$ & *** \\
\hline
\end{tabular}

Table: Pearson correlation coefficients for single bivariate correlations with \% annual deforestation 2008 - 16; with error probabilities; $N=80$ polygons. $* * * p<0.01,{ }^{*} p<0.05,{ }^{*} p<0.1$. 


\section{Acknowledgements}

The study is part of the project Landscape Forestry in the Tropics (LaForeT) conducted in Ecuador by the Thünen Institute of International Forestry and Forest Economics, Hamburg, Germany and the Universidad Estatal Amazónica of Ecuador. It was funded by the conducting institutions as well as by the German Federal Ministry of Food and Agriculture and the German Federal Office of Agriculture and Food (BLE) due to a decision of the Deutscher Bundestag, Project number 281-006-01. We acknowledge the support of the Universidad Luis Vargas Torres, Esmeraldas for facilitating logistics for the field campaign and opening the doors to the local communities. 
Review

\title{
Insights from the ground level? A content analysis review of multi-national REDD + studies since 2010
}

\author{
Richard Fischer *, Yvonne Hargita, Sven Günter \\ Thünen Institute for International Forestry and Forest Economics, Leuschnerstrasse 91, 21033, Hamburg, Germany
}

\section{A R T I C L E I N F O}

\section{Article history:}

Received 29 June 2015

Received in revised form 26 October 2015

Accepted 10 November 2015

Available online 19 November 2015

\section{Keywords:}

REDD +

Warsaw Framework

Results based finance

Co-benefits

Tenure rights

\begin{abstract}
A B S T R A C T
The REDD program ("Reducing Emissions from Deforestation and Degradation”) was launched in 2007. Two years later it was modified into REDD + . Since then, numerous sub-national initiatives have implemented REDD + or REDD +-like mechanisms. Now, shortly before the COP (United Nations Framework Convention on Climate Change, Conference of the Parties) in Paris 2015 it is timely and necessary to analyze insights and to draw upon lessons learned. This study reviews multi-national REDD+ studies by applying qualitative content analysis using the UNFCCC Warsaw Framework for categorization.

Experiences with the implementation of core REDD+ topics like institutional responsibility and results-based financing are mostly not encouraging. Monitoring systems require further development, and guidance for jurisdictional approaches is lacking. Experiences with reference levels, permanence and leakage have hardly been reported. More general topics like stakeholder participation, tenure clarification and biodiversity co-benefits are in turn more advanced. But these are not necessarily effects of REDD+ components in the projects. The projects obviously offer a platform to advance classical development issues.

We conclude that financial signals from the upcoming COP in Paris are essential to encourage further development and implementation. This supports conclusions in accordance with the UNFCCC session in Bonn 2015 stating that methodologies are now complete and implementation must begin. Additional conclusions are drawn for specific topics of the Warsaw Framework. Authors claim that REDD+ should stimulate and support transformational change.
\end{abstract}

(C) 2015 Published by Elsevier B.V.

\section{Contents}

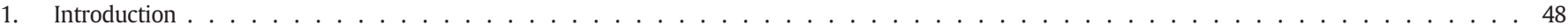

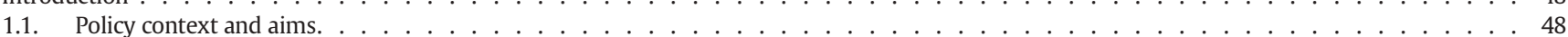

1.2. The REDD + mechanism . . . . . . . . . . . . . . . . . . . . . . . . . . . . . . . . . . 49

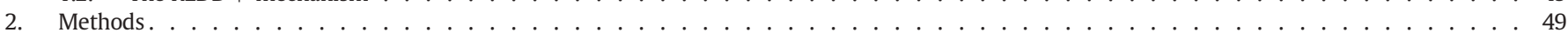

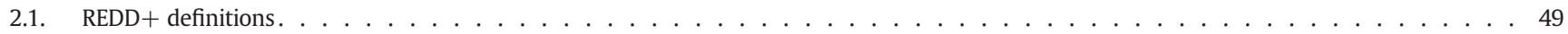

2.2. Definition of the material: studies and sources used for the review . . . . . . . . . . . . . . . . . . . . . . . . 50

2.3. Direction of the analysis and differentiation of subcomponents: the Warsaw Framework . . . . . . . . . . . . . . . . . . . . 50

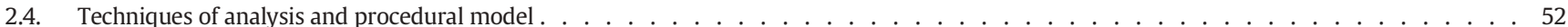

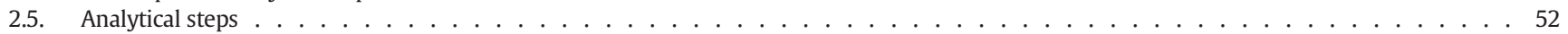

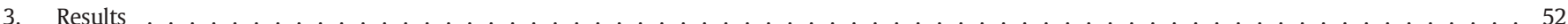

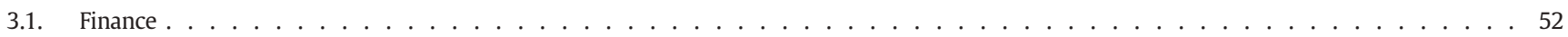

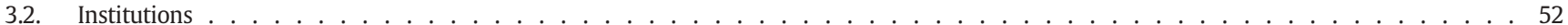

3.3. Monitoring and scales . . . . . . . . . . . . . . . . . . . . . . . . . . . . . . . . . . . . . . . 52

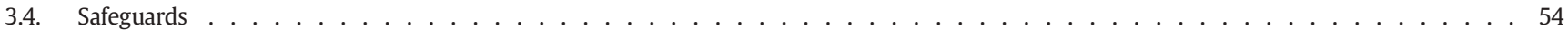

3.4.1. National forest program, international conventions and agreements $\quad \ldots \ldots \ldots$

3.4.2. Governance and tenure rights. . . . . . . . . . . . . . . . . . . . . . . . . . . . 54

3.4.3. Indigenous people and stakeholder consultation . . . . . . . . . . . . . . . . . . . . . . . . . . 54

3.4.4. Permanence and leakage . . . . . . . . . . . . . . . . . . . . . . . . . . . . . 54

\footnotetext{
* Corresponding author.

E-mail address: richard.fischer@ti.bund.de (R. Fischer).
} 


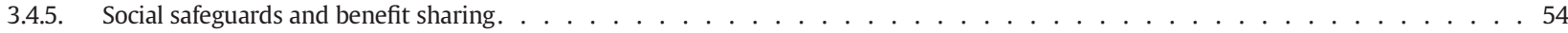

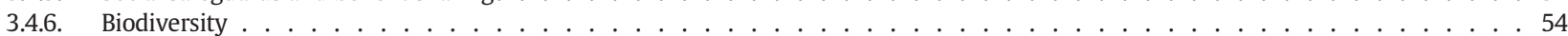

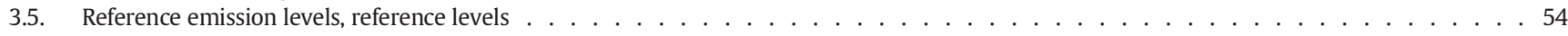

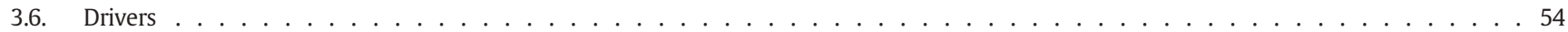

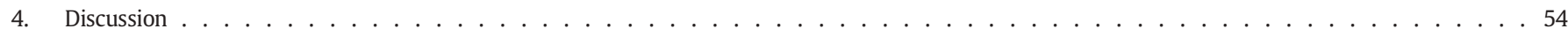

4.1. How much REDD+ is in the projects? . . . . . . . . . . . . . . . . . . . . . . . . . . . . . . . . 55

4.2. No breakthrough for results-based financing . . . . . . . . . . . . . . . . . . . . . . . . . . . . 55

4.3. Benefit sharing systems need to be country specific . . . . . . . . . . . . . . . . . . . . . . . . . . . . . . . 55

4.4. Land tenure is always essential. . . . . . . . . . . . . . . . . . . . . . . . . . . . . 55

4.5. No clear picture on socio-economic and biodiversity co-benefits. . . . . . . . . . . . . . . . . . . . . . . . . . . . 55

4.6. Real change needs to be transformational . . . . . . . . . . . . . . . . . . . . . . . . . . . . 55

4.7. Can project experience provide recommendations for the national level? . . . . . . . . . . . . . . . . . . . . . . 56

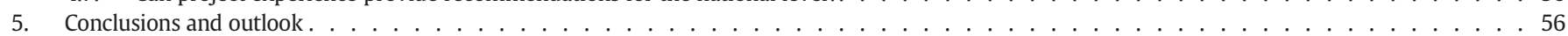

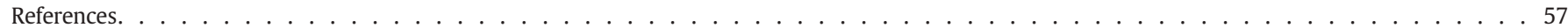

\section{Introduction}

\subsection{Policy context and aims}

Forests play a crucial role in the context of climate change. A total of $12 \%$ of total greenhouse gas emissions in the period 2000-2009 were from forests and other forms of land use (IPCC, 2014). On a global level, deforestation is still high. Around 13 million hectares of forests were lost each year in the first decade of the millennium (FAO, 2010), most of these in tropical countries (GFW, 2015). In 2007, the REDD ("Reducing Emissions from Deforestation and Degradation") process was launched in Bali under the United Nations Framework Convention on Climate Change (UNFCCC, 2007a). Two years later it was modified into REDD + . The program was designed, developed and promoted as an innovative approach to reduce deforestation based on broad cooperation and shared responsibilities between developing and developed countries. The core idea is that developed countries would financially compensate losses due to avoided deforestation and degradation. These conditional payments would depend on a verified monitoring of carbon stocks and fluxes by developing countries. REDD + raised high expectations as it was hoped that it would mobilize billions of dollars to compensate for the opportunity costs of forest conservation.

Eight years later no binding international agreement has yet been reached on how to pay for or reimburse verified net emission reductions or enhanced removals of greenhouse gases. However, in the readiness phases, preparation activities and pilot projects, a wealth of expertise and experiences has become available on different aspects and functionalities of the REDD + mechanism. In the present analysis we aim to review scientific publications and reports that summarize results from a larger number of such formal and informal REDD + activities in order to check for ground-level information supporting REDD+ implementation. We also seek information to provide lessons that can be learned for the further development and implementation of the REDD + process. The results and conclusions aim at supporting policy makers, as expectations for international agreement are high in this pre-conference period of the Conference of the Parties in Paris 2015. In order to verify whether the manifold initiatives on the ground provide compatible perceptions of the political UNFCCC Framework,

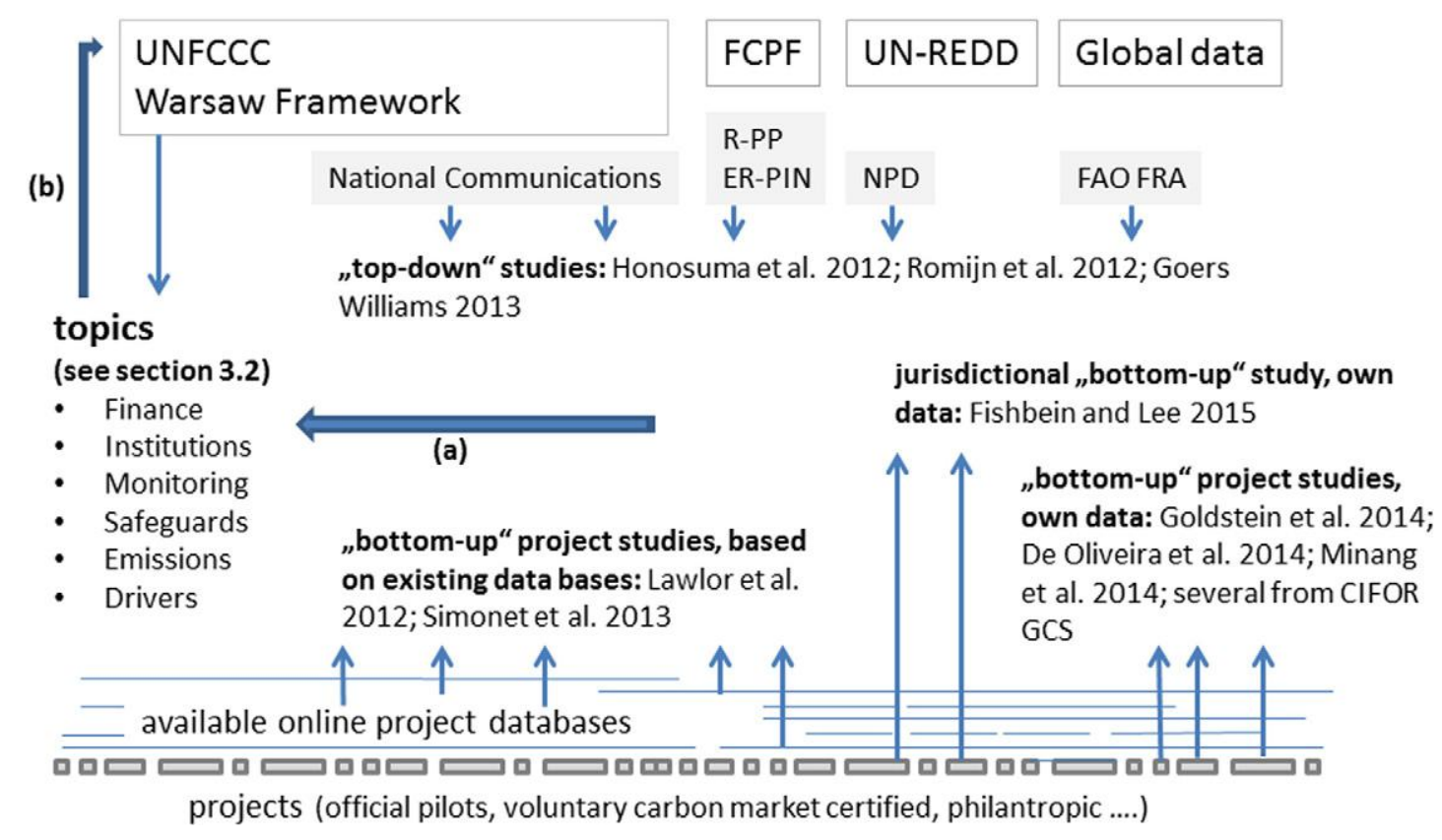

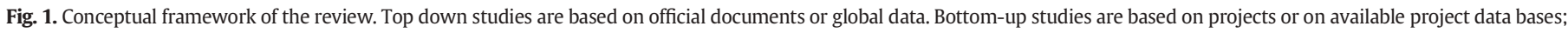

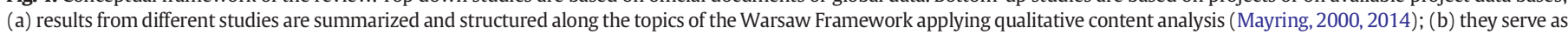
input to the policy level. Further explanations in the text, abbreviations explained in caption to Table 1. 
1. Definition of the material, analysis of the situation of origin, formal characteristics of the material

2. Direction of the analysis

3. Differentiation of subcomponents of the problem

4. Determination of techniques of analysis, establishment of a concrete procedural model, and definition of content analytical units

5. Analytical steps taken by means of the category system

6. Re-checking the category system by applying it to theory and material

7. Interpretation of the results in relation to the main problem and issue

Fig. 2. Steps within qualitative content analysis (simplified after (Mayring, 2014)).

discussion also focused on the differing conclusions between "top down" or "bottom up" studies.

\subsection{The REDD + mechanism}

REDD + is implemented in three phases (UNFCCC, 2011), including (i) the development of national strategies or action plans, policies and measures, and capacity-building, followed by (ii) the implementation of national policies and measures and (iii) results-based actions that should be fully measured, reported and verified. The initial phase is usually called the "readiness phase" and is supported by institutions like the UN-REDD program, or the Forest Carbon Partnership Facility (FCPF) of the World Bank. The current status of national REDD+ activities is reported in formal documents such as "readiness proposals" and national communications. The requirements for implementing REDD+ are laid down in the Warsaw Framework (UNFCCC, 2013). With this framework, "REDD + made much progress - on financing, transparency and safeguards, and monitoring and verification" (Morgan et al., 2014). But even pledges to the Convention's Green Carbon Fund made at the last COP meeting in Lima passed the 10 billion USD mark, no agreement has yet been reached on how to pay for or reimburse verified net emission reductions or enhanced removals of greenhouse gases.

While the formal REDD + process under UNFCCC is still under discussion, numerous REDD + projects have been installed in developing countries. They include REDD+ pilot projects that are linked to national REDD + strategies as a response to a call for demonstration activities (UNFCCC, 2007b). Simonet et al. (2014) show that $23 \%$ of all REDD + projects are pilot projects integrated into national REDD + strategies. In addition, there is a wide variety of informal approaches, concepts and self-defined REDD+ projects that are labeled as REDD + by their proponents. Thus, most of these activities do not formally operate under the REDD+ process of UNFCCC, even though that they all aim to cover main elements defined by UNFCCC. Nevertheless, there is great interest in learning from their experiences for the development of the formal REDD+ process and these initiatives can indeed be regarded as "the laboratory in which the REDD+ experiment is being conducted" (Sunderlin in Sills et al., 2014).

\section{Methods}

Our study reviews material published from different sources and compiles the lessons learned within the structure of the Warsaw Framework as input to the UNFCCC policy level (Fig. 1).

We used qualitative content analysis as an approach for the systematic analysis of the published articles. Qualitative content analysis is a mixed methods approach. It includes categorization of the text into sub-components text as a qualitative step, working through text passages and analysis of sub-components as a quantitative part (Mayring, 2000, 2014). The analysis is based on the methodological steps shown in Fig. 2.

The important characteristics of the method are feedback loops from Steps 6 and 7 back to Step 3 which makes the method an iterative approach in which the differentiation of the subcomponents, analysis techniques and procedural model are successively adapted during analysis.

\section{1. $R E D D+$ definitions}

The main differences of the REDD+ projects compared to the UNFCCC REDD + process are that (i) they are mostly based on other standards like the Verified Carbon Standard (VCS) or the Climate, Community \& Biodiversity Alliance (CCBA), (ii) often aim at financing through the international voluntary carbon market and (iii) they are sub-national, whereas REDD + by definition is a national exercise (with a few interim exceptions). In our review, REDD+ project definitions vary substantially and influence the basis and results of each study. A specific ambiguity is related to afforestation and reforestation $(\mathrm{A} / \mathrm{R})$. It often remains unclear if afforestation and reforestation projects are included within the studies reviewed. Under UNFCCC, the REDD+ activity "enhancement of forest carbon stocks" may be understood to include afforestation and reforestation (Angelsen et al., 2011; Iverson et al., 2014), but at the same time the Clean Development Mechanism under the Kyoto Protocol also allows the generation of emission reduction certificates from afforestation/reforestation projects, which does not make a REDD+ project definition easier. Among the studies reviewed, Sills et al. (2014) only rely on projects that "do not derive most of their carbon benefits from afforestation/reforestation outside

Table 1

Studies reviewed. In gray: studies based on the CIFOR "Global Comparative Study" (GCS).

\begin{tabular}{|c|c|c|c|c|c|c|}
\hline & $\begin{array}{l}\text { Year } \\
\text { of } \\
\text { public. }\end{array}$ & $\begin{array}{l}\mathrm{N} \\
\text { pro- } \\
\text { jects }\end{array}$ & $\begin{array}{l}\mathrm{N} \\
\text { coun- } \\
\text { tries }\end{array}$ & Sources & \begin{tabular}{|l|} 
Scient. \\
review \\
$\mathrm{Y} / \mathrm{N}$
\end{tabular} & Main topic \\
\hline \multicolumn{7}{|c|}{ "Top-down" studies based on REDD + documents } \\
\hline Hosonuma et al. & 2012 & & 46 & $\begin{array}{l}\text { FCPF R-PINs and } \\
\text { R-PP, UNFCCC } \\
\text { NatComm, Lit, } \\
\text { CIFOR country } \\
\text { profiles }\end{array}$ & $\mathrm{Y}$ & $\begin{array}{l}\text { Drivers for deforestation } \\
\text { and degradation }\end{array}$ \\
\hline Romijn et al. & 2012 & & 99 & FAO FRA & $\mathrm{Y}$ & $\begin{array}{l}\text { Forest monitoring } \\
\text { systems }\end{array}$ \\
\hline Goers Williams & 2013 & & 32 & $\begin{array}{l}\text { FCPF R-PP, } \\
\text { UN-REDD NPD }\end{array}$ & $\mathrm{N}$ & Several \\
\hline \multicolumn{7}{|c|}{ "Bottom up" studies based on existing online data bases } \\
\hline Lawlor et al. & 2013 & 41 & 22 & CCBA & $\mathrm{Y}$ & $\begin{array}{l}\text { Community } \\
\text { participation and } \\
\text { benefits }\end{array}$ \\
\hline Simonet et al. & 2014 & 329 & 47 & Own data base & $\mathrm{N}$ & Several \\
\hline \multicolumn{7}{|c|}{ "Bottom up" studies with own assessments } \\
\hline Goldstein et al. & 2014 & 417 & 39 & Own data base & $\mathrm{N}$ & Carbon market \\
\hline Fishbein and Lee & 2015 & 8 & 7 & $\begin{array}{l}\text { Project } \\
\text { descriptions, } \\
\text { own research }\end{array}$ & $\mathrm{N}$ & $\begin{array}{l}\text { Jurisdictional } \\
\text { approaches }\end{array}$ \\
\hline De Oliveira et al. & 2014 & 6 & 6 & Own research & $\mathrm{N}$ & Several \\
\hline Minang et al. & 2014 & & 4 & Own research & $\mathrm{Y}$ & Several \\
\hline Sills et al. & 2014 & 23 & 6 & CIFOR GCS & $\mathrm{N}$ & Several \\
\hline Sunderlin et al. & $2014 a$ & 23 & 6 & CIFOR GCS & $\mathrm{N}$ & Several \\
\hline Sunderlin et al. & 2014b & 23 & 6 & CIFOR GCS & $\mathrm{Y}$ & Tenure \\
\hline Murdiyarso et al. & 2012 & 23 & 6 & CIFOR GCS & $\mathrm{Y}$ & Several \\
\hline Jagger et al. & 2014 & 16 & 3 & CIFOR GCS & $\mathrm{Y}$ & Safeguards \\
\hline Luttrell et al. & 2013 & 20 & 6 & CIFOR GCS & $\mathrm{Y}$ & Benefit sharing \\
\hline Joseph et al. & 2013 & 21 & 6 & CIFOR GCS & $\mathrm{Y}$ & MRV \\
\hline Korhonen-Kurki et al. & 2014 & & 12 & CIFOR GCS & $\mathrm{Y}$ & MRV, institutions \\
\hline
\end{tabular}

Studies excluded from the further evaluation. Further explanations in the text.

CCBA - Climate, Community \& Biodiversity Alliance; CIFOR - Center for International Forestry Research; ER-PIN Emission Reduction Program Idea Note; FAO - Food and Agriculture Organization; FCPF - Forest Carbon Partnership Facility; FRA - Forest Resource Assessment; GCS - Global Comparative Study; MRV - Monitoring Reporting Verification; NatComm - National Communication; NPD - National Program Document; R-PP - Readiness Preparation Proposal; UN-REDD - United Nations Collaborative Initiative on Reducing Emissions from Deforestation and Forest Degradation. 
of existing forest." Lawlor et al. (2013) explicitly include A/R projects. Simonet et al. (2014) explicitly distinguish REDD, A/R and Improved Forest Management (IFM) projects but include them all in their study. Other studies do not specify the selection criteria for the projects, which is the reason for the fact that we included all of the selected studies. Due to the missing definitions in a number of studies, a selection according to an own REDD+ definition was simply not possible. The resulting vagueness needs to be taken into account.

\subsection{Definition of the material: studies and sources used for the review}

We applied a basic search in Science Direct (www.sciencedirect. com) with "REDD" and "project" in the title, abstract or keywords and with publication date $>2010$ and a second search with "REDD" and "readiness" in the title, abstract or keywords. This yielded 92 results. In the Web of Knowledge (www.webofknowledge.com) we used the same words as topic and yielded 420 articles. Gray literature was added from an own EndNote library, which was a collection of 187 REDD + related publications compiled by the authors during previous ongoing research. As we were searching for multi-national studies we consecutively removed all those studies that mentioned one specific country in the title. This reduced the number of publications by over $50 \%$. On the basis of abstracts, introduction and methods we selected those that contained results from REDD + activities in at least three countries in order to focus on overview studies and generalizing conclusions that reach beyond single case studies. Further on we only selected studies providing conclusions from REDD + activities to at least one of the topics of the Warsaw Framework (Section 2.3). In cases where results from the same studies were provided in different publications, we prioritized reviewed scientific articles. We found 21 studies that matched our formal selection criteria. From these we excluded four studies: Cerbu et al. (2011) and Caplow et al. (2011) which were very early studies with rather preliminary results; Nguon and Kulakowski (2013), which had a very specific topical focus on natural disturbances and FCPF \& UN-REDD (2012) which was based on a questionnaire among partner countries which we interpreted as a policy targeted "wish list" rather than a scientific study. We grouped the remaining 17 studies (Table 1 ) according to their information sources into:

- studies relying on national REDD + documents under UNFCCC, FCPF and UN-REDD, as well as global data; we called these studies "topdown" studies;

- studies using online data bases and maps of REDD+ projects including project descriptions and design documents; we called these studies "bottom-up" studies; and

- studies from research projects with own field assessments; we called these studies "bottom-up" studies.

Only three studies were top-down studies, i.e. based on official REDD + documents or based on global data sets. There were two bottom-up studies based on existing online project data bases. A list of publicly available project data bases that are a substantial basis for these studies is provided in the supplementary material (Supplementary material, Table A). With twelve studies the largest share of the material is based on own, original data collection. CIFOR's Global Comparative study (GCS) played a dominant role. Eight studies in the review rely on this project. There are more publications from the project that are not included in the review because these studies tackle only single countries (Resosudarmo et al., 2014; Awono et al., 2014; Dokken et al., 2014; Cromberg et al., 2014; Duchelle et al., 2014; political economy studies introduced by Brockhaus et al. (2014a)), tackle topics that are beyond the operational level of the Warsaw Framework (Brockhaus et al., 2014b), or because the results are included in other GCS studies (Larson et al., 2013; Brockhaus and Di Gregorio, 2014). All CIFOR GCS studies were treated as one respondent in the quantitative
Table 2

Topics and summary of the UNFCCC REDD+ "Warsaw Framework" (UNFCCC, 2013; Climate Law\&Policy, 2014).

\begin{tabular}{|c|c|}
\hline Sub-component/topic & Summarized content \\
\hline Results-based financing & $\begin{array}{l}\text { - Encourage adequate and predictable } \\
\text { results-based financing from variety of sources } \\
\text { - Key role of Green Climate Fund } \\
\text { - Incentivize non-carbon benefits }\end{array}$ \\
\hline Institutional arrangements & $\begin{array}{l}\text { - Set up of national REDD+ entities or focal } \\
\text { points }\end{array}$ \\
\hline $\begin{array}{l}\text { National forest monitoring } \\
\text { systems }\end{array}$ & $\begin{array}{l}\text { - Establish robust and transparent national } \\
\text { forest monitoring systems } \\
\text { - Guided by IPCC guidelines. } \\
\text { - Sub-national forest monitoring systems as } \\
\text { interim measure }\end{array}$ \\
\hline $\begin{array}{l}\text { Monitoring, reporting, } \\
\text { verification }\end{array}$ & $\begin{array}{l}\text { - Measure, report and verify anthropogenic } \\
\text { forest-related emissions by sources and re- } \\
\text { movals by sinks, forest carbon stocks, and } \\
\text { forest carbon stock and forest-area changes } \\
\text { - As part of the National Forest Monitoring } \\
\text { System } \\
\text { - Parties' biennial update reports } \\
\text { - Verified by a team of technical experts }\end{array}$ \\
\hline $\begin{array}{l}\text { Forest reference emission levels } \\
\text { and/or forest reference levels }\end{array}$ & $\begin{array}{l}\text { - These benchmarks are a precondition for } \\
\text { results-based payments } \\
\text { - Sub-national levels may be elaborated as an } \\
\text { interim measure }\end{array}$ \\
\hline Safeguard reporting & $\begin{array}{l}\text { - Take into account national forest programs, } \\
\text { international conventions and agreements } \\
\text { - Governance } \\
\text { - Rights of indigenous peoples } \\
\text { - Stakeholder participation } \\
\text { - Natural forests, Biodiversity } \\
\text { - Risks of reversals } \\
\text { - Emission displacement }\end{array}$ \\
\hline $\begin{array}{l}\text { Drivers of deforestation and } \\
\text { forest degradation }\end{array}$ & $\begin{array}{l}\text { - Parties are encouraged to take action to reduce } \\
\text { drivers and to share the results of their work }\end{array}$ \\
\hline
\end{tabular}

analysis as many authors collaborate in several publications and all results are from similar projects. With regard to the State of the Forest Carbon Markets report (Goldstein et al., 2014) we used only the most recent report within this annual series, as the latest version includes the previous years' data as historical information as well.

\subsection{Direction of the analysis and differentiation of subcomponents: the Warsaw Framework}

The REDD + framework of the UNFCCC provided a structure for differentiating the existing information into subcomponents. Within the so-called Warsaw Framework, UNFCCC has specified the fields relevant for the implementation of REDD + . These specific fields were used as subcomponents within our content analysis. We called them topics. Scientific input, if relevant to the policy and development of the formal REDD+ process, needs to deal with and discuss these topics. Most studies had a specific topical focus and did not provide results and conclusions on all of the topics.

Table 3

Key expressions for the interpretation of study conclusions when answering on a five level Likert scale reaching from 1 (fully agree) to 5 (completely disagree).

\begin{tabular}{ll}
\hline Scale & Key expressions \\
\hline 1 & "always", "in all countries" \\
2 & "mostly applied", "in many cases" \\
3 & "not sure", "neither yes nor no", "may potentially be" \\
4 & "not applicable in most countries", "little clarity" \\
5 & "not applicable in all countries", "topic was a major obstacle", "completely unclear" \\
\hline
\end{tabular}


Table 4

Statements and related scores for each of the studies on a five level Likert scale from 1 (fully agree) to 5 (completely disagree). In cases where scores to a specific statement were available from several CIFOR GCS studies, we only used the study with the most detailed and substantiated content (repeated in column "summary CIFOR GCS") and disregarded the other studies (scores in brackets).

\begin{tabular}{|c|c|c|c|c|c|c|c|c|c|c|c|c|c|c|c|c|c|c|c|}
\hline Statement & 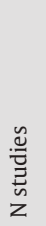 & 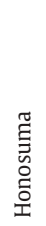 & : & 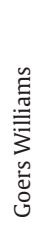 & 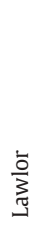 & $\underset{\stackrel{\Xi}{\Xi}}{\stackrel{\Xi}{\Xi}}$ & $\begin{array}{l}\frac{\Xi}{ \pm} \\
\frac{\tilde{n}}{0} \\
\frac{0}{0}\end{array}$ & 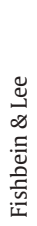 & 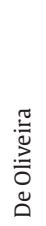 & $\stackrel{\infty}{\stackrel{0}{\Xi}}$ & 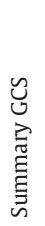 & $\cong$ & 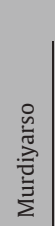 & 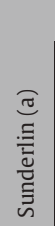 & 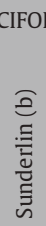 & 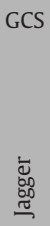 & $\begin{array}{l}\bar{\Xi} \\
\stackrel{\Xi}{\Xi}\end{array}$ & $\begin{array}{l}\tilde{\bar{\nu}} \\
\stackrel{\tilde{\nu}}{\simeq}\end{array}$ & 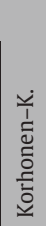 \\
\hline \multicolumn{20}{|l|}{ 3.1 Finance } \\
\hline \multicolumn{20}{|c|}{ Conditional and results-based payments on project-and jurisdictional level presently play a significant role } \\
\hline & 5 & & & & & 4 & *) & 4 & & & 4 & 4 & & $(4)$ & & & & & \\
\hline \multicolumn{20}{|c|}{$\begin{array}{l}\text { Conditional and results-based payments at project or jurisdictional scale are regarded as a promising cornerstone of future } \\
\text { REDD + implementation }\end{array}$} \\
\hline & 6 & & & & & 3 & 3 & 3 & 4 & & 3 & 3 & & (3) & & & & & \\
\hline \multicolumn{20}{|l|}{3.2 Institutions } \\
\hline \multicolumn{20}{|l|}{ There are clear inst } \\
\hline 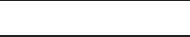 & 7 & & & 4 & & & & 4 & 4 & 2 & 4 & & $(4)$ & & & & $(5)$ & & 4 \\
\hline \multicolumn{20}{|l|}{ 3.3 Monitoring } \\
\hline \multicolumn{20}{|c|}{ The status of monitoring systems is satisfying } \\
\hline & 9 & & 4 & 3 & & & & & 4 & 4 & 3 & (3) & $(5)$ & & $(4)$ & & & 3 & $(4)$ \\
\hline \multicolumn{20}{|c|}{ There are promising options for technical cooperation on MRV systems } \\
\hline & 4 & & 2 & & & & & & 2 & & 2 & $(2)$ & & & & & & 2 & \\
\hline \multicolumn{20}{|c|}{$\begin{array}{l}\text { Based on clear guidance for bridging the project and national scales, jurisdictional approaches are on the way to becoming } \\
\text { milestones in the global REDD + implementation }\end{array}$} \\
\hline & 6 & & & & & 3 & 3 & 3 & & 4 & 4 & 4 & & & & & & $(4)$ & \\
\hline \multicolumn{20}{|l|}{ 3.4 Safeguards } \\
\hline \multicolumn{20}{|c|}{ 3.4.1 National forest programs } \\
\hline \multicolumn{20}{|c|}{ REDD + activities take into accour } \\
\hline+2 & 1 & & & & & & & & & & 1 & & & & & 1 & & & \\
\hline \multicolumn{20}{|c|}{ 3.4.2 Governance (incl. tenure) } \\
\hline Tenure rights are $c$ & $\mathrm{DD}+$ & proje & ts or & urisc & ction & & & & & & & & & & & & & & \\
\hline & 10 & & & 4 & 2 & & 2 & 3 & 2 & 4 & 4 & (4) & (4) & $(4)$ & 4 & & & & \\
\hline REDD + provides a & newo & $\mathrm{k} / \mathrm{pr}$ & cess & o cla & fy te & iure $\mathrm{r}$ & ghts & & & & & & & & & & & & \\
\hline & 7 & & & & 1 & & 3 & 2 & 2 & & 2 & (3) & & $(2)$ & 2 & & & & \\
\hline 3.4.3 Indigenous $\mathrm{p}$ & akeh & Ider & artic & patio & & & & & & & & & & & & & & & \\
\hline Indigenous people & ders & are in & olve & in $\mathrm{R}$ & DD+ & ictivi & & & & & & & & & & & & & \\
\hline & 7 & & & 2 & 2 & 2 & & 2 & 3 & 1 & 2 & 2 & & & & & & & \\
\hline The level of partici & the & ackg & ounc & infor & natio & pro & ided & o sta & $\overline{\text { rehol }}$ & ers is & adec & 1ate & & & & & & & \\
\hline & 5 & & & & 5 & 4 & & & 4 & 3 & 4 & 4 & & & & & & & \\
\hline 3.4.4 Permanence & & & & & & & & & & & & & & & & & & & \\
\hline Experience on perı & leak & ge is & provi & ed $\mathrm{fr}$ & $\mathrm{m} \mathrm{pr}$ & jects & & & & & & & & & & & & & \\
\hline & 0 & & & & & & & & & & & & & & & & & & \\
\hline 3.4.5 Social safegu & efit sl & aring & & & & & & & & & & & & & & & & & \\
\hline Social and/or biolog & repo & ing & eceiv & s atte & tion & $n$ the & REDD & act & ities & nd is & mple & nente & d base & d on & ocun & ented & proce & dures & \\
\hline & 4 & & & 3 & & & & & 4 & 2 & 4 & & & & & 4 & & & \\
\hline Socio-economic cc & pro & ided & & & & & & & & & & & & & & & & & \\
\hline & 5 & & & & 3 & 3 & 3 & & & & 4 & 4 & & (3) & & & & & \\
\hline Procedures for ben & are d & finec & & & & & & & & & & & & & & & & & \\
\hline & 6 & & & 4 & & & & & 4 & 3 & 4 & (3) & & & & (4) & 4 & & \\
\hline Procedures for ben & re il & iplen & entec & & & & & & & & & & & & & & & & \\
\hline & 4 & & & 4 & & & & & & 5 & 4 & (4) & & & & & 4 & & \\
\hline 3.4.6 Natural fores & & & & & & & & & & & & & & & & & & & \\
\hline Conservation and & ervic & sare & provi & & & & & & & & & & & & & & & & \\
\hline & 4 & & & & & 3 & 3 & 2 & & & 3 & & & 3 & & & & & \\
\hline 3.5 Forest referenc & els & $\mathrm{nd} / \mathrm{o}$ & fores & refe & ence & evels & & & & & & & & & & & & & \\
\hline There are unambig & ds ar & d cap & acitie & to se & refe & ence & evels & $\mathrm{n} \mathrm{pr}$ & jects & & & & & & & & & & \\
\hline & 4 & & & & & & & & & 3 & 3 & & (5) & (3) & & & & 3 & \\
\hline 3.6 Drivers of defo & fore & tdeg & adati & & & & & & & & & & & & & & & & \\
\hline Project specific dri & esta & on at & $\mathrm{d} \mathrm{deg}$ & radat & on ar & take & intc & acco & & & & & & & & & & & \\
\hline & 11 & 3 & & & 2 & 2 & 3 & 1 & 2 & 5 & 2 & & (3) & $(2)$ & (1) & & & 2 & \\
\hline Number of topics & & 1 & 2 & 7 & 6 & 8 & 8 & 9 & 11 & 11 & 18 & 12 & 5 & 8 & 4 & 3 & 3 & 5 & 2 \\
\hline
\end{tabular}

*) Study not taken into account as (Goldstein et al., 2014) exclusively focus on projects with conditional payments. 


\subsection{Techniques of analysis and procedural model}

A category system within qualitative content analysis that we specifically developed for our study constitutes the central instrument used to structure and analyze the text. We formulated policy relevant questions and statements as sub-components and scored our reviewed material on this basis.

First, we coded all main messages within the studies referring to the topics of the Warsaw Framework. Coding was carried out using the signaling tool in Acrobat Reader. In parallel we copied the relevant texts into an MS Excel table assigning it to columns for the respective topics. Based on overview literature (e.g. Angelsen et al., 2012) and the topics formulated in the Warsaw Framework (Table 2) we then deducted policy relevant statements/questions. The formulation of statements/ questions is an iterative process that reflects the feedback loops in qualitative content analysis. The final statements/questions are presented in Table 4.

\subsection{Analytical steps}

Qualitative content analysis is a mixed method in which quantitative components gain particular importance when generalization of the results is required (Mayring, 2014). We defined our content analysis units as a five level Likert scale reaching from 1 (fully agree) to 5 (completely disagree). In a second step we then analyzed the coded texts and for each study answered to the statements/questions "on behalf" of the authors. Having key expressions in mind (Table 3) we thus interpreted the conclusions of the studies according to the scale. Converting thematic analysis into Likert scales constitutes a data transformation based on an intensity scale (Castro et al., 2010). A number of constraints related to qualitative content analysis are mentioned in literature. Mayring (2000) mentions that the method is not appropriate if the research question is highly open-ended, explorative or variable, which was not the case, as we had the Warsaw Framework to structure and define our categories. Kohlbacher (2006) points to the fact that "replicating a mixed method package is hardly possible", which is true and might be a constraint in our study. Therefore, and in order to at least make our decisions and interpretations transparent we copied key statements in the reviewed studies related to each topic into a single table (Supplementary material, Table B). However, this table should be used with care as single and isolated sentences mostly transport shortened messages and cannot replace the full understanding of the studies. Elo et al. (2014) mention the possible failure to develop a complete understanding of the context. This is a general problem of qualitative content analysis, which we aimed to overcome by thorough reading of the text and discussions in the research team. Here, we tried to produce an interpretation based on expert knowledge and a best possible understanding of the texts. The saturation of data which is referred to by the same authors was not a constraint in our case, as the material was predefined based on our literature selection criteria.

\section{Results}

The results chapter starts with overarching study findings and identifies sub-topics. In the sub-sections, findings within single topics are considered in more detail.

The most frequently raised questions address drivers of deforestation and tenure questions; they are tackled in $65 \%$, respectively, $59 \%$, of the studies. In contrast, conclusions on permanence and leakage were not provided in any of the reviewed literature (Table 4, Fig. 3). Hosonuma et al. (2012) and Romijn et al. (2012) focus only on very selected topics, whereas other studies like Sills et al. (2014); De Oliveira et al. (2014) and Minang et al. (2014) provide a broader view with answers to $63 \%$, respectively, $58 \%$ of the statements. Not surprisingly, as based on several studies, the CIFOR GCS project provides scores for nearly all statements.

Overall, there were more negative scores ( 32 "no" answers in Fig. 3) than positive ones (22 "yes" answers in Fig. 3). The status and implementation of activities under REDD + specific topics like financing and benefit sharing, REDD+ institutions and monitoring systems were perceived rather negatively (listed on top in Fig. 3). Technical REDD+ topics like reference emission levels and permanence and leakage, were hardly tackled at all in the studies. Topics that are not REDD + specific, like tenure rights, participation, conservation and biodiversity, as well as consideration of project specific drivers received more positive ratings (listed at the bottom part of Fig. 3).

There were no systematic differences in results and conclusions between bottom-up and top-down studies. However, the number of studies and of topics covered in most studies was too low to analyze possible differences statistically.

\subsection{Finance}

Three studies present expertise with results-based financing. All three studies consistently disagree whether this financial mechanism plays a central role of at present. Sunderlin et al.'s (2014) “doubt about its centrality" summarizes the general perception. Of 329 projects assessed globally by Simonet et al. (2014), only $21 \%$ are at present engaged in carbon transactions. With four out of 23 projects $(=17.4 \%)$ selling carbon credits, the share is comparable for the CIFOR GCS sites (Sills et al., 2014). Also most jurisdictions studied are currently driven by official development assistance (ODA) and not by results-based payments (Fishbein and Lee, 2015). The low shares may partly be due to the fact that the projects need more time to develop the framework at the ground level. This is reflected by the fact that a larger share of projects is expecting to sell credits in the future: this applies to $53 \%$ of the 329 globally assessed projects and 78\% of the GCS projects. Nevertheless and in general, the authors of the studies remain noncommittal as concerns a possible future role of conditional payments. The hope "that applying conditionality at a higher scale, outside of site boundaries, will make sense" (Sunderlin et al., 2014) is countered by the perception from the jurisdictional projects as in general this "ambitious scale greatly raises the bar on the challenges" (Fishbein and Lee, 2015).

\subsection{Institutions}

Only one publication (Minang et al., 2014) identifies clear institutional responsibilities, whereas four other studies taking a look at institutional development are rather skeptical. 59\% of the studies do not deal at all with these issues. Goers Williams (2013) shows that readiness proposals did not identify specific next steps to establish mechanisms for coordination and coherence of proposed new REDD+ bodies with existing forest sector institutions. Korhonen-Kurki et al. (2014) report "serious shortcomings in effective horizontal, cross-sectoral coordination mechanisms" in nearly all countries. Within the jurisdictions studied, institutional arrangements were in many cases still not clear or created. However, jurisdictional approaches were seen as a platform to involve at least local governments and to stimulate institutional development (Fishbein and Lee, 2015).

\subsection{Monitoring and scales}

In the five studies that tackle National Forest Monitoring Systems (NFMS) including Monitoring, Reporting and Verification (MRV) systems, the status of the monitoring systems was either not satisfying or unclear. Based on ongoing and recent REDD+ projects Joseph et al. (2013) offer a more positive conclusion, whereas the critical results of Romijn et al. (2012) are based on all non-Annex I countries in a de facto pre-REDD + situation. Technical cooperation was generally seen as a promising opportunity to improve the situation. However, De 
3.4.5 Social safeguards and benefit sharing

Social and/or biological safeguard reporting receives attention in the REDD+ activities and is implemented based on documented procedures

Socio-economic co-benefits are provided

Procedures for benefit-sharing are defined

Procedures for benefit-sharing are implemented

\subsection{Institutions}

There are clear institutional responsibilities related to REDD+ implementation in the countries/jurisdictions

\subsection{Finance}

Conditional and results based payments on projectand jurisdictional level presently play a significant role Conditional and results based payments are regarded a promising cornerstone of future REDD+ implementation

\subsection{Monitoring}

The status of monitoring systems is satisfying

There are promising options for technical cooperation on MRV systems

There is clear guidance and options for bridging the project and national scales in jurisdictional approaches

\subsection{Reference (emission ) levels}

There are unambiguous standards and capacities to set reference levels in projects

\subsubsection{Indigeneous people and stakeholder consultation}

Indigenous people and stakeholders are involved in REDD+ activities

The level of participation and/or the background information provided to stakeholders is adequate

\subsubsection{Tenure rights}

Tenure rights are clarified in REDD+ projects or jurisdictions

REDD+ provides a valuable framework/process to clarify tenure rights

\subsubsection{Conservation and biodiversity}

Conservation and biodiversity services are provided

\subsection{Drivers}

Project specific drivers for deforestation and degradation are taken into account

\subsubsection{National forest programmes}

REDD+ activities take into account national forest programmes and/or international agreements beyond UNFCCC

\subsubsection{Permanence and leakage}

Experience on permanence and leakage is provided from projects

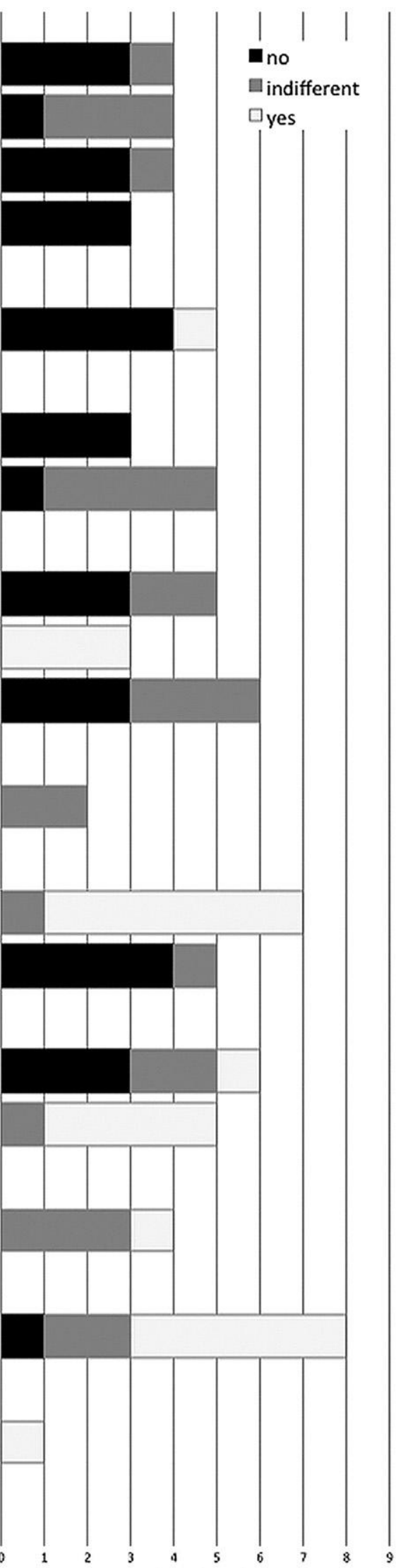

Number of studies

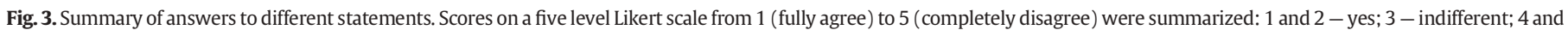
5 - no. Topics are sorted from those with strongest disagreement to strongest agreement. 
Oliveira et al. (2014) point to the fact that "the MRV component of forest-carbon initiatives generally involves external agencies and consultants" which can create a dependency.

At present there are obviously no clear options for bridging project and national scales in jurisdictional monitoring systems. Sills et al. (2014) identify scale as one of the largest uncertainties, as the link between local project based systems and the national scale is not at all clear. The IPCC guidelines have been developed for generating national greenhouse gas inventories. But on the project level guidelines of carbon certifiers play an important role. Related to the scales problem, the Verified Carbon Standard (VCS) to date provides the only defined standard for nesting scales in jurisdictional approaches. Also, a number of projects are engaged with a government entity on integrating project baselines with regional efforts (Goldstein et al., 2014). However, these are individually negotiated solutions and there is no harmonized approach under UNFCCC.

\subsection{Safeguards}

Safeguards include a number of topics that we evaluated separately.

3.4.1. National forest program, international conventions and agreements Only one study (Jagger et al., 2014) reports on dialogs with national forest programs. This positive report is based on projects in three countries.

\subsubsection{Governance and tenure rights}

From the broad range of aspects included under a definition of modern governance (Giessen and Buttoud, 2014), tenure rights are the most widely studied factor in our review. Tenure questions are high on the agenda in most projects but perceptions of tenure seem to be case specific. Tenure rights are one of the most pressing and influential factors for the complete REDD+ process among the CIFOR GCS projects (Sunderlin et al., 2014) and most of these projects "have not yet succeeded in creating a secure tenure foundation for REDD + activities" (Sills et al., 2014). The survey by Fishbein and Lee (2015) is more positive, as their interview partners "suggested it is not always the most difficult challenge that a jurisdiction faces" and for De Oliveira et al. (2014) the "cases presented no apparent conflicts coming from land tenure." Independent of the status of tenure, REDD+ projects are obviously helping populations to clarify tenure rights.

\subsubsection{Indigenous people and stakeholder consultation}

The necessity to involve and empower indigenous people as well as to enable stakeholder participation is widely perceived and taken into account in REDD+ projects. A majority of projects obtain local populations' free, prior, and informed consent (Lawlor et al., 2013) or inform them through a participatory rural appraisal (Simonet et al., 2014). However, the level of participation seems to be mostly inadequate. People "are rarely involved in decision-making and project design" (Simonet et al., 2014), individuals and communities lack "detailed information about project risks and opportunities" (Lawlor et al., 2013), and "many participatory processes are reduced to a few workshops" (De Oliveira et al., 2014). With respect to the REDD+ approach, project developers seem to be reluctant to propagate it too actively being afraid to raise expectations that cannot be fulfilled (Sills et al., 2014).

\subsubsection{Permanence and leakage}

Avoidance of the risks of reversals (permanence) and actions to reduce displacement of emissions (leakage) are not considered in any of the reviewed studies.

\subsubsection{Social safeguards and benefit sharing}

Social safeguard reporting seems to be neglected in most REDD+ projects. De Oliveira et al. (2014) point to the fact that there are simply "too many social and environmental safeguards and different organizations use different processes to guarantee the safeguards." This limited internal attention is in conflict to external information demands, because there are clear expectations on poverty alleviation and nature conservation linked to carbon projects. One third of all REDD+ projects worldwide are certified by a social standard, which illustrates the "importance of having a social label to sell in the voluntary market" (Simonet et al., 2014). Goldstein et al. (2014) point to the fact that "buyers demand to know the 'story' behind the offset".

There is no clear picture on livelihood co-benefits. These are complex and difficult to design, implement and monitor, as they "encompass different scales, a large and varied body of stakeholders and heterogeneous conditions on the ground" (Sills et al., 2014). For many projects, "it is simply too early to assess whether they have produced material benefits for communities" (Lawlor et al., 2013). Socioeconomic benefits that are mentioned by Simonet et al. (2014) are mostly not provided as co-benefits of the REDD + procedure but through input-based and ODA-related finance in the same project.

As concerns benefit sharing, procedures were neither defined nor implemented in most cases. Many countries had several alternative proposals on the table, e.g., one for national and several others for projects (Luttrell et al., 2013).

\subsubsection{Biodiversity}

Conservation, as well as species and watershed protection play an important role in many REDD+ projects. This is partly due to the fact that many of them were former conservation projects that developed a "new" REDD + component later on. About 30\% of the globally analyzed projects are thus located in a protected area. Climate is presented as the main objective of only $14 \%$ of the projects, far behind conservation (35\%) (Simonet et al., 2014). There were forest protection activities at 20 of the 23 CIFOR GCS sites (Sunderlin et al., 2014). Twenty percent of carbon dioxide equivalents certified by VCS were from projects developed within a land area that was certified by the Forest Stewardship Council (FSC) (Goldstein et al., 2014).

\subsection{Reference emission levels, reference levels}

There is not much evidence on the status or lessons learned from previous activities on reference (emission) levels in the reviewed material. Murdiyarso et al. (2012) detected large capacity gaps for developing reference levels and Joseph et al. (2013) complain about "ambiguity in methodological guidelines on how to set reference emission level in REDD+ projects”.

\subsection{Drivers}

The awareness of and the need to take specific drivers for deforestation and degradation into account is reflected in most studies, with 11 out of 17 studies offering summarizing results or drawing dedicated conclusions. The ranking and importance varies between the studies. Hosonuma et al. (2012) give a widely accepted summary stating that "commercial agriculture is the most important driver of deforestation, followed by subsistence agriculture. Timber extraction and logging drives most of the degradation, followed by fuelwood collection and charcoal production, uncontrolled fire and livestock grazing".

\section{Discussion}

Given the broad range of REDD + topics included in the Warsaw Framework, and the policy focus of our review, we concentrate the discussion on politically controversial issues like financing and benefit sharing, tenure rights, and co-benefits (see subsections). Topics for which we perceive no controversial discussions in recent literature are not discussed. This applies for stakeholder participation (Gebara, 2013; Awono et al., 2014; Lawlor et al., 2013), institutional responsibilities (Kanowski et al., 2011) integration of REDD+ programs with other 
policies (Nepstad et al., 2014; Corbera and Schroeder, 2011; Robiglio et al., 2014) and safeguard reporting (Arhin, 2014). Our discussion starts with general thoughts on REDD+ projects and ends with methodological considerations.

\subsection{How much REDD+ is in the projects?}

The core principles of REDD+ are financial compensation for the consequences of avoided deforestation and degradation by developed countries. They are based on a set of novel mechanisms and tools that include result-based financial transfers, specific monitoring systems, dedicated institutions, reference levels as benchmarks for emission reductions, permanence of the reductions and avoided emission displacement (leakage) in order to guarantee for climate effectiveness (UNFCCC, 2013). Our review shows either negative experience or low implementation and negligence of these REDD + core topics in most of the reviewed studies. Specifically, results-based financing has been implemented to a rather low extent and most authors remain undecided on its future potential. Responsible institutions were rated as being hardly operational. The authors acknowledge the development of monitoring systems as proceeding slowly. Astonishingly, reference levels were only discussed by the CIFOR GCS and one additional study. Leakage and permanence were not dealt with at all. Based on our review it is hard to answer why these core themes of the REDD+ approach were not covered in the multitude of projects. It seems that either the voluntary standards applied are clear in this respect or that the topics are not perceived to be of high relevance on the project level.

In addition to these specific REDD + related topics, the Warsaw Framework includes tenure rights, participation, livelihood and biodiversity co-benefits as well as specific drivers of deforestation. These may be rather "old", but nevertheless urgent development topics, well known from integrated conservation and development projects (ICDP) and numerous other global initiatives. Surprisingly, these topics received greater attention and/or more positive ratings in the reviewed studies than specific REDD + topics like benefit sharing and resultsbased financing. Is REDD + at the ground level consistently just a new framework to tackle these issues? How much REDD + really remains beyond the safeguards and co-benefits? Is the program just old wine in new skins? Positively spoken, fears voiced by Buizer et al. (2014) whereby REDD + would displace progress on such topics by focusing on measurability of carbon stocks do not seem to be substantiated.

For effects on tenure rights, participation, biodiversity and drivers there is evidence for some positive effects in the so-called REDD+ projects. But the studies provide hints that these effects are not necessarily due to REDD + components of the projects which are obviously not (yet) operational in many cases. Simonet et al. (2014) note that socio-economic benefits are mostly not provided as co-benefits of the REDD+ procedure but through ICDP inputs in the same project. Thus, the reviewed studies reveal that in addition to creating new financing and accounting tools, REDD + obviously offers a platform to advance classical development issues.

\subsection{No breakthrough for results-based financing}

There is no doubt that the global financial potential falls short of what has originally been expected and what would be needed to implement the REDD + approach in the original extent. Norman and Nakhooda (2014) report on pledges of US\$8.7 billion for the period between 2006 and March 2014, but with the pace of new pledges slowing after 2010. After the COP in Lima 2014, pledges to the Green Climate fund passed the US\$10 billion mark. In contrast, the Eliasch Review had assumed "that the finance required to halve emissions from the forest sector by 2030 could be around US\$17-US\$33 billion per year" (Eliasch, 2008). Specifically, after 2011, there was a strong decline of project starts (Simonet et al., 2014) which is in line with a decline of donor financing to recipient countries after 2011 (REDD + Partnership, 2013).

This global situation has direct implications for the project level. The uncertainty has potentially prevented the broad implementation of results-based financing (Sunderlin et al., 2014). But on the other hand, and in the absence of success stories from the ground level, the reluctance of donor countries may be understandable. As long as the lessons learned from the pilot projects, related to conditional payments are negative it might be hard to mobilize the funds needed.

\subsection{Benefit sharing systems need to be country specific}

The scientific debate on incentive systems within the countries is controversial with different proposals being elaborated and argued for (Skutsch et al., 2011; Skutsch et al., 2013; Balderas Torres and Skutsch, 2012; Karsenty and Ongolo, 2012; Pfund et al., 2011; Vatn and Vedeld, 2013). It is obviously left to the countries to develop, test and implement own systems and these will certainly be country specific. Ha Hoang et al. (2013) present an example with substantial results based financing components for Vietnam, whereas Maraseni et al. (2014) for Nepal is an example proposing to shift away from market-based incentives to input-based support.

\subsection{Land tenure is always essential}

With regard to land tenure, an important global change in land use rights has been observed globally since the 1980s, with a number of countries granting new tenure rights to communities living in and around forests (Larson, 2011; Sunderlin, 2011; Agrawal, 2007). Also, the relevance of secure tenure for REDD+ has been mentioned frequently (Corbera et al., 2011; Resosudarmo et al., 2014; Karsenty and Assembe, 2011). The studies in this review confirm that REDD+ projects are intrinsically interwoven with national tenure situations, because on the one hand, REDD + depends on secure tenure rights and, on the other hand, may have a potential to foster ongoing tenure clarification and security. Lawlor et al. (2013) find this is an "important, transformational effect that projects can have - and likely more enduring than carbon payments". But on the other hand, REDD+ cannot "replace broader, national programs for land tenure reform" (Larson et al., 2013). In such national programs REDD+ will have to compete with other land use forms, which bears additional challenges (Brockhaus et al., 2012).

\subsection{No clear picture on socio-economic and biodiversity co-benefits}

Non-carbon benefits were discussed intensively at the most recent UNFCCC session in Bonn (Leonard, 2015), probably based on a wish to tackle additional immediate challenges like poverty and conservation issues within the existing framework. However, the question of whether and in how far REDD + projects provide socio-economic or biodiversity co-benefits can simply not be answered by this review, as many projects are mixtures of biodiversity, socio-economic and carbon components. But given the complex and slowly proceeding development and implementation of REDD +, the integration of additional biodiversity modules in REDD+ programs (Gardner et al., 2012) or a specific decoupling of biodiversity services (Potts et al., 2013) seems challenging. Project proponents and national REDD + managers should be aware of trade-offs between carbon and biodiversity or poverty (Potts et al., 2013; Phelps et al., 2012; Pistorius and Reinecke, 2013; Visseren-Hamakers et al., 2012, Lawlor et al., 2013).

\subsection{Real change needs to be transformational}

Transformational change is a keyword emphasized in the reviewed studies (Murdiyarso et al., 2012; Sunderlin et al., 2014; Brockhaus et al., 2014b; Fishbein and Lee, 2015) and probably the only basis on which sustainable development, including reduced emissions, can 
take place. (Brockhaus and Angelsen, 2012) define transformational change as a "shift in discourse, attitudes, power relations, and deliberate policy and protest action that leads policy formulation and implementation away from business as usual policy". Babon et al. (2014) list "more transparent and participatory policy processes, functioning multistakeholder governance arrangements, attention to equity and a review of existing or planned policies that enable deforestation" as more operational aspects of transformational change. The results of our study show that many of these components have not been satisfactorily implemented in REDD+ projects. Beyond these single components a fundamental change in perception, values and attitudes seems to be essential for real change (Hauser, 2014). Ownership (OECD, 2005) is another core condition. Within the reviewed papers, De Oliveira et al. (2014) report that "funding and the idea of forest-carbon projects [was] in all cases from international or outside organizations". Such financing may probably stimulate and support, but not automatically implement, transformational change. It also supports earlier findings showing globally that REDD+ was primarily steered and influenced by donor countries (Gallemore and Munroe, 2013).

\subsection{Can project experience provide recommendations for the national level?}

Project level experience with REDD+ is an important efficiency check for REDD + and we consider a review of existing experiences as necessary and essential. However, transferring project experience into policy recommendations has to consider that most of the reviewed projects are self-proclaimed REDD + projects, with differing REDD+ definitions and rather following certification standards and NGO guidelines but not necessarily the formal UNFCCC Warsaw Framework. UNFCCC, in contrast, has been designed for national scales and implementation will differ from project applications. Our approach to validate project experience by differentiating between top-down and bottomup conclusions could not add clarity here as the number of top down studies was too low. The ultimate reality check can thus only be based on the implementation which is hoped to be definitely launched in Paris 2015 (UNFCCC, 2015).

The representativeness of the projects needs to be questioned. Selection criteria either tend to prioritize project areas which are more promising for earning carbon credits or simply rely on existing projects. De Oliveira et al. (2014) explicitly mention that, "one reason for the inexistence of conflicts in the projects may have been that the proponents may have had as criteria to choose areas for the initiative where there is no land tenure conflict." Lawlor et al. (2013) study CCBA certified projects only and the study has good scores for tenure and participation. But it may be assumed that these CCBA projects are best case scenarios and most likely not representative for all non-Annex I countries. Sills et al. (2014) evaluate the representativeness of the CIFOR GCS projects by comparing key features to the full set of REDD + projects given by Simonet et al. (2014), but the representativeness of the latter remains open.

Many projects did not explicitly compare their observed outcomes to a reference scenario when reporting their impacts. The CIFOR GCS project is the only one that explicitly assesses and reports control data, but only for one of the GCS studies (Sunderlin et al., 2014).

\section{Conclusions and outlook}

Based on a review of 17 multinational studies we show that implementation of REDD + in readiness phases and projects on the ground level is proceeding rather slowly. Project experience is not convincing for key topics such as 'results based finance', 'institutions', 'incentives', 'monitoring systems' and 'jurisdictional approaches' or is hardly reported in the case of 'reference levels', 'leakage' and 'permanence'. There is, however, progress in classical development topics such as 'tenure rights', 'participation' and 'biodiversity'.
Despite substantial international efforts and support, the development of REDD + on the ground has in many cases not yet succeeded in acquiring results-based financing. Also the future potential and role of such financing mechanisms remains open. Some projects claim that they need more time to develop these mechanisms from a bottom-up approach. However, signals from the political process under UNFCCC are also required in a top-down approach. Especially in the context of the upcoming COP in Paris, this is essential to encourage further development and implementation. Stronger financial commitments and a release of funds for national implementation of REDD + would thus have a stimulating effect for activities on the project level.

The positive effects of REDD + activities on 'tenure clarification' and 'participation' and to some extent also on 'socioeconomic co-benefits' and 'biodiversity' can partly be attributed to the positive legacy of previous project phases under official development assistance. We conclude that through these 'safeguards' REDD + initiatives are, on the one hand, successfully linked to essential development topics. However, on the other hand, there is slow progress in core REDD+ aspects. This implies the danger that initiatives are losing the carbon storage and emission reduction focus even when they are sailing under the REDD+ flag. Harmonized safeguard reporting and impact assessments are needed to disentangle effects of REDD+ activities and mostly older, input-based, project components.

Climate efficiency can only be ensured if 'permanence' of the emission reduction is guaranteed and 'leakage' is avoided. These issues were hardly considered in the reviewed studies, indicating that they require stronger attention in the projects and probably also in the subsequent national implementation. Whereas there is a clear methodology in the context of accreditation for the voluntary carbon market, it is unclear how these issues are tackled in numerous self-proclaimed REDD+ projects. In order to link projects to sub-national (and in the future also to national) levels, jurisdictional approaches need to be further elaborated and clear guidance would also be needed under UNFCCC on how to account, monitor and share benefits across scales. Specifically for 'benefit sharing' it became clear that country specific-solutions need to be elaborated and one-size-fits-all approaches are not desirable. 'Monitoring systems' remain a crucial backbone for REDD+. The studies show that technical MRV cooperation also between countries of the South is promising and should be further supported. The broad range of topics touched by REDD + calls for improved cross sectoral coordination between 'institutions', specifically as institutional development was reported to be weak in most reviewed articles.

Research in the REDD + arena is complex with consequently high requirements on availability, transparency and reliability of data sets. Its geographical scope is global and it needs to be interdisciplinary due to the wide range of topics. Most of the reviewed studies focused only on a small number of selected REDD + topics. Our review is restricted to transnational studies, leaving aside the huge amount of information which we showed to be publicly available from various sources for over 300 projects (Supplementary material, Table A). It remains a rewarding challenge to elaborate on these specifically with approaches going beyond summarizing descriptions. From a methodological point of view, it might be challenging to consider how to use such a large "found sample" (Overton et al., 1993) in order to derive reliable and valid results.

Only one of our studies used reference scenarios (Sunderlin et al., 2014), which is essential to show the effects of REDD + and which should be considered for additional studies. More research is needed related to what we called 'top down' approaches, i.e. national activities, such as readiness phases, impacts of REDD + strategies, or hopefully in the near future related to payments for verified emission reductions on national level in final REDD + phases. Only then can we learn about impact and possible success of REDD + in complex reality and not only in the laboratories of single projects.

A number of reviewed studies underline the relevance of transformational change if REDD + is to have sustained effects. On the long 
term such change leads away from business-as-usual scenarios and must be accompanied by a fundamental shift in perception, values and attitudes. Transformational change is hardly measurable and therefore rightly not included in the Warsaw Framework. Nevertheless, it is an important topic for both science and practice. Transformational change is evidently necessary for the idea of REDD + to be translated into practice on a scale that makes a difference.

Supplementary data to this article can be found online at http://dx. doi.org/10.1016/j.forpol.2015.11.003.

\section{References}

Agrawal, A., 2007. Forests, governance, and sustainability: common property theory and its contributions. Int. J. Commons 1 (1), 111.

Angelsen, A., Boucher, D., Brown, S., Merckx, V., Streck, C., Zarin, D., 2011. Modalities for REDD + Reference Levels: Technical and Procedural Issues. Meridian Institute.

Angelsen, A., Brockhaus, M., Sunderlin, W.D., Verchot, L., 2012. Analysing REDD +. Challenges and Choices. CIFOR, Bogor.

Arhin, A.A., 2014. Safeguards and Dangerguards: a Framework for Unpacking the Black Box of Safeguards for REDD +. Forest Policy and Economics 45 pp. 24-31. http://dx. doi.org/10.1016/j.forpol.2014.05.003.

Awono, A., Somorin, O.A., Eba'a Atyi, R., Levang, P., 2014. Tenure and Participation in Local REDD + Projects: Insights From Southern Cameroon. Environmental Science \& Policy 35 pp. 76-86. http://dx.doi.org/10.1016/j.envsci.2013.01.017.

Babon, A., McIntyre, D., Gowae, G.Y., Gallemore, C., Carmenta, R., Di Gregorio, M. Brockhaus, M., 2014. Advocacy coalitions, REDD +, and forest governance in Papua New Guinea: how likely is transformational change? Ecol. Soc. 19 (3). http://dx.doi. org/10.5751/ES-06486-190316.

Balderas Torres, A., Skutsch, M., 2012. Splitting the Difference: a Proposal for Benefit Sharing in Reduced Emissions From Deforestation and Forest Degradation (REDD+). Forest 3 (4) pp. 137-154. http://dx.doi.org/10.3390/f3010137.

Brockhaus, M., Angelsen, A., 2012. Seeing REDD + through 4Is analysing REDD + (2012) In: Angelsen, A., Brockhaus, M., Sunderlin, W.D., Verchot, L. (Eds.), Analysing REDD + Challenges and Choices. CIFOR, Bogor.

Brockhaus, M., Di Gregorio, M., 2014. Ecology \& Society 19 (4). http://dx.doi.org/10.5751/ ES-06643-190414.

Brockhaus, M., Di Gregorio, M., Carmenta, R., 2014a. REDD+ Policy Networks: Exploring Actors and Power Structures in an Emerging Policy Domain. Ecology \& Society 19 (4) http://dx.doi.org/10.5751/ES-07098-190429.

Brockhaus, M., Di Gregorio, M., Mardiah, S., 2014b. Governing the Design of National REDD +: an Analysis of the Power of Agency. Forest Policy and Economics 49 pp. 23-33. http://dx.doi.org/10.1016/j.forpol.2013.07.003.

Brockhaus, M., Obidzinski, K., Dermawan, A., Laumonier, Y., Luttrell, C., 2012. An Overview of Forest and Land Allocation Policies in Indonesia: is the Current Framework Sufficient to Meet the Needs of REDD + ? Foreign Policy Economics 18 pp. 30-37. http://dx.doi.org/10.1016/j.forpol.2011.09.004

Buizer, M., Humphreys, D., Jong, W.d., 2014. Climate Change and Deforestation: the Evolution of an Intersecting Policy Domain. Environmental Science \& Policy 35 pp. 1-11.

Caplow, S., Jagger, P., Lawlor, K., Sills, E., 2011. Evaluating Land Use and Livelihood Impacts of Early Forest Carbon PROJECTS: LESSONS for Learning About REDD +. Environmental Science \& Policy 14 (2) pp. 152-167. http://dx.doi.org/10.1016/j.envsci.2010.10. 003.

Castro, F.G., Kellison, J.G., Boyd, S.J., Kopak, A., 2010. A Methodology for Conducting Integrative Mixed Methods Research and Data Analyses. Journal of mixed methods research 4 (4) pp. 342-360. http://dx.doi.org/10.1177/1558689810382916.

Cerbu, G.A., Swallow, B.M., Thompson, D.Y., 2011. Environmental Science \& Policy 14 (2), 168-180. http://dx.doi.org/10.1016/j.envsci.2010.09.007.

Climate Law\&Policy, 2014. Unpacking the "Warsaw Framework for REDD +". Briefing Note (Online under http://theredddesk.org/sites/default/files/resources/pdf/cop19_ assessment_by_clp_2014.pdf, last visited January 2015).

Corbera, E., Schroeder, H., 2011. Governing and Implementing REDD +. Environmental Science \& Policy 14 (2) pp. 89-99. http://dx.doi.org/10.1016/j.envsci.2010.11.002.

Corbera, E., Estrada, M., May, P., Navarro, G., Pacheco, P., 2011. Rights to Land, Forests and Carbon in REDD +: Insights from Mexico, Brazil and Costa Rica. Forest 2 (4) pp. 301-342. http://dx.doi.org/10.3390/f2010301.

Cromberg, M., Duchelle, A., Rocha, I., 2014. Local Participation in REDD+: Lessons From the Eastern Brazilian amazon. Forest 5 (4) pp. 579-598. http://dx.doi.org/10.3390/ f5040579.

De Oliveira, J.A.P., Telwala, Y., Ma, H.-O., Rastall, R., 2014. Strengthening Development in International-Local Institutional Linkages in REDD +: Lessons From Existing ForestCarbon Initiatives. United Nations University, Tokyo, Japan (UNU-IAS Policy Report, 2014/13)

Dokken, T., Caplow, S., Angelsen, A., Sunderlin, W., 2014. Tenure Issues in REDD + Pilot Project Sites in Tanzania. Forest 5 (2) pp. 234-255. http://dx.doi.org/10.3390/ f5020234.

Duchelle, A.E., Cromberg, M., Gebara, M.F., Guerra, R., Melo, T., Larson, A., et al., 2014 Linking Forest Tenure Reform, Environmental Compliance, and Incentives: Lessons From REDD + Initiatives in the Brazilian Amazon. World Development 55 pp. 53-67. http://dx.doi.org/10.1016/j.worlddev.2013.01.014.

Eliasch, J., 2008. Climate Change: Financing Global Forests. Office of Climate Change, 2012 London (https://www.gov.uk/government/uploads/system/uploads/attachment data/file/228833/9780108507632.pdf, last visited January 2015).
Elo, S., Kääriäinen, M., Kanste, O., Pölkki, T., Utriainen, K., Kyngäs, H., 2014. Qualitative content analysis. SAGE Open 4 (1).

FAO, 2010. Global Forest Resources Assessment 2010. Food and Agriculture Organization, Rome ((FAO Forestry Paper, 163). http://www.fao.org/docrep/013/i1757e/i1757e. pdf, last visited January 2015).

FCPF \& UN-REDD, 2012. Country needs assessment: a report on REDD + Readiness among UN-REDD programme and Forest Carbon Partnership Facility member countries UNREDD/PB9/2012/II/6 Forest Carbon Partnership Facility, UN-REDD.

Fishbein, G., Lee, D., 2015. Early Lessons from Jurisdictional REDD + and Low Emissions Development Programs. The Nature Conservancy, FCPF, World Bank Group (http:// www.nature.org/media/climatechange/REDD+_LED_Programs.pdf, last visited February 2015).

Gallemore, C., Munroe, D.K., 2013. Centralization in the Global Avoided Deforestation Collaboration Network. Global Environmental Change 23 pp. 1199-1210. http://dx. doi.org/10.1016/j.gloenvcha.2013.04.004.

Gardner, T.A., Burgess, N.D., Aguilar-Amuchastegui, N., Barlow, J., Berenguer, E., Clements, T., et al., 2012. A Framework for Integrating Biodiversity Concerns Into National REDD + Programmes. Biological Conservation 154 pp. 61-71. http://dx.doi.org/10. 1016/j.biocon.2011.11.018

Gebara, M.F., 2013. Importance of local participation in achieving equity in benefitsharing mechanisms for REDD + : a case study from the Juma Sustainable Development Reserve. International Journal of the Commons 7 (2).

GFW, 2015. Climate Domains Ranked in Order of Greatest Tree Cover Loss. Internet Analysis. (Washington, DC. http://www.globalforestwatch.org/countries/overview, last visited January 2015)

Giessen, L., Buttoud, G., 2014. Defining and Assessing Forest Governance. Forest Policy and Economics 49 pp. 1-3. http://dx.doi.org/10.1016/j.forpol.2014.11.009.

Goers Williams, L., 2013. Putting the Pieces Together for Good Governance of REDD +. An Analysis of 32 REDD + Country Readiness Proposals. WRI, Washington, DC. (http:// www.wri.org/sites/default/files/pdf/putting_the_pieces_together_for_good governance of redd.pdf, last visited March 2015).

Goldstein, A., Gonzalez, G., Peters-Stanley, M., 2014. Turning Over a New Leaf, State of the Forest Carbon Markets 2014. Ecosystem Marketplace, Washington, D.C., USA (http:// www.forest-trends.org/documents/files/doc_4770.pdf, last visited January 2015).

Ha Hoang, M., Hoan Do, T.T., Thoa Pam, M.M., van Noordwijk, M.M., Minang, P.P.A.A., 2013. Benefit distribution across scales to reduce emissions from deforestation and forest degradation (REDD+) in Vietnam. Land Use Policy 31, pp. 48-60.

Hauser, M, 2014. Transformative Change Towards Sustainable Livelihoods - Too Big for Development-oriented Research? Paper presented at the Tropentag, Prague. (http:// www.tropentag.de/2014/proceedings/proceedings.pdf).

Hosonuma, N., Herold, M., Sy, V.d., Fries, D., Ruth, S., Brockhaus, M., Verchot, L., et al., 2012. An Assessment of Deforestation and Forest Degradation Drivers in Developing Countries. Environmental Research Letters 7 p. 044009. http://dx.doi.org/10.1088/ $1748-9326 / 7 / 4 / 044009$

IPCC, 2014. Chapter 11: Agriculture, Forestry and Other Land Use (AFOLU). Climate Change 2014 : Mitigation of Climate Change (http://report.mitigation2014.org/ drafts/final-draft-postplenary/ipcc_wg3_ar5_final-draft_postplenary_chapter11.pdf, last visited March 2015).

Iverson, P., Lee, D., Rocha, M., 2014. Understanding Land Use in the UNFCCC. (http:// www.climateandlandusealliance.org/uploads/PDFs/Understanding_Land_Use_in_ the_UNFCCC.pdf, last visited March 2015).

Jagger, P., Brockhaus, M., Duchelle, A., Gebara, M., Lawlor, K., Resosudarmo, I., Sunderlin, W., 2014. Multi-Level Policy Dialogues, Processes, and Actions: Challenges and Opportunities for National REDD + Safeguards Measurement, Reporting, and Verification (MRV). Forest 5 pp. 2136-2162. http://dx.doi.org/10.3390/f5092136.

Joseph, S., Herold, M., Sunderlin, W.D., Verchot, L.V., 2013. REDD + Readiness: Early Insights on Monitoring, Reporting and Verification Systems of Project Developers. Environmental Research Letters 8 p. 034038. http://dx.doi.org/10.1088/1748-9326/ 8/3/034038.

Kanowski, P.J., McDermott, C.L., Cashore, B.W., 2011. Implementing REDD +: Lessons From Analysis of Forest Governance. Environmental Science \& Policy 14 pp. 111-117. http://dx.doi.org/10.1016/j.envsci.2010.11.007.

Karsenty, A., Assembe, S., 2011. Land Tenure and REDD + in Central Africa. Land Tenure Journal 2 pp. 105-129 (http://www.fao.org/nr/tenure/land-tenure-journal/index. php/LTJ/article/view/35/75)

Karsenty, A Ongolo, S., 2012 Can "Fragile States" Decide to Reduce Their Deforestation? The Inappropriate Use of the Theory of Incentives With Respect to the REDD Mechanism. Foreign Policy and Economics 18 pp. 38-45. http://dx.doi.org/10.1016/j.forpol. 2011.05.006.

Kohlbacher, F., 2006. The use of qualitative content analysis in case study research. Forum Qual. Sozialforschung/Forum: Qual. Soc. Res. 7 (1)

Korhonen-Kurki, K., Sehring, J., Brockhaus, M., Di Gregorio, M., 2014. Enabling Factors for Establishing REDD + in a Context of Weak Governance. Climate Policy 14 pp. 167-186. http://dx.doi.org/10.1080/14693062.2014.852022.

Larson, A.M., 2011. Forest Tenure Reform in the Age of Climate Change: Lessons for REDD +. Global Environmental Change 21 (2) pp. 540-549. http://dx.doi.org/10. 1016/j.gloenvcha.2010.11.008

Larson, A.M., Brockhaus, M., Sunderlin, W.D., Duchelle, A., Babon, A., Dokken, T., et al., 2013. Land Tenure and REDD +: the Good, the Bad and the Ugly. Global Environmental Change 23 (3) pp. 678-689. http://dx.doi.org/10.1016/j.gloenvcha.2013.02.014.

Lawlor, K., Madeira, E., Blockhus, J., Ganz, D., 2013. Community Participation and Benefits in REDD + : a Review of Initial Outcomes and Lessons. Forest 4 (2) pp. 296-318. http://dx.doi.org/10.3390/f4020296.

Leonard, S., 2015. The REDD + Framework: Finally Complete After Almost 10 Years. CIFOR (Internet Blog,. http://blog.cifor.org/29000/the-redd-framework-finally-completeafter-almost-10-years\#.VXr1jUYX-B0, last visited June 2015). 
Luttrell, C., Loft, L., Fernanda Gebara, M., Kweka, D., Brockhaus, M., Angelsen, A., Sunderlin W.D., 2013. Who Should Benefit From REDD+? Rationales and Realities. Ecology \& Society 18. http://dx.doi.org/10.5751/ES-05834-180452.

Maraseni, T.N., Neupane, P.R., Lopez-Casero, F., Cadman, T., 2014. An Assessment of the Impacts of the REDD + Pilot Project on Community Forests User Groups (CFUGs) and Their Community Forests in Nepal. Journal of Environmental Management 136 pp. 37-46. http://dx.doi.org/10.1016/j.jenvman.2014.01.011.

Mayring, P., 2000. Forum: Qual. Soc. Res. 1 (2) (Art 25. http://nbn-resolving.de/urn:nbn: de:0114-fqs0002204).

Mayring, P., 2014. Qualitative Content Analysis: Theoretical Foundation, Basic Procedures and Software Solution. Open Access Repository, Klagenfurt (http://nbn-resolving.de/ urn:nbn:de:0168-ssoar-395173).

Minang, P.A., van Noordwijk, M., Duguma, L.A., Alemagi, D., Do, T.H., Bernard, F., et al., 2014. REDD + Readiness Progress Across Countries: Time for Reconsideration. Climate Policy 14 pp. 685-708. http://dx.doi.org/10.1080/14693062.2014.905822.

Morgan, J., Waskow, D., Dagnet, Y., McGray, H., Elliott, C., Ballesteros, A., Anderson, J., Lefevre, B., 2014. COP20 Lays the Groundwork for Paris Climate Pact: 7 Key Developments. World Resources Institute (Internet Blog, http://www.wri.org/blog/2014/12 / cop20-lays-groundwork-paris-climate-pact-7-key-developments, last visited January 2015).

Murdiyarso, D., Brockhaus, M., Sunderlin, W.D., Verchot, L., 2012. Some Lessons Learned From the First Generation of REDD + Activities. Current Opinion in Environmental Sustainability 4 pp. 678-685. http://dx.doi.org/10.1016/j.cosust.2012.10.014.

Nepstad, D., Irawan, S., Bezerra, T., Boyd, W., Stickler, C., Shimada, J., et al., 2014. More Food, More Forests, Fewer Emissions, Better Livelihoods: Linking REDD +. Sustainable Supply Chains and Domestic Policy in Brazil, Indonesia and Colombia. Carbon Management 4 (6) pp. 639-658. http://dx.doi.org/10.4155/CMT.13.65.

Nguon, P., Kulakowski, D., 2013. Natural Forest Disturbances and the Design of REDD+ Initiatives. Environmental Science \& Policy 33 pp. 332-345. http://dx.doi.org/10. 1016/j.envsci.2013.04.011.

Norman, M., Nakhooda, S., 2014. The State of REDD + Finance. (Working Paper, 378). Center for Global Development, Washington, DC (http://www.cgdev.org/sites/ default/files/CGD_Climate_Forests_5-State_REDD_Forests-Norma_Nakhooda.pdf, last visited January 2015).

OECD, 2005. The Paris Declaration on Aid Effectiveness. Ownership, Harmonisation, Alignment, Results and Mutual Accountability (Paris).

Overton, J.M., Young, T.C., Overton, W.S., 1993. Using 'found' data to augment a probability sample: procedure and case study. Environ. Monit. Assess. 26, 65-83.

Pfund, J.-L., Watts, J.D., Boissière, M., Boucard, A., Bullock, R.M., Ekadinata, A., et al., 2011. Understanding and integrating local perceptions of trees and forests into incentives for sustainable landscape management. Environmental Management 48, pp. 334-349. http://dx.doi.org/10.1007/s00267-011-9689-1.

Phelps, J., Friess, D.A., Webb, E.L., 2012. Win-Win REDD + Approaches Belie CarbonBiodiversity Trade-offs. Biological Conservation 154 pp. 53-60. http://dx.doi.org/10. 1016/j.biocon.2011.12.031.

Pistorius, T., Reinecke, S., 2013. The Interim REDD + Partnership: Boost for Biodiversity Safeguards? Foreign Policy and Economics 36 pp. 80-86. http://dx.doi.org/10.1016/ j.forpol.2012.10.007

Potts, M.D., Kelley, L.C., Doll, H.M., 2013. Maximizing Biodiversity Co-benefits Under REDD +: a Decoupled Approach. Environ. Res. Lett. 8 (2) p. 024019. http://dx.doi. org/10.1088/1748-9326/8/2/024019.

REDD+ Partnership, 2013. Towards Transparency in Public Financing for REDD +. An Analysis of Data Submitted to the Voluntary REDD + Database. (http://www.fao. org/forestry/vrd/process_reports/VRD_Analytic_Report_2013.pdf).

Resosudarmo, I.A.P., Atmadja, S., Ekaputri, A.d., Intarini, D.Y., Indriatmoko, Y., Astri, P., 2014. Does Tenure Security Lead to REDD + Project Effectiveness? Reflections From
Five Emerging Sites in Indonesia. World Development 55 pp. 68-83. http://dx.doi. org/10.1016/j.worlddev.2013.01.015.

Robiglio, V., Armas, A.D., Silva Aguad, C., White, D., 2014. Beyond REDD + Readiness: Land-use Governance to Reduce Deforestation in Peru. Climate Policy 14 (6) pp. 734-747. http://dx.doi.org/10.1080/14693062.2014.962467.

Romijn, E., Herold, M., Kooistra, L., Murdiyarso, D., Verchot, L., 2012. Assessing capacities of non-Annex I countries for national forest monitoring in the context of REDD + Environmental Science \& Policy 19-20, pp. 33-48. http://dx.doi.org/10.1016/j. envsci.2012.01.005.

Sills, E.O., Atmadja, S., Sassi, C.d., Duchelle, A.E., Kweka, D.L., Resosudarmo, I.A.P., Sunderlin, W.D., 2014. REDD + on the Ground. A Case Book of Subnational Initiatives Across the Globe. CIFOR, Bogor.

Simonet, G., Karsenty, A., Perthuis, C.d., Newton, P., Schaap, B., 2014. REDD + Projects in 2014: an Overview Based on a New Database and Typology. Paris-Dauphine University, Climate Economics Chair. Information and Debate Series 32, Paris.

Skutsch, M., Simon, C., Velazquez, A., Fernandez, J.C., 2013. Rights to Carbon and Payments for Services Rendered Under REDD +: Options for the Case of Mexico. Global Environmental Change 23 pp. 813-825.

Skutsch, M., Vickers, B., Georgiadou, Y., McCall, M., 2011. Alternative Models for Carbon Payments to Communities Under REDD +: a Comparison Using the Polis Model of Actor Inducements. Environmental Science \& Policy 14 (2) pp. 140-151. http://dx. doi.org/10.1016/j.envsci.2010.12.005.

Sunderlin, W.D., 2011. The global forest tenure transition: background, substance and prospects. In: Sikor, T., Stahl, J. (Eds.), Forests and People. Earthscan, London.

Sunderlin, W.D., Ekaputri, A.d., Sills, E.O., et al., 2014. The Challenge of Establishing REDD + on the Ground. Insights from 23 Subnational Initiatives in Six Countries. CIFOR ((Occasional Paper, 104). http://www.cifor.org/publications/pdf_files/ OccPapers/OP-104.pdf, last visited January 2015).

UNFCCC, 2007a. Decision 2/CP.13. Reducing Emissions From Deforestation in Developing Countries: Approaches to Stimulate Action. (http://www.unfccc.int/resource/docs/ 2007/cop13/eng/06a01.pdf\#page=8, (last visited January 2015).

UNFCCC, 2007b. Decision 2/CP.13: Reducing Emissions From Deforestation in Developing Countries: Approaches to Stimulate Action. FCCC/CP/2007/6/Add.1 (http://www. unfccc.int/resource/docs/2007/cop13/eng/06a01.pdf\#page=8, last visited May 2015).

UNFCCC 2011. Decision 1/CP.16. The Cancun Agreements: Outcome of the Work of the Ad Hoc Working Group on Long-term Cooperative Action under the Convention. FCCC/CP/2010/7/Add.1 (http://www.unfccc.int/resource/docs/2010/cop16/eng/ 07a01.pdf, last visited May 2015).

UNFCCC, 2013. Warsaw Framework for REDD +. Decisions 9-15/CP.19. (http://www. unfccc.int/land_use_and_climate_change/redd/items/8180.php, last visited May 2015).

UNFCCC, 2015. Press Release: Rising Number of Initiatives by Cities and Better Land Management Show Pathways Towards Carbon Neutral Future. (Bonn. http://www. newsroom.unfccc.int/media/1605/pr20141506_sb40_close.pdf, last visited June 2015).

Vatn, A., Vedeld, P.O., 2013. National Governance Structures for REDD+. Global Environmental Change 23 (2) pp. 422-432. http://dx.doi.org/10.1016/j.gloenvcha.2012.11. 005.

Visseren-Hamakers, IJ., McDermott, C., Vijge, M.J., Cashore, B., 2012. Trade-offs, Cobenefits and Safeguards: Current Debates on the Breadth of REDD +. Current Opinion in Environmental Sustainability 4 (6) pp. 646-653. http://dx.doi.org/10.1016/j.cosust. 2012.10.005. 


\title{
Exploring patterns of forest governance quality: Insights from forest frontier communities in Zambia's Miombo ecoregion
}

\author{
Hellen Nansikombi ${ }^{\mathrm{a}, \mathrm{b}, *}$, Richard Fischer ${ }^{\mathrm{b}}$, Gillian Kabwe ${ }^{\mathrm{c}}$, Sven Günter ${ }^{\mathrm{a}, \mathrm{b}}$ \\ ${ }^{a}$ Chair of Ecosystem Dynamics and Forest Management, Department of Ecology and Ecosystem Services, TUM School of Life Sciences Weihenstephan, Technical University \\ of Munich, 85354 Freising, Germany \\ ${ }^{\mathrm{b}}$ Thünen Institute of International Forestry and Forest Economics, Leuschnerstraße 91, 21031 Hamburg, Germany \\ ${ }^{\mathrm{c}}$ Copperbelt University, School of Natural Resources, P.O Box 21692, Kitwe, Zambia
}

\section{A R T I C L E I N F O}

\section{Keywords:}

Forest governance

Governance of Forests Initiatives (GFI)

indicator framework

Community perceptions

Miombo ecoregion

\begin{abstract}
A B S T R A C T
Good forest governance is a prerequisite for sustainable forest management and the successful implementation of initiatives that aim to reduce deforestation and forest degradation. The necessity for good governance is high in Zambia's Miombo ecoregion, which is characterised by persistent deforestation that also threatens forest-dependent livelihoods. Zambia has adopted policies and initiatives to improve forest governance. We use the Governance of Forests Initiatives (GFI) indicator framework from the World Resource Institute in 24 communities in the Miombo ecoregion to examine Zambia's status in this respect. The Wilcoxon rank test is applied to compare the de facto governance performance between different arrangements with differing tenures and restrictions to forest access and use. We employ factor analysis to test the applicability of the GFI framework based on community perceptions and cluster analysis to examine whether patterns of community clusters reflect the governance structure of the provincial local government administration. Comparative results show low mean scores for governance indicators, which do not differ significantly between arrangements. This indicates a weak de facto forest governance performance across arrangements, specifically characterised by an inadequate enforcement of rules and restrictions on use, insufficient institutional financial, human and technical capacities and unsatisfactory participatory land use planning and forest policy-making processes. We recommend support for financial and technical institutional capacities combined with coordination mechanisms to permit the satisfactory enforcement of forest rules. Frequent monitoring, apprehension and graduated sanctions are proposed as part of the rule enforcement procedures. Stringent de jure requirements coupled with capacity building for participatory land use planning and public policy participation also need to be adopted. This would also contribute towards achieving targets for Zambia's climate change response strategy, national development plan 2017-2021 and REDD + preparedness phase. The factor analysis largely confirms the GFI framework's suitability for governance analysis on the ground since factors generally mirror GFI indicators. However, because de facto governance processes sometimes do not precisely reflect thematic areas of the framework, we warn against the use of single indicators to exclusively represent a thematic area. Similarly, specific attention has to be paid to customary rules and institutions when applying the GFI framework because compared to the framework, the respective aspects are more clearly differentiated on the ground. Cluster analysis reveals a high variability of governance processes within and across provinces. Decentralization measures should take into account clusters that may in some cases follow administrative levels or in other cases go beyond the established administrative boundaries. Specifically, initiatives to integrate customary structures into the decentralized governance structure should take these regional differences into account.
\end{abstract}

\section{Introduction}

Globally, forests are under enormous pressure from deforestation and forest degradation. Approximately 7.6 million hectares of forest are lost annually, especially in the poorest tropical regions (FAO, 2015).
Deforestation is a result of several factors, many of them related to poor forest governance (Eliasch, 2012; Umemiya et al., 2010; Kanninen et al., 2007; Kaimowitz, 2012), which has failed to regulate anthropogenic pressures. Deforestation is linked to increased greenhouse gas emissions (Seymour and Busch, 2016), the loss of a functioning forest

\footnotetext{
* Corresponding author at: Thünen Institute of International Forestry and Forest Economics, Leuschnerstraße 91, 21031 Hamburg, Germany

E-mail address: hellennansikombi@thuenen.de (H. Nansikombi).
} 
ecosystem (Millennium Ecosystem Assessment, 2003), and the deterioration of socio-economic conditions, particularly in Africa with its more than 160 million forest-dependent households (FAO, 2018). There is thus a need for improved forest governance, especially since governance is considered a precondition for sustainable forest management and for the successful implementation of global initiatives such as Reducing Emissions from Deforestation and Forest Degradation (REDD +), Payment for Ecosystem Services (PES) (Pettenella and Brotto, 2012) and forest landscape restoration (Mansourian, 2016).

The necessity for improved forest governance is high in countries like Zambia, which has alarmingly high deforestation rates with around $0.63 \%$ annual forest loss between 2000 and 2018 (Hansen et al., 2013; Global Forest Watch, 2018). The greatest loss is reported in the Miombo ecoregion, the most extensive forest type in Zambia, covering $45 \%$ of the total land area (Matakala et al., 2015). The Miombo is characterized by the dominance of Brachystegia, Julbernardia and Isoberlinia tree species (Matakala et al., 2015). The woodlands are of significant economic importance, providing a variety of ecosystem goods and services essential for human wellbeing including firewood, charcoal, timber and non-timber forest products (Turpie et al., 2015). The ecosystems are experiencing considerable deforestation due to charcoal production, firewood collection and clearing for farming (Kalinda et al., 2008). Deforestation not only threatens the livelihoods of rural Zambians, who derive nearly $44 \%$ of their income from the Miombo forest ecosystem goods and services (Kalaba, 2013), it also undermines Zambia's commitment towards the Aichi biodiversity targets, i.e. to reduce biodiversity loss through deforestation and forest degradation by $25 \%$ by 2020 (MLNREP, 2015).

Several definitions are proposed for governance. In general, recent definitions understand governance as a broad and comprehensive concept that goes far beyond governments. Common governance definitions all denote rules/structures, actors and processes/practices (Mansourian, 2017; Larson and Petkova, 2011; Broekhoven et al., 2012; Giessen and Buttoud, 2014; Kishor and Rosenbaum, 2012). A widely accepted forest governance definition "comprises a) all formal and informal, public and private regulatory structures, i.e. institutions consisting of rules, norms, principles, decision procedures, concerning forests, their utilisation and their conservation, b) the interactions between public and private actors therein and c) the effects of either on forests" (Giessen and Buttoud, 2014). Since it is difficult to cover all aspects within the methodology of one study, while simultaneously maintaining scientific rigour, the definition can be adapted to reflect the relevant aspects (Giessen and Buttoud, 2014). As our study does not reflect on effects on forests, we define forest governenace as the "norms, processes, instruments, people and organizations that control how people interact with forests" (Kishor and Rosenbaum, 2012). The concept of "forest governance" is operationalized by several indicator frameworks. They include the "framework for assessing and monitoring forest governance" of the Food and Agriculture Organization (Kishor and Rosenbaum, 2012), the "natural resource governance framework assessment guide" of the International Union for Conservation of Nature (Campese, 2016), and the "governance of forest initiatives indicator framework" of the World Resource Institute (Davis et al., 2013). While these frameworks do not offer direct inferences on the economic, ecological and social outcomes of governance systems, they provide a comprehensive understanding of governance processes that is likely to contribute to improvements in the quality of decision-making and implementation (Rauschmayer et al., 2009). The Governance of Forest Initiative (GFI) indicator framework is widely recommended for forest governance assessments given its comprehensive coverage, providing a series of indicators for analysing different dimensions of forest governance systems (Agung et al., 2014; Brito et al., 2009). Although primarily practise-oriented, we hypothesize that the the GFI framework builds on aspects necessary for applying the normative concept (Giessen and Buttoud, 2014) as a scientific analytical approach, i.e value judegments on desirable conditions within a methodological framework to provide recommendations towards selected ends. Thus, it permits the integration of scientific and practical aspects and provides added value to real world challenges. Moreover, while previous models underscore either actors (Hardin, 1968) or rules/institutions (Goodin, 1996; Ostrom, 1990) as the theoretical basis, the GFI framework, with its practise-oriented approach, is able to integrate both aspects (Arts et al., 2014) as, based on theoretical foundations of the governance concept, it includes agency and structure components (Fischer et al., 2020). It emphasiszes the diversity of actors, the links between formal and informal practises and the rules that shape governance (Davis et al., 2013).

A few scientific studies have utilized the GFI framework to quantitatively analyze progress towards proposed governance improvements: Agung et al. (2014) and Pettenella and Brotto (2012) analyse the impact of REDD + readiness on forest governance in Indonesia and the successful features for REDD + project organizations, respectively. Such progress needs to be assessed specifically for communities with diverse forest governance arrangements. This implies the need to scientifically test the applicability of the proposed indicators on the basis of community perceptions. Community perceptions can indicate the extent to which governance structures are legitimated by community members (DeCaro and Stokes, 2013). Community perceptions have also been found to correlate with local compliance with rules for common pool resource management (Jenny et al., 2007). Furthermore, community perceptions may capture the de facto reality that exists on the ground, which was found to differ substantially from the fact-based de jure notions of laws (Kaufmann et al., 2011). Although perceptionbased measures have been criticized as reflecting factors other than governance, such as economic performance or poverty (Kurtz and Schrank, 2007), Kaufmann et al. (2007) found this notion does not withstand empirical scrutiny.

Several African countries including Zambia have adopted policies and initiatives that take the importance of forest governance into account. In Zambia, the revised decentralization policy of 2013 provides for the devolution of decision-making power, functions, responsibilities and resources to the provincial, district and sub-district levels to improve the quality of service delivery at the sub-national level, including forest management (GRZ, 2002). Zambia also developed a national strategy for reducing emissions from deforestation and forest degradation (REDD +), which integrates strengthening forest governance in the preparatory phase (Matakala et al., 2015). Zambia's National development plan 2017-2021 similarly proposes improved forest governance as part of its strategies towards achieving sustainable forest use (Ministry of National Development Planning, 2017). The country has also developed strategies for the Convention on Biological Diversity, the United Nations Convention to Combat Desertification and the United Nations Framework Convention on Climate Change (Kalaba et al., 2014), all of which contribute to sustainable development goal 15 on sustainable forest management (United Nations, 2015). Moreover, Zambia's Forest Act of 2015 and Forest Policy of 2014 provide for the establishment of diverse forest governance arrangements. These range from (i) hierarchical command and control systems in state-owned National Forest Reserves and National Parks to (ii) participatory arrangements with restrictions of forest use and management in stateowned Local Forest Reserves, and Game Management Areas, to (iii) inclusion of communities, customary institutions and private entities into forest conservation initiatives in customary and private forests (GRZ, 2015a, 2015b). However, there has been almost no comparative examination of the governance status within these diverse arrangements. Given the co-existence of customary and formal institutions, with overlapping jurisdictions and operating within parallel customary and formal legislation (GRZ, 2015a, 2015b), it is imperative to understand how interrelationships amongst these distinct structures of authority shape forest governance outcomes in Zambia. As hypothesised by several scholars (e.g. ANDERSON et al., 1998; Rescher, 1993), conflicts between overlapping regulations and institutions are often 
inevitable. As this is likely to have implications on governance progress, knowledge about forest governance performance in Zambia is crucial for the further development of policy in the context of legal and institutional pluralism, which is typical for many African countries in the post-colonial era.

\section{Aims}

This study aims to contribute to a more robust understanding of forest governance assessment tools and governance structures and purposes to identify the possible influence of overlapping formal and customary administrative structures on de facto governance. Methodologically, we aim to draw conclusion on the applicability of the GFI framework at a community level. The study addresses three key research questions: (i) How does forest governance differ across different governance arrangements with differing tenure and restrictions to forest access and use? (ii) Given the broad and very comprehensive understanding of forest governance, does the GFI framework help to differentiate distinct aspects of forest governance based on the perception of the local population? (iii) Can communities be clustered into distinct groups of similar governance conditions? If so, does the pattern of community clusters reflect the governance structure of the provincial local government administration? By answering these questions, we aim to draw conclusions on the strengths and weaknesses of different restriction regimes as instruments of national policy implementation on the ground in communities, which are influenced by customary and governmental rules and actors.

\subsection{Forest administrative structure in Zambia}

Zambia's forest administration has been decentralized to provide citizens with more authority and power in decision-making at the local level. The central government agency with a legal mandate to manage forest resources is the Forest Department of the Ministry of Lands and Natural Resources. Forest department is responsible for formulating and reviewing all legislation related to forest management in addition to coordinating its implementation (Chileshe, 2001; Ministry of Tourism, Environment and Natural Resources, 2009). The sub-national government levels are structured into the provincial, district, and sub-district administration units i.e. area and ward (Fig. 1). Provincial and district units are responsible for formulating and enforcing by-laws, and facilitating the proper and smooth administration of forest estate, in accordance with the forestry policy and existing legal framework (Chileshe, 2001; Ministry of Tourism, Environment and Natural Resources, 2009). The district unit is additionally responsible for providing extension services, collecting revenues from the sale of forest products, the enforcement of regulation through licences and patrols, managing forest woodlots and plantations and coordinating and monitoring lower administrative levels (Chileshe, 2001). Currently, Zambia has 10 provinces and 117 districts, each comprising a district council, which is the main policy and decision-making body at the district level. At the sub district level, the council is represented by the Area Development Committees (ADCs). The ADCs are democratically elected, local governance structures that ought to work together with members in each ward to develop natural resource plans and participate in the management thereof (GZR, 2015). Although the ADCs are theoretically the official focal point of local collective action for the improvement of the environment and livelihoods on customary lands, these governance structures in reality appear to be dysfunctional and are not viewed as a political administrative unit in some communities (Mfune, 2013).

There is a strong customary administrative structure operating in parallel to the aforementioned political administration within each district that is guaranteed by the Constitution of the Republic of Zambia (Mason-Case, 2011). Customary administration is made up of 73 tribes headed by 240 chiefs, 8 senior chiefs and 4 paramount chiefs, who delegate rights and responsibilities to headpersons and sub-chiefs within their jurisdictions (Mason-Case, 2011). Traditional leaders are mandated to administer customary lands based on local traditions. Traditional leaders determine land use, access and user rights on customary land. The political administration often has little authority over traditional administration and must engage in consultations with traditional institutions before undertaking any activities on customary lands.

In practice, however, the central government is unwilling to relinquish power over protected forests to local governments (Mfune, 2013). Moreover, local government's financial, human and technical capacity to manage open forests is limited. Furthermore, local government's involvement in the governance of customary forests is constrained by the contradicting land tenure policies (Chikulo, 2009). While the Local Government Act of 1991 gives the district council a mandate to plan

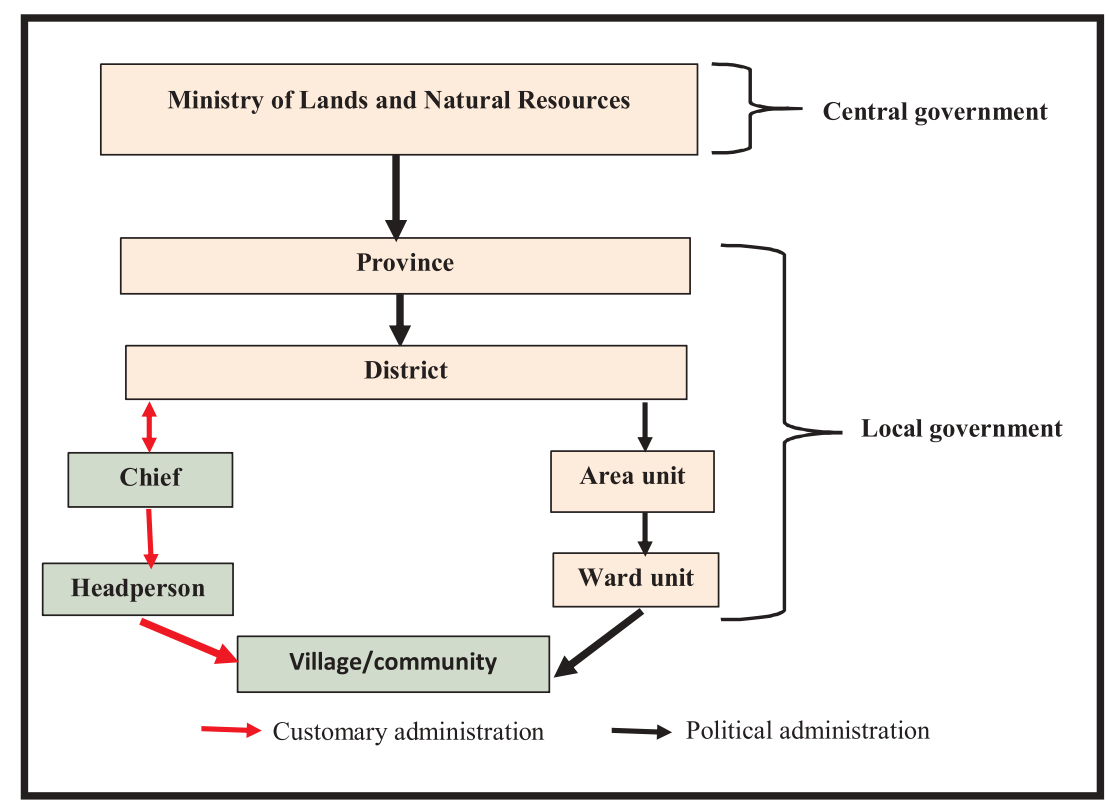

Fig. 1. Administrative units of central, local and traditional government in Zambia's decentralised forest governance structure (Chileshe, 2001, Ministry of Tourism, Environment and Natural Resources, 2009). 
and lead the management of customary forests, the Land Act of 1995 places the administration of these lands under customary authority. Besides, customary authorities sometimes challenge the authority of the sub-district governance structures (Mfune, 2013).

\subsection{Zambia's forest governance arrangements}

The forest governance arrangements of Zambia are grounded in the land reform of 1924, dating back to the colonial period. During this period, land in Zambia was demarcated into crown and native reserve land, designated for exclusive use by Africans and European settlers, respectively (Van Loenen, 1999; Brown, 2005). The chiefs administered forests on native reserves based on customary law. In contrast, forests on crown land were administered by the British colonial government based on formal law (Brown, 2005). At independence, customary land administration was sub-ordinated to formal law, which previously only applied to crown land. However, the method of customary land alienation continued under customary law. Following Zambia's independence in 1964, crown land was converted to state land and subsequently administered by the Ministry of Lands (Brown, 2005).

Zambia currently has various forest governance arrangements under the responsibility of different institutions, across different tenure categories and with differing access and use restrictions (Table 1). The majority (65.7\%) of Zambia's forest is on customary land as either individual or communal forests. These either have or lack cultural norms, such as graveyard forests, which are governed by chiefs and their representatives including village headpersons and sub-chiefs under customary law (GRZ, 2015a; Kalinda et al., 2008). Under formal law, the commercial use of forest products without a licence on customary lands is restricted, although access and subsistence use are not (GRZ, 2015a). Other forests (23.7 \%) in Zambia are located on state lands. State forests include National and Local Forest Reserves, administered by the Forest Department (GRZ, 2015a; Kalinda et al., 2008), as well as National Parks and Game Management Areas, administered by the Department of National Parks and Wildlife (GRZ, 2015b). Under formal law, access to and use of forest resources in state forests is restricted, except with special permits. Private forests also exist on state lands, which constitute $10.6 \%$ of the total forest area. These are owned by registered individuals or companies through leasehold tenure.

\section{Methods}

\subsection{Study sites and site selection}

The study was conducted in the Miombo woodland, which is the major forest type in Zambia, and employed a nested design to capture the diversity of communities in the Miombo ecoregion. Three provinces, namely Copperbelt, North Western and Eastern were selected to represent different socio-economic and demographic conditions as well as different forest cover and deforestation contexts (Table 2). North Western is characterised by a low population density of 6 persons $/ \mathrm{km}^{2}$ (Central Statistical Office, 2010), high forest cover (81.1\%) and low rate of forest loss (0.43\% annually) between 2000 and 2018 (Global Forest Watch, 2018), mostly from unsustainable timber extraction (Shakacite et al., 2016). According to the same sources, Eastern province has a medium population density of 31 persons $/ \mathrm{km}^{2}$, low forest cover (50.4\%) and a relatively low rate of forest loss ( $0.48 \%$ annually) between 2000 and 2018 (Global Forest Watch, 2018), mostly from small scale crop farming. Copperbelt is characterised by a very high population density of 63 persons $/ \mathrm{km}^{2}$, a medium to high forest cover (76.6\%) and high rate of forest loss (1.3\% annually) between 2000 and 2018, mostly from charcoal production.

Four landscapes each of $12 * 12 \mathrm{~km}$, with typical land-use, socioeconomic, demographic and biophysical attributes and a distinct traditional administration (chiefdom) were selected for the study within

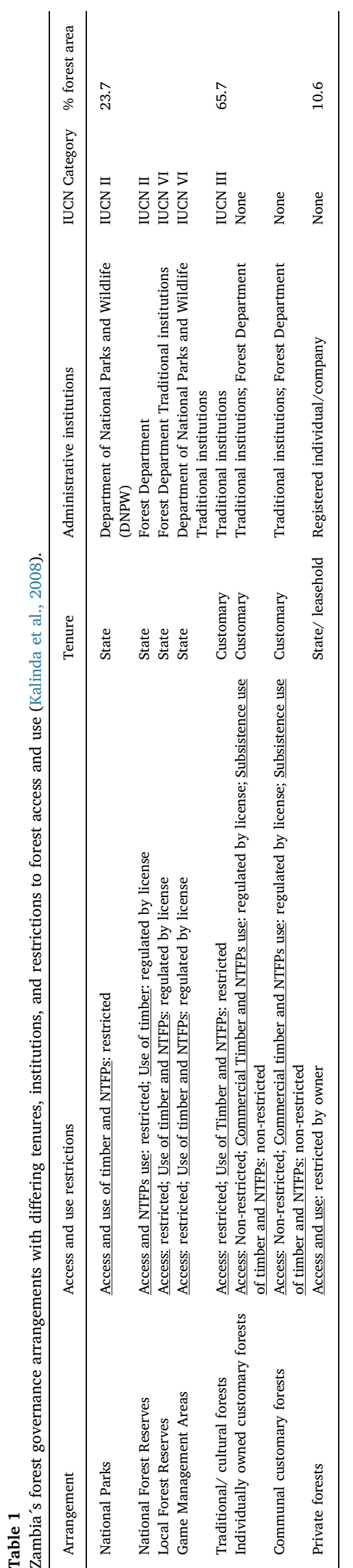


Table 2

Description of demographic, forest cover and deforestation attributes of study provinces (Global Forest Watch, 2018; Central Statistical Office, 2010; Shakacite et al., 2016).

\begin{tabular}{llll}
\hline Attributes & Copperbelt & North Western & Eastern \\
\hline $\begin{array}{l}\text { Forest area (\%) } \\
\text { Annual forest loss (\%) }\end{array}$ & 76.6 & 81.1 & 50.4 \\
$\begin{array}{c}\text { Population density } \\
\quad\left(\text { people } / \mathrm{km}^{2} \text { ) }\right.\end{array}$ & 63 & 0.43 & 0.48 \\
$\begin{array}{c}\text { Main driver of } \\
\text { deforestation }\end{array}$ & $\begin{array}{l}\text { Charcoal } \\
\text { production }\end{array}$ & $\begin{array}{l}\text { Unsustainable timber } \\
\text { extraction }\end{array}$ & $\begin{array}{l}\text { Small scale } \\
\text { farming }\end{array}$ \\
\hline
\end{tabular}

each of the three provinces, thus a total of 12 landscapes. Two communities within each landscape were selected for the study, thus a total of twenty-four communities (Fig. 2). Areas of distinct de jure governance arrangements, representing different tenure and restrictions to forest access and use, were identified a priori within the communities through scoping visits to the traditional headperson's offices and forest department maps. Five types of governance arrangements were identified:

i State forests with restrictions to access and use

ii Individual customary forests with no restrictions to access and use iii Communal customary forests with no restrictions to access and use iv Communal customary forests with cultural restrictions to access and use

v Private forests with use decided by the registered land owner

\subsection{Governance indicator assessment}

The study relies on the Governance of Forests Initiatives framework of the World Resource Institute. The GFI framework provides a comprehensive diagnostic tool that covers six core governance issues in forestry. These are: 1) forest tenure, 2) land use planning, 3) forest management, 4) forest revenues, 5) cross-cutting institutions and 6) cross-cutting issues, denoted as thematic areas (Davis et al., 2013). The framework assesses these governance areas through a set of detailed indicators, each specified by five elements of quality that are rated on a scale of pre-coded statements, ranging from lack of good governance to good practice.

The GFI framework recommends that the indicators should be "adapted based on contextual factors such as scale of assessment, type of forest biome, or ownership regime" from the large multitude of governance aspects covered. After a thorough literature analysis, coupled with a pre-test workshop conducted with 15 community participants in Zambia, we selected at least one indicator from each of the thematic areas, choosing those that reflect pertinent issues in Zambia's

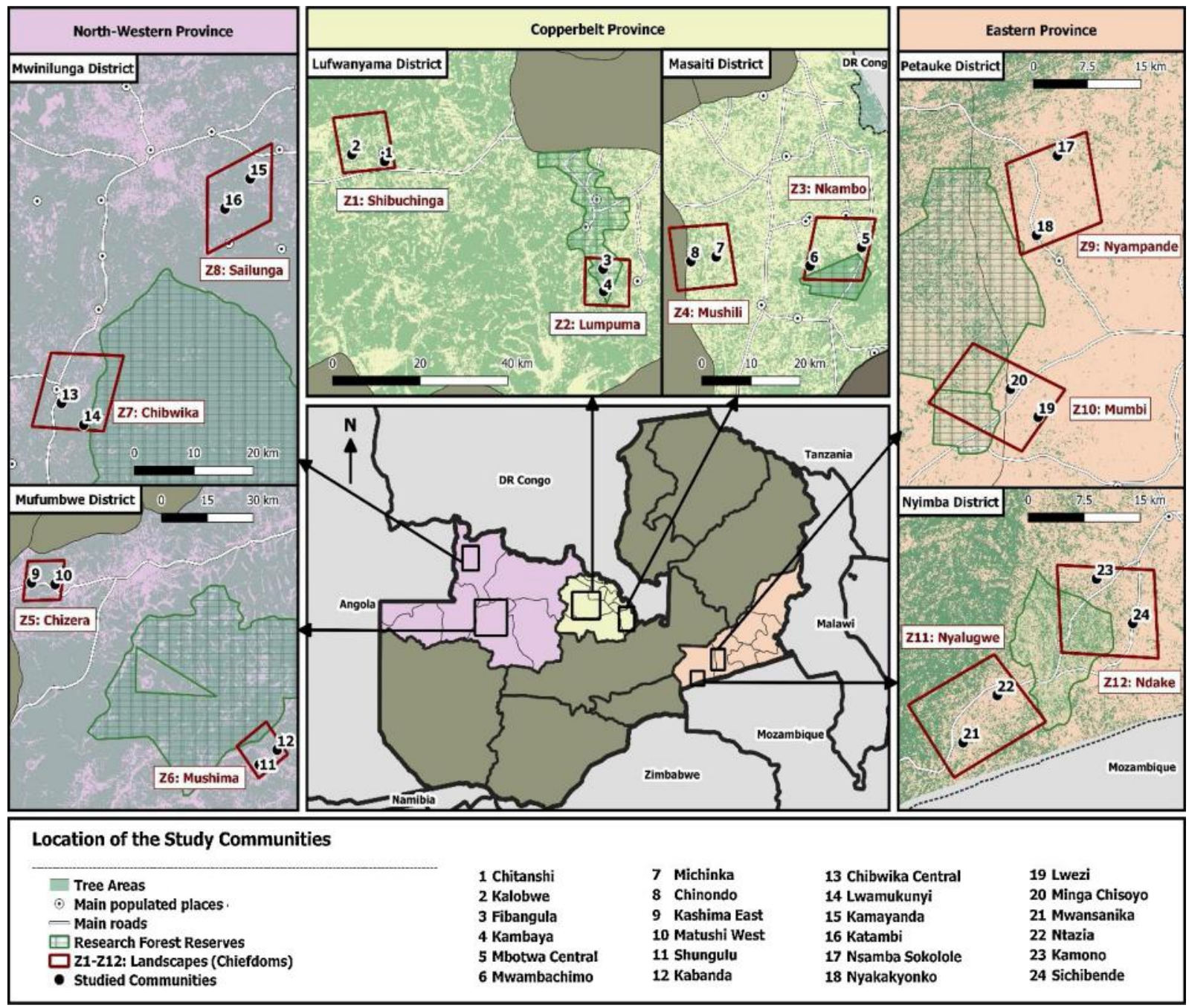

Fig. 2. Locations of the study provinces, landscapes and communities in Zambia. Landscapes are labelled according to the chiefdoms within which they are located. Sources: Tree Areas (ESA, 2017), main populated places (SERVIR, 2015), main roads (Center for International Earth Science Information Network et al., 2013) and Research Forest Reserves (UNEP-WCMC and IUCN, 2016). 
forest governance. We finally selected 19 quantitative governance indicators covering all thematic areas of the GFI and adapted them to the Zambian context as follows:

- Thematic area "forest tenure": (1) recognition and protection of tenure rights

- Thematic area "land use": (2) formal land use planning.

- Thematic area "forest management": (3) implementation of land use strategies and plans, administration of licences for (4) timber, (5) charcoal and, (6) non-timber forest products, implementation of (7) reforestation, (8) forest protection and conservation, (9) payment for ecosystem services, (10) sustainable, forest-based livelihood programs and enforcement of (11) formal and (12) customary forest laws.

- Thematic area "revenues": (13) forest revenue distribution and, (14) implementation of benefit sharing mechanisms.

- Thematic area "cross-cutting institutions": capacities and efficiencies of (15) central, (16) local government, (17) non-government organizations and (18) customary institutions

- Thematic area "cross-cutting issues": (19) public participation in policy-making.

A)

Each indicator was specified by five elements of quality (Appendix

Mapping of the governance arrangements on the ground and de facto scoring of governance elements of quality was carried out through focus group discussions. Mapping was essential to create an awareness of the different governance arrangements and to ensure correct spatially differentiated subsequent scoring for the different arrangements. Scoping visits were conducted in each landscape to organise the focus group discussions. These enabled the establishment of contacts to representatives from all communities and major stakeholder groups. Focus group discussions were carried out in all 24 communities, each with fifteen key stakeholder representatives including sub-village leaders, customary leaders and forest committee representatives. Participants comprised men, women, young people and long-term members of the community. During the focus group discussions, mapping was carried out on print outs of high-resolution Google satellite images of approximately 80*120 cm for the period November 2017 and October 2018. Prior to mapping, participants were asked to discuss the categories of governance arrangements within their community based on tenure, use restrictions and formal and customary institutions. When participants could distinguish between arrangements, they were tasked to map out the boundaries of each arrangement in their community. The mapping produced seventy three de facto governance polygons from the twenty four communities: 24 individual customary forests without access and use restrictions, 22 communal customary forest without access and use restrictions, 10 state forests with access and use restrictions, 8 communal customary forests with cultural access and use restrictions (in this case norms) and 9 private forests (Appendix B).

In the governance assessments, focus group participants were asked to discuss and agree on governance scores that were assigned to each of the governance polygons as Likert scores (Likert, 1932) on a scale from 0 (not present), 1 (very low) to 5 (very high) per element of quality (Appendix A). Likert scales transform qualitative data to quantitative data (Flynn et al., 1990). This permits the reliable integration of information across observations or cases (Kirk et al., 1986). Moreover, although criticized for producing ordinal data, Likert scales have been found to provide interval data that is suitable for parametric statistical analysis (Parker et al., 2002). It was not possible to establish contacts to private landowners to a meaningful extent, thus we could not score governance on private land. The Likert scores of all five elements of quality per indicator were aggregated as an arithmetic mean in order to derive indicator values for each of the governance polygons. All qualitative comments made for the governance scores were also noted.

\subsection{Data analysis}

A non-parametric, Wilcoxon rank test was applied to determine whether governance quality differed between the restricted state, nonrestricted communal customary, non-restricted individual customary and culturally restricted communal customary arrangements. This test is recommended for comparing mean ranks, when the assumption of data normality is violated (Bridge and Sawilowsky, 1999). Since the data remained skewed, even when a log transformation was performed, we applied this test.

We applied factor analysis (FA), using principal component factoring and varimax rotation methods, to examine the relationships between the elements of quality, indicators and thematic areas of the GFI framework. FA tests whether hypothesized constructs are represented by the measured variables by identifying variables that are correlated with each other (Byrne, 2016). Our aim here was to examine whether the factors reproduce the hypothesised relationships between the different elements of quality, indicators and thematic areas of the GFI. The eigenvalue criterion $(>1)$ was used to determine the number of factors. Based on recommendations from Comrey and Lee, 2013, only those variables with loadings of $0.5,-0.5$, or greater were considered significant items, and thus good indicators of a factor. To confirm whether the resulting factors represent their postulated measurement variables, we performed a bivariate correlation analysis between the loadings of the assigned factors and the respective mean Likert scores of the corresponding indicators. Coefficients $(r)$ range between +1 and -1 , where 1 is the total positive linear correlation, 0 is no linear correlation, and -1 is total negative linear correlation (Bewick et al., 2003). Furthermore, low p-values below the significance level of 0.05 indicate that relationships are statistically significant (Bewick et al., 2003). To determine whether the correlated variables formed a reliable scale that effectively measured the factors, Cronbach's reliability analysis was also conducted. Coefficients $(\alpha)$ range from 0 to 1 , with values over 0.7 indicating a reliable measure of the underlying concept (Nunnally and Bernstein, 1967; Kline, 2013). Only when indicators belonging to the same GFI thematic area were loaded on the same factor did we conclude that these indicators actually reflect the thematic areas of the GFI framework.

We used a hierarchical cluster analysis based on the factor scores from the preceding factor analysis to identify patterns in governance performance of communities. Hierarchical clustering, unlike other clustering procedures, does not require a pre-specified number of clusters (Kaushik and Mathur, 2014). Accordingly, it was appropriate for this study, which was aimed at exploring the likelihood for the emergence of clusters. Moreover, by using the factor scores, we wanted to avoid any potential multicollinearity, which could result in an overrepresentation of variables (Sarstedt and Mooi, 2014). In particular, we ran the Ward criterion with Euclidean distances, which is often recommended as the best method for detecting group structures in data (Lassar and Kerr, 1996). Communities falling within the same cluster were interpreted as reflecting similar governance conditions. As data on factor scores were not distributed normally, a non-parametric Wilcoxon rank test was used for the comparison of clusters. Conversely, the data on mean factor scores were distributed normally so that the Student $t$-test was used for the comparison of clusters. A principal component analysis (PCA) was also performed to determine whether community clusters reflect the provincial governance structure. PCA results were visualised using a score plot showing the distribution of community clusters along the two principal components that constituted the largest variations. The closer the communities were together on the score plot, the more similar their performance was related to the two principal components. Additionally, when all of the communities from one province were grouped exclusively in the same cluster, it was inferred that provincial administrative structures determine patterns of community clusters, thus forest governance performance, and vice versa. All of the analyses were conducted using JMP 
Table 3

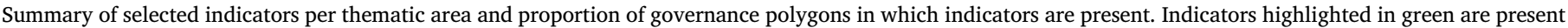
in all governance polygons $(\mathrm{N}=64)$.

\begin{tabular}{lllc}
\hline Thematic area & \multicolumn{2}{l}{ Indicator } & $\begin{array}{c}\text { Percentage of governance } \\
\text { polygons }(\mathrm{N}=64)\end{array}$ \\
\hline Forest tenure & 1. & Tenure rights recognition and protection & 100 \\
\hline Land use & 2. & Formal land use planning & 100 \\
\hline Forest management & 3. & Implementation of land use plans and strategies & 16 \\
& 4. & Timber licences administration & 88 \\
& 5. & Charcoal licences administration & 72 \\
& 6. & Non-timber forest products licences administration & 88 \\
& 7. & Implementation of reforestation programs & 4 \\
& 8. & Protection and conservation & 28 \\
& 9. & Implementation of payment of ecosystem services program & 0 \\
& 10. & Implementation of forest-based livelihood program & 14 \\
& 11. & Formal law enforcement & 100 \\
\hline Revenues & 12. Customary law enforcement & 100 \\
\hline Cross-cutting institutions & 13. & Forest revenue administration & 88 \\
& 14. Implementation of benefit sharing mechanisms & 0 \\
\hline 16. & Local government capacities and effectiveness & 100 \\
\hline 17. Traditional institutions capacities and effectives & 100 \\
\hline 18. Forest non-government organisations capacities and effectiveness & 100 \\
\hline 19. Public policy participation & 9 \\
\hline
\end{tabular}

statistical software.

\section{Results}

\subsection{Forest governance quality}

Sixty four governance polygons were mapped and scored with governance indicators in 24 communities. Of the 19 selected indicators, only eight were present in all governance arrangements (Table 3). Only these could be used to calculate comparable mean governance scores (Table 4). All of these indicators represent different thematic areas of the GFI framework, namely: thematic area "forest tenure"; (1) recognition and protection of tenure rights; thematic area "land use"; (2) formal land use planning; thematic area "forest management" (3) formal law enforcement and (4) customary law enforcement; thematic area "cross-cutting institutions" (5) central government, (6) local government and (7) traditional institutions; thematic area "cross-cutting issues" (8) public participation in policy-making.

Other indicators from the thematic area "forest management", including administration of timber (88 \%) and charcoal licences (72\%) as well as protection and conservation ( $28 \%$ ), were only applicable in a lower proportion of polygons (Table 3). However, since at least one of these indicators could be measured for each polygon and these all represent procedures for regulating forest use, they were grouped into one indicator referred to as forest use restrictions, which in this case reflects forest conservation measures. Forest use restrictions then constituted the ninth indicator in the comparative assessment.

The remaining indicators were only present in specific polygons and

Table 4

Summary of mean governance scores for different indicators per thematic area and type of governance arrangement. Indicators highlighted in green are present in all arrangements. Mean scores $0=$ non - existent; $1=$ very low; $2=$ low; $3=$ average, $4=$ high, $5=$ very high. Different superscript letters indicate means that differ significantly between arrangements at $\mathrm{p}<0.05$, using the non - parametric Wilcoxon rank test. $\mathrm{CC}=$ non - restricted communal customary forest; State $=$ restricted state forest; $\mathrm{CI}=$ non - restricted individual customary forest; CTP = culturally - restricted communal customary forest, No indicates the number of polygons with observations.

\begin{tabular}{|c|c|c|c|c|c|c|c|c|c|}
\hline \multirow[t]{3}{*}{ Thematic area } & \multirow[t]{3}{*}{ Indicator } & \multicolumn{8}{|c|}{ Governance arrangements } \\
\hline & & \multicolumn{2}{|c|}{$\mathrm{CC}$} & \multicolumn{2}{|c|}{ CTP } & \multicolumn{2}{|c|}{$\mathrm{CI}$} & \multicolumn{2}{|c|}{ State } \\
\hline & & No & Mean & No & Mean & No & Mean & No & Mean \\
\hline Forest tenure & Tenure rights recognition and protection & 22 & $3.9^{\mathrm{AB}}$ & 8 & $4.1^{\mathrm{A}}$ & 24 & $4.1^{\wedge}$ & 10 & $3.4^{\mathrm{B}}$ \\
\hline Land use & Formal land use planning & 22 & $0.2^{\mathrm{B}}$ & 8 & $0.0^{8}$ & 24 & $0.2^{\mathrm{B}}$ & 10 & $0.6^{\mathrm{A}}$ \\
\hline \multirow{8}{*}{ Forest management } & Implementation of land use plans and strategies & - & NA & - & NA & _- & NA & 4 & 1.9 \\
\hline & $\begin{array}{l}\text { Forest use restrictions: timber, charcoal licences \& protection } \\
\text { conservation }\end{array}$ & 22 & $1.3^{\mathrm{B}}$ & 8 & $4.2^{\mathrm{A}}$ & 24 & $1.4^{\mathrm{B}}$ & 10 & $1.8^{\mathrm{B}}$ \\
\hline & Non-timber forest products licence administration & 1 & $2.2^{\wedge}$ & NA & NA & 1 & $2.2^{\wedge}$ & 1 & $2.2^{\wedge}$ \\
\hline & Implementation of reforestation program & _- & NA & - & NA & 2 & $2.9 \mathrm{~A}$ & 2 & $2.2^{\wedge}$ \\
\hline & Implementation of forest-based livelihood program & 3 & $2.3^{\wedge}$ & NA & NA & 6 & $3.1^{\wedge}$ & 1 & $3.0^{\wedge}$ \\
\hline & Implementation of payment of ecosystem service program & - & NA & - & NA & - & NA & - & NA \\
\hline & Formal law enforcement & 22 & $1.0^{\mathrm{AB}}$ & 8 & $0.5^{\mathrm{B}}$ & 24 & $0.5^{\mathrm{B}}$ & 10 & $2.3^{\wedge}$ \\
\hline & Customary law enforcement & 22 & $1.6^{\wedge}$ & 8 & $2.0^{\mathrm{A}}$ & 24 & $1.4^{\wedge}$ & 10 & $0.7^{\mathrm{A}}$ \\
\hline \multirow{2}{*}{ Revenues } & Implementation of benefit sharing mechanisms & - & NA & - & NA & - & NA & - & $\mathrm{NA}$ \\
\hline & Forest revenue administration & 8 & $1.6^{\mathrm{A}}$ & & NA & 11 & $1.9^{\mathrm{A}}$ & 5 & $2.2^{\mathrm{A}}$ \\
\hline \multirow{4}{*}{ Cross-cutting institutions } & Central government capacities and effectiveness & 22 & $1.7^{\mathrm{AB}}$ & 8 & $1.3^{\mathrm{B}}$ & 24 & $1.7^{\mathrm{AB}}$ & 10 & $2.1^{\mathrm{A}}$ \\
\hline & Local government capacities and effectiveness & 22 & $0.1^{\mathrm{A}}$ & 8 & $0.1^{\mathrm{A}}$ & 24 & $0.1^{\mathrm{A}}$ & 10 & $0.0^{\wedge}$ \\
\hline & Traditional institutions capacities and effectiveness & 22 & $2.2^{\mathrm{A}}$ & 8 & $1.4^{\mathrm{A}}$ & 24 & $1.8^{\mathrm{A}}$ & 10 & $1.5^{\mathrm{A}}$ \\
\hline & Non-government organizations capacities and effectiveness & 3 & $3.5^{\mathrm{A}}$ & & NA & 3 & $3.5^{\mathrm{A}}$ & 3 & $3.5^{\mathrm{A}}$ \\
\hline Cross-cutting issues & Public policy participation & 22 & $0.0^{\mathrm{A}}$ & 8 & $0.0^{\mathrm{A}}$ & 24 & $0.0^{\mathrm{A}}$ & 10 & $0.0^{\mathrm{A}}$ \\
\hline \multicolumn{2}{|c|}{ Governance score (only indicators applicable in all arrangements) } & 22 & $1.3^{\mathrm{A}}$ & 8 & $1.5^{\mathrm{A}}$ & 24 & $1.2^{\mathrm{A}}$ & 10 & $1.4^{\mathrm{A}}$ \\
\hline \multicolumn{2}{|c|}{ Governance score (only site specific indicators) } & 12 & $2.2^{\mathrm{A}}$ & & NA & 15 & $2.7^{\mathrm{A}}$ & 9 & $2.6^{\mathrm{A}}$ \\
\hline \multicolumn{2}{|c|}{ Final governance score (all indicators) } & 22 & $1.5^{\mathrm{B}}$ & 8 & $1.5^{\mathrm{B}}$ & 24 & $1.7^{\mathrm{AB}}$ & 10 & $2.1^{\mathrm{A}}$ \\
\hline
\end{tabular}


thus not comparable across arrangements (Table 3). These indicators were nevertheless taken into consideration in the computation of the final mean governance score (Table 4).

Overall, mean governance as the mean value of the nine governance indicators that were applicable in all arrangements, was very low, with values between 1.2 and 1.5, and did not differ significantly between arrangements (Table 4). Of the nine fully comparable indicators, only tenure rights recognition and protection consistently scored above the average Likert score of 3 . Tenure rights recognition and protection moreover, scored significantly higher in the customary than in state arrangements. The governance aspect of forest use restrictions, which in this case reflects conservation measures, scored significantly higher in the arrangements with cultural use restrictions than in those devoid of cultural restrictions. Other fully comparable indicators of formal land use planning and formal law enforcement, central government capacities and effectiveness scored significantly higher in state than in the customary arrangements. Public participation is forest policy formulation was completely absent in all arrangements.

Taking all indicators into account, including those only present in specific sites, state arrangements (with more indicators present) had significantly higher mean governance scores than customary arrangements (with less indicators present) (Table 4). The individual, sitespecific indicators did not differ significantly between arrangements even though they led to higher mean governance scores in all the arrangements in which they were present.

A comparative analysis of the elements of quality in governance arrangements revealed that gender equity was significantly lower in individually-owned customary forests compared to state and communal customary arrangements (Appendix C). Apprehension, compliance and monitoring of customary law was significantly lower in state than customary forests.

\subsection{Relationships between the GFI thematic areas, indicators and elements of quality}

Factor analysis resulted in seven main factors that together explain $76.5 \%$ of the variation. The first three factors, which together explain $52.58 \%$ of the variation, are characterized by loadings of five elements of quality (Table 5). The first factor, accounting for $18 \%$ of the variance, correlated primarily with the indicator of formal law enforcement from the thematic area "forest management". The second factor, constituting $17.6 \%$ of the variance, correlated primarily with the indicator of formal land use planning from the thematic area "land use". The third factor, which explained $17 \%$ of the variance, was highly correlated with the indicator of customary law enforcement from the thematic area "forest management".

Each of the remaining four factors was characterized by loadings of a few (less than five) elements of quality (Table 5). Those elements allow the following interpretation of the meaning of these factors: the fourth represents central government capacities and effectiveness from the thematic area "cross-cutting institutions"; the fifth, traditional institutions capacities and effectiveness, thematic area "cross-cutting institutions"; the sixth, local government capacities and effectiveness, thematic area "cross-cutting institutions" and the seventh, tenure rights enforcement, thematic area "forest tenure". Moreover, some elements of quality loaded on different thematic areas than those they were hypothesised to represent i.e. factor five comprised tenure rights recognition from the thematic area "forest tenure" and traditional institution capacities and effectiveness from the thematic area "crosscutting institutions".

A bivariate analysis that related the factor loadings to the respective mean Likert scores of the assigned indicators showed significant correlations between the first three factors and the respective indicators. The $r$ coefficients are 0.96 for factor one and the mean score of the indicator of formal law enforcement, 0.95 for factor two and the mean score of the indicator of formal land use planning and 0.94 for factor three and the mean score of the indicator of customary law enforcement. Cronbach's reliability analysis confirmed that the elements of quality, which correlated with the first three factors, formed reliable measures for these underlying dimensions, with $\alpha$ coefficients of 0.92 for formal law enforcement, 0.89 for formal land use planning and 0.92 for customary law enforcement (Table 5).

Other elements of quality representing use restrictions (thematic area "forest management"), public policy participation (thematic area "cross-cutting issues") and several institutional capacities including human resource, financial and scientific and technical information (all thematic area "cross-cutting issues") did not load whatsoever (Table 5)

\subsection{Patterns of governance clusters for forest frontier communities in Zambia's Miombo}

Cluster analysis was carried out based on all the factor scores for governance attributes related to the communities. It allowed the identification of four main clusters of communities in which perceptions of forest governance conditions were similar. Similar groupings of communities were also revealed by the PCA results computed on the basis of the two principal components that constituted the largest variations, i.e. formal law enforcement, $20.9 \%$, and land use planning, $18.3 \%$ (Fig. 3).

Cluster one, which is the smallest, comprises one community from North Western province. The cluster shows the highest score in formal land use planning and the highest overall mean factor score. Cluster three, which is the second smallest, comprises two communities, both from North Western province. These communities score significantly higher in formal law enforcement. Cluster two, the second largest, is composed of nine communities, mainly from North Western and Copperbelt provinces. The largest cluster, four, comprises 12 communities, mainly from Eastern and Copperbelt provinces. Communities in clusters two score significantly higher in central government capacities and effectiveness and tenure rights enforcement than those in cluster four (Table 6). Moreover, the results show a weak provincial grouping of communities since communities from the same province (Eastern) only fall exclusively in the same group in one of the cases, cluster four.

\section{Discussion and implications}

\subsection{Forest governance quality}

Our results show low mean scores for governance indicators. This implies weak de facto governance in the Zambian Miombo forests. This is in line with the findings of scholars (Musole and Chunda-Mwango, 2018; Kalaba, 2016; Vinya et al., 2011) in Zambia and Gumbo et al. (2018) elsewhere in the Miombo, who report weak forest governance characterized by the unsatisfactory implementation of relevant rules and governance processes on the ground. This is remarkable, especially following the propitious de jure governance reforms in Zambia's forest sector that embrace decentralization (Ministry of Tourism Environment and Natural Resources, 2009), the demarcation of restricted forest reserves (GRZ, 2015a) and participatory forest governance. Our results may suggest that existing strategies have remained largely at a rhetoric policy level, with hardly any influence on forest management on the ground. In Zambia's strategy for REDD +, the improvement of governance is a key issue within the preparatory phase as a basis for incentive-based mechanisms (Matakala et al., 2015). However, up to now the REDD + strategy has only been implemented to a limited extent (Ministry of Lands and Natural Resources and Ministry of National Development Planning, 2019). The weak enforcement of forest rules is mentioned as constituting the underlying driver of deforestation in the tropics (Korhonen-Kurki et al., 2014; Kanninen et al., 2007; Stickler et al., 2017; Umemiya et al., 2010). Moreover, weak forest governance is linked to the failure of mechanisms that aim to address deforestation and forest degradation (Korhonen-Kurki et al., 2014). In this regard, our 
Table 5

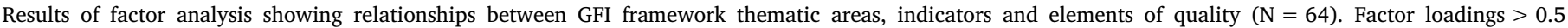
(highlighted in red) imply that variable correlated highly with the factor. Cronbach's $\alpha>0.7$ implies a reliable measure of the underlying indicator.

\begin{tabular}{|c|c|c|c|c|c|c|c|c|c|}
\hline \multirow{3}{*}{ Thematic area } & \multirow{3}{*}{ Indicator } & \multirow{3}{*}{ Elements of quality } & \multicolumn{7}{|c|}{ Assigned meaning of the Factors } \\
\hline & & & $\begin{array}{l}\text { Formal law } \\
\text { enforcement }\end{array}$ & $\begin{array}{l}\text { Land use } \\
\text { planning }\end{array}$ & $\begin{array}{l}\text { Customary law } \\
\text { enforcement }\end{array}$ & $\begin{array}{c}\text { Central } \\
\text { government }\end{array}$ & $\begin{array}{l}\text { Traditional } \\
\text { institutions }\end{array}$ & $\begin{array}{c}\text { Local } \\
\text { government }\end{array}$ & $\begin{array}{l}\text { Tenure rights } \\
\text { enforcement }\end{array}$ \\
\hline & & & Factor 1 & Factor 2 & Factor 3 & Factor 4 & Factor 5 & Factor 6 & Factor 7 \\
\hline \multirow{5}{*}{ Forest tenure } & \multirow{5}{*}{$\begin{array}{l}\text { Tenure rights recognition } \\
\text { and protection }\end{array}$} & Recognition & -0.17 & 0.09 & -9.10 & -0.18 & 0.77 & 0.14 & 0.03 \\
\hline & & Demarcation & 0.22 & -0.15 & -0.02 & 0.07 & -0.23 & 0.18 & 0.64 \\
\hline & & Enforcement & 0.17 & 0.14 & 0.36 & 0.20 & -0.16 & -0.18 & 0.49 \\
\hline & & Gender equity & 0.24 & 0.03 & 0.28 & 0.21 & -0.27 & 0.10 & -0.65 \\
\hline & & Tenure harmony & -0.52 & 0.02 & 0.07 & 0.40 & -0.12 & 0.28 & 0.10 \\
\hline \multirow{5}{*}{ Land use } & \multirow{5}{*}{ Formal land use planning } & Procedures & 0.41 & 0.57 & -0.04 & 0.12 & -0.37 & -0.07 & -0.16 \\
\hline & & Transparency & -0.08 & 0.98 & 0.17 & 0.01 & 0.05 & 0.02 & -0.01 \\
\hline & & Participation & -0.08 & 0.98 & 0.17 & 0.01 & 0.05 & 0.02 & -0.01 \\
\hline & & Representation & -0.08 & 0.98 & 0.17 & 0.01 & 0.05 & 0.02 & -0.01 \\
\hline & & Capacities & -0.08 & 0.98 & 0.17 & 0.01 & 0.05 & 0.02 & -0.01 \\
\hline \multirow{11}{*}{ Forest management } & Use restrictions & No elements loaded & & & & & & & \\
\hline & \multirow{5}{*}{ Formal law enforcement } & Apprehension & 0.91 & -0.02 & 0.00 & 0.16 & -0.19 & -0.05 & 0.03 \\
\hline & & Consistency & 0.95 & -0.05 & 0.02 & 0.06 & 0.01 & 0.01 & 0.07 \\
\hline & & Compliance & 0.92 & -0.06 & 0.06 & 0.12 & 0.00 & 0.24 & 0.08 \\
\hline & & Monitoring & 0.90 & -0.04 & 0.03 & 0.12 & 0.00 & -0.07 & 0.00 \\
\hline & & Transparency & 0.49 & -0.11 & 0.41 & 0.26 & 0.18 & -0.03 & 0.10 \\
\hline & \multirow{5}{*}{ Customary law enforcement } & Apprehension & 0.02 & 0.33 & 0.72 & 0.01 & -0.13 & 0.04 & 0.14 \\
\hline & & Consistency & -0.10 & 0.16 & 0.89 & 0.05 & 0.00 & -0.01 & -0.09 \\
\hline & & Compliance & 0.05 & 0.11 & 0.91 & 0.07 & 0.07 & 0.08 & 0.01 \\
\hline & & Monitoring & 0.11 & 0.11 & 0.86 & 0.09 & 0.13 & $-0,20$ & -0.02 \\
\hline & & Transparency & 0.04 & 0.08 & 0.85 & 0.05 & 0.10 & 0.19 & -0.11 \\
\hline \multirow{5}{*}{ Cross-cutting institutions } & \multirow{2}{*}{ Central government } & Knowledge and skills & 0.14 & 0.00 & 0.09 & 0.87 & 0.10 & -0.04 & -0.01 \\
\hline & & Effectiveness & 0.34 & 0.06 & 0.09 & 0.62 & -0.18 & $-0,08$ & -0.02 \\
\hline & \multirow{2}{*}{ Traditional instiutions } & Knowledge and skills & -0.07 & 0.14 & 0.15 & 0.35 & 0.51 & -0.36 & -0.14 \\
\hline & & Effectiveness & 0.25 & -0.05 & 0.27 & 0.08 & 0.62 & -0.06 & -0.12 \\
\hline & Local government & Knowledge and skills & 0.00 & 0.06 & 0.09 & -0.07 & 0.03 & 0.94 & -0.02 \\
\hline \multirow[t]{5}{*}{ Cross-cutting issues } & Public policy participation & No elements not loaded & & & & & & & \\
\hline & Eigen value & & 5.83 & 4.92 & 2.89 & 1.69 & 1.52 & 1.15 & 1.12 \\
\hline & Variance explained (\%) & & 18.04 & 17.58 & 16.96 & 6.86 & 6.82 & 5.41 & 4.81 \\
\hline & Cumulative Variance (\%) & & 18.04 & 35.62 & 52.58 & 59.44 & 66.26 & 71.66 & 76.48 \\
\hline & Cronbach's $a$ & & 0.92 & 0.89 & 0.92 & 0.53 & 0.24 & 0.00 & 0.03 \\
\hline
\end{tabular}

results indicate the necessity of strengthening the implementation of forest rules and governance processes at the local level (Pettenella and Brotto, 2012).

We find that forest governance quality does not differ significantly between the restricted state and non-restricted customary arrangements, when comparable indicators are used. This challenges common assumptions that de jure state control and its associated restrictions are likely to result in better de facto governance compared to customary governance, with more open access and fewer use restrictions (Ferraro et al., 2013; Hardin, 1968) and vice versa (Agrawal and Ostrom, 2001; Ostrom, 2008). In fact, the satisfactory enforcement of rules combined with good institutional capacities is likely to produce better governance performance on the ground (Brenes et al., 2018; Agrawal et al., 2014; Ostrom, 1993; Hayes and Persha, 2010; Ostrom, 2009). Despite the distinct policy interventions, forest rules in Zambia are hardly enforced due to the absence of adequate financial and human institutional

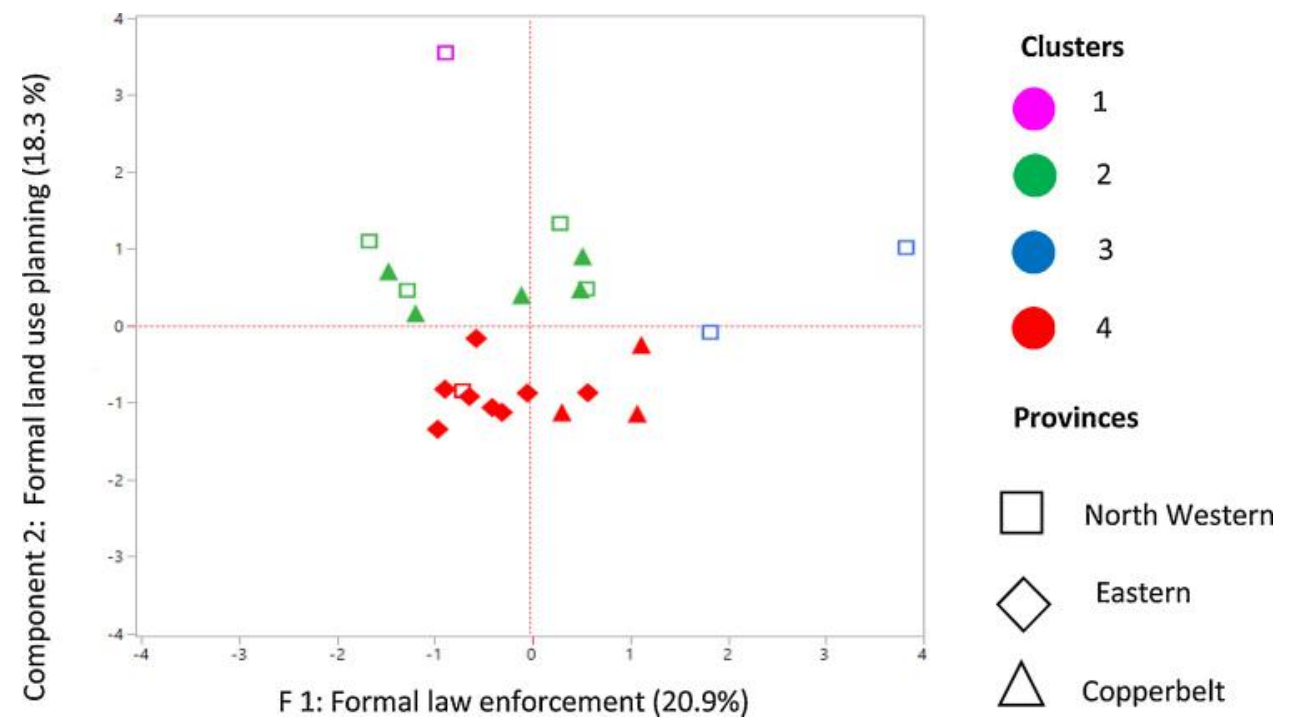

Fig. 3. Patterns of community clusters along two principal components $(\mathrm{N}=64)$. The colour indicates cluster assignment based on cluster analysis. The symbol indicates the Province. 
Table 6

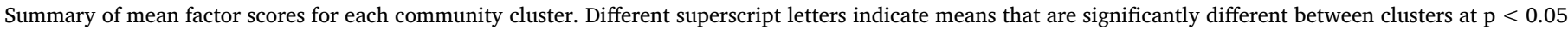
$(\mathrm{N}=64)$.

\begin{tabular}{|c|c|c|c|c|c|c|}
\hline \multirow[t]{2}{*}{ Factors } & \multirow[t]{2}{*}{ Assigned factor meaning } & \multirow[t]{2}{*}{ Statistical test } & \multicolumn{4}{|c|}{ Mean factor score by community clusters } \\
\hline & & & Cluster $1(\mathrm{~N}=1)$ & Cluster $2(\mathrm{~N}=9)$ & Cluster $3(\mathrm{~N}=2)$ & Cluster $4(\mathrm{~N}=12)$ \\
\hline 1 & Formal law enforcement & Non-parametric Wilcoxon rank test & $-0.47^{\mathrm{B}}$ & $-0.39^{\mathrm{B}}$ & $1.48^{\mathrm{A}}$ & $-0.07^{\mathrm{B}}$ \\
\hline 2 & Formal land use planning & & $3.57^{\mathrm{A}}$ & $-0.24^{\mathrm{A}}$ & $-0.36^{\mathrm{A}}$ & $-0.13^{\mathrm{A}}$ \\
\hline 3 & Customary law enforcement & & $0.96^{\mathrm{A}}$ & $-0.02^{\mathrm{A}}$ & $1.24^{\mathrm{A}}$ & $-0.23^{\mathrm{A}}$ \\
\hline 4 & Central government capacity and effectiveness & & $0.08^{\mathrm{AB}}$ & $0.58^{\mathrm{A}}$ & $1.16^{\mathrm{A}}$ & $-0.48^{\mathrm{B}}$ \\
\hline 5 & Traditional institutions capacity and effectiveness & & $0.18^{\mathrm{A}}$ & $0.16^{\mathrm{A}}$ & $-0.45^{\mathrm{A}}$ & $0.17^{\mathrm{A}}$ \\
\hline 6 & Local government capacity and effectiveness & & $0.13^{\mathrm{A}}$ & $0.20^{\mathrm{A}}$ & $0.13^{\mathrm{A}}$ & $-0.12^{\mathrm{A}}$ \\
\hline 7 & Tenure rights enforcement & & $0.77^{\mathrm{AB}}$ & $0.64^{\mathrm{A}}$ & $-0.53^{\mathrm{AB}}$ & $-0.41^{\mathrm{B}}$ \\
\hline \multicolumn{2}{|c|}{ Mean overall factor score } & Student's t- test & $0.74^{\mathrm{A}}$ & $0.13^{\mathrm{B}}$ & $0.38^{\mathrm{AB}}$ & $-0.18^{\mathrm{C}}$ \\
\hline
\end{tabular}

capacities (Kalaba, 2016). In light of that, the results affirm the need to increase the financial and human capacities of relevant institutions, as this is likely to improve their rule enforcement capabilities.

The higher mean governance score in state than in customary arrangements when site-specific indicators are considered to some extent reveals the de facto implications of contradicting land tenure policies in customary lands. While Zambia's local government act authorises state institutions to manage customary forests, the land act places the administration of these forests under customary authorities, creating ambiguous responsibility and institutional tension (Chikulo, 2009). In the absence of effective institutional coordination and appropriate accountability mechanisms (Kalaba, 2016), the situation may constrain the implementation of non-legally binding governance processes on customary lands, including reforestation and livelihood programs. These processes drive the higher overall mean governance scores on state land. Moreover, as the same processes were implemented by nongovernment organizations and private enterprises, the results might mirror the role of non-state institutions in improving forest governance, which was also remarked by (Turner et al., 2014; Hayes and Persha, 2010) in the tropics. In this respect, the results indicate the necessity for legal reforms to address the inconsistencies in institutional mandates coupled with augmented formal support for the non-state institutions in Zambia's forest sector. An alternative interpretation, in line with recommendations by Williams, 2011, is that merely relying on mean governance values can be deceptive, as these varied greatly depending on the indicators under consideration. In agreement with (Dwyer et al., 2008; Turner et al., 2014), the findings imply the need to systematically understand the organisation and context of governance processes, especially when discussing policy implications.

The relatively high scores for tenure rights recognition, particularly on customary lands, mirror the de jure, de facto discrepancy vis-à-vis the security of tenure on customary lands in Zambia. Whereas customary land is the least secure de jure option due to an absence of formal documentation to prove the landholders' de facto rights (Mulolwa, 2016; Bojang and Ndeso-Atanga, 2013), similar to other studies (Stickler et al., 2017; Jain et al., 2016), our results indicate that people in Zambia feel secure in their rights to customary forests. Despite the absence of any formal documentation, de facto customary tenure may be more socially legitimated and thus more dominant than de jure tenure (Payne and Durand-Lasserve, 2012). As customary forests account for the largest proportion of forests in Zambia, this result is promising, especially as tenure security is acknowledged to foster sustainable use, efficient forest investment behaviour (Irwin and Ranganathan, 2007) and the desire of local people to protect their forests from encroachment (Larson et al., 2010; Mayers and Vermeulen, 2002). Besides, tenure security is reputed to lessen conflicts resulting from overlapping claims of ownership between different formal and customary institutions (Robinson et al., 2018). Nonetheless, de jure requirements for formal documentation could further strengthen customary tenure security.

The differences in scores for central government institutions and formal processes of land use planning and law enforcement between the state and customary forests again reflect the de jure weakness vis-à-vis formal processes in customary forests. While Zambia's Urban and Regional Planning Act of 2015 recommends formal land use planning, the activity is not strictly required on customary lands. Furthermore, although formal institutions are legally mandated to manage all forests, the control of customary forests is largely enshrined in customary laws, which are articulated by the traditional institutions and lack systematic procedures (Kalinda et al., 2008). Moreover, since the customary institutions occasionally challenge the authority of local government actors (Mfune, 2013), their willingness to enforce formal governance processes on customary lands is likely to lessen. Formal activities are also constrained by the inadequate implementation of forest management plans and strategies and the poor monitoring of illegal activities due to inadequate funds and staff (Kalaba, 2016). Since formal land use planning and law enforcement are crucial for regulating unsustainable forest use (McDermott et al., 2010; Kaimowitz, 2012), it is imperative to establish legally binding requirements for these processes on customary lands. Additionally, augmented support for human and financial capacities and coordination amongst institutions could foster greater enforcement exercises (Kalinda et al., 2008).

The differences in scores for use restrictions between the culturallyrestricted forests and those not restricted by traditions demonstrate the role of traditional values and norms in promoting forest conservation, as has been reported by other scholars too (Colding and Folke, 2001; Jimoh et al., 2012). The results indicate the need to reinforce traditional norms within prevailing forest governance arrangements as they reflect locally important cultural values of forest resources, and are likely to foster voluntary compliance with access and use restrictions, even in the absence of effective law enforcement systems. This could be strengthened by a greater harmonization of state and customary structures within the existing decentralization system in order to lessen opposition during the implementation of pertinent forest governance processes in Zambia's Miombo.

The differences in gender equity between the individually-owned customary forests and other arrangements (state and communal) reflect the actual de jure inconsistency in women's control over and ownership rights to individual forestland. While Zambia's statutory law recognizes men and women equally in terms of property rights, i.e. access, use and ownership of forestlands, customary law, which dominates the distribution of rights to forestlands, discriminates women's ownership and control rights (Spichinger and Kabala, 2014; Machina, 2002). As these rights shape the opportunities and constraints that women face in securing their livelihoods (Daley, 2013), it is essential to support their enforcement in the more socially legitimated, de facto forest tenure systems.

The finding that the apprehension, compliance with and monitoring of customary law was significantly lower in state-owned than in customary forests once more echoes the unsatisfactory decentralization process that was also highlighted by (Mfune, 2013; Chikulo, 2009). The forest policy and act provide for the participation of customary 
institution in the management of state forests through Joint Forest Management programs. However, analogous to other studies in Zambia (Bwalya, 2007), there is no real recognition of traditional leader's rights to make fundamental decisions in state forests. The Forest Department still has complete control and approves all the important decisions, including apprehending and penalizing forest lawbreakers. The scenario leads to the under-utilization of the customary institution's capacity to contribute to sustainable forest management. This is particularly true given that the traditional leaders are socially recognized as legitimate arbitrators, including forest offenses (Bwalya, 2007). The situation conforms the need to better integrate customary structures into the decentralized governance structure and to strengthen their capacity to participate in forest management.

\subsection{Relationships between the GFI thematic areas, indicators and elements of quality}

The results show that the framework explains $76.5 \%$ of the variance. This demonstrates that the GFI indicator set is a valuable tool to describe overall governance on the ground, as was highlighted by Davis et al. (2013). We find that each factor reflects a distinct indicator of the GFI framework, either exclusively, i.e. the first three strongest factors, or to a certain degree, i.e. the remaining four factors. This may imply that the GFI framework distinguishes underlying de facto governance processes in Zambia's Miombo, underscoring its fitness in this respect. The distinct first and third factor demonstrate that formal and customary laws issues are independent factors in the Zambian forest governance context, along with central government, local government and traditional institutions (Kalinda et al., 2008; Caron and Fenner, 2017). This implies that merely outlining governance themes, i.e. laws and institutions, can be misleading, particularly in the context of overlapping customary and formal laws and institutions, as is the case in Zambia. In line with Williams, 2011, we recommend specifying and differentiating between formal and customary governance legislation and institutions.

Some indicators that are posited to characterize similar thematic areas load as separate factors. This may imply that thematic areas at a higher hierarchical level are not precisely reflected by the de facto governance processes or functions of the different GFI indicators across the Zambian Miombo. This indicates that thematic areas might be useful to categorize different indicators. However, they are not always mechanisms of distinct governance functioning, as they can comprise different independent indicators.

The first three factors, i.e. formal law enforcement, formal use planning and customary law enforcement, are consistently loaded by elements of quality of the same indicators. This could indicate the overlapping nature of the respective elements, which were not easily distinguishable by participants. The detailed assessment through five elements of quality could be simplified to reflect the most relevant processes

The results show an association between customary institutions and tenure rights recognition, both of which were loaded on the fifth factor, contrary to the GFI postulations. In Zambia, customary institutions are legally mandated and socially legitimated to drive the recognition of tenure rights, especially on customary lands (Payne and DurandLasserve, 2012; GRZ, 2015a; Caron and Fenner, 2017). Because similar situations are likely in several other African countries that have customary land governance structures, such as Botswana, Mozambique and Tanzania (Knight, 2010), we recommend adapting the GFI indicators to suit the local governance context. This can be ascertained through scoping visits and a review of the existing legal framework.

\subsection{Patterns of governance clusters for forest frontier communities in Zambia's Miombo}

In the cluster analysis, we identified four main community clusters.
The existence of varied clusters reflects different governance approaches amongst communities, generally differentiated by the processes of formal and customary law enforcement and land use planning.

The community in cluster one is characterized by high scores for formal land use planning. Unlike in other communities, participatory land use planning on customary land within this community has been executed through a collaboration between the United Nations Development Programs (UNDP), Global Environmental Facility (GEF), Forest Department and the traditional leaders. Since this community had the highest mean factor/governance score, the result again underscores the significance of participatory land use planning in improving de facto governance.

Communities in cluster three had high scores for formal law enforcement, which might result from the presence of timber concessions in these communities. This finding is consistent with that of NG'ANDWE et al. (2015), who report a comparatively higher enforcement of forest use restrictions by the Forest Department in forests with timber concessions than in those without in Zambia. This is mainly because the concessionaires usually provide transportation and other resources for the forest officers to conduct forest inventories, consultation with the communities and monitoring of the concession.

It is notable that cluster two mainly comprises communities from North Western and Copperbelt and cluster four, from Eastern and Copperbelt. As these are the largest clusters, as distinguished clearly by the loadings of several factors, the results might indicate that governance processes of North Western and Eastern are generally distinct, while in Copperbelt we can find patterns from both regions. This finding might reflect a de facto variation in the coordination between customary and formal institutions across the different regions. Zambia's provincial officials operate under the same forest policy and legal framework that assigns the same general rights and responsibilities to all local governments (Ministry of Tourism Environment and Natural Resources, 2009). At the lower levels, provincial officials are required to harmonise with the customary institutions to facilitate the enforcement of forest laws and the proper administration of forest estates, in line with the forestry policy and existing legal framework (Chileshe, 2001; Ministry of Tourism Environment and Natural Resources, 2009). In Eastern province, communities reported recurrent conflicts over forest ownership between customary and formal institutions. This might explain the very low scores for central government capacities and effectiveness and tenure rights enforcement that differentiate the Eastern communities, in cluster four, from those in cluster two, from North Western and Copperbelt. The result confirms the necessity for consistency in the integration of customary structures into the decentralized governance structure, taking into account regional and local differences.

\section{Conclusion and recommendations}

Our data show low mean scores for governance indicators, implying weak de facto governance in Zambia's Miombo forests. Various forest governance arrangements with differing tenure as well as access and use restriction exist de jure. However, our results show that they lack the implementation of relevant rules (customary and formal) and governance processes on the ground, particularly concerning land use planning, forest use restrictions and public participation in forest policy formulation. In addition, there are inadequate financial, technical and human institutional capacities to enable effective enforcement processes. As weak governance is linked to forest loss, the results may partly explain the persistent deforestation in Zambia's Miombo. In light of that, the increased enforcement of forest rules and use restrictions comprising regular monitoring, apprehension and graduated sanctions for law breakers is recommended. This can undoubtedly be strengthened by the establishment of robust coordination mechanisms between customary and formal institutions, coupled with better support for their financial, human and technical capacities. Participatory land use 
planning and policy formulation processes are needed. This would also contribute towards achieving the targets of Zambia's national climate change response strategy and the national development plan 2017-2021. These national initiatives propose the integration of strengthened forest governance to combat climate change and promote sustainable forest use, although without specific operational measures for its implementation (Ministry of Tourism, Environment and Natural Resources, 2010; Ministry of National Development Planning, 2017). Moreover, the REDD + strategy proposes the same governance measures, but again without specific details of their implementation (Matakala et al., 2015). In the light of a controversial general discussion on the success and future of REDD + and the applicability of resultsbased payments in international forest policy (Angelsen, 2017; Fischer et al., 2016; Fletcher et al., 2016), and taking into account critical voices that have been raised against REDD + in other countries such as Uganda and Nepal (Dawson et al., 2018), we conclude that REDD + can be promising. However, it should certainly not overshadow Zambia's own national initiatives mentioned above.

We have shown that formal and customary rules and institutions are clearly differentiated on the ground. This justifies the fact that Zambia's legislation, including the constitution, recognizes and takes into account the importance of customary rules and institutions. Our findings, however, imply the possibility of conflicts between customary and formal institutions resulting from overlapping claims on customary forest management. As this is likely to impede the execution of pertinent governance processes, we recommend legal reforms to address the inconsistencies in institutional mandates and the coherent integration of customary structures and cultural values into the decentralized structure. We believe that the recognition of customary tenure rights and use restrictions actually work quite well, despite the absence of any formal documentation. Nevertheless, de jure requirements for formal documentation that also takes gender issues into account could further strengthen these rights.

We found the GFI framework to be a very useful tool for assessing governance processes on the ground since the factors generally mirror GFI indicators. However, because de facto governance processes in some cases do not precisely reflect thematic areas of the framework, and as a factor analysis reveals several distinct factors, we warn against the use of single indicators to exclusively represent a thematic area. This is not intended by the authors of the GFI framework, but could be the pragmatic interpretation of users in the field. As the local setting may have some influence on the relationships between certain elements of quality, we suggest adapting the elements to suit the local context and also refining these to reflect the most relevant governance processes.

Our statistical analysis reveals clusters of distinct governance within and across provinces. Specific processes have a differing relevance within or across such different spatial jurisdictions. Examples include forest concessions that influence governance processes, especially in the North Western, or unclear tenure situations that influence the broader governance situation in the Eastern province, whereas Copperbelt communities are more diverse and cannot be assigned to specific clusters. This highlights the need to improve and streamline de facto and de jure governance factors beyond the established administrative boundaries. This should be taken into account in the design of comanagement strategies as well as in jurisdictional and landscape approaches. Communities that are part of different governance pattern clusters within the same province may need different policy measures. Initiatives to integrate customary structures into the decentralized governance structure are required across all of the different governance clusters, though different coordination mechanisms may be needed between customary and formal institutions.

\section{CRediT authorship contribution statement}

Hellen Nansikombi: Conceptualization, Methodology, Validation, Formal analysis, Investigation, Data curation, Writing - original draft, Writing - review \& editing, Visualization. Richard Fischer: Conceptualization, Methodology, Investigation, Validation, Data curation, Writing - review \& editing, Supervision. Gillian Kabwe: Investigation, Writing - review \& editing. Sven Günter: Conceptualization, Methodology, Validation, Writing - review \&editing, Supervision, Project administration, Funding acquisition.

\section{Declaration of Competing Interest}

The authors declare no conflict of interest. The funders were not involved in the collection, analysis and interpretation of data, in the writing of the manuscript or in the decision to submit the article for publication.

\section{Acknowledgements}

The study is part of the Landscape Forestry in the Tropics (LaForeT) project conducted in Zambia by the Thünen Institute of International Forestry and Forest Economics, Hamburg, Germany, and by the Copperbelt University, School of Natural Resources, Kitwe, Zambia. It was funded by the conducting institutions as well as the German Federal Ministry of Food and Agriculture and the German Federal Office of Agriculture and Food (BLE) based on a decision of the Deutscher Bundestag, Project number 281-006-01. We acknowledge the support of the Centre for International Forests Research (CIFOR), Zambia. We are also grateful to Peter Elsasser for his valuable suggestions that have greatly enriched this paper. Special thanks go to the Landscape Forestry in the Tropics (LaForeT) project team, especially Moses Kazungu, Christina Jany and Rubén Ferrer, for their contribution in selecting the study landscape in Zambia. We are also indebted to the communities in Zambia for their invaluable information and time.

\section{Funding}

The Thünen Institute and German Ministry of Food and Agriculture (BMEL) funded this work.

\section{Appendix A}

Description of elements of quality by indicators and thematic area

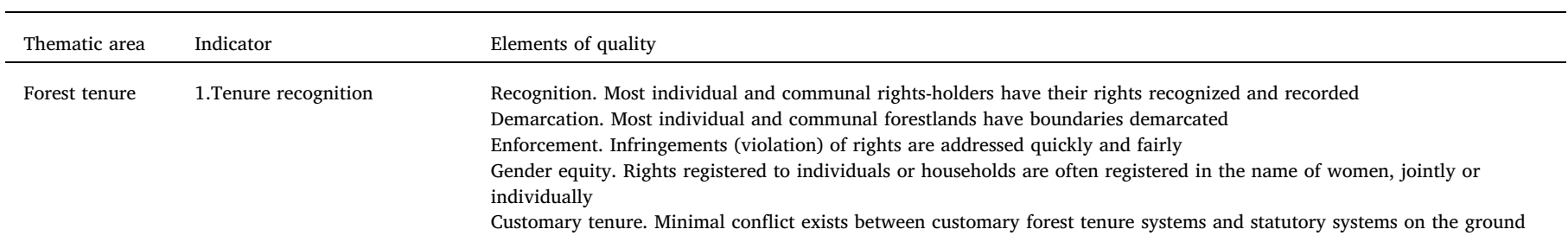


Land use 2. Land use planning

Forest manage- $\quad 3 . S t r a t e g i e s$ and plans ment
Licences:

4. Timber

5. Charcoal

6. Non-timber forest products

7. Reforestation programs

8. Protection and conservation

9. Payment for Ecosystem Services Programs 10. Forest-based livelihood pro-
grams

Law enforcement:

11. Formal law

12. Customary law

Revenues 13. Revenues

14. Benefit-sharing mechanisms

Cross-cutting Ins- Capacities and effectiveness titutions

\section{Central government}

16. Local government

17. Non-government organiza-

tions

18. Customary institutions

Cross-cutting is- 19. Participatory policy-making
Procedure. Land use decisions are taken in a formally-established process

Transparency. Planning process is transparent and procedures are clearly defined

Opportunities for participation. Communities or entitled individuals have the chance to participate in land use planning processes

Representation. Representatives in land-use planning processes reflect a range of community perspectives, including women and different socioeconomic classes

Capacity to engage. Representatives in land-use planning have the information and skills to effectively engage and participate in land-use planning processes

Coordination. Implementing agencies/persons/enterprises effectively coordinate when performing their roles and responsibilities

Timeliness. Implementation takes place according to the timeline specified by the plan/strategy

Monitoring. Implementation is subject to regular monitoring of impacts and effectiveness

Transparency. Land-use plans and monitoring reports are publicly disclosed on a regular basis

Review. Plans and strategies are reviewed and updated regularly

Procedural clarity. Clear administrative procedures regulate the obtaining of licenses and permits

Transparency. Application status can be tracked

Accessibility. The process for acquiring a license or permit is not prohibitively complicated and expensive

Timeliness. Licenses and permits can be obtained in a reasonable time and within the time prescribed

Implementation. Licenses and permits are honoured during harvesting and transport of forest products

Procedures. Stakeholders understand the procedures and terms of the program, including planting sites and species, duration as well as associated benefits and responsibilities

Coordination. The implementing agency coordinates the implementation by establishing clear agreements with people and organizations

Capacities. Communities have been capacitated to implement the program

Benefits. Participants have received compensation as agreed

Monitoring. Implementation is subject to regular monitoring to ensure compliance and effectivity

Demarcation. Boundaries of protected or conservation forests areas are clearly demarcated.

Use restrictions. Stakeholders clearly understand the timeframe and what activities are allowed and not allowed within the protection or conservation area

Enforcement. Implementing agencies are aware of and effectively coordinate the performance of their roles and responsibilities

Penalties. Stakeholders understand penalties for failing to comply with the rules of the arrangement

Monitoring. Implementation is subject to regular monitoring of impacts and effectiveness

Procedures. The procedures for establishing PES have been made clear to the stakeholders

Coverage. PES schemes have been established on the ground.

Benefit sharing. The schemes for benefit sharing have been jointly decided, understood and accepted by the stakeholders

Protection. The protection of the forests providing these ecosystem services has been put in place

Monitoring. Implementation is subject to regular monitoring

Procedures. Stakeholders clearly understand the procedures for setting up sustainable livelihood projects.

Coordination. Government agencies coordinate and provide support in implementing and sustaining projects Resources. Forest resources are adequate to sustain livelihoods

Facilities. Credit facilities and capacity building were made available to local communities

Benefits. Community members receive shares and benefits equitably

Apprehension. Violators are apprehended and brought to trial by concerned authorities

Consistency. Assigned penalties are generally consistent with the law and appropriate given the nature of the offense

Compliance. Penalties are served or are paid in full in a timely manner

Monitoring of compliance. Compliance with penalties is monitored and further legal action is taken in cases of noncompliance

Transparency. Information about penalties and their state of compliance is publicly disclosed

Fairness. Fees collected are reasonable and the basis of computation is understood.

Transparency. Field staff generate comprehensive and accurate records of all fees collected and these are made available to the public.

Awareness. The government takes action to ensure that non-governmental "payers" are aware of their obligations.

Timeliness. Fees are collected in a timely manner.

Monitoring. Regular monitoring evaluates whether appropriate fees are collected as agreed

Participation. Community has participated in the design of local benefit-sharing arrangements.

Compliance. Benefits are delivered in accordance with the agreed terms set out in relevant legal or project documents

Awareness. Community members are aware of benefits received and obligations associated with these benefits

Fairness. The type and extent of benefits are fair and appropriate

Monitoring. Regular monitoring evaluates whether benefits as agreed have reached intended recipients

Knowledge and skills. Institutions capacitated with up to date knowledge and skills to play an active role in forest management

Human resources. Institutions capacitated with an adequate number of staff to play an active role in forest management Financial resources. Institutions capacitated with sufficient financial resources to play an active role in forest management Scientific and technical information. Institutions capacitated with relevant scientific and technical information to play an active role in forest management

Effective. Institutions are effective in implementing forest management objectives

Awareness. Community members are notified in due time of policies to be developed, reviewed and revised that are relevant for land use in their community

Platforms. Platforms are provided for multi-stakeholder participation in policy-making

Representation. Policy-making platforms allow the participation of key representatives from the different forestry sectors

Effectiveness. Facilitation methods allow key stakeholders to participate actively in the process

Transparency. The stakeholders are informed of the results of policy engagements

\section{Appendix B}

Summary of governance polygons by arrangements and community within each landscape and province. Landscapes named by the name of 
chiefdom in which they occur. CC = non-restricted communal customary forest; State = restricted state forest; CI = non-restricted individual customary forest; CTP = culturally restricted communal customary forest

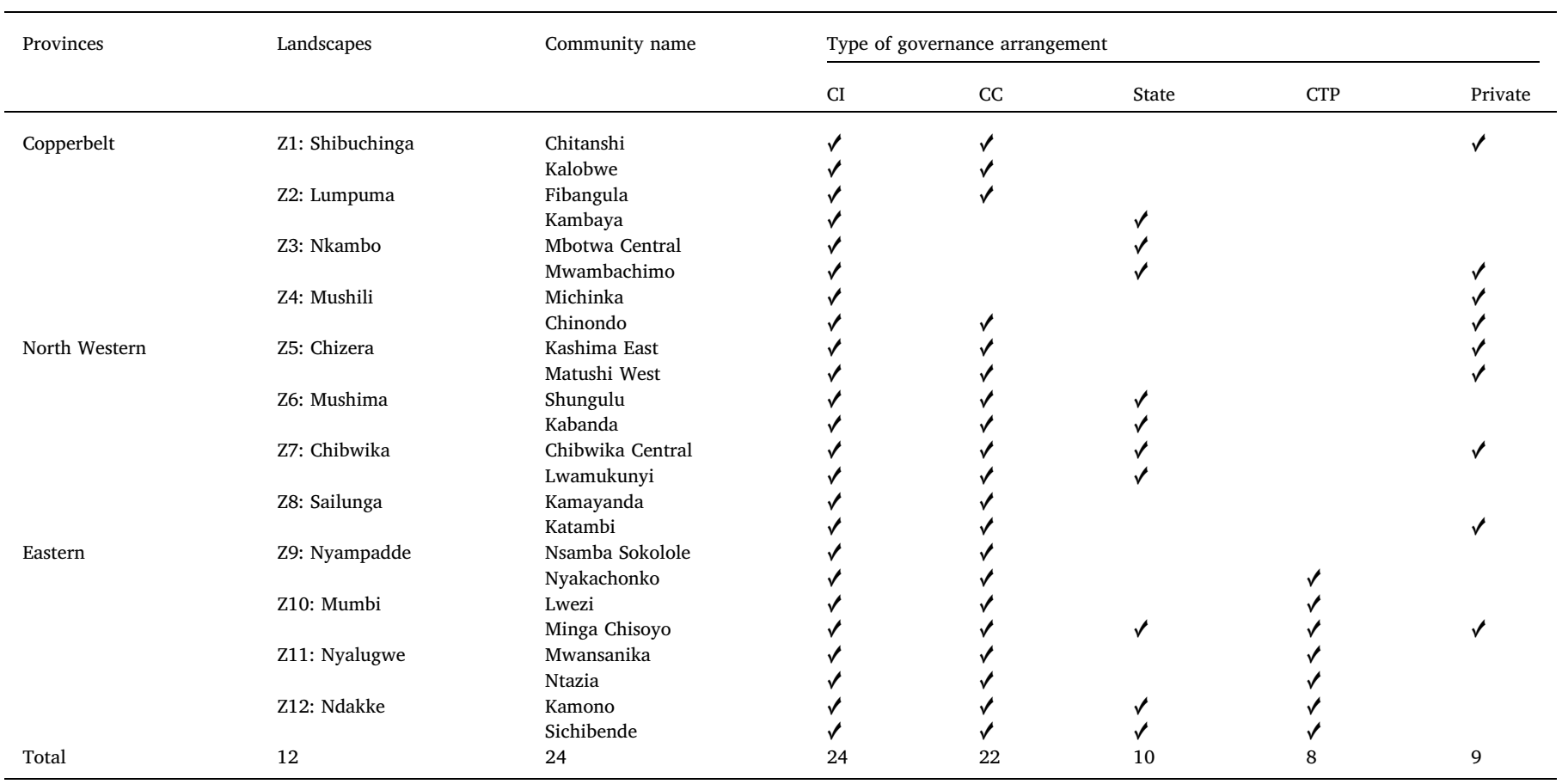

\section{Appendix C}

Summary of mean governance scores for the elements of quality with significant results using the non - parametric Wilcoxon rank test at $\mathrm{p}<0.05$. Mean scores: $0=$ non - existent; $1=$ very low; $2=$ low; $3=$ average, $4=$ high, $5=$ very high. Different superscript letters indicate means that differ significantly between arrangements. $\mathrm{CC}=$ non-restricted communal customary forest; State $=$ restricted state forest; $\mathrm{CI}=$ non - restricted individual customary forest; $\mathrm{CTP}=$ culturally restricted communal customary forest $(\mathrm{N}=64)$

\begin{tabular}{|c|c|c|c|c|c|c|}
\hline \multirow[t]{2}{*}{ Thematic area } & \multirow[t]{2}{*}{ Indicator } & \multirow[t]{2}{*}{ Elements } & \multicolumn{4}{|c|}{ Mean score by governance arrangements } \\
\hline & & & $\mathrm{CC}(\mathrm{N}=22)$ & CTP $(\mathrm{N}=8)$ & $\mathrm{CI}(\mathrm{N}=24)$ & State $(\mathrm{N}=10)$ \\
\hline Forest tenure & Tenure rights recognition & Gender equality & $4.9^{\mathrm{A}}$ & $5.0^{\mathrm{A}}$ & $3.5^{\mathrm{B}}$ & $4.9^{\mathrm{A}}$ \\
\hline \multirow[t]{3}{*}{ Forest management } & Informal law enforcement & Apprehension & $1.1^{\mathrm{A}}$ & $2.4^{\mathrm{A}}$ & $0.6^{\mathrm{A}}$ & $0.0^{\mathrm{B}}$ \\
\hline & & Compliance & $1.9^{\mathrm{A}}$ & $1.9^{\mathrm{A}}$ & $1.9^{\mathrm{A}}$ & $1.0^{\mathrm{B}}$ \\
\hline & & Monitoring & $1.9^{\mathrm{A}}$ & $1.9^{\mathrm{A}}$ & $1.8^{\mathrm{A}}$ & $1.0^{\mathrm{B}}$ \\
\hline
\end{tabular}

\section{Appendix D. Supplementary data}

Supplementary material related to this article can be found, in the online version, at doi:https://doi.org/10.1016/j.landusepol.2020.104866.

\section{References}

Agrawal, A., Ostrom, E., 2001. Collective action, property rights, and decentralization in resource use in India and Nepal. Polit. Soc. 29, 485-514.

Agrawal, A., Wollenberg, E., Persha, L., 2014. Governing agriculture-forest landscapes to achieve climate change mitigation. Glob. Environ. Change 29, 270-280.

Agung, P., Galudra, G., Van Noordwijk, M., Maryani, R., 2014. Reform or reversal: the impact of REDD + readiness on forest governance in Indonesia. Climate Policy 14, 748-768.

Anderson, J., Clément, J., Crowder, L.V., 1998. Accommodating Conflicting Interests in Forestry-Concepts Emerging from Pluralism. UNASYLVA-FAO-, pp. 3-10.

Angelsen, A., 2017. REDD + as result-based aid: General lessons and bilateral agreements of Norway. Rev. Dev. Econ. 21, 237-264.

Arts, B., Behagel, J., Turnhout, E., De Koning, J., Van Bommel, S., 2014. A practice based approach to forest governance. For. Policy Econ. 49, 4-11.

Bewick, V., Cheek, L., Ball, J., 2003. Statistics review 7: correlation and regression. Crit. Care 7, 451.

Bojang, F., Ndeso-Atanga, A., 2013. Promoting good governance in natural resource management in Africa. Nature and Faune. FAO/UNEP.
Brenes, C.L.M., Jones, K.W., Schlesinger, P., Robalino, J., Vierling, L., 2018. The impact of protected area governance and management capacity on ecosystem function in Central America. PloS One 13, e0205964.

Bridge, P.D., Sawilowsky, S.S., 1999. Increasing physicians' awareness of the impact of statistics on research outcomes: comparative power of the t-test and Wilcoxon ranksum test in small samples applied research. J. Clin. Epidemiol. 52, 229-235.

Brito, B., Micol, L., Santos, P., Thuault, A., 2009. The Governance of Forests Initiative Preliminary results of the Brazil Assessment.

Broekhoven, G., Savenije, H., Von Scheliha, S., 2012. Moving Forward with Forest Governance. Tropenbos International, Wageningen, Netherlands.

Brown, T., 2005. Contestation, confusion and corruption: Market-based land reform in Zambia. Competing Jurisdictions: Settling Land Claims in Africa. pp. 79-102.

Byrne, B.M., 2016. Structural Equation Modeling with AMOS: Basic Concepts, Applications, and Programming. Routledge.

Bwalya, B., 2007. Katanino Joint Forest Management Area, Masaiti District, Zambia. Challenges and Opportunities.

Campese, J., 2016. Natural resource governance framework assessment Guide: learning for improved natural resource governance. IUCN/CEESP NRGF Working Paper.

Caron, C., Fenner, S., 2017. Forest access and polycentric governance in Zambia's Eastern Province: insights for REDD +. Int. For. Rev. 19, 265-277. 
Center For International Earth Science Information Network, Columbia University and Information Technology Outreach Services (Itos) \& University Of Georgia, 2013. Global Roads Open Access Data Set, Version 1 (gROADSv1). 2013. NASA Socioeconomic Data and Applications Center (SEDAC) [Online], Palisades, NY. https://doi.org/10.7927/H4VD6WCT. [Accessed 1st March 2019].

Central Statistical Office, 2010. Census of Population and Housing [Online]. Government of the Republic of Zambia, Lusaka, Zambia [Accessed 12. 04 2019].

Chikulo, B., 2009. Local governance reforms in Zambia: a review. Commonw. J. Local Gov. 98

Chileshe, A., 2001. Forestry Outlook Studies in Africa (FOSA): Zambia. Forestry Department, Ministry of Environment and Natural Resources and Food and Agriculture Organization of the United Nations, Lusaka and Rome.

Colding, J., Folke, C., 2001. Social taboos:"invisible" systems of local resource management and biological conservation. Ecol. Appl. 11, 584-600.

Comrey, A.L., Lee, H.B., 2013. A first course in factor analysis. Psychology Press.

Daley, E., 2013. Governing Land for Women and Men: A Technical Guide to Support the Achievement of Responsible Gender-equitable Governance of Land Tenure. Food \& Agriculture Org.

Davis, C., Williams, L., Lupberger, S., Daviet, F., 2013. Assessing Forest Governance: the Governance of Forests Initiative Indicator Framework. World Resources Institute, Washington D. C., USA.

Dawson, N.M., Mason, M., Mwayafu, D.M., Dhungana, H., Satyal, P., Fisher, J.A., Zeitoun, M., Schroeder, H., 2018. Barriers to equity in REDD +: deficiencies in national interpretation processes constrain adaptation to context. Environ. Sci. Policy 88, 1-9.

Decaro, D., Stokes, M., 2013. Public participation and institutional fit: a social-psychological perspective. Ecol. Soc. 18.

Dwyer, J., Bradley, D., Hill, B., 2008. Towards an enhanced evaluation of European Rural Development policy reflections on United Kingdom experience. Économie rurale. Agricultures, Alimentations, Territoires. pp. 53-79.

Eliasch, J., 2012. Climate Change: Financing Global Forests: The Eliasch Review. Routledge.

ESA, 2017. CCI Land Cover - S2 Prototype Land Cover 20m Map of Africa 2016.

FAO, 2015. Global Forest Resources Assessment 2015: How Are the World's Forests Changing? Food and Agriculture Organization of the United Nations.

FAO, 2018. The State of the World's Forests 2018: Forest Pathways to Sustainable Development. Rome, Italy. .

Ferraro, P.J., Hanauer, M.M., Miteva, D.A., Canavire-Bacarreza, G.J., Pattanayak, S.K., Sims, K.R., 2013. More strictly protected areas are not necessarily more protective: evidence from Bolivia, Costa rica, Indonesia, and Thailand. Environ. Res. Lett. 8, 025011.

Fischer, R., Giessen, L., Günter, S., 2020. Governance effects on deforestation in the tropics: a review of the evidence. Environ. Sci. Policy (Accepted).

Fischer, R., Hargita, Y., Günter, S., 2016. Insights from the ground level? A content analysis review of multi-national REDD + studies since 2010. For. Policy Econ. 66, 47-58.

Fletcher, R., Dressler, W., Büscher, B., Anderson, Z.R., 2016. Questioning REDD + and the future of market-based conservation. Conserv. Biol. 30, 673-675.

Flynn, B.B., Sakakibara, S., Schroeder, R.G., Bates, K.A., Flynn, E.J., 1990. Empirical research methods in operations management. J. Oper. Manage. 9, 250-284.

Giessen, L., Buttoud, G., 2014. Defining and Assessing Forest Governance. Elsevier.

Global Forest Watch, 2018. Tree Cover Loss in Zambia.

Goodin, R.E., 1996. Institutions and their design. The Theory of Institutional design 1. pp. 9-53.

GRZ, 2002. The National Decentralisation Policy "towards Empowering the People". Lusaka, Zambia. .

GRZ, 2015a. The Forests Act, No. 4 of 2015. Government of the Republic of Zambia (GRZ), Lusaka, Zambia.

GRZ, 2015b. The Zambia Wildlife Act, No. 14 of 2015. Government of the Republic of Zambia (GRZ).

Gumbo, D., Dumas-Johansen, M., Muir, G., Boerstler, F., Zuzhang, X., 2018. Sustainable Management of Miombo Woodlands: Food Security, Nutrition and Wood Energy. FAO.

GZR, 2015. In: Zambia, G.O.T.R.O. (Ed.), Local Government Act, Lusaka, Zambia Available online: http://www.parliament.gov.zm/sites/default/files/documents/ acts/Local\%20Government\%20Act.pdf. Accessed on 11. April. 2017: Government of the republic of Zambia (2015).

Hansen, M.C., Potapov, P.V., Moore, R., Hancher, M., Turubanova, S., Tyukavina, A., Thau, D., Stehman, S., Goetz, S., Loveland, T., 2013. High-resolution global maps of 21st-century forest cover change. Science 342, 850-853.

Hardin, G., 1968. The tragedy of the commons. Science 162, 1243-1248.

Hayes, T., Persha, L., 2010. Nesting local forestry initiatives: Revisiting community forest management in a REDD + world. For. Policy Econ. 12, 545-553.

Irwin, F., Ranganathan, J., 2007. Restoring Nature's Capital. An Action Agenda to Sustain Ecosystem Services. World Resource Institute, Washington DC.

Jain, N., Chileshe, R., Muwowo, F., Lupiya, M., 2016. Perceptions of customary land tenure security in western province of Zambia. Int. J. Soc. Sci. Stud. 4, 78.

Jenny, A., Fuentes, F.H., Mosler, H.-J., 2007. Psychological factors determining individual compliance with rules for common pool resource management: the case of a Cuban community sharing a solar energy system. Hum. Ecol. 35, 239-250.

Jimoh, S.O., Ikyaagba, E.T., Alarape, A.A., Obioha, E.E., Adeyemi, A.A., 2012. The role of traditional laws and taboos in wildlife conservation in the Oban Hill Sector of Cross River National Park (CRNP), Nigeria. J. Hum. Ecol. 39, 209-219.

Kaimowitz, D., 2012. Forest law enforcement and rural livelihoods. Illegal Logging. Routledge.

Kalaba, F.K., 2013. Forest ecosystem services, rural livelihoods and carbon storage in Miombo woodland in the Copperbelt region of Zambia. University of Leeds.
Kalaba, F.K., 2016. Barriers to policy implementation and implications for Zambia's forest ecosystems. Forest Policy Econ. 69, 40-44.

Kalaba, F.K., Quinn, C.H., Dougill, A.J., 2014. Policy coherence and interplay between Zambia's forest, energy, agricultural and climate change policies and multilateral environmental agreements. Int. Environ. Agree. 14, 181-198.

Kalinda, T., Bwalya, S., Mulolwa, A., Haantuba, H., 2008. Use of integrated land use assessment (ILUA) data for forestry and agricultural policy review and analysis in Zambia. Report prepared for the Forestry Management and Planning Unit of the Department of Forestry, FAO, and the Zambian Forestry Department. Ministry of Tourism, Environment, and Natural Resource Management, Lusaka, Zambia.

Kanninen, M., Murdiyarso, D., Seymour, F., Angelsen, A., Wunder, S., German, L., 2007. Do Trees Grow on Money? The Implications of Deforestation Research for Policies to Promote Redd. Cifor.

Kaufmann, D., Kraay, A., Mastruzzi, M., 2007. Growth and governance: a reply. J. Polit. 69, 555-562.

Kaufmann, D., Kraay, A., Mastruzzi, M., 2011. The worldwide governance indicators: methodology and analytical issues. Hague J. Rule Law 3, 220-246.

Kaushik, M., Mathur, M.B., 2014. Comparative study of K-means and hierarchical clustering techniques. Int. J Softw. Hardware Res. Eng. (IJSHRE) 2.

Kirk, J., Miller, M.L., Miller, M.L., 1986. Reliability and Validity in Qualitative Research. Sage.

Kishor, N., Rosenbaum, K., 2012. Assessing and Monitoring Forest Governance: A user's Guide to a Diagnostic Tool.

Kline, P., 2013. Handbook of psychological testing. Routledge.

Knight, R.S., 2010. Statutory recognition of customary land rights in Africa: an investigation into best practices for lawmaking and implementation. FAO Legislative Study.

Korhonen-Kurki, K., Sehring, J., Brockhaus, M., Di Gregorio, M., 2014. Enabling factors for establishing REDD + in a context of weak governance. Clim. Policy 14, 167-186.

Kurtz, M.J., Schrank, A., 2007. Growth and governance: Models, measures, and mechanisms. J. Polit. 69, 538-554.

Larson, A.M., Barry, D., Dahal, G.R., 2010. New rights for forest-based communities? Understanding processes of forest tenure reform. Int. For. Rev. 12, 78-96.

Larson, A.M., Petkova, E., 2011. An introduction to forest governance, people and REDD + in Latin America: Obstacles and opportunities. Forests 2, 86-111.

Lassar, W.M., Kerr, J.L., 1996. Strategy and control in supplier-distributor relationships: an agency perspective. Strategic Manage. J. 17, 613-632.

Likert, R., 1932. A technique for the measurement of attitudes. Archives of psychology.

Machina, H., 2002. Women's land rights in Zambia: Policy provisions, legal framework and constraints. In: Regional Conference on Women's Land Rights. held in Harare, Zimbabwe, from. pp. 26-30 Citeseer.

Mansourian, S., 2016. Understanding the relationship between governance and forest landscape restoration. Conserv. Soc. 14, 267.

Mansourian, S., 2017. Governance and forest landscape restoration: a framework to support decision-making. J. Nat. Conserv. 37, 21-30.

Mason-Case, S., 2011. Legal preparedness for REDD + in Zambia: Country study. IDLO, Rome.

Matakala, P., Kokwe, M., Statz, J., 2015. Zambia National Strategy to Reduce Emissions from Deforestation and Forest Degradation (REDD +). Forestry Department. Ministry of Lands Natural Resources and Environmental Protection. In Cooperation with Food and Agriculture Organization (FAO) UNDP, and United Nations Environment Programme. Government of the Republic of Zambia.

Mayers, J., Vermeulen, S., 2002. Power from the trees: how good forest governance can help reduce poverty. Opinion: World Summit on Sustainable Development. IIED, London.

Mcdermott, C., Cashore, B.W., Kanowski, P., 2010. Global environmental forest policies: an international comparison. Earthscan.

Mfune, O., 2013. Has decentralisation of forest resources to local governments really taken off on the ground? Experiences from Chongwe District in central Zambia. J. Sustain. Dev. 6, 57.

Millennium Ecosystem Assessment, M, 2003. Ecosystems and human well-being: a framework for assessment. Report of the Conceptual Framework Working Group of the Millennium Ecosystem Assessment.

Ministry Of Lands And Natural Resources, Ministry Of National Development Planning, 2019. Zambia's First REDD + Safeguards Summary of Informationorestry Department and National Safeguards Technical Working Group (NSTWG)Lusaka. Zambia s1.

Ministry of National Development Planning, 2017. Seventh National Development Plan: 2017-2021. Ministry of National Development Planning, Lusaka, Zambia.

Ministry of Tourism Environment and Natural Resources, 2009. National Forestry policy (Draft). Ministry of Tourism, Environment and Natural Resources, Lusaka, Zambia.

Ministry of Tourism Environment And Natural Resources, 2010. 'National Climate Change Response Strategy'(First Draft). Lusaka, Zambia. .

MLNREP, 2015. United Nations Convention on Biological Diversity. Fifth Nationa Report. Ministry of Lands Natural Resources and Environmental Protection, Lusaka, Zambia.

Mulolwa, A., 2016. Land Governance Assessment: Zambia Country Report. World Bank.

Musole, K.J., Chunda-Mwango, N., 2018. Lessons for REDD + implementation: Insights from assessment of forest governance in the joint forest management system in Zambia. J. Biodiversity Environ. Sci. (JBES).

Ng'andwe, P., Mwitwa, J., Muimba-Kankolongo, A., 2015. Forest Policy, Economics, and Markets in Zambia. Academic Press.

Nunnally, J.C., Bernstein, I.H., 1967. Psychometric Theory. McGraw-Hill, New York.

Ostrom, E., 1990. Governing the Commons: The Evolution of Institutions for Collective Action. Cambridge University Press.

Ostrom, E., 1993. Design principles in long-enduring irrigation institutions. Water Resour. Res. 29, 1907-1912. 
Ostrom, E., 2008. Design Principles of Robust Property-Rights Institutions: What Have We Learned.

Ostrom, E., 2009. A general framework for analyzing sustainability of social-ecological systems. Science 325, 419-422.

Parker, P.L., Mcdaniel, H.S., Crumpton-Young, L.L., 2002. Do research participants give interval or ordinal answers in response to likert scales? In: IIE Annual Conference. Proceedings. Citeseer. pp. 1.

Payne, G., Durand-Lasserve, A., 2012. Holding on: security of tenure-types, policies, practices and challenges. Research Paper Prepared for the Special Rapporteur on Adequate Housing as a Aomponent of the Right to an Adequate Standard of Living, and on the Right to Non-discrimination. http://www.ohchr.org/Documents/Issues/ Housing/SecurityTenure/Payne-Durand-Lasserve-BackgroundPaper-JAN2013.pdf.

Pettenella, D., Brotto, L., 2012. Governance features for successful REDD + projects organization. For. Policy Econ. 18, 46-52.

Rauschmayer, F., Berghöfer, A., Omann, I., Zikos, D., 2009. Examining processes or/and outcomes? Evaluation concepts in European governance of natural resources. Environ. Policy Govern. 19, 159-173.

Rescher, N., 1993. Pluralism: Against the demand for consensus.

Robinson, B.E., Masuda, Y.J., Kelly, A., Holland, M.B., Bedford, C., Childress, M., Fletschner, D., Game, E.T., Ginsburg, C., Hilhorst, T., 2018. Incorporating land tenure security into conservation. Conserv. Lett. 11, e12383.

Sarstedt, M., Mooi, E., 2014. A concise guide to market research. The Process, Data.

Servir, 2015. Zambia Populated Places 2015. [Online]. https://cs4rd.org/data-map/. [Accessed 1st March 2019].

Seymour, F., Busch, J., 2016. Why forests? Why now?: The science, economics, and politics of tropical forests and climate change. Brookings Institution Press.

Shakacite, O., Chungu, D., Ng'andwe, P., Chendauka, B., Siampale, A., Tavani, R. Roberts, W., Vesa, L., 2016. Integrated Land Use Assessment Phase II-report for Zambia. The Food and Agriculture Organization of the United Nations and the
Forestry Department, Ministry of Lands and Natural Resources, Lusaka, Zambia Lusaka, Zambia Viewed at www.zmb-nfms.org/iluaii/index.php.

Spichinger, R., Kabala, E., 2014. Gender equality and land administration: the case of zambia. DIIS Working Paper.

Stickler, M.M., Huntington, H., Haflett, A., Petrova, S., Bouvier, I., 2017. Does de facto forest tenure affect forest condition? Community perceptions from Zambia. For. Policy Econ. 85, 32-45.

Turner, R.A., Fitzsimmons, C., Forster, J., Mahon, R., Peterson, A., Stead, S.M., 2014. Measuring good governance for complex ecosystems: perceptions of coral reef-dependent communities in the Caribbean. Glob. Environ. Change 29, 105-117.

Turpie, J., Warr, B., Ingram, J., 2015. Benefits of Forest Ecosystems in Zambia and the Role of REDD + in a Green Economy Transformation. United Nations Environment Programme (UNEP). Retrieved from http://www.unredd. net/documents/global-programme--191/redd--and--the--green--economy--1294/forest--ecosystem--valuation--and--economics/14059--benefits--of--forest--ecosystems--in--zambia--and--the-role--of--redd--in--a--green--economy--transformation.html. .

Umemiya, C., Rametsteiner, E., Kraxner, F., 2010. Quantifying the impacts of the quality of governance on deforestation. Environ. Sci. Policy 13, 695-701.

UNEP-WCMC, IUCN, 2016. Protected planet. The world database on protected areas (WDPA). The Global Database on Protected Areas Management Effectiveness (GDPAME). . [Online]. Cambridge, UKwww.protectedplanet.net. [Accessed 1st March 2019].

United Nations, 2015. Transforming Our World: the 2030 Agenda for Sustainable Development. United Nations, Department of Economic and Social Affairs, New York. Van Loenen, B., 1999. Land tenure in Zambia.

Vinya, R., Syampungani, S., Kasumu, E., Monde, C., Kasubika, R., 2011. Preliminary Study on The Drivers of Deforestation snd Potential For Redd + In Zambia. FAO/ Zambian Ministry of Lands and Natural Resources, Lusaka, Zambia.

Williams, G., 2011. What makes a good governance indicator. Policy Practice Brief. pp. 6. 


\title{
Can de facto governance influence deforestation drivers in the Zambian Miombo?
}

\author{
Hellen Nansikombi ${ }^{\mathrm{a}, \mathrm{b}, *}$, Richard Fischer ${ }^{\mathrm{a}}$, Rubén Ferrer Velasco ${ }^{\mathrm{a}, \mathrm{b}}$, Melvin Lippe ${ }^{\mathrm{a}}$, \\ Felix Kanungwe Kalaba ${ }^{c}$, Gillian Kabwe ${ }^{\mathrm{c}}$, Sven Günter ${ }^{\mathrm{a}, \mathrm{b}}$ \\ a Thünen Institute of International Forestry and Forest Economics, Leuschnerstraße 91, Hamburg 21031, Germany \\ ${ }^{\mathrm{b}}$ Chair of Ecosystem Dynamics and Forest Management, Department of Ecology and Ecosystem Services, TUM School of Life Sciences Weihenstephan, Technical University \\ of Munich, 85354 Freising, Germany. \\ ${ }^{\mathrm{c}}$ Copperbelt University, School of Natural Resources, P.O Box 21692, Kitwe, Zambia
}

\section{A R T I C L E I N F O}

\section{Keywords:}

Forest governance

Drivers of deforestation

Local scale

Zambia

Miombo

\begin{abstract}
A B S T R A C T
Weak forest governance is posited as a key underlying driver of deforestation and forest degradation, but empirical evidence of this linkage is scarce. Many related studies capture the de jure (legal) conditions and miss out the de facto (implementation practices on the ground), particularly when considering the proximate drivers and other factors of deforestation. However, this is central for identifying the specifics of governance for curbing deforestation and forest degradation. We analyse the influence of de facto governance quality on deforestation, accounting for proximate drivers and other factors using stepwise regression. We further compare deforestation rates and drivers across different governance arrangements with differing institutions, tenure and forest access restrictions using Wilcoxon tests to derive conclusions for promising policy instruments that address deforestation. Data for the analysis were obtained through participatory mapping, focus group discussions and geographical information systems. To generate empirical evidence, 238,296 ha of land were mapped within 24 communities spanning three provinces, Copperbelt, North-Western and Eastern, in the Zambian Miombo. Regression results revealed that de facto governance quality has some effect but proximate drivers particularly charcoal production, crop agriculture and proximity to roads explain most of the deforestation patterns in the Zambian Miombo. Those drivers seem hardly affected by the weak governance processes. Since scores of governance quality were in general low and hardly varying, we conclude that in our case they were too weak to show effects on the proximate drivers. Only the governance indicator 'local government capacity and effectiveness' although still weak, was significantly linked to low deforestation rates. Comparative results further showed that restricted arrangements (state and traditionally restricted) exhibit lower deforestation than nonrestricted arrangements (communal, forests with overlapping community claims, private and individual customary forests). But while crop agriculture was negligible, forest resource extraction was still substantial in restricted state forests, indicating a higher possibility for forest degradation instead. Although private and individual customary forests had higher tenure security, they showed higher deforestation rates than communal and state arrangements. This challenges the notion that tenure security alone guarantees successful forest conservation. Our results suggest that governance can only affect deforestation drivers positively above certain thresholds. This needs to be further complemented by specific measures such as sustainable production systems, incentives and alternative livelihoods to regulate the proximate and other underlying drivers of deforestation.
\end{abstract}

\section{Introduction}

\subsection{Deforestation in the Zambian Miombo}

Deforestation and forest degradation are threats to biodiversity, ecosystem functioning and well-being of millions of humans who derive their livelihoods from forests (Millennium Ecosystem Assessment, 2003, FAO, 2018, Naeem et al., 2016). This is particularly important in Africa, with the largest annual rate of net forest loss at 3.9 million ha, between 2010 and 2020 (FAO, 2020) and is projected to increase by $4 \%$ by 2030 (d'Annunzio et al., 2015). With Africa's forests linked to the rural livelihoods of over two-thirds of its population and $70 \%$ of its

\footnotetext{
*Corresponding author at: Thünen Institute of International Forestry and Forest Economics, Leuschnerstraße 91, Hamburg 21031, Germany.

E-mail address: hellen.nansikombi@thuenen.de (H. Nansikombi).
} 
households'energy requirements (FAO, 2018), it is imperative to curb deforestation and forest degradation on this continent.

In sub-Saharan Africa (SSA), the countries with relatively weak forest cover e.g. Madagascar, Ivory Coast and Nigeria and those predominated by dry forests e.g. Zambia exhibit higher deforestation rates than the humid forest-rich countries e.g. Congo and Gabon (Rudel, 2013; Mayaux et al., 2013). In Zambia, although available estimates differ due to methodological differences (Kamelarczyk and Gamborg, 2014), studies report escalating deforestation and forest degradation. According to Phiri et al. (2019a) the annual rate of deforestation in Zambia ranged from $0.54 \%$ to $3.05 \%$ between 1972 and 2016, higher than reported by FAO (2015) at $0.3 \%$. Similarly, according to Global Forest Watch (2019), the mean annual tree cover loss rate of the country, considering a $30 \%$ tree cover threshold, increased from $0.22 \%$ to $0.54 \%$, when comparing the $2000-2009$ and the $2010-2018$ periods. Forest loss is likely to adversely impact the functioning of the Zambian Miombo woodland, the major forest type in the country.

The Miombo woodland is the most extensive dryland forest ecosystem in SSA, covering about 2.7 million $\mathrm{km}^{2}$ (Gumbo et al., 2018; Frost, 1996). Characterized by the dominance of Brachystegia, Julbernadia and Isoberlinia species (Matakala et al., 2015), the Miombo is one of the five global biodiversity hotspots (Mittermeier et al., 2003), harbouring about 8500 higher plant species (Frost, 1996), 54\% of which are endemic (Rodgers et al., 1996). Additionally, on average the woodland sequesters between 0.5 and 0.9 tons of carbon per hectare annually (Chidumayo, 2014; Williams et al., 2008), contributing to global climate change mitigation. Further, over 100 million rural people directly rely on Miombo's timber and non-timber forest products for income (Gumbo et al., 2018; Bradley and Dewees, 1993). Despite its importance, deforestation and forest degradation persist in the Miombo (Vinya et al., 2011; Chomba et al., 2012; Kalinda et al., 2008), weakening its ability to provide forest ecosystems goods and services (Millennium Ecosystem Assessment, 2003).

\subsection{Drivers of deforestation in the Zambian Miombo}

Many studies report small scale crop agriculture as a key proximate driver of deforestation and forest degradation in SSA and accordingly Zambia (Phiri et al., 2019b; Mayaux et al., 2013; Curtis et al., 2018). Timber logging, infrastructure extension, charcoal production, firewood collection and livestock grazing are also notable proximate drivers of forest loss in SSA (Kissinger et al., 2012; Hosonuma et al., 2012). The underlying drivers of deforestation and forest degradation in SSA are demographic/population pressure, economic, technological, governance and socio-cultural factors (Geist and Lambin, 2001; Rudel, 2013). Amongst the underlying drivers, mostly population density/ growth is linked to deforestation and forest degradation in SSA (Mayaux et al., 2013; Rudel, 2013; DeFries et al., 2010) because it is interrelated with increased demand for agricultural land and forest products (Rademaekers et al., 2010).

An equally important underlying driver is weak forest governance, with $90 \%$ of the SSA countries in the reduced emissions from deforestation and degradation (REDD + ) readiness phase, including Zambia, linking it to the detected forest loss (Kissinger et al., 2012). Weak governance fails to limit unsustainable anthropogenic forest use activities, which also constitute the proximate drivers of deforestation and forest degradation (Geist and Lambin, 2001). Forest governance "comprises all formal and informal, public and private regulatory structures i.e. institutions consisting of rules, norms, principles, decision procedures, concerning forests, their utilization and their conservation, the interactions between public and private actors therein and c) the effects of either on forests" (Giessen and Buttoud, 2014). In Zambia, the Miombo included, forest governance is characterized by weak institutions that fail to adequately enforce forest policies, rules and regulations, weak policy and insecure and unclear land tenure (Nansikombi et al., 2020; Gumbo et al., 2018; Kalaba, 2016). Because of this situation, there is demand for improved governance solutions in Zambia's Miombo forests (Gumbo et al., 2018; Dewees et al., 2010; Stickler et al., 2017).

\subsection{Research gap}

Although improved forest governance is posited a prerequisite for reducing deforestation and forest degradation in the Zambian Miombo (Matakala et al., 2015; Gumbo et al., 2018; Kazungu et al., 2020), there is limited understanding of the specifics of governance that are likely to foster successful outcomes (Umemiya et al., 2010). Moreover, as governance attributes are only part of the underlying drivers (Geist and Lambin, 2001; Hosonuma et al., 2012), it is necessary to account for the role of the proximate and other drivers in governance-deforestation relationships. Specific governance attributes that have been linked to forest conservation are tenure security (Robinson et al., 2014), land use planning (Nolte et al., 2017), participatory policy processes (Wright et al., 2016), law enforcement (Nugroho et al., 2018; Tacconi et al., 2019) and government, non-government and customary institutions (Banana et al., 2001; Ostrom, 2009). Likewise, included are the diverse arrangements that indicate the tenure (Holland et al., 2014; Robinson et al., 2014), access and use restrictions (Pfaff et al., 2014), and the institutions with the responsibility for forest management (Lund et al., 2009). In Zambia, these range from (i) restricted command and control arrangements in state-owned National Forest Reserves and National Parks, (ii) participatory arrangements with restrictions of forest use and management in state-owned Local Forest Reserves, and Game Management Areas, to (iii) inclusion of communities, customary institutions and private entities into forest conservation initiatives in customary and private forests (GRZ, 2015a; GRZ, 2015b). However, not in all cases these governance attributes are equally supportive of forest conservation (Wehkamp et al., 2018; Bray et al., 2008). Besides, different studies underscore differing institutional arrangements i.e. communal (Rights and Initiative, 2018; Oldekop et al., 2019), private (Koyuncu and Yilmaz, 2013b; Koyuncu and Yilmaz, 2013a) and state (Dudley and Stolton, 2010; Wilshusen et al., 2002), as optimal policy options for effective forest conservation. The mixed results imply the necessity for further studies in this respect, also recommended for the Zambian Miombo by Nansikombi et al. (2020).

Understanding governance-deforestation relationships has also become a priority topic in the global deliberations on forests e.g. New York declaration on forests (United Nations Climate Summit, 2014). The subject has as well received growing attention in the recent global environmental change research (Umemiya et al., 2010; Wehkamp et al., 2018; Bhattarai and Hammig, 2004; Li and Reuveny, 2006; Abman, 2018). However, the respective studies use rather general than forestspecific governance indicators such as corruption democracy, voice and accountability, political stability, violence and rule of law. Although they provide valuable insights, general governance indicators may capture broader phenomena and mask the effects of forest-specific governance aspects on deforestation (Kishor and Belle, 2004; Wehkamp et al., 2018). Besides, in absence of reliable governance data at the local scale (Secco et al., 2014), most studies are conducted at the national scale and only capture the de jure (legal) conditions. As de jure notions have been found to differ substantially from the de facto, reality that exists on the ground (Agarwala and Ginsberg, 2017; Kaufmann et al., 2007; Ribot, 2003), such studies fail to account for variations from differential implementation of forest policy and institutional reforms on the ground (Wehkamp et al., 2018; Puyravaud, 2003).

\subsection{Aim/research question}

We examine the influence of forest governance quality on deforestation in the Zambian Miombo, accounting for the proximate drivers and other factors. We aim to identify the specifics of forest governance with potential for reversing deforestation trends in the Miombo. We 
also aim to highlight more clearly the potential implications of tackling underlying drivers, herein governance challenges, without adequate consideration for the proximate drivers and vice versa. This is relevant for Zambia's initiatives for reducing emissions from deforestation and forest degradation (Matakala et al., 2015) and climate change strategies (Ministry of Tourism Environment and Natural Resources, 2010), which propose improved forest governance to curb forest loss. We additionally compare deforestation across diverse governance arrangements with differing institutions, tenure and restrictions to forest access and use, aiming to develop conclusions for promising policy instruments for addressing deforestation on the ground in the Miombo.

We address three research questions. (i) How does the annual rate of deforestation vary between diverse forest governance arrangements with differing institutions, tenure and restrictions to forest access and use? (ii) Which are the proximate drivers and other factors that influence deforestation rates in the Zambian Miombo? (iii) Does governance quality explain deforestation patterns if considered in addition, and if yes, which specific governance attributes play a significant role?

We employ a research approach that combines participatory mapping, focus group discussions, and geographical information systems (GIS) to collect data and use the comparative statistical approach (Wilcoxon test) and stepwise multiple regression models for the analysis:

\subsection{De jure forest governance arrangements in Zambia}

Zambia has diverse forest governance arrangements, under the responsibility of different institutions, across different tenure categories and with varying access and use restrictions (Appendix A). $23.7 \%$ of forests in Zambia occurs on state land, administered by either the Department of National Parks and Wildlife or Forest Department (GRZ, 2015b). Under the formal law, access and use of forest resources on state forests is restricted except with special permits. $65.7 \%$ forest occurs on either individual or communal customary lands, governed by chiefs and their representatives (GRZ, 2015a; Kalinda et al., 2008). Under the formal law, commercial use of forest products without a license on customary lands is restricted although access and subsistence use are not (GRZ, 2015a). Private forests (10.6\% of the total forest area) also exist on state lands. These are owned by registered individuals or firms through leasehold tenure (GRZ, 2015a, Kalinda et al., 2008).

\section{Conceptual framework}

The post-colonial concept of steering decision-making and administration of forests specifically in developing countries focussed on governments that exercised authority through state agencies (Peters and Pierre, 1998; Rhodes, 2007). Starting in the 1980s and due to overexploitation, corruption and policy failure associated with state agencies, there was a transition from an entirely state-driven to multiactor governance (Arts, 2014). The contemporary governance concept recognizes forest governance as broader than governments, covering many actors in society including civil society, communities and the private sector (Agrawal et al., 2008; Arts, 2014; Mwangi and Wardell, 2012). Taking into account the definition of Giessen and Buttoud (2014), we conceptualize governance as being based on (A) multiple actors and (B) formal and informal rules of forest-related decisions and their implementation (Fig. 1). In addition to these two components, we take into account (C) interactions amongst actors and (D) interactions between actors and rules and (E) the effects of either on forests to compose a comprehensive governance framework (Giessen and Buttoud, 2014; Davis et al., 2013; Kishor and Rosenbaum, 2012). Because it is difficult to cover all these components within the methodology of one study, while simultaneously maintaining scientific rigour, it is recommended to focus on certain components (Giessen and Buttoud, 2014). In this study, we explicitly analyse the effects (E) of institutions, rules and their interactions on deforestation at the local level, where implementation processes occur in practise (de facto).
Governance arrangements (Appendix A) are specific expressions and combinations of these basic governance components and constitute key spatial units of assessment in governance studies.

To assess the quality of rules, and institutions/actors and their interactions we use a set of governance indicators (Section 3.2.4) from the Governance of Forests Initiative (GFI) framework of the World Resource Institute (Davis et al., 2013). Like in other governance assessment frameworks (de Graaf et al., 2017; Kishor and Rosenbaum, 2012; Worldbank, 2006), these indicators reflect compilations of operational aspects that were found to be relevant for forest governance. The GFI framework groups the relevant issues into six thematic areas: 1 ) forest tenure, 2) land use planning, 3) forest management, 4) forest revenues, 5) crosscutting institutions and 6) crosscutting issues (Davis et al., 2013). The indicators are clustered according to these thematic areas. Although the GFI framework is primarily practise-oriented, the indicators capture the different components of the above described theory-based governance concept (Davis et al., 2013).

Weak forest governance is an underlying driver i.e. a fundamental force that underpins the proximate drivers of deforestation and forest degradation (Geist and Lambin, 2001; Turner et al., 1993; Hosonuma et al., 2012). Therefore, we incorporate the role of proximate drivers of deforestation (Fig. 1). Proximate drivers are human activities that directly affect the forest (Geist and Lambin, 2001, Turner et al., 1993, Hosonuma et al., 2012). They include agricultural expansion, wood extraction and infrastructure extension (Vinya et al., 2011; Armenteras et al., 2017; Geist and Lambin, 2001). We also account for other factors that work as catalytic attributes, leading to changes in human-environment conditions i.e. slope and size of the forest. Other important underlying drivers of deforestation in SSA are also considered i.e. demographic/population density (Mayaux et al., 2013), economic and socio-cultural drivers (Geist and Lambin, 2001; Kissinger et al., 2012).

\section{Materials and methods}

\subsection{Study area and site selection}

The study was conducted in the Zambian Miombo woodland. Three provinces, Copperbelt, North-Western and Eastern (Fig. 2) were selected to represent different socio-economic and demographic conditions as well as different forest cover and deforestation contexts (Table 1). North-Western is characterized by a low population density, estimated at 8 persons $/ \mathrm{km}^{2}$ in 2017 (WorldPop, 2018), high forest cover $(71 \%)$ with a tree cover larger than $30 \%$ in 2010 (Global Forest Watch, 2019), and unsustainable timber extraction as the main driver of deforestation (Shakacite et al., 2016). Medium to low deforestation rates have been observed, with an annual average tree cover loss of 0.30\% between 2013 and 2017 (Global Forest Watch, 2019). According to the same sources, Eastern province has a medium population density, estimated at 38 persons $/ \mathrm{km}^{2}$ in 2017 , low tree cover (14\%) and a relatively low rate of tree cover loss ( $0.40 \%$ annually) between 2013 and 2017, mostly from small-scale crop agriculture. Copperbelt is characterized by a very high population density, estimated at 76 persons/ $\mathrm{km}^{2}$ in 2017 , medium to high tree cover $(60 \%)$, and high rate of tree cover loss (1.16\% annually) between 2013 and 2017, mostly from unsustainable charcoal production.

Within each of the three provinces, four landscapes of approximately $150 \mathrm{~km}^{2}$ each were selected, thus a total of 12 landscapes (Fig. 2). These landscapes corresponded to twelve distinct traditional administration units (chiefdoms), each with typical land-use, socioeconomic, demographic and biophysical attributes of their respective province (Fig. 2). Within each landscape, two communities were selected for the study, thus a total of 24 communities. A community, constitutes a group of people living together who share natural resources and are tied together by local traditions, rules and values under the leadership of a section head/sub-chief (Twumasi and Freund, 1985; Madzudzo et al., 2013). 


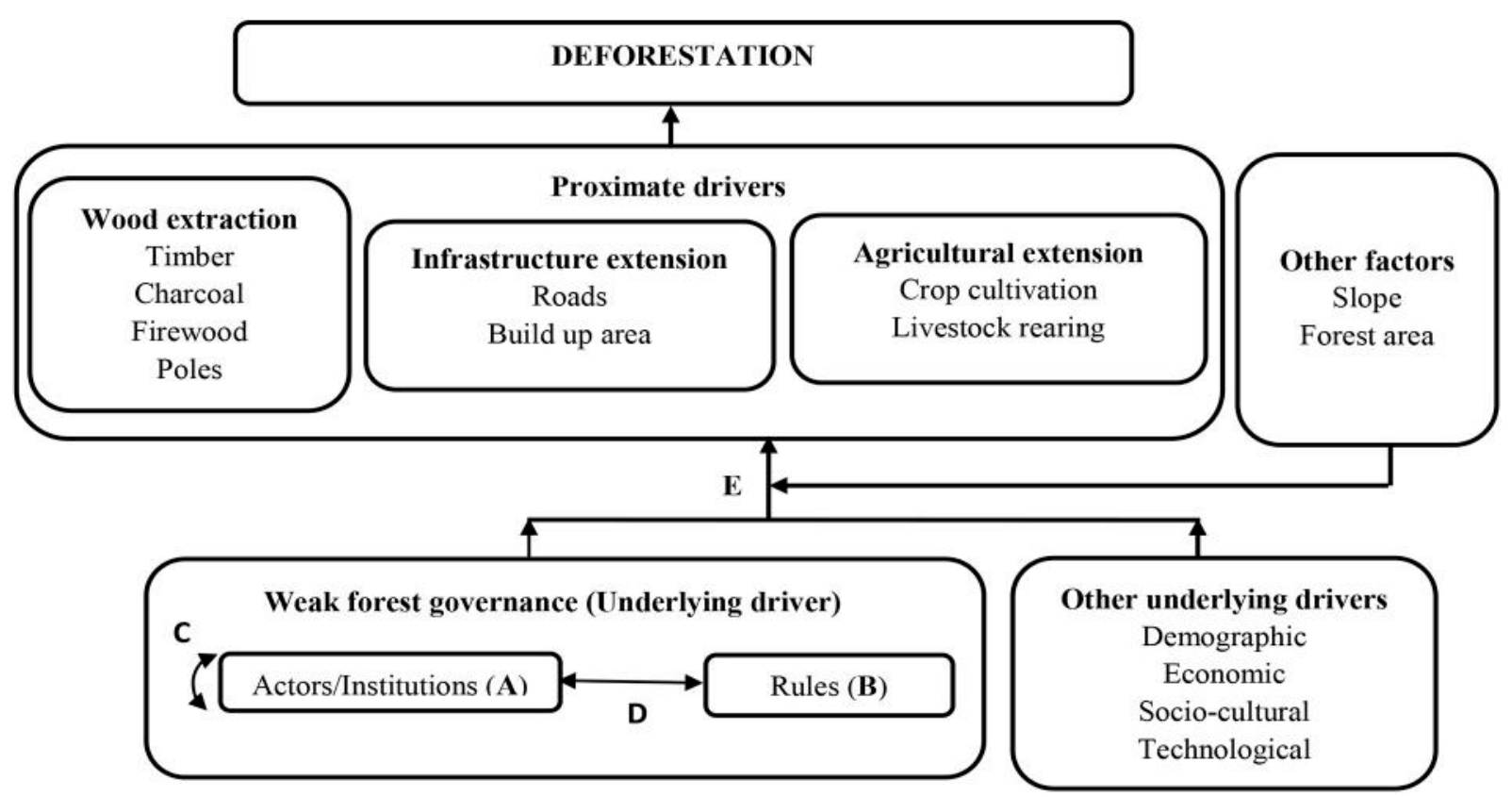

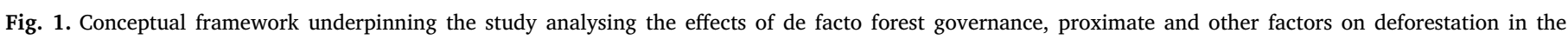

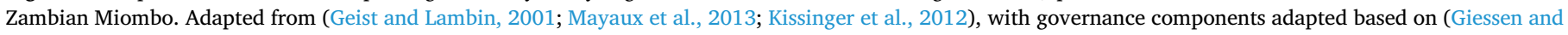
Buttoud, 2014; Arts, 2014).

\subsection{Data sources and preparation}

\subsubsection{Participatory mapping exercises and focus group discussions (FGD)}

Focus group discussions (FDG) (O. Nyumba et al., 2018) were carried out to conduct governance assessment and participatory mapping exercises aiming to identify the locally perceived, de facto, governance arrangements and land use patterns. Focus group discussions were carried out in all 24 communities, each with 15 key stakeholder representatives including sub-village leaders, customary leaders and forest committee representatives. Participants comprised men, women, youth (18-30 years), and long-term members of the community. This enabled broad representation of decision makers and social groups in the community. Despite the fact that FGDs are perception-based methods, they capture the reality that exists on the ground, which differs from the factbased notions of laws (Kaufmann et al., 2011). Participatory mapping (Martin et al., 2012) was essential to create awareness on the focus governance arrangements and to ensure that subsequent governance assessment was done in a spatially consistent manner. The participatory mapping exercises were carried out between November 2017 and October 2018, using recent colour print outs of high-resolution Google Earth satellite images of approximately $80 * 120 \mathrm{~cm}$.

\subsubsection{Classification and delineation of governance arrangements}

In the participatory mapping exercise, while making reference to the de jure categories of governance arrangements in Zambia, participants were asked to distinguish and delineate the de facto arrangements within their community using the satellite image print outs. Outcomes of these exercises were summarized into five categories, taking into account the local conditions including the institutions with the responsibility for forest control, tenure and access and use restrictions. These are (i) state forests with restrictions to access and use, (ii) communal customary forests with traditional restrictions to access and use, (iii) communal customary forest without restrictions to access and use, (iv) individual customary forests with no restrictions to access and use and (v) private forests with use decided by the registered landowner. The polygons of the mapped governance arrangements within each community were subsequently digitized using QGIS (illustrated in Fig. 3, Map 3).
The participatory mapping exercises from the 24 communities and subsequent digitization resulted in 70 identified de facto governance arrangements. The arrangements specify the institutions with the responsibitity to control forests (state, community and private), tenure (customary and state) and access and forest use restrictions (restricted and non-restrcited), at the level of implementation (de facto). They constitute 6 state forests with access and use restrictions, 8 communal customary forests with traditional restrictions to access and use, 22 communal customary forests without restrictions to access and use, 24 individual customary forests with no restrictions to access and use and 10 private forests. As polygons of some governance arrangements were overlapping between neighbouring communities co-existing in the same landscape, we created an additional category of arrangement referred to as "forests with overlapping community claims". This category constituted 21 cases in the 24 communities raising the number of polygons to 91 . The forest governance arrangements were used as units of analysis because they represent the lowest level of forest governance in Zambia (Kalinda et al., 2008; GRZ, 2015a).

\subsubsection{Classification and delineation of main land use types}

FGD participants were asked to delineate land use patterns in their community using a classification based on Di Gregorio and Jansen (2005) as a reference, also taking into account the local conditions. Overall, 11 main land use classes (Appendix B) could be distinguished and spatially delineated during the participatory mapping exercises. These were also digitized using QGIS (Fig. 3, Map 2).

\subsubsection{Other governance attributes: governance indicators}

In addition to the categories of governance arrangements (Section 3.2.2), the GFI indicators were included as governance attributes. The GFI framework recommends that from the large multitude of governance aspects covered, the indicators should be "adapted based on contextual factors such as scale of assessment, type of forest biome, or ownership regime." After thorough literature analysis coupled with a pre-test workshop in Zambia, we selected at least one indicator from each of the thematic areas (see Section 2), choosing those that reflect pertinent issues in Zambia's forest governance. Altogether we selected 19 quantitative governance indicators covering all thematic areas of the 

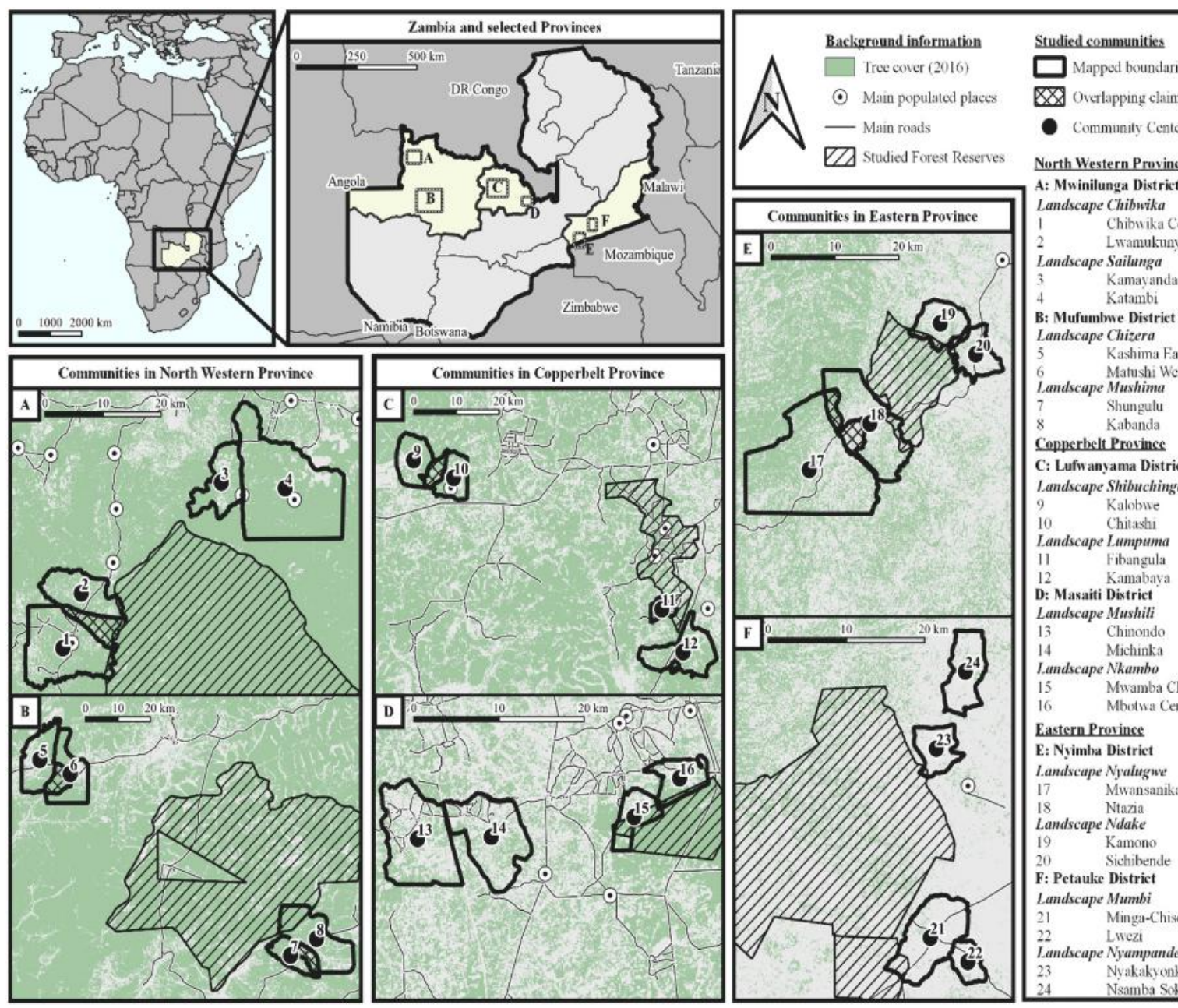

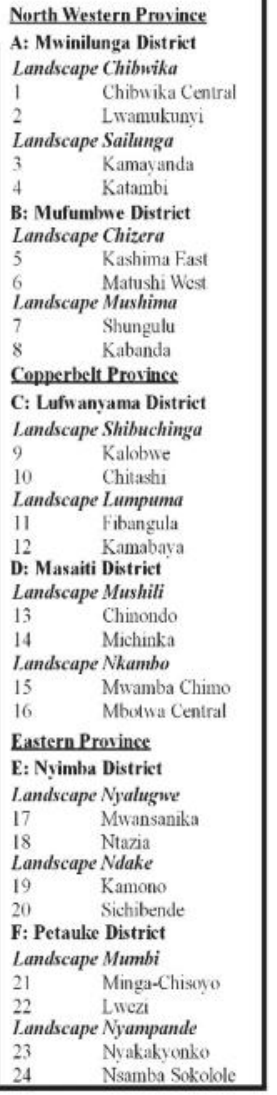

Fig. 2. A Map showing the locations of the study provinces, districts, landscapes and communities in Zambia in the Southern part of Africa. Landscapes are labelled according to the chiefdoms within which they are located. Sources: Tree Areas (ESA, 2017), Main populated places (SERVIR, 2015), Main roads (OpenStreetMap, 2020) and Research Forest Reserves (UNEP-WCMC and IUCN, 2016).

GFI and adapted them to the Zambian context as follows:

- Thematic area "forest tenure": (1) recognition and protection of tenure rights

- Thematic area "land use": (2) formal land use planning.

- Thematic area "forest management": (3) implementation of land use strategies and plans, administration of licences for (4) timber, (5) charcoal and, (6) non-timber forest products, implementation of (7) reforestation, (8) forest protection and conservation, (9) payment for ecosystem services, (10) forest-based livelihood programs/projects and enforcement of (11) formal and (12) customary forest laws.
- Thematic area "revenues": (13) forest revenue distribution and, (14) implementation of benefit-sharing mechanisms.

- Thematic area "crosscutting institutions" capacities and efficiencies of (15) central, (16) local government, (17) non-government organizations and (18) customary institutions.

- Thematic area "cross-cutting issues": (19) public participation in policy-making.

Each selected indicator was specified by five elements of quality, rated on a scale of pre-coded statements, from lack of good governance to good practice (Appendix C). In the FGD, participants were asked to discuss

Table 1

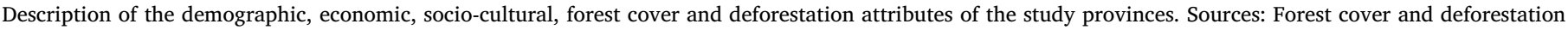

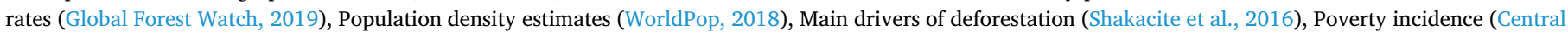
Statistical Office, 2018). Dominant ethnicity and share of urbanized population (Central Statistical Office, 2016).

\begin{tabular}{|c|c|c|c|c|}
\hline Attributes & Zambia & Copperbelt & North-Western & Eastern \\
\hline Forest cover $(2010)$ (Tree cover $>30 \%)$ & $30 \%$ & $60 \%$ & $71 \%$ & $14 \%$ \\
\hline Deforestation rates & High & High & Medium-Low & Medium-Low \\
\hline (Mean annual tree cover $>30 \%$ loss 2013-17) & $-0.52 \%$ & $-1.16 \%$ & $-0.30 \%$ & $-0.40 \%$ \\
\hline Population density 2017 (people $/ \mathrm{km}^{2}$ ) & 22 & 76 & 8 & 38 \\
\hline Poverty incidence (\%) & - & 30.80 & 66.40 & 70.00 \\
\hline Urban share of the population (\%) & 41.80 & 83.00 & 27.20 & 12.20 \\
\hline Dominant ethnicity & - & Bemba & Luvale & Chewa \\
\hline Main driver of deforestation & - & Charcoal production & Timber extraction & Small-scale farming \\
\hline
\end{tabular}




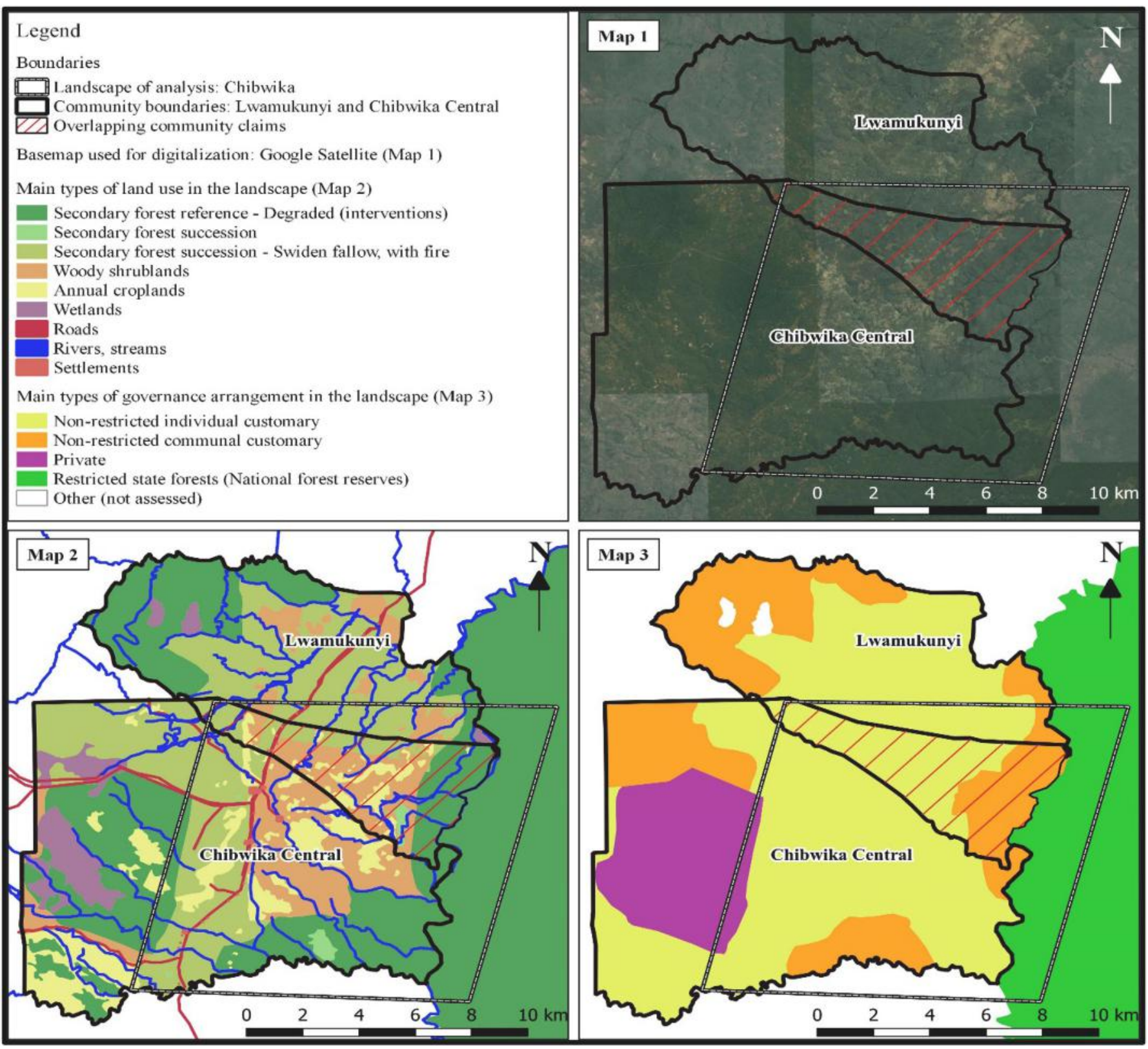

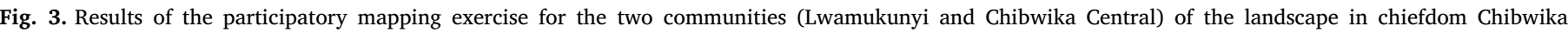

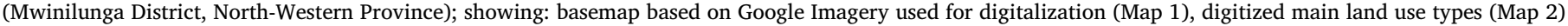
and digitized governance arrangements (Map 3).

(based on their experiences) and agree on scores for governance performance, which was assigned as a Likert score (Likert, 1932) on a scale from 0 (not present), 1 (very low) to 5 (very high) to each element of quality (Appendix C) within each of the governance arrangements. Likert scales constitute data transformation from qualitative to quantitative form (Flynn et al., 1990). This permits the reliable integration of information across observations or cases (Kirk et al., 1986). Moreover, although criticized for producing ordinal data, Likert scales have been found to provide interval data, suitable for parametric statistical analysis (Parker et al., 2002). Likert scores of all five elements of quality per indicator were aggregated as the arithmetic mean in order to derive indicator values for each of the governance arrangements. The governance scores for the overlapping arrangements were generated as the arithmetic mean of the scores assigned by both communities for the given arrangement category. We further calculated the mean (aggregated) score of all governance indicators for each governance arrangement in addition to the governance scores of the 19 GFI indicators. All qualitative comments that were given for the governance scores were noted. It was not possible to establish contacts to private landowners to a meaningful extent; thus we could not score governance on private forests. Accordingly, the 10 private arrangements and one overlapping arrangement with private claims were excluded from the later analysis where governance indicators were needed.

\subsubsection{Deforestation}

Deforestation was used as the dependent variable in our statistical analysis. The average annual rate of tree cover loss was used as a proxy for the annual rate of deforestation relying on data from Hansen et al. (2013) as provided by Global Forest Watch (Global Forest Watch, 2018). Similar to related studies in Africa (Potapov et al., 2012; Zabala, 2018; Venter et al., 2018), Hansen et al. (2013) provide tree cover and change estimates for the study period. The data consists of $30 \mathrm{~m}$ ground resolution tree cover maps, based on Landsat's satellite imagery for the entire globe, and allows calculating extent and change of tree cover globally. We calculated the average annual rate of tree cover loss (\%) 
using a $30 \%$ tree cover threshold for each individual governance arrangement within our 24 communities for a five-year period previous to the fieldwork (2013-2017). Visual validation using Google Earth and Bing Maps suggested 30\% as a reasonable threshold to estimate forest cover in our landscapes. Tree cover does not necessarily correspond to forest cover, and can be also related to plantations or trees outside forest.

\subsubsection{Proximate drivers and other underlying drivers and factors}

The proximate and other drivers of deforestation were included as control variables to enable a realistic examination of the relationship between the different governance attributes and deforestation. Eight variables represented potential proximate drivers: i) timber, ii) charcoal, iii) pole and iv) firewood use indicated wood extraction; v) livestock grazing and vi) percentage of area under crop agriculture characterized agricultural pressure; vii) distance to the road and viii) percentage of build-up area denoted infrastructure expansion (Table 2). Two variables, slope and area of governance arrangement, represented other factors. Amongst the other underlying drivers, we considered population because it is strongly linked to deforestation in SSA (Mayaux et al., 2013; Rudel, 2013; DeFries et al., 2010). However, the population estimates from WorldPop (2018), the data with the best precision for our study period 2017, are mostly accurate at larger spatial scales and disaggregation would give biased results. For the rough estimation of its influence, we estimated the total population in 2017 per governance arrangement $(N=91)$ and established its correlation with the selected infrastructure variables using the Spearman's correlation (Appendix D). Similar to (Burgess et al., 2007; Shoshany and Goldshleger, 2002; Stamber et al., 2016), population was strongly correlated with distance to roads and percentage of build-up area. Those variables were included in the model. Economic and socio-cultural drivers e.g. poverty incidence, level of urbanization and ethnicity were accounted for in the differences across the provinces (Table 1). Accordingly, we integrated provincial dummies in our analysis.

Data on extraction of charcoal, firewood, timber and poles and livestock grazing were obtained through the same focus group discussions as already described in Section 3.2.1. First, participants were asked to discuss and distribute 100 pebbles between benefits based on their importance to the community. Subsequently, they were tasked to locate the land use classes (generated in Section 3.2.3) from which each benefit is gained on the map. For each governance arrangement, we computed the degree of extraction/use per benefit as a ratio of the community's assigned pebble score, compared to the size (hectares) of the land use polygon that offers the benefit, expressed as a proportion of the size (hectares) of governance arrangement in which the land use polygon is located. Forest use by people other than community members is mainly captured in the arrangements with overlapping community claims.

Data on slope were derived from the SRTM $90 \mathrm{~m}$ Digital Elevation Database v4.1(Jarvis et al., 2008). Distances to roads were computed from the nearest point of a delineated and digitized governance polygon using open street map data extracts. Provincial boundaries were computed from the Zambia boundary map for Africa 2007 and percentages of crop and built-up area from the ESA CCI land cover map 2016. The sources of data and units of measurement for each variable are summarized in Table 2.

\subsection{Data analysis}

\subsubsection{Comparative analysis of governance arrangements}

To determine whether forest governance quality, the average annual rate of deforestation/tree cover loss and the proximate and other drivers of deforestation differed between the governance arrangements we applied non-parametric Wilcoxon rank tests since the assumption of data normality was violated (Bridge and Sawilowsky, 1999).

\subsubsection{Regression models}

We applied stepwise multiple regressions to analyse linkages between deforestation, governance attributes, proximate and other drivers. Our stepwise regression model had the form:
$Y=B_{0}+B_{1} X_{1}+B_{2} X_{2}+\ldots+B_{k} X_{k}+\varepsilon$

Here, $Y$ is the dependent variable, average annual rate deforestation between 2013 and 2017; $\mathrm{X}_{1}, \mathrm{X}_{2} \ldots . \mathrm{X}_{\mathrm{k}}$ predictors; B's, the parameters estimates or regression coefficients and $\varepsilon$, error. The error, $\varepsilon$ is assumed to follow a normal distribution with zero mean and variance $\sigma^{2}$ for any values of predictors.

We used the backward elimination method to determine the set of optimal predictors. Backward elimination is appropriate for selecting those factors that contribute most strongly to the regression model when the number of variables is high (Hocking, 1976), as was the case in this analysis. Akaike Information Criteria (AIC) was used to judge the importance of variables (Motulsky and Christopoulos, 2004). A variation inflation factor set limit $<2.5$ was used to confirm the absence of multicollinearity between the predictors in the model (Craney and Surles, 2002).

We specified two models in our analysis, both using the average annual rate of deforestation between 2013 and 2017 as the dependent variable. The models differed in the initial variables that constituted the predictors. In the first model, only the proximate and other drivers constituted the predictors. The second model added governance attributes (governance indicators and arrangements) to the predictors of the first model.

Due to the absence of governance data for the private (10) and overlapping arrangements with private claims (1), only 80 of the 91 observations were included in the regression analyses. A non-parametric Kruskal Wallis test was conducted to compare the annual rate of deforestation between the excluded and considered observations. The test verified the absence of elimination bias from the exclusion of the private and overlapping arrangement with private claims. Results (Appendix E) revealed that the mean annual rate of tree cover loss did not differ significantly between the excluded and considered observations with a $p$-value of 0.75 .

Although we initially selected nineteen governance indicators, we only used nine in our second model, as the rest were not applicable in all study sites and communities (see details in Table 3). The regression model with indicators that are applicable in all sites enabled better comparison across all study sites and communities. Of the nine recurrent indicators, only eight were present in all governance arrangements.

The dependent variable, average annual rate of deforestation was found positively skewed via a Shapiro-Wilk test with a p-value < 0.0001 . It was thus transformed with a square root function to ensure normal distribution (Freeman and Tukey, 1950; Thacker and Bromiley, 2001). To ensure comparability of units all observations for the predictors were standardised (Dytham, 2011). All analyses were executed using JMP software (SAS Institute Inc., 2017).

\subsubsection{Model validation}

Shapiro-Wilk tests were applied to the residuals generated by the models to verify conformity to the assumptions of normality (Dytham, 2011). To verify whether the multiple regression models conform to the assumption of homoscedasticity (Hayes and Cai, 2007), we applied Bartlett's test for homogeneity of variances by comparing the residuals across two categories of predicted values, generated by a median split (Bartlett, 1937).

\section{Results}

\subsection{Governance performance across arrangements}

The mean (aggregated) scores of the nine governance indicators applicable for all sites, which were also included in the second regression model, were very low, with values between 1.23 and 1.51 per governance arrangement (Table 3 ).

As regards to the single indicators, only the indicator of tenure rights recognition scored consistently above the average Likert score of 3 in all arrangements. Tenure rights recognition scored significantly higher in the customary than in state arrangements. Conservation and 
Table 2

Description of variables for analysing linkages between deforestation, forest governance, and proximate and other drivers. I indicates that the indicator predominantly represents the governance component on interactions amongst actors or between actors and rules, R, rules and Inst, institutions.

\begin{tabular}{|c|c|c|c|}
\hline Variable description & Indicator & Measurement unit & Data source \\
\hline \multicolumn{4}{|l|}{ Dependent variable } \\
\hline Deforestation & $\begin{array}{l}\text { Average annual tree cover loss } \\
\text { 2013-2017 }\end{array}$ & Percentage & Global Forest Watch (Hansen et al., 2013) \\
\hline \multicolumn{4}{|l|}{ Predictor variables } \\
\hline \multicolumn{4}{|l|}{ Underlying drivers } \\
\hline \multicolumn{4}{|l|}{ Governance attributes } \\
\hline$I$ & Tenure rights recognition and protection & Likert score & Focus group discussions \\
\hline$I$ & Land use planning & Likert score & Focus group discussions \\
\hline$I$ & $\begin{array}{l}\text { Implementation of land use strategies } \\
\text { and plans }\end{array}$ & Likert score & Focus group discussions \\
\hline$R$ & Timber license administration & Likert score & Focus group discussions \\
\hline$R$ & Charcoal license administration & Likert score & Focus group discussions \\
\hline$R$ & $\begin{array}{l}\text { Non-timber forest products license } \\
\text { administration }\end{array}$ & Likert score & Focus group discussions \\
\hline$R$ & Protection and conservation & Likert score & Focus group discussions \\
\hline$R$ & Formal law enforcement & Likert score & Focus group discussions \\
\hline$R$ & Customary law enforcement & Likert score & Focus group discussions \\
\hline$I$ & $\begin{array}{l}\text { Implementation of benefit-sharing } \\
\text { mechanisms }\end{array}$ & Likert score & Focus group discussions \\
\hline$I$ & $\begin{array}{l}\text { Implementation of forest-based } \\
\text { livelihood programs/projects }\end{array}$ & Likert score & Focus group discussion \\
\hline$I$ & Forest revenue administration & Likert score & Focus group discussions \\
\hline Inst & $\begin{array}{l}\text { Central government capacities and } \\
\text { effectiveness }\end{array}$ & Likert score & Focus group discussions \\
\hline Inst & $\begin{array}{l}\text { Local government capacities and } \\
\text { effectiveness }\end{array}$ & Likert score & Focus group discussions \\
\hline Inst & $\begin{array}{l}\text { Customary government capacities and } \\
\text { effectiveness }\end{array}$ & Likert score & Focus group discussions \\
\hline Inst & $\begin{array}{l}\text { Non-government organizations } \\
\text { capacities and effectiveness }\end{array}$ & Likert score & Focus group discussions \\
\hline \multirow[t]{3}{*}{$I$} & Public policy participation & Likert score & Focus group discussions \\
\hline & Aggregated governance indicator & Likert score & Focus group discussions \\
\hline & Type of governance arrangements & Dummies & Focus group discussions \\
\hline \multicolumn{4}{|l|}{ Control variables } \\
\hline \multicolumn{4}{|l|}{ Proximate drivers } \\
\hline \multirow[t]{4}{*}{ Wood extraction } & Timber extraction & $\begin{array}{l}\text { Area weighted pebble } \\
\text { score }\end{array}$ & Focus group discussions \\
\hline & Poles extraction & $\begin{array}{l}\text { Area weighted pebble } \\
\text { score }\end{array}$ & Focus group discussions \\
\hline & Charcoal production & $\begin{array}{l}\text { Area weighted pebble } \\
\text { score }\end{array}$ & Focus group discussions \\
\hline & Firewood extraction & $\begin{array}{l}\text { Area weighted pebble } \\
\text { score }\end{array}$ & Focus group discussions \\
\hline \multirow[t]{2}{*}{ Agriculture expansion } & Percentage area under crop agriculture & Percentage & Africa ESA CCI land cover maps \\
\hline & Livestock grazing & $\begin{array}{l}\text { Area weighted pebble } \\
\text { score }\end{array}$ & Focus group discussions \\
\hline \multirow{2}{*}{$\begin{array}{l}\text { Infrastructure extension (Correlated with } \\
\text { estimated total population) }\end{array}$} & Distance to the road & Metres & Open street maps (https://download.geofabrik.de/2. \\
\hline & Percentage of built-up area & Percentage & $\frac{\text { Africa ESA CCI land cover map (http:// }}{2016 \text { africalandcover20m.esrin.esa.int/2. }}$ \\
\hline \multirow[t]{2}{*}{ Other factors } & Mean slope & Degrees & SRTM for the globe (Jarvis et al., 2008) \\
\hline & Area of governance arrangement & Hectares & Participatory mapping \& digitization \\
\hline $\begin{array}{l}\text { Economic and socio-cultural drivers (differ } \\
\text { between provinces) }\end{array}$ & Region/province & Dummies & Zambia boundary maps for Africa 2007 \\
\hline
\end{tabular}

use restrictions also scored above the average Likert score of 3 in the traditionally restricted communal customary forests. This score differed significantly from that in the arrangements lacking traditional use restrictions, which consistently scored below the average Likert score of 3 (Table 3). The indicators of formal land use planning and formal law enforcement scored significantly higher in the state than in the customary arrangements. Most of the individual indicators did not show significant differences between governance arrangements.

\subsection{Variation of proximate drivers and other factors across governance arrangements}

The restricted state arrangements and forests with overlapping community claims were located the furthest from roads of all arrangements (Table 4).
Charcoal, pole and firewood use was greatest in the forest with overlapping claims, as shown by the high mean scores (Table 4). Mean scores for timber extraction and livestock grazing were highest in the restricted state arrangements (Table 4). Percentages of crop and built-up area were highest in the non-restricted individual customary arrangements (Table 4).

\subsection{Average annual rate of deforestation across governance arrangements}

The restricted arrangements (state and traditional) showed a considerably lower deforestation rate than the non-restricted arrangements (Table 5). Deforestation rate was lowest in the traditionally restricted communal forests. The forests with overlapping community claims showed a relatively lower deforestation rate than other non-restricted arrangements (Table 5). Deforestation rates were highest in the 
Table 3

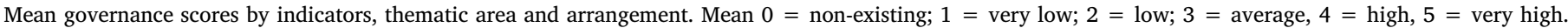

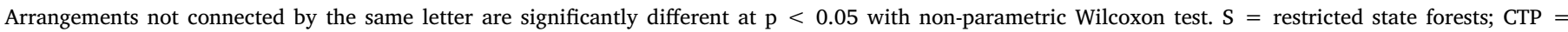

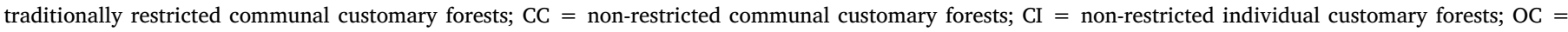

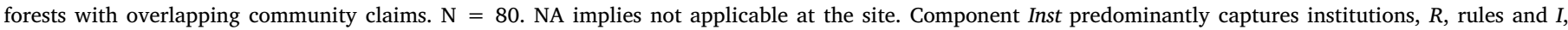
interactions amongst actors or between actors and rules.

\begin{tabular}{|c|c|c|c|c|c|c|c|c|c|c|c|c|}
\hline \multirow[t]{3}{*}{ Thematic area } & \multirow[t]{3}{*}{ Indicator } & \multicolumn{11}{|c|}{ Mean score by governance arrangement } \\
\hline & & \multirow[b]{2}{*}{$\begin{array}{l}\text { Component } \\
\text { assessed }\end{array}$} & \multicolumn{2}{|l|}{$\mathrm{S}$} & \multicolumn{2}{|c|}{ CTP } & \multicolumn{2}{|l|}{$\mathrm{CC}$} & \multicolumn{2}{|l|}{$\mathrm{CI}$} & \multicolumn{2}{|l|}{ OC } \\
\hline & & & $\mathrm{N}$ & Mean & $\mathrm{N}$ & Mean & $\mathrm{N}$ & Mean & $\mathrm{N}$ & Mean & $\mathrm{N}$ & Mean \\
\hline Forest tenure & Tenure rights recognition \& protection & $I$ & 6 & $3.28^{\mathrm{B}}$ & 8 & $4.08^{\mathrm{A}}$ & 22 & $3.85^{\mathrm{AB}}$ & 24 & $4.08^{\mathrm{A}}$ & 20 & $3.91^{\mathrm{AB}}$ \\
\hline Land use & Formal land use planning & $I$ & 6 & $0.58^{\mathrm{A}}$ & 8 & $0.00^{\mathrm{B}}$ & 22 & $0.23^{\mathrm{B}}$ & 24 & $0.21^{\mathrm{B}}$ & 20 & $0.50^{\mathrm{AB}}$ \\
\hline \multirow[t]{8}{*}{ Forest management } & Implementation of land use plans and strategies & $I$ & 3 & 1.79 & - & NA & - & NA & - & NA & - & NA \\
\hline & $\begin{array}{l}\text { Conservation and use restrictions (includes mean scores of } \\
\text { timber, charcoal licences protection and conservation) }\end{array}$ & $R$ & 6 & $1.63^{\mathrm{B}}$ & 8 & $4.23^{\mathrm{A}}$ & 22 & $1.28^{\mathrm{B}}$ & 24 & $1.43^{\mathrm{B}}$ & 20 & $1.43^{\mathrm{B}}$ \\
\hline & Non-timber forest products licence administration & $R$ & 1 & $2.17^{\mathrm{A}}$ & - & NA & 1 & $2.17^{\mathrm{A}}$ & 1 & $2.17^{\mathrm{A}}$ & 1 & $2.17^{\mathrm{A}}$ \\
\hline & Implementation of reforestation program & $I$ & 2 & $2.20^{\mathrm{A}}$ & - & NA & - & NA & 2 & $2.90^{\mathrm{A}}$ & - & NA \\
\hline & Implementation of forest-based livelihood program/projects & $I$ & 1 & $3.00^{\mathrm{A}}$ & - & NA & 3 & $2.28^{\mathrm{A}}$ & 6 & $3.14^{\mathrm{A}}$ & 5 & $2.48^{\mathrm{A}}$ \\
\hline & Implementation of payment of ecosystem service program & $I$ & - & NA & - & NA & - & NA & - & NA & - & NA \\
\hline & Formal law enforcement & $R$ & 6 & $2.03^{\mathrm{A}}$ & 8 & $0.50^{\mathrm{BC}}$ & 22 & $1.04^{\mathrm{ABC}}$ & 24 & $0.49^{\mathrm{C}}$ & 20 & $0.79^{\mathrm{B}}$ \\
\hline & Customary law enforcement & $R$ & 6 & $0.58^{\mathrm{A}}$ & 8 & $1.98^{\mathrm{A}}$ & 22 & $1.59^{\mathrm{A}}$ & 24 & $1.41^{\mathrm{A}}$ & 20 & $1.49^{\mathrm{A}}$ \\
\hline \multirow[t]{2}{*}{ Revenues } & Implementation of benefit sharing mechanisms & $I$ & - & NA & - & NA & - & NA & - & NA & - & NA \\
\hline & Forest revenue administration & $I$ & 3 & $2.28^{\mathrm{A}}$ & - & NA & 9 & $1.67^{\mathrm{A}}$ & 10 & $2.08^{\mathrm{A}}$ & 8 & $1.84^{\mathrm{A}}$ \\
\hline \multirow[t]{4}{*}{ Crosscutting institutions } & Central government capacities \& effectiveness & Inst & 6 & $1.92^{\mathrm{A}}$ & 8 & $1.34^{\mathrm{A}}$ & 22 & $1.65^{\mathrm{A}}$ & 24 & $1.66^{\mathrm{A}}$ & 20 & $1.57^{\mathrm{A}}$ \\
\hline & Local government capacities \& effectiveness & Inst & 6 & $0.02^{\mathrm{AB}}$ & 8 & $0.06^{\mathrm{AB}}$ & 22 & $0.07^{\mathrm{B}}$ & 24 & $0.07^{\mathrm{B}}$ & 20 & $0.16^{\mathrm{A}}$ \\
\hline & Customary institutions` capacities \& effectiveness & Inst & 6 & $1.54^{\mathrm{A}}$ & 8 & $1.39^{\mathrm{A}}$ & 22 & $2.20^{\mathrm{A}}$ & 24 & $1.76^{\mathrm{A}}$ & 20 & $1.69^{\mathrm{A}}$ \\
\hline & Non-government organizations capacities and effectiveness & Inst & 2 & $3.30^{\mathrm{A}}$ & - & NA & 3 & $3.53^{\mathrm{A}}$ & 3 & $3.53^{\mathrm{A}}$ & 4 & $4.00^{\mathrm{A}}$ \\
\hline \multirow[t]{3}{*}{ Crosscutting issues } & Public policy participation & $I$ & 6 & $0.00^{\mathrm{A}}$ & 8 & $0.00^{\mathrm{A}}$ & 22 & $0.00^{\mathrm{A}}$ & 24 & $0.00^{\mathrm{A}}$ & 20 & $0.00^{\mathrm{A}}$ \\
\hline & $\begin{array}{l}\text { Mean Governance score (aggregated for the } 9 \text { indicators } \\
\text { applicable in all sites) }\end{array}$ & & 6 & $1.29^{\mathrm{A}}$ & 8 & $1.51^{\mathrm{A}}$ & 22 & $1.32^{\mathrm{A}}$ & 24 & $1.23^{\mathrm{A}}$ & 20 & $1.28^{\mathrm{A}}$ \\
\hline & Final mean governance score (aggregated for all 19 indicators) & & 6 & $1.98^{\mathrm{A}}$ & 8 & $1.53^{\mathrm{A}}$ & 22 & $1.47^{\mathrm{A}}$ & 24 & $1.68^{\mathrm{A}}$ & 20 & $1.68^{\mathrm{A}}$ \\
\hline
\end{tabular}

individualized arrangements (private and customary individual). The private forests exhibited a lower deforestation rate than the individual customary forests (Table 5).

\subsection{Proximate and other drivers of deforestation in the Zambian Miombo}

In both models, three proximate predictors (distance to the road, percentage of area under crop agriculture and charcoal production) were statistically significant (Table 6).

As indicated by the magnitude of the regression coefficients, percentage of area under crop agriculture, with the highest magnitude, was the proximate driver with the strongest influence on the annual rate of deforestation. Charcoal production and distance to the road followed respectively.

Percentages of area under crop agriculture and charcoal production were positively related with the rate of deforestation, i.e. the higher the percentage of area under crop agriculture and the higher the production of charcoal, the higher the rate of deforestation. On the other hand, location further from roads was associated with lower rates of deforestation.

Regarding the other factors (Model 2), two regional dummies (Eastern and North-Western) were statistically significant (Table 6). Eastern and North-Western regions, as compared to the reference regional dummy of Copperbelt, were associated with lower rates of deforestation.

\subsection{Influence of governance on deforestation and its proximate and other drivers}

The regression which includes governance attributes (Model 2), showed a slightly higher adjusted coefficient of determination of $50.0 \%$ than the model without governance attributes (Model 1), whose adjusted coefficient of determination was $43.3 \%$ (Table 6 ).

The comparison between the two models (Table 6) indicates that the

Table 4

Comparative results of proximate and other drivers of deforestation across governance arrangements in all 24 communities using unstandardized parameters. Arrangements not connected by the same letter are significantly different at $\mathrm{p}<0.05$ with non-parametric Wilcoxon test. State $=$ restricted state forests; CTP $=$ traditionally restricted communal customary forests; $\mathrm{CC}=$ non-restricted communal customary forests; $\mathrm{CI}=$ non-restricted individual customary forests; OC $=$ forests with overlapping community claims. $\mathrm{N}=80$.

\begin{tabular}{|c|c|c|c|c|c|}
\hline \multirow[t]{2}{*}{ Attributes } & \multicolumn{5}{|c|}{ Mean value by type of governance arrangement } \\
\hline & State & СТP & CC & CI & OC \\
\hline Number of observations & 6 & 8 & 22 & 24 & 20 \\
\hline Area (hectares) & $2,933.89^{\mathrm{AB}}$ & $882.83^{\mathrm{C}}$ & $3017.13^{\mathrm{B}}$ & $5,158.03^{\mathrm{A}}$ & $706.96^{\mathrm{C}}$ \\
\hline Distance to road (metres) & $2,095.27^{\mathrm{AB}}$ & $118.84^{\mathrm{B}}$ & $549.17^{\mathrm{B}}$ & $0.00^{\mathrm{C}}$ & $995.12^{\mathrm{A}}$ \\
\hline Built up-area (\%) & $0.02^{\mathrm{AB}}$ & $0.01^{\mathrm{AB}}$ & $0.00^{\mathrm{B}}$ & $0.05^{\mathrm{A}}$ & $0.00^{\mathrm{B}}$ \\
\hline Mean slope (degrees) & $2.82^{\mathrm{AB}}$ & $4.35^{\mathrm{A}}$ & $2.69^{\mathrm{AB}}$ & $2.30^{\mathrm{B}}$ & $3.61^{\mathrm{AB}}$ \\
\hline Percentage of crop area (\%) & $8.34^{\mathrm{B}}$ & $18.11^{\mathrm{AB}}$ & $13.30^{\mathrm{B}}$ & $23.31^{\mathrm{A}}$ & $11.40^{\mathrm{B}}$ \\
\hline Charcoal extraction (area weighted pebble score) & $2.35^{\mathrm{AB}}$ & $0.03^{\mathrm{C}}$ & $1.97^{\mathrm{B}}$ & $2.04^{\mathrm{B}}$ & $4.93^{\mathrm{A}}$ \\
\hline Timber extraction (area weighted pebble score) & $5.28^{\mathrm{A}}$ & $0.45^{\mathrm{B}}$ & $1.94^{\mathrm{A}}$ & $1.25^{\mathrm{A}}$ & $3.25^{\mathrm{A}}$ \\
\hline Pole extraction (area weighted pebble score) & $2.68^{\mathrm{BC}}$ & $0.15^{\mathrm{C}}$ & $3.28^{\mathrm{B}}$ & $2.34^{\mathrm{B}}$ & $6.83^{\mathrm{A}}$ \\
\hline Firewood extraction (area weighted pebble score) & $5.90^{\mathrm{B}}$ & $0.47^{\mathrm{C}}$ & $8.16^{\mathrm{B}}$ & $8.39^{\mathrm{B}}$ & $18.37^{\mathrm{A}}$ \\
\hline Livestock grazing (area weighted pebble score) & $2.00^{\mathrm{A}}$ & $0.25^{\mathrm{A}}$ & $1.85^{\mathrm{A}}$ & $1.71^{\mathrm{A}}$ & $1.64^{\mathrm{A}}$ \\
\hline
\end{tabular}


Table 5

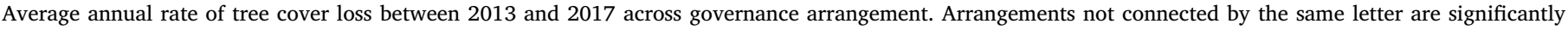
different at $p<0.05$ when non-parametric Wilcoxon test is applied. $N=91$ using unstandardized variables.

\begin{tabular}{|c|c|c|}
\hline \multirow[t]{2}{*}{ Governance arrangement } & \multicolumn{2}{|c|}{ Average annual rate of tree cover loss between 2013 and 2017 (\%) } \\
\hline & Number of observations & Mean \\
\hline Restricted state forests & 6 & $0.29^{\mathrm{BC}}$ \\
\hline Traditionally restricted communal customary forests & 8 & $0.04^{\mathrm{C}}$ \\
\hline Non-restricted communal customary forests & 22 & $0.54^{\mathrm{B}}$ \\
\hline Forests with overlapping community claims & 21 & $0.42^{\mathrm{B}}$ \\
\hline Non-restricted individual customary forests & 24 & $0.73^{\mathrm{A}}$ \\
\hline Private forests & 10 & $0.57^{\mathrm{AB}}$ \\
\hline
\end{tabular}

Table 6

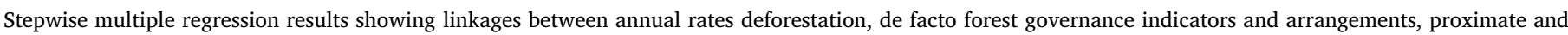

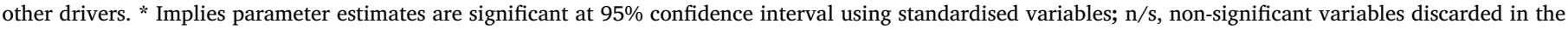

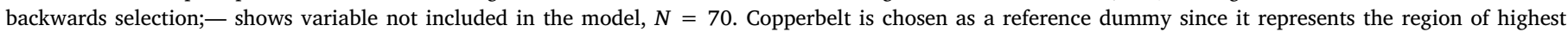
deforestation (Global Forest Watch, 2019).

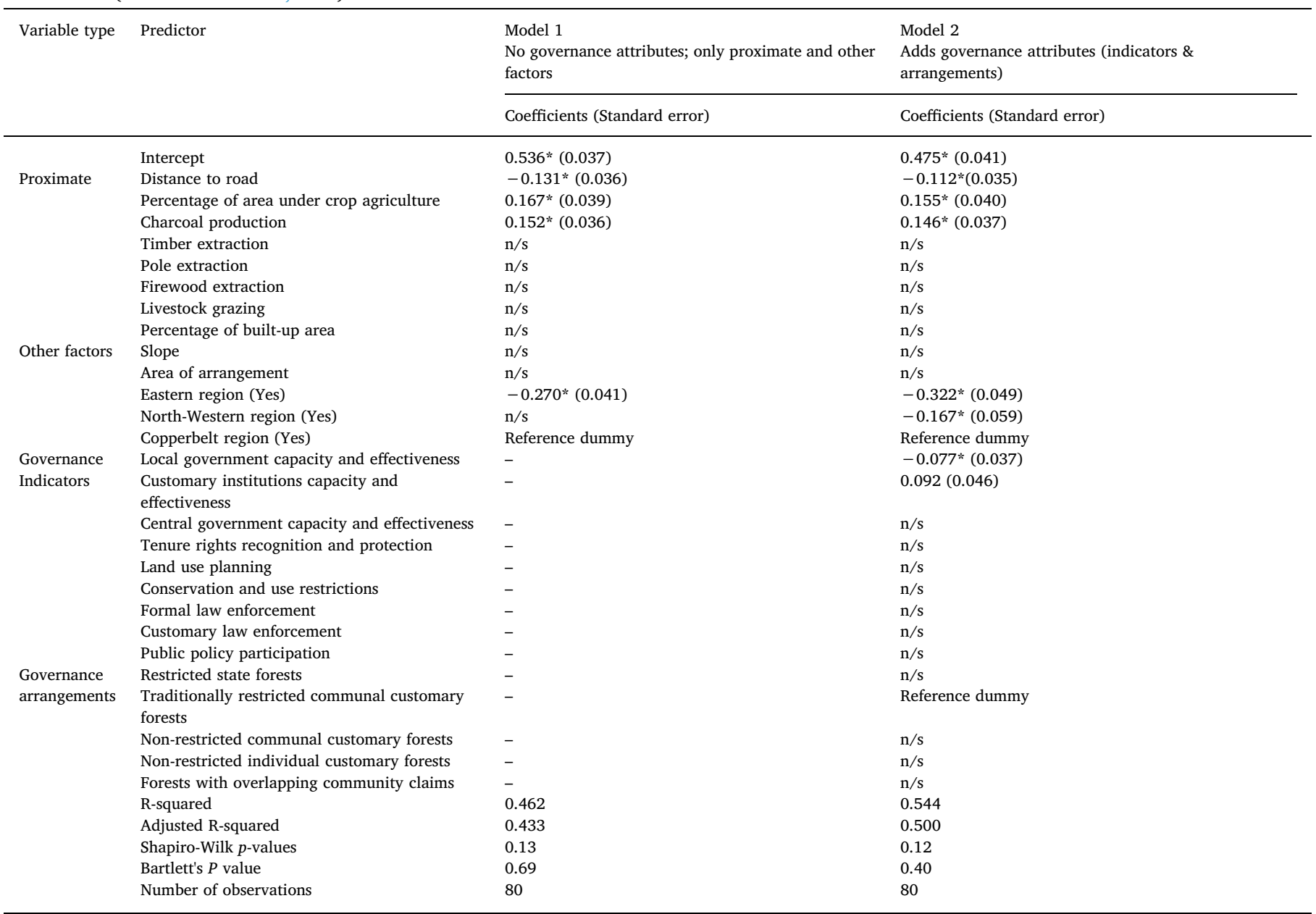

regression coefficients of the proximate drivers -(i) distance to the road, (ii) percentage of area under crop agriculture and (iii) charcoal production- remained significant when governance attributes were introduced in the analysis. The same coefficients only decreased slightly with the introduction of governance attributes i.e. -0.131 to -0.112 for distance to the road, 0.167 to 0.155 for percentage area under crop agriculture and 0.152 to 0.146 for charcoal production.

The regression coefficient of regional dummy for Eastern increased from -0.270 to-0.322, while that of North-Western became significantly negative with the introduction of governance attributes in the analysis.

Only two governance attributes, (i) local government capacity and effectiveness and (ii) customary institution's capacity and effectiveness, were retained in the model 2 , which includes governance (Table 6). Local government capacity and effectiveness showed a significant negative association with the rate of deforestation i.e. effective local government institutions, with adequate capacities were associated with lower rates of deforestation. On the other hand, although not statistically significant, customary institution's capacity and effectiveness were positively related to deforestation i.e. effective customary institutions, with adequate capacities were associated with higher rates of deforestation. Other governance indicators and the arrangements, were not statistically significant and discarded in the backward elimination. 


\section{Discussion and policy implications}

\subsection{Deforestation rates and drivers across governance arrangements}

The restricted arrangements (state and traditional) exhibited lower deforestation rates than the non-restricted arrangements. Similar to (Nolte et al., 2013; Andam et al., 2008; Ferraro et al., 2013), this result supports the narrative that restrictions on forest access and use lead to lower deforestation than the approaches that permit consumptive use. However, restrictions have been found to increase illegal extraction in the areas with limited livelihood alternatives (Amoah and Wiafe, 2012; Mackenzie et al., 2012; Shova and Hubacek, 2011) and are costly to implement (Pfaff et al., 2017). Thus, augmented support for alternative livelihoods and institutional capacities could improve the enforcement of restrictions in forest-reliant communities.

The very low deforestation rate in the traditionally restricted forests demonstrates the importance of traditional norms and taboos in promoting forest conservation (Li, 2018; Furusawa, 2016; Lingard et al., 2003). The finding also supports the assumption that shared beliefs shape actor behaviour towards forest conservation (Sabatier, 2019; Sabatier, 1999). Together with overlapping claims areas, traditionally restricted communal customary forests, with ancestral burial sites, had the smallest mean areas (Table 4) and also constitute a very small proportion of Zambia's forests. However, even in the absence of effective enforcement mechanisms, given the strong cultural value attached, under the assumption of shared beliefs, there is voluntary compliance with the traditional access and use restrictions (Handavu et al., 2019). Even so, given the upsurge in the marginalization of cultural norms and beliefs following immigration and modernization (Infield et al., 2018), protecting existing traditional norms should be part of the initiatives that promote forest conservation in Zambia.

In the state forests, the low deforestation rates may besides the restrictions, be attributed to remoteness (Table 4), which renders them less attractive for crop agriculture, given the high transport-related transaction costs (Pujiono et al., 2019). Moreover, although still weak, state forests scored better in land use planning, which is associated with sustainable forest use (McDermott et al., 2010; Kaimowitz, 2012). Particular aspects of law enforcement i.e. fining and confiscation of illegal timber and charcoal (Tacconi et al., 2019; Davis et al., 2013) were also reported more prevalent in the state forests. But, whereas crop agriculture was negligible, similar to findings by (Kazungu et al., 2020), forest resource extraction (timber, charcoal and poles) was substantial in state forests, indicating a higher possibility for forest degradation instead.

Compared to other non-restricted arrangements, forests with overlapping community claims showed relatively lower deforestation rates. Although charcoal, poles and firewood extraction was considerable, the forests with overlapping community claims were less subjected to crop agriculture. This is perhaps because of remoteness and the accompanying transport-related transaction costs (Stifel and Minten, 2008). Nonetheless, the prevalence of forest resources makes them attractive for extraction, which when unregulated may cause degradation. Besides, while they presently go unnoticed by the communities involved, overlapping ownership claims reflect unclear resource boundaries. This presents potential conflicts and a challenge to exclude unauthorized users (Ostrom, 2008; Ostrom and Benjamin, 1993). In this regard, land use planning that clarifies community resource boundaries together with joint management strategies and conflict resolution measures would guarantee long-enduring common forest resources of neighbouring communities.

The non-restricted communal forests showed lower deforestation rates than the non-restricted individual forests (customary individual and private). In the communal, contrary to the individualized arrangements, customary leaders and community members have jointly established collective rules to regulate the cutting of trees. According to community members, violators are sometimes punished with monetary or in-kind (goat, chicken, farm labour) fines imposed by the customary leaders. Collective-choice theory predicts a high likelihood for successful common-pool resource management when individuals self-organize and collectively design their own local institutions (Ostrom, 1990; Ostrom et al., 1999). However, certain conditions should be fulfilled to guarantee sustainable outcomes. These include clearly defined boundaries, collective decision-making processes, effective monitoring, graduated sanctions, proportional equivalence between benefits and costs, conflict resolution mechanism, minimal recognition of rights to organize, and nested enterprises (Ostrom, 1990; Ostrom and Benjamin, 1993). In Zambia, owing to limited institutional capacities, these conditions are hardly fulfilled in practice in the communal arrangements. This might explain the considerable rates of deforestation in the communal forests although lower than in the private and customary individual forests.

The individual arrangements (customary individual and private) exhibited higher deforestation rates than the state and communal forests. The result challenges the assumption that individual ownership is more efficient than other forms, given its ability to internalize the externality that would arise from the self-interested behaviour of community members in extracting common pool resources (Kijima et al., 2000; Gordon, 1954). In Zambia, while individualized arrangements permit the exclusion of other community users, forest owner's use decision is barely regulated de facto due to inadequate institutional capacity. In the absence of land use planning and effective institutions, rational choice theory predicts a high likelihood for forest owners to convert forestlands to more potentially profitable alternatives such as agriculture, given their profit maximizing nature (Simon, 1959; Simon, 1955; Zafirovski, 2003). Moreover, unlike in the communal and state forests, the law permits cultivation in the individual arrangements (GRZ, 2015a). The individual arrangements were also the least remote (Table 4) and thus, with lower transport-related transaction costs (Chomwitz and Gray, 1996). In this view, incentivizing forest owners would increase the profitability therefore, the preference for forests over agriculture (March and Olsen, 2010). Actually farmers in Zambia are willing to refrain from forest clearing if incentivized (Vorlaufer et al., 2017).

The titled private forests showed slightly lower deforestation rates than the non-titled individual arrangements. In Zambia, private unlike individual customary forest owners possess legal rights to exclude other community members from using their forests (GRZ, 2015a; Caron and Fenner, 2017). Hypothetically, the ability of landholders to legally exclude competing users is the core mechanism by which tenure affects resource use and land cover (Wong, 2004; Bayley, 2015). Thus, similar to (Xie et al., 2016; Holland et al., 2017), we propose formal support for titling on customary lands. This is likely to improve tenure security therefore, forest conservation. However, as shown by the still high deforestation rates in the private forests, tenure security alone will not guarantee successful forest conservation. It should be accompanied by effective institutions, land use planning, and incentives for avoided deforestation or sustainable use.

\subsection{Proximate and other drivers of deforestation in the Zambian Miombo}

The results suggest that the percentage of area under crop agriculture is the most important proximate predictor of deforestation in the Zambian Miombo. This is not surprising since scholars in Zambia (Phiri et al., 2019b; Vinya et al., 2011; Mwitwa et al., 2012; Handavu et al., 2019) and elsewhere in the tropics (Acheampong et al., 2019; Hosonuma et al., 2012; Ferrer Velasco et al., 2020) have reported similar findings. According to community members, diminishing soil fertility and the accompanying reduction in crop yield force farmers to abandon their crop fields and open up new forest areas for agriculture. Community members also reported clearing of forest areas for crop agriculture following immigration and high birth rates. Sustainable agriculture intensification practices e.g. crop rotation, conservation 
tillage and mulching (Wezel et al., 2015) could increase crop yield and reduce forest clearing for agriculture.

Charcoal production also emerged as a significant predictor of deforestation. Differing from (Chomba et al., 2012; Ratnasingam et al., 2014; Vinya et al., 2011), firewood and timber extraction were not significant. In Zambia there is a high market demand for charcoal because it is the major source of energy for cooking in the urban areas (Handavu et al., 2019; Gumbo et al., 2013). Charcoal also generates higher income than firewood (Kazungu et al., 2020). Moreover, unlike timber, which is mostly extracted by external private firms and, predominantly in North-Western, charcoal is produced by the community members in nearly all three provinces (Gumbo et al., 2013; Ngandwe et al., 2015). Besides, although in some cases Miombo woodlands can recover rapidly from the influence of charcoal production (Chidumayo, 1993), a considerable share of forests initially cut for charcoal are subsequently converted to croplands, reducing the possibility for recovery. We propose augmented monitoring of charcoal licences to curb illegal production. This is less likely to adversely impact food security and rural incomes, with many farmers depending on agricultural income and, with charcoal production predominated by the affluent households (Kazungu et al., 2020). Guidelines for sustainable charcoal production systems are also proposed given the high regenerating ability of the Miombo forests (Campbell, 1996).

Our results suggest proximity to roads as another important driver of deforestation. Deforestation rate is higher closer to the roads than in distant forests. Roads open up forests for settlement, agriculture and wood extraction by lowering transport-related transaction costs (Pujiono et al., 2019; Phiri et al., 2019b; Barber et al., 2014; Laurance et al., 2002; Poor et al., 2019). Because roads are inevitable for economic development through enhanced rural connectivity (Gibson and Rozelle, 2003) and for facilitating market access and commercialization of products (Luna et al., 2020), greater control over newly accessible forests through regular patrols is needed.

Similar to our study categorization of deforestation contexts (Table 1), North-Western and Eastern regions showed lower deforestation rates than Copperbelt. Copperbelt is more urbanized (Central Statistical Office, 2016) and has a higher population density than North-Western and Eastern (WorldPop, 2018). High population density and growth implies an increasing demand for food and a corresponding need to convert forests to agriculture (Asongu and Jingwa, 2012). High population density is also associated with high demand for charcoal and firewood therefore, high deforestation (Collins, 1984). Actually, charcoal productions is greatest in Copperbelt (Kalinda et al., 2008). There is need to promote forest restoration in Copperbelt to meet the rising demand for wood thus, reducing pressure on the remnant forests (Fay, 2012). In Eastern province, with deforestation mainly caused by smallscale crop cultivation (Shakacite et al., 2016), we suggest promoting sustainable agriculture intensification. In North-Western, with deforestation attributed to unsustainable timber extraction (Shakacite et al., 2016), we recommend promoting sustainable forest management.

\subsection{Influence of governance on deforestation and its proximate and other} drivers

There was only a small increase in the explanatory power of the model explaining deforestation (Table 6) when governance attributes were introduced in the analysis. This demonstrates that governance has some effect, but proximate drivers explain most deforestation in the Zambian Miombo. Similar to (Larson and Petkova, 2011; Tacconi, 2007), the results suggest that improvement of forest governance alone does not exclusively guarantee successful forest outcomes. Measures that tackle governance drivers should be complemented with strategies that specifically tackle the proximate and other underlying drivers e.g. sustainable production systems, incentive mechanisms and alternative livelihood and poverty eradication measures. This is relevant for REDD + and climate change adaptation initiatives that propose governance improvement to reduce deforestation and forest degradation.

Additionally and surprisingly, proximate drivers remained at unchanged significance levels when governance attributes were included in the analysis. This is perhaps because governance was hardly varying between arrangements and was in general very low (Table 3). Statistically, it is hard to explain deforestation by a predictor that is mostly the same in all governance arrangements. Actually, the only governance indicator that was significant was amongst those that showed differences between the arrangements (Table 3). Scholars (Hayes and Persha, 2010; Davis et al., 2013; Eklund and Cabeza-Jaimejuan, 2017; Fischer et al., 2020) underline the high quality of forest governance as a prerequisite for regulating human-induced drivers of deforestation.

There are lower deforestation rates where local government institutions are effective and posses adequate capacities. In Zambia, local government institutions are responsible for developing land use plans to guide sustainable forest management in addition to controlling the extraction and transportation of forest products (Mfune, 2013). District local councils occasionally monitor transportation of timber and charcoal contingent on their financial and human capacities. Similar to (Larson, 2002; Kaimowitz et al., 2000), the result emphasizes that strengthened institutional capacities (financial, human, technical) are vital for successful forest conservation. Besides, local government institutions represent a fundamental decentralization structure (Andersson and Gibson, 2004; Andersson, 2006) and thus reveal the potential for curbing deforestation through effective decentralization. Their influence might still be increased by financial and human resources and the state's willingness to cede power over forest management (Kalaba, 2016; Mfune, 2013).

Although not significant, there are higher deforestation rates where customary institutions are effective and possess adequate capacities. Zambia's customary institutions are responsible for granting rights of use over customary forests to new immigrants (Mason-Case, 2011) and for mineral exploration (Mwitwa et al., 2011). New immigrants are likely to convert forests to agriculture to protect them from being reallocated (Unruh et al., 2005). Moreover, the results may imply that the customary institutions prioritize agriculture over forest conservation (Lund et al., 2014), with the law permitting agriculture on customary lands. We suggest the need for efficient land use planning and formal mechanisms that hold customary institutions accountable.

None of governance arrangements was retained in the model. This result is surprising given that we found distinct deforestation differences between the governance arrangements (Table 5) and that governance arrangements have been emphasized to influence deforestation patterns owing to the different use restriction and ownership rights attached (Robinson et al., 2014). This could imply that the significant drivers are associated with specific governance arrangements. For example, charcoal is mostly produced in the forests with overlapping community claims, whereas crop agriculture predominates the individualized customary forests (Table 4).

The regression coefficients of the regional dummies for Eastern and North-Western increase, and become significantly negative, respectively, when governance attributes are included in the analysis. This implies that the significant governance attribute, local institutions' capacities and effectiveness, is region-specific. This means that local institutions' capacities and effectiveness are different across regions and certainly related to deforestation in all places. In agreement with (Nansikombi et al., 2020), the result suggest that regional differences ought to be reflected in the strategies for strengthening local-level institutional capacities and effectiveness.

\section{Conclusions}

In the context of persistent deforestation posing a substantial threat to the existence and functioning of the dry forest Miombo biome in subSaharan Africa, we challenge the notion that improved forest governance alone will successfully halt deforestation. Our data show that 
governance has some effect, but proximate drivers, particularly crop agriculture, charcoal production and road proximity explain most deforestation in the Zambian Miombo. We recommend complementing governance measures with strategies to specifically address the proximate and other underlying drivers including sustainable production systems, incentive mechanisms and alternative livelihood and poverty eradication measures. This is particularly relevant for REDD + and climate change adaptation initiatives that propose governance improvement to reduce deforestation and forest degradation. On the other hand, de facto governance in our data set was consistently weak, with hardly any variation and thus with limited statistical effects on deforestation and related proximate drivers. Across all analysed governance arrangements, scores for governance performance were mostly very low. This highlights the need for strengthening the implementation of forest laws and regulations as well as administrative reforms in Zambia. Our data shows noticeably high rates of deforestation, especially in the individualized arrangements (private and customary individual) that on the other hand exhibit higher tenure security. Although these are the arrangements with legal agricultural land use and thus explainable forest conversion into croplands, it challenges the notion that tenure security will guarantee successful forest conservation. Rather it should be accompanied by incentive mechanisms, effective institutions and land use planning to guide sustainable use and production systems. Restricted arrangements (state and traditional) exhibited lower deforestation rates than the non-restricted ones. But, while crop agriculture is negligible, forest resource extraction is substantial in the state forests. This implies that state forests are instead more susceptible to degradation. The regression results show that local government institutions seem to play an important role in reducing deforestation, particularly when they are functioning and with adequate capacity. On the other hand, while not significant, the customary institutions appear to exacerbate deforestation, probably because of their legal mandate, which permits them to allocate forest land for agriculture and mineral exploration. Also, this might imply that traditional institutions prioritize agriculture production over forest conservation. We point to the need for effective participatory land use planning and formal mechanisms that hold customary institutions accountable. However, because land use planning has been linked to inequitable land allocation and the accompanying displacement and migration of the marginalized people into forestlands (Bluwstein et al., 2018), it should be complemented by social safeguard policies to protect the local people's land rights.

\section{Funding}

The study is part of the Landscape Forestry in the Tropics (LaForeT) project. It was conducted by the Thünen Institute of International Forestry and Forest Economics, Hamburg, Germany and co-funded by the Germany Federal Ministry of Food and Agriculture (BMEL) through the Germany Federal Office for Agriculture and Food (BLE) based on a decision of the Deutscher Bundestag, Project number 281-006-01.

\section{Declaration of Competing Interest}

The authors declare that they have no known competing financial interests or personal relationships that could have appeared to influence the work reported in this paper.

\section{Acknowledgements}

The study is part of the Landscape Forestry in the Tropics (LaForeT) project conducted in Zambia by the Thünen Institute of International Forestry and Forest Economics, Hamburg, Germany, and by the Copperbelt University, School of Natural Resources, Kitwe, Zambia. It was funded by the conducting institutions as well as the German Federal Ministry of Food and Agriculture and the German Federal Office of Agriculture and Food (BLE) based on a decision of the Deutscher Bundestag, Project number 281-006-01. We acknowledge the support of the Centre for International Forests Research (CIFOR), Zambia. We are also grateful to Peter Elsasser and Eliza Zhunusova for their valuable suggestions that have greatly enriched this paper. Additionally appreciated are Mario Peters, Magdalena Fischer and Friso Junge for digitizing the maps. Also, recognized are the local communities of Zambia that provided the information that was used in the study.

\section{Appendices}

Appendix A: Zambia's forest governance arrangements with differing tenure and restrictions to forest access and use (Kalinda et al., 2008; GRZ, 2015a; GRZ, 2015b)

\begin{tabular}{|c|c|c|c|c|c|}
\hline Arrangement & Access and use restrictions & Tenure & Administration Institutions & $\begin{array}{l}\text { IUCN } \\
\text { Category }\end{array}$ & $\begin{array}{l}\% \text { total } \\
\text { forest area }\end{array}$ \\
\hline National Parks & Access and use of timber and NTFPs: restricted & State & $\begin{array}{l}\text { Department of National } \\
\text { Parks and Wildlife }\end{array}$ & IUCN II & 23.7 \\
\hline $\begin{array}{l}\text { National Forest Reserv- } \\
\text { es }\end{array}$ & Access and NTFPs use: restricted; Use of timber: regulated by license & State & Forest Department & IUCN II & \\
\hline Local Forest Reserves & $\underline{\text { Access: }}$ restricted; Use of timber and NTFPs: regulated by license & State & $\begin{array}{l}\text { Forest Department } \\
\text { Traditional institutions }\end{array}$ & IUCN VI & \\
\hline $\begin{array}{l}\text { Game Management Ar- } \\
\quad \text { eas }\end{array}$ & Access: restricted; Use of timber and NTFPs: regulated by license & State & $\begin{array}{l}\text { Department of National } \\
\text { Parks and Wildlife } \\
\text { Traditional institutions }\end{array}$ & IUCN VI & \\
\hline $\begin{array}{l}\text { Traditional/ cultural f- } \\
\quad \text { orests }\end{array}$ & Access: restricted; Use of Timber and NTFPs: restricted & Customary & Traditional institutions & IUCN III & 65.7 \\
\hline $\begin{array}{l}\text { Individually owned cu- } \\
\text { stomary forests }\end{array}$ & $\begin{array}{l}\text { Access: Non-restricted; Commercial Timber and NTFPs use: regulated by license; } \\
\text { Subsistence use of timber and NTFPs: non-restricted }\end{array}$ & Customary & $\begin{array}{l}\text { Traditional institutions } \\
\text { Forest Department }\end{array}$ & None & \\
\hline $\begin{array}{l}\text { Communal customary } \\
\text { forests }\end{array}$ & $\begin{array}{l}\text { Access: Non-restricted; Commercial timber and NTFPs use: regulated by license; } \\
\text { Subsistence use of timber and NTFPs: non-restricted }\end{array}$ & Customary & $\begin{array}{l}\text { Traditional institutions } \\
\text { Forest Department }\end{array}$ & None & \\
\hline Private forests & Access and use: restricted by owner & $\begin{array}{l}\text { State/ lea- } \\
\text { sehold }\end{array}$ & $\begin{array}{l}\text { Registered individual/ } \\
\text { company }\end{array}$ & None & 10.6 \\
\hline
\end{tabular}


Appendix B: Description of major land use classes from the community participatory mapping exercises

\begin{tabular}{|c|c|c|}
\hline Land use type & Description & Area (ha) \\
\hline $\begin{array}{l}\text { Secondary forest reference-Degraded (inter- } \\
\text { ventions) }\end{array}$ & Forest with anthropogenic disturbance from extraction followed by natural regeneration. & $133,737.67$ \\
\hline Secondary forest succession & $\begin{array}{l}\text { Forest once completely deforested for crop agriculture and abandoned. With natural regeneration greater than or equal } \\
\text { to five meters height. }\end{array}$ & $37,509.97$ \\
\hline Plantation forest & Forest once completely deforested followed by anthropogenic regeneration & 29.02 \\
\hline Woody shrubland & $\begin{array}{l}\text { Forest once completely deforested for crop agriculture and abandoned. With natural regeneration, less than five meters } \\
\text { height. }\end{array}$ & $50,035.42$ \\
\hline Annual croplands & Land used for growing annual crops & $53,672.94$ \\
\hline Wetlands & Land consisting of marshes or swamps & $13,774.13$ \\
\hline Roads & Hard ground that is built to facilitate movement from one place to the other. & 256.77 \\
\hline Water bodies & Rivers and lakes & 9705.94 \\
\hline Bare surfaces & Land covered by only soil & 232.67 \\
\hline Settlements & Land where people have established buildings & 1509.06 \\
\hline Grasslands & Land that mostly contains grasses & 3112.60 \\
\hline
\end{tabular}

Appendix C: Description of the governance indicators and the elements of quality by thematic areas of the GFI framework. Component Inst predominantly captures institutions, $R$, rules and I, interactions amongst actors/ between actors and rules

\begin{tabular}{|c|c|c|c|}
\hline Thematic area & Indicator & Component & Elements of quality \\
\hline Forest tenure & $\begin{array}{l}\text { 1.Tenure rights recognition } \\
\text { and protection }\end{array}$ & $I$ & Recognition. Most individual and communal rights-holders have their rights recognized and recorded \\
\hline
\end{tabular}

Demarcation. Most individual and communal forestlands have boundaries demarcated

Gender equity. Rights registered to individuals or households are often registered in the names of women, jointly or individually

Customary tenure. Minimal conflict exists between customary forest tenure systems and statutory systems on the ground

Land use $\quad$ 2. Land use planning $\quad I$

Procedure. Land use decisions are taken in a formally established process

Transparency. Planning process is transparent and procedures are clearly defined

Opportunities for participation. Communities or entitled individuals have the possibility for participation in land use planning processes

Representation. Representatives to land use-planning processes reflect a range of community perspectives,

including women and different socioeconomic classes

Capacity to engage. Representatives in land-use planning have information and skills to effectively engage and participate in land use planning processes

Forest manage- $\quad$ 3.Strategies and plans $\quad I$ ment

Licences:

4. Timber

5. Charcoal

6. Non-timber forest products

7. Reforestation programs

$I$

$R$

7. Protection and conservation

9. Payment for Ecosystem I Services programs

10. Forest-based livelihood programs/projects
Coordination. Implementing agencies/persons/enterprise effectively coordinate in carrying out their roles and responsibilities

Timeliness. Implementation happens according to the timeline specified by the plan/strategy

Monitoring. Implementation is subject to regular monitoring of impacts and effectiveness

Transparency. Land use plans and monitoring reports are publicly disclosed on a regular basis

Review. Plans and strategies are reviewed and updated regularly

Procedural clarity. Clear administrative procedures regulate the obtaining of licences and permits

Transparency. Application status can be tracked

Accessibility. The process for acquiring a license or permit is not prohibitively complicated and expensive

Timeliness. Licences and permits can be obtained in a reasonable time and within the time prescribed Implementation. Licences and permits are honoured during harvesting and transport of forest products Procedures. Stakeholders understand the procedures and terms of the program, including planting sites and species, duration, and associated benefits and responsibilities

Coordination. The implementing agency coordinates implementation by establishing clear agreements with people and organizations

Capacities. Communities have been capacitated to implement the program

Benefits. Participants have received compensation as agreed

Monitoring. Implementation is subject to regular monitoring to ensure compliance and effectivity

Demarcation. Boundaries of protected or conservation forests areas are clearly demarcated.

Use restrictions. Stakeholders clearly understand the timeframe and what activities are allowed and not allowed within the protection or conservation area

Enforcement. Implementing agencies are aware and effectively coordinate to carry out their roles and responsibilities

Penalties. Stakeholders understand penalties for failing to comply with the rules of the arrangement

Monitoring. Implementation is subject to regular monitoring of impacts and effectiveness

Procedures. The procedures for establishing PES have been made clear to the stakeholders

Coverage. PES schemes have been established on the ground.

Benefit-sharing. The schemes for benefit sharing have been jointly decided, understood and acceptable to the stakeholders

Protection. The protection of the forests providing these ecosystem services has been put in place

Monitoring. Implementation is subject to regular monitoring

Procedures. Stakeholders clearly understand the procedures for setting up sustainable livelihood projects.

Coordination. Government agencies coordinate and provide support in implementing and sustaining projects Resources. Forest resources are adequate to sustain livelihoods 
Law enforcement:

11. Formal law

12. Customary law

Revenues

13. Revenues

14. Benefit-sharing mechan- $\quad I$ isms

15. Central government

16. Local government

17. Non-government organiza-

tions

17. Customary institutions

Crosscutting is- 19. Participatory policymaking $I$
Facilities. Credit facilities and capacity building were made available to local communities

Benefits. Community members receive shares and benefits equitably

Apprehension. Violators are apprehended and brought to trial by concerned authorities

Consistency. Assigned penalties are generally consistent with the law and appropriate given the nature of the offence

Compliance. Penalties are served or are paid in full in a timely manner

Monitoring of compliance. Compliance with penalties is monitored and further legal action is taken in cases of non-compliance

Transparency. Information about penalties and their state of compliance is publicly disclosed

Fairness. Fees collected are reasonable and basis of computation are understood.

Transparency. Field staff generate comprehensive and accurate records of all fees collected and are made available to the public.

Awareness. The government takes action to ensure that non-governmental "payers" are aware of their

obligations.

Timeliness. Fees are collected in a timely manner.

Monitoring. Regular monitoring evaluates whether appropriate fees are collected as agreed

Participation. The community has participated in the design of local benefit-sharing arrangements.

Compliance. Benefits are delivered in accordance with the agreed terms set out in relevant legal or project documents

Awareness. Community members are aware of the benefits received and obligations associated with those benefits

Fairness. The type and magnitude of benefits are fair and appropriate

Monitoring. Regular monitoring evaluates whether benefits, as agreed, have reached intended recipients

Knowledge and skills. Institutions capacitated with up to date knowledge and skills to take an active role in forest management

Human resources. Institutions capacitated with an adequate number of staff personnel to take an active role in forest management

Financial resources. Institutions capacitated with sufficient financial resources to take an active role in forest management

Scientific and technical information. Institutions capacitated with relevant scientific and technical information to take an active role in forest management

Effective. Institutions are effective in implementing forest management objectives

Awareness. Community members are aware in a timely manner of policies to be developed, reviewed and revised that are relevant for land use in their community

Platforms. Platforms are provided for multi-stakeholder participation in policymaking

Representation. Policymaking platforms allowed participation of key representatives from the different forestry sector

Effectivity. Facilitation methods allowed key stakeholders to participate actively in the process

Transparency. The stakeholders are informed of the results of policy engagements

Appendix D: Correlation between estimated population and variables on infrastructure development at 95\% confidence interval using standardised variables. Coefficients $(\rho)$ range between +1 and -1 , where 1 is the total positive linear correlation, 0 is no linear correlation and -1 is total negative linear correlation. Low p-values below the significance level of 0.05 indicate that relationships are statistically significant (Bewick et al., 2003), Number of observations $=91$

\begin{tabular}{lll}
\hline Infratructure Variable & Number of people & P-value \\
\cline { 2 - 3 } & Spearman $(\rho)$ & $<0.0001$ \\
\hline Built up area (\%) & 0.4125 & $<0.0001$ \\
Distance to roads (Meters) & -0.504 & $<$ \\
\hline
\end{tabular}

Appendix E: Average annual rate of deforestation 2013-2017 for the observed and included observations in the regression models. The same letter implies means are significantly similar at 95\% significance level when non-parametric Kruskal Wallis test is applied. $N=91$ using unstandardized variables

\begin{tabular}{|c|c|c|c|}
\hline Consideration status & Number of observations & Mean & Standard deviation \\
\hline Included & 80 & $0.534^{\mathrm{A}}$ & 0.644 \\
\hline Excluded & 11 & $0.520^{\mathrm{A}}$ & 0.507 \\
\hline
\end{tabular}

\section{References}

Abman, R., 2018. Rule of law and avoided deforestation from protected areas. Ecol. Econ. 146, 282-289.

Agarwala, M., Ginsberg, J.R., 2017. Untangling outcomes of de jure and de facto community-based management of natural resources. Conserv. Biol. 31, 1232-1246.

Agrawal, A., Chhatre, A., Hardin, R., 2008. Changing governance of the world's forests. science $320,1460-1462$

Amoah, M., Wiafe, E., 2012. Livelihoods of fringe communities and the impacts on the management of conservation area: the case of Kakum National Park in Ghana. Int. For. Rev. 14, 131-144.
Andam, K.S., Ferraro, P.J., Pfaff, A., Sanchez-Azofeifa, G.A., Robalino, J.A., 2008. Measuring the effectiveness of protected area networks in reducing deforestation. Proc. Natl. Acad. Sci. 105, 16089-16094.

Andersson, K.P., Gibson, C.C., 2004. Decentralization reforms: help or hindrance to fores conservation. In: Draft presented to the Conference on the International Association of Common Property (IASCP) in Oaxaca, Mexico, pp. 9-13.

Andersson, K., 2006. Understanding decentralized forest governance: an application of the institutional analysis and development framework. Sustainability 2.

Armenteras, D., Espelta, J.M., Rodríguez, N., Retana, J., 2017. Deforestation dynamics and drivers in different forest types in Latin America: three decades of studies (1980-2010). Glob, Environ. Chang, 46, 139-147.

Arts, B., 2014. Assessing forest governance from a 'triple G'perspective: government, 
governance, governmentality. Forest Policy Econ. 49, 17-22.

Asongu, S., Jingwa, B., 2012. Population growth and forest sustainability in Africa. Int. J. Green Econ. 6, 145-166.

Banana, A., Gombya-Sembajjwe, W., Bahati, J., 2001. Explaining Deforestation: The Role of Forest Institutions in Uganda Forests. A Policy Brief. UFRIC, Makerere University, Kampala Uganda, Kampala.

Barber, C.P., Cochrane, M.A., Souza, C.M., Laurance, W.F., 2014. Roads, deforestation, and the mitigating effect of protected areas in the Amazon. Biol. Conserv. 177, 203-209.

Bartlett, M.S., 1937. Properties of sufficiency and statistical tests. Proc. Roy. Soc. Lond Series A 160, 268-282.

Bayley, D., 2015. Tropical deforestation: can property rights stem the tide? Surg. J. 8, 45-54.

Bewick, V., Cheek, L., Ball, J., 2003. Statistics review 7: correlation and regression. Crit. Care 7, 451.

Bhattarai, M., Hammig, M., 2004. Governance, economic policy, and the environmental Kuznets curve for natural tropical forests. Environ. Dev. Econ. 9, 367-382.

Bluwstein, J., Lund, J.F., Askew, K., Stein, H., Noe, C., Odgaard, R., Maganga, F., Engström, L., 2018. Between dependence and deprivation: the interlocking nature of land alienation in Tanzania. J. Agrar. Chang. 18, 806-830.

Bradley, P., Dewees, P., 1993. Indigenous woodlands, agricultural production and household economy in the communal areas. World Bank Technical Paper, 63-63.

Bray, D.B., Duran, E., Ramos, V.H., Mas, J.-F., Velazquez, A., Mcnab, R.B., Barry, D., Radachowsky, J., 2008. Tropical deforestation, community forests, and protected areas in the Maya Forest. Ecol. Soc. 13.

Bridge, P.D., Sawilowsky, S.S., 1999. Increasing physicians' awareness of the impact of statistics on research outcomes: comparative power of the t-test and Wilcoxon ranksum test in small samples applied research. J. Clin. Epidemiol. 52, 229-235.

Burgess, N.D., Balmford, A., Cordeiro, N.J., Fjeldså, J., Küper, W., Rahbek, C., Sanderson, E.W., Scharlemann, J.P., Sommer, J.H., Williams, P.H., 2007. Correlations among species distributions, human density and human infrastructure across the high biodiversity tropical mountains of Africa. Biol. Conserv. 134, 164-177.

Campbell, B.M., 1996. The Miombo in transition: woodlands and welfare in Africa. Cifor.

Caron, C., Fenner, S., 2017. Forest access and polycentric governance in Zambia's Eastern Province: insights for REDD +. Int. For. Rev. 19, 265-277.

Central Statistical Office, 2016. 2015 Living Conditions Monitoring Survey (LCMS) Report.

Central Statistical Office, 2018. Zambia in Figures- 2018. Central Statistical Office, Lusaka, Zambia.

Chidumayo, E.N., 1993. Zambian charcoal production. Energy Policy 21, 586-597.

Chidumayo, E.N., 2014. Estimating tree biomass and changes in root biomass following clear-cutting of Brachystegia-Julbernardia (miombo) woodland in Central Zambia. Environ. Conserv. 41, 54-63.

Chomba, B., Tembo, O., Mutandi, K., Mtongo, C., Makano, A., 2012. Drivers of Deforestation, Identification of Threatened Forests and Forest Co-Benefits Other than Carbon from REDD + Implementation in Zambia. Natural Resources and Environmental Protection, Lusaka, Zambia.

Chomwitz, K., Gray, D.A., 1996. Roads, land use, and deforestation: a spatial model applied to Belize. World Bank Econ. Rev. 10, 487-512.

Collins, N., 1984. The impact of population pressure on conservation and development. Res. Reproduct. 1, 1-2.

Craney, T.A., Surles, J.G., 2002. Model-dependent variance inflation factor cutoff values. Qual. Eng. 14, 391-403.

Curtis, P.G., Slay, C.M., Harris, N.L., Tyukavina, A., Hansen, M.C., 2018. Classifying drivers of global forest loss. Science 361, 1108-1111.

D'annunzio, R., Sandker, M., Finegold, Y., Min, Z., 2015. Projecting global forest area towards 2030. For. Ecol. Manag. 352, 124-133.

Davis, C., Williams, L., Lupberger, S., Daviet, F., 2013. Assessing Forest Governance: The Governance of Forests Initiative Indicator Framework. World Resources Institute, Washington, D. C., USA.

De Graaf, M., Buck, L., Shames, S., Zagt, R., 2017. Assessing landscape governance, a participatory approach. Tropenbos EcoAgriculture, Washington, Wageningen.

Defries, R.S., Rudel, T., Uriarte, M., Hansen, M., 2010. Deforestation driven by urban population growth and agricultural trade in the twenty-first century. Nat. Geosci. 3, 178-181.

Dewees, P.A., Campbell, B.M., Katerere, Y., Sitoe, A., Cunningham, A.B., Angelsen, A., Wunder, S., 2010. Managing the Miombo woodlands of southern Africa: policies, incentives and options for the rural poor. J. Nat. Resourc. Policy Res. 2, 57-73.

Di Gregorio, A., Jansen, L., 2005. Land Cover Classification System Classification Concepts and User Manual. Food and Agriculture Organization of the United Nations, Rome.

Dudley, N., Stolton, S., 2010. Arguments for Protected Areas: Multiple Benefits for Conservation and Use. Routledge.

Dytham, C., 2011. Choosing and Using Statistics: A biologist's Guide. John Wiley \& Sons.

Eklund, J.F., Cabeza-Jaimejuan, M.D.M., 2017. Quality of governance and effectiveness of protected areas: crucial concepts for conservation planning. Ann. New York Acad. Sci. 1399, 27-41.

ESA, 2017. CCI Land Cover - S2 Prototype Land Cover 20m Map of Africa 2016.

FAO, 2015. Global Forest Resources Assessment 2015: How Are the World's Forests Changing? Food and Agriculture Organization of the United Nations.

FAO, 2018. The State of the World's Forests 2018: Forest pathways to sustainable development. FAO, Rome, Italy.

FAO, 2020. Global Forest Resources Assessment 2020 - Key Findings. FAO, Rome.

Fay, M., 2012. Inclusive Green Growth: The Pathway to Sustainable Development. World Bank Publications.

Ferraro, P.J., Hanauer, M.M., Miteva, D.A., Canavire-Bacarreza, G.J., Pattanayak, S.K.,
Sims, K.R., 2013. More strictly protected areas are not necessarily more protective: evidence from Bolivia, Costa Rica, Indonesia, and Thailand. Environ. Res. Lett. 8, 025011.

Ferrer Velasco, R., Köthke, M., Lippe, M., Günter, S., 2020. Scale and context dependency of deforestation drivers: insights from spatial econometrics in the tropics. PLoS One 15, e0226830.

Fischer, R., Giessen, L., Günter, S., 2020. Governance effects on deforestation in the tropics: a review of the evidence. Environ. Sci. Pol. 105, 84-101.

Flynn, B.B., Sakakibara, S., Schroeder, R.G., Bates, K.A., Flynn, E.J., 1990. Empirical research methods in operations management. J. Oper. Manag. 9, 250-284.

Freeman, M.F., Tukey, J.W., 1950. Transformations related to the angular and the square root. Ann. Math. Stat. 607-611.

Frost, P., 1996. The ecology of miombo woodlands. In: The Miombo in Transition: Woodlands and Welfare in Africa, pp. 11-57.

Furusawa, T., 2016. Customary rules and wisdom related to conservation. In: Living with Biodiversity in an Island Ecosystem. Springer.

Geist, H.J., Lambin, E.F., 2001. What drives tropical deforestation. LUCC Report series 4, 116.

Gibson, J., Rozelle, S., 2003. Poverty and access to roads in Papua New Guinea. Econ. Dev. Cult. Chang. 52, 159-185.

Giessen, L., Buttoud, G., 2014. Assessing forest governance-analytical concepts and their application. Forest Policy Econ. 49, 1-71.

Global Forest Watch, 2018. Tree Cover Loss in Zambia.

Global Forest Watch, 2019. Tree Cover Loss and Gain Area.

Gordon, H.S., 1954. The Economic Theory of a Common-Property Resource: The Fishery: Classic Papers in Natural Resource Economics. Springer.

GRZ, 2015a. The Forests Act, No. 4 of 2015. Government of the Republic of Zambia (GRZ), Lusaka, Zambia.

GRZ, 2015b. The Zambia Wildlife Act, No. 14 of 2015. Government of the Republic of Zambia (GRZ).

Gumbo, D.J., Moombe, K.B., Kandulu, M.M., Kabwe, G., Ojanen, M., Ndhlovu, E., Sunderland, T.C., 2013. Dynamics of the Charcoal and Indigenous Timber Trade in Zambia: A Scoping Study in Eastern. Northern and Northwestern Provinces, CIFOR.

Gumbo, D., Dumas-Johansen, M., Muir, G., Boerstler, F., Zuzhang, X., 2018. Sustainable Management of Miombo Woodlands: Food Security, Nutrition and Wood Energy. FAO.

Handavu, F., Chirwa, P.W., Syampungani, S., 2019. Socio-economic factors influencing land-use and land-cover changes in the miombo woodlands of the Copperbelt province in Zambia. Forest Policy Econ. 100, 75-94.

Hansen, M.C., Potapov, P.V., Moore, R., Hancher, M., Turubanova, S., Tyukavina, A., Thau, D., Stehman, S., Goetz, S., Loveland, T.R., 2013. High-resolution global maps of 21st-century forest cover change. Science 342, 850-853.

Hayes, A.F., Cai, L., 2007. Using heteroskedasticity-consistent standard error estimators in OLS regression: an introduction and software implementation. Behav. Res. Methods 39, 709-722.

Hayes, T., Persha, L., 2010. Nesting local forestry initiatives: revisiting community forest management in a REDD + world. Forest Policy Econ. 12, 545-553.

Hocking, R.R., 1976. A biometrics invited paper. The analysis and selection of variables in linear regression. Biometrics 32, 1-49.

Holland, M.B., De Koning, F., Morales, M., Naughton-Treves, L., Robinson, B.E., Suárez, L., 2014. Complex tenure and deforestation: implications for conservation incentives in the Ecuadorian Amazon. World Dev. 55, 21-36.

Holland, M.B., Jones, K.W., Naughton-Treves, L., Freire, J.-L., Morales, M., Suárez, L., 2017. Titling land to conserve forests: the case of Cuyabeno Reserve in Ecuador. Glob. Environ. Chang. 44, 27-38.

Hosonuma, N., Herold, M., De Sy, V., De Fries, R.S., Brockhaus, M., Verchot, L., Angelsen, A., Romijn, E., 2012. An assessment of deforestation and forest degradation drivers in developing countries. Environ. Res. Lett. 7, 044009.

Infield, M., Entwistle, A., Anthem, H., Mugisha, A., Phillips, K., 2018. Reflections on cultural values approaches to conservation: lessons from 20 years of implementation. Oryx 52, 220-230.

Jarvis, A., Reuter, H.I., Nelson, A., Guevara, E., 2008. Hole-Filled SRTM for the Globe Version 4, Available from the CGIAR-CSI SRTM 90m Database.

Kaimowitz, D., 2012. Forest law enforcement and rural livelihoods. In: Illegal Logging. Routledge.

Kaimowitz, D., Flores, G., Johnson, J., Pacheco, P., Pavéz, I., Montgomery Roper, J., Vallejos, C., Vélez, R., 2000. Local Government and Biodiversity Conservation: A Case from the Bolivian Lowlands. A Case Study for Shifting the Power: Decentralization and Biodiversity Conservation. Biodiversity Support Program, Washington, DC (EUA).

Kalaba, F.K., 2016. Barriers to policy implementation and implications for Zambia's forest ecosystems. Forest Policy Econ. 69, 40-44.

Kalinda, T., Bwalya, S., Mulolwa, A., Haantuba, H., 2008. Use of integrated land use assessment (ILUA) data for forestry and agricultural policy review and analysis in Zambia. In: Report Prepared for the Forestry Management and Planning Unit of the Department of Forestry, FAO, and the Zambian Forestry Department, Ministry of Tourism, Environment, and Natural Resource Management. Lusaka, Zambia.

Kamelarczyk, K.B., Gamborg, C., 2014. Spanning boundaries: science-policy interaction in developing countries-the Zambian REDD + process case. Environ. Dev. 10, 1-15.

Kaufmann, D., Kraay, A., Mastruzzi, M., 2007. The Worldwide Governance Indicators Project: Answering the Critics. The World Bank.

Kaufmann, D., Kraay, A., Mastruzzi, M., 2011. The worldwide governance indicators: methodology and analytical issues. Hague J. Rule Law 3, 220-246.

Kazungu, M., Zhunusova, E., Yang, A.L., Kabwe, G., Gumbo, D.J., Günter, S., 2020. Forest use strategies and their determinants among rural households in the Miombo woodlands of the Copperbelt Province, Zambia. Forest Policy Econ. 111, 102078. 
Kijima, Y., Sakurai, T., Otsuka, K., 2000. Iriaichi: collective versus individualized management of community forests in postwar Japan. Econ. Dev. Cult. Chang. 48, 867-886.

Kirk, J., Miller, M.L., Miller, M.L., 1986. Reliability and Validity in Qualitative Research. Sage.

Kishor, N., Belle, A., 2004. Does improved governance contribute to sustainable forest management? J. Sustain. For. 19, 55-79.

Kishor, N., Rosenbaum, K., 2012. Assessing and Monitoring Forest Governance: A user's Guide to a Diagnostic Tool.

Kissinger, G., Herold, M., De Sy, V., 2012. Drivers of Deforestation and Forest Degradation: A Synthesis Report for REDD + Policymakers. Lexeme Consulting.

Koyuncu, C., Yilmaz, R., 2013a. Deforestation, corruption, and private ownership in the forest sector. Qual. Quant. 47, 227-236.

Koyuncu, C., Yilmaz, R., 2013b. Impact of private forest ownership on deforestation and poverty. Qual. Quant. 47, 1657-1664.

Larson, A.M., 2002. Natural resources and decentralization in Nicaragua: are local governments up to the job? World Dev. 30, 17-31.

Larson, A.M., Petkova, E., 2011. An introduction to forest governance, people and REDD + in Latin America: obstacles and opportunities. Forests 2, 86-111.

Laurance, W. F., Albernaz, A. K., Schroth, G., Fearnside, P. M., Bergen, S., Venticinque, E. M. \& DA Costa, C. 2002. Laurance. J. Biogeogr., 29, 737-748.

Li, S., 2018. Community-based forestry and the functions of institutions: a case study of Fung Shui forests in Hong Kong. Int. For. Rev. 20, 362-374.

Li, Q., Reuveny, R., 2006. Democracy and environmental degradation. Int. Stud. Q. 50, 935-956.

Lingard, M., Raharison, N., Rabakonandrianina, E., Rakotoarisoa, J.-A., Elmqvist, T., 2003. The role of local taboos in conservation and management of species: the radiated tortoise in southern Madagascar. Conserv. Soc. 1, 223.

Luna, T.O., Zhunusova, E., Günter, S., Dieter, M., 2020. Measuring forest and agricultural income in the Ecuadorian lowland rainforest frontiers: do deforestation and conservation strategies matter? Forest Policy Econ. 111, 102034.

Lund, J.F., Balooni, K., Casse, T., 2009. Change we can believe in? Reviewing studies on the conservation impact of popular participation in forest management. Conserv. Soc. 7, 71-82.

Lund, J.F., Burgess, N.D., Chamshama, S.A., Dons, K., Isango, J.A., Kajembe, G.C., Meilby, H., Moyo, F., Ngaga, Y.M., Ngowi, S.E., 2014. Mixed method approaches to evaluate conservation impact: evidence from decentralized forest management in Tanzania.

Acheampong, E.O., Macgregor, C.J., Sloan, S., Sayer, J., 2019. Deforestation is driven by agricultural expansion in Ghana's forest reserves. Scientific African 5, e00146.

Mackenzie, C.A., Chapman, C.A., Sengupta, R., 2012. Spatial patterns of illegal resource extraction in Kibale National Park, Uganda. Environ. Conserv. 39, 38-50.

Madzudzo, E., Mulanda, A., Nagoli, J., Lunda, J., Ratner, B., 2013. A Governance Analysis of the Barotse Floodplain System, Zambia: Identifying Obstacles and Opportunities. (WorldFish).

March, J.G., Olsen, J.P., 2010. Rediscovering Institutions. Simon and Schuster.

Martin, M., Peters, B., Corbett, J., 2012. Participatory asset mapping in the Lake Victoria Basin of Kenya. J. Urban Regional Inform. Syst. Assoc. 24.

Mason-Case, S., 2011. Legal Preparedness for REDD + in Zambia: Country Study. IDLO, Rome.

Matakala, P., Kokwe, M., Statz, J., 2015. Zambia national strategy to reduce emissions from deforestation and forest degradation (REDD+). In: Forestry Department. Ministry of Lands Natural Resources and Environmental Protection. In Cooperation with Food and Agriculture Organization (FAO) UNDP, and United Nations Environment Programme. Government of the Republic of Zambia.

Mayaux, P., Pekel, J.-F., Desclée, B., Donnay, F., Lupi, A., Achard, F., Clerici, M., Bodart, C., Brink, A., Nasi, R., 2013. State and evolution of the African rainforests between 1990 and 2010. Philos. Trans. Roy. Soc. B 368, 20120300.

Mcdermott, C., Cashore, B.W., Kanowski, P., 2010. Global Environmental Forest Policies: An International Comparison. Earthscan.

Mfune, O., 2013. Has decentralisation of forest resources to local governments really taken off on the ground? Experiences from Chongwe District in Central Zambia. J. Sustain. Develop. 6, 57.

Millennium Ecosystem Assessment, M, 2003. Ecosystems and human well-being: A framework for assessment. In: Report of the Conceptual Framework Working Group of the Millennium Ecosystem Assessment.

Ministry of Tourism Environment and Natural Resources, 2010. 'National Climate Change Response Strategy'(First Draft). Ministry of Tourism Environment and Natural Resources, Lusaka, Zambia.

Mittermeier, R.A., Mittermeier, C.G., Brooks, T.M., Pilorim, J.D., Konstant, W.R., Da Fonseca, G.A., Kormos, C., 2003. Wilderness and biodiversity conservation. Proc. Natl. Acad. Sci. 100, 10309-10313.

Motulsky, H., Christopoulos, A., 2004. Fitting Models to Biological Data Using Linear and Nonlinear Regression: A Practical Guide to Curve Fitting. Oxford University Press.

Mwangi, E., Wardell, A., 2012. Multi-level governance of forest resources (editorial to the special feature). Int. J. Commons 6.

Mwitwa, J., German, L., Paumgarten, F., 2011. Evaluating the Impacts of Expanded Trade and Investment in Mining on Forests: Customary Rights and Societal Stakes in the Copper Belt of Zambia.

Mwitwa, J., Vinya, R., Kasumu, E., Syampungani, S., Monde, C., Kasubika, R., 2012 Drivers of Deforestation and Potential for REDD + Interventions in Zambia. UNREDD + Zambia National Programme, Lusaka.

Naeem, S., Chazdon, R., Duffy, J.E., Prager, C., Worm, B., 2016. Biodiversity and human well-being: an essential link for sustainable development. Proc. R. Soc. B Biol. Sci. 283, 20162091.

Nansikombi, H., Fischer, R., Kabwe, G., Günter, S., 2020. Exploring patterns of forest governance quality: insights from forest frontier communities in Zambia's Miombo ecoregion. Land Use Policy 99, 104866.

Ngandwe, P., Mwitwa, J., Muimba-Kankolongo, A., 2015. Forest Policy, Economics, and Markets in Zambia. Academic Press.

Nolte, C., Agrawal, A., Silvius, K.M., Soares-Filho, B.S., 2013. Governance regime and location influence avoided deforestation success of protected areas in the Brazilian Amazon. Proc. Natl. Acad. Sci. 110, 4956-4961.

Nolte, C., Gobbi, B., De Waroux, Y.L.P., Piquer-Rodríguez, M., Butsic, V., Lambin, E.F., 2017. Decentralized land use zoning reduces large-scale deforestation in a major agricultural frontier. Ecol. Econ. 136, 30-40.

Nugroho, H.Y., Van Der Veen, A., Skidmore, A.K., Hussin, Y.A., 2018. Expansion of traditional land-use and deforestation: a case study of an adat forest in the Kandilo Subwatershed, East Kalimantan, Indonesia. J. For. Res. 29, 495-513.

Nyumba, O., Wilson, K., Derrick, C.J., Mukherjee, N., 2018. The use of focus group discussion methodology: Insights from two decades of application in conservation. Methods Ecol. Evol. 9, 20-32.

Oldekop, J.A., Sims, K.R., Karna, B.K., Whittingham, M.J., Agrawal, A., 2019. Reductions in deforestation and poverty from decentralized forest management in Nepal. Nat. Sustain. 2, 421-428.

Openstreetmap, 2020.

Ostrom, E., 1990. Governing the Commons: The Evolution of Institutions for Collective Action. Cambridge University Press.

Ostrom, E., 2008. Design Principles of Robust Property-Rights Institutions: What Have we Learned.

Ostrom, E., 2009. A general framework for analyzing sustainability of social-ecological systems. Science 325, 419-422.

Ostrom, E., Benjamin, P., 1993. Design principles and the performance of farmer managed irrigation systems in Nepal. Manor, S. y J. Chambouleyron (eds.). pp. 53-62.

Ostrom, E., Burger, J., Field, C.B., Norgaard, R.B., Policansky, D., 1999. Revisiting the commons: local lessons, global challenges. science 284, 278-282.

Parker, P.L., Mcdaniel, H.S., Crumpton-Young, L.L., 2002. Do Research Participants Give Interval or Ordinal Answers In Response to Likert Scales? In: IIE Annual Conference. Proceedings, Citeseer, 1.

Peters, B.G., Pierre, J., 1998. Governance without government? Rethinking public administration. J. Public Adm. Res. Theory 8, 223-243.

Pfaff, A., Robalino, J., Lima, E., Sandoval, C., Herrera, L.D., 2014. Governance, location and avoided deforestation from protected areas: greater restrictions can have lower impact, due to differences in location. World Dev. 55, 7-20.

Pfaff, A., Santiago-Ávila, F., Joppa, L., 2017. Evolving protected-area impacts in Mexico: political shifts as suggested by impact evaluations. Forests $8,17$.

Phiri, D., Morgenroth, J., Xu, C., 2019a. Four decades of land cover and forest connectivity study in Zambia—an object-based image analysis approach. Int. J. Appl. Earth Obs. Geoinf. 79, 97-109.

Phiri, D., Morgenroth, J., Xu, C., 2019b. Long-term land cover change in Zambia: an assessment of driving factors. Sci. Total Environ. 697, 134206.

Poor, E.E., Jati, V.I., Imron, M.A., Kelly, M.J., 2019. The road to deforestation: edge effects in an endemic ecosystem in Sumatra, Indonesia. PLoS One 14.

Potapov, P.V., Turubanova, S.A., Hansen, M.C., Adusei, B., Broich, M., Altstatt, A., Mane L., Justice, C.O., 2012. Quantifying forest cover loss in Democratic Republic of the Congo, 2000-2010, with Landsat ETM + data. Remote Sens. Environ. 122, 106-116.

Pujiono, E., Sadono, R., Imron, M.A., 2019. Assessment of causes and future deforestation in the mountainous tropical forest of Timor Island, Indonesia. J. Mt. Sci. 16, 2215-2231.

Puyravaud, J.-P., 2003. Standardizing the calculation of the annual rate of deforestation. For. Ecol. Manag. 177, 593-596.

Rademaekers, K., Eichler, L., Berg, J., Obersteiner, M., Havlik, P., Aioki, K., Fritz, S. Moisner, A., Sørensen, L., Overmars, K., 2010. Study on the Evolution of some Deforestation Drivers and their Potential Impacts on the Costs of an Avoiding Deforestation Scheme. (European Commission Directorate-General for Environment).

Ratnasingam, J., Ng'andwe, P., Ioras, F., Abrudan, I., 2014. Forestry and forest products industries in Zambia and the role of REDD + initiatives. Int. For. Rev. 16, 474-484.

Rhodes, R.A., 2007. Understanding governance: ten years on. Organ. Stud. 28, 1243-1264.

Ribot, J.C., 2003. Democratic decentralization of natural resources. In: Beyond Structural Adjustment the Institutional Context of African Development. Springer.

Rights \& Initiative, R, 2018. At a Crossroads: Consequential Trends in Recognition of Community-Based Forest Tenure from 2002-2017. Rights and Resources Initiative, Washington, DC

Robinson, B.E., Holland, M.B., Naughton-Treves, L., 2014. Does secure land tenure save forests? A meta-analysis of the relationship between land tenure and tropical deforestation. Glob. Environ. Chang. 29, 281-293.

Rodgers, A., Salehe, J., Howard, G., 1996. The biodiversity of miombo woodlands. In: The Miombo in transition: Woodlands and welfare in Africa. 12.

Tacconi, L., Rodrigues, R.J., Maryudi, A., Muttaqin, M.Z., 2019. Law enforcement and deforestation: lessons for Indonesia from Brazil. Forest Policy Econ. 108, 1-10 101943.

Rudel, T.K., 2013. The national determinants of deforestation in sub-Saharan Africa. Philos. Trans. Roy. Soc. B 368, 20120405.

Sabatier, P.A., 1999. Theories Ofthe Policy Process. Westview, Boulder, CO.

Sabatier, P., 2019. Theories of the Policy Process. Routledge.

SAS INSTITUTE INC, 2017. Discovering JMP $13^{\oplus}$. SAS Institute Inc, Cary, NC.

Secco, L., Da Re, R., Pettenella, D.M., Gatto, P., 2014. Why and how to measure forest governance at local level: a set of indicators. Forest Policy Econ. 49, 57-71.

SERVIR, 2015. Zambia Populated Places 2015. [Online]. https://cs4rd.org/data-map/.

Shakacite, O., Chungu, D., Ng'andwe, P., Chendauka, B., Siampale, A., Tavani, R., Roberts, W., Vesa, L., 2016. Integrated land use assessment phase II-report for 
Zambia. The Food and Agriculture Organization of the United Nations and the Forestry Department, Ministry of Lands and Natural Resources, Lusaka, Zambia, Lusaka, Zambia Viewed at www. zmb-nfms. org/iluaii/index. php.

Shoshany, M., Goldshleger, N., 2002. Land-use and population density changes in Israel-1950 to 1990: analysis of regional and local trends. Land Use Policy 19, 123-133.

Shova, T., Hubacek, K., 2011. Drivers of illegal resource extraction: an analysis of Bardia National Park, Nepal. J. Environ. Manag. 92, 156-164.

Simon, H.A., 1955. A behavioral model of rational choice. Q. J. Econ. 69, 99-118.

Simon, H.A., 1959. Theories of decision-making in economics and behavioral science. Am. Econ. Rev. 49, 253-283.

Stamber, K.L., Unis, C.J., Shirah, D.N., Gibson, J.A., Fogleman, W.E., Kaplan, P., 2016. Population as a proxy for infrastructure in the determination of event response and recovery resource allocations. J. Homeland Security Emergency Manag. 13, 35-50.

Stickler, M.M., Huntington, H., Haflett, A., Petrova, S., Bouvier, I., 2017. Does de facto forest tenure affect forest condition? Community perceptions from Zambia. Forest Policy Econ. 85, 32-45.

Stifel, D., Minten, B., 2008. Isolation and agricultural productivity. Agric. Econ. 39, 1-15.

Tacconi, L., 2007. Decentralization, forests and livelihoods: theory and narrative. Glob. Environ. Chang. 17, 338-348.

Thacker, N.A., Bromiley, P.A., 2001. The effects of a square root transform on a Poisson distributed quantity. Tina Memo 10, 2001.

Turner, B.L., Moss, R.H., Skole, D., 1993. Relating land use and global land-cover change. [No source information available].

Twumasi, P.A., Freund, P.J., 1985. Local politicization of primary health care as an instrument for development: a case study of community health workers in Zambia. Soc. Sci. Med. 20, 1073-1080.

Umemiya, C., Rametsteiner, E., Kraxner, F., 2010. Quantifying the impacts of the quality of governance on deforestation. Environ. Sci. Pol. 13, 695-701.

UNEP-WCMC AND IUCN, 2016. Protected Planet. The World Database on Protected Areas (WDPA), the Global Database on Protected Areas management Effectiveness (GDPAME) [Online]. Cambridge, UK. www.protectedplanet.net.

United Nations Climate Summit, 2014. New York Declaration on Forests. United Nations, New York, NY.

Unruh, J., Cligget, L., Hay, R., 2005. Migrant land rights reception and 'clearing to claim'in sub-Saharan Africa: A deforestation example from southern Zambia. Natural Resources Forum 190-198 Wiley Online Library.

Venter, Z., Cramer, M., Hawkins, H., 2018. Drivers of woody plant encroachment over
Africa. Nat. Commun. 9, 2272.

Vinya, R., Syampungani, S., Kasumu, E., Monde, C., Kasubika, R., 2011. Preliminary Study on the Drivers of Deforestation and Potential for REDD + in Zambia. FAO/ Zambian Ministry of Lands and Natural Resources, Lusaka, Zambia.

Vorlaufer, T., Falk, T., Dufhues, T., Kirk, M., 2017. Payments for ecosystem services and agricultural intensification: evidence from a choice experiment on deforestation in Zambia. Ecol. Econ. 141, 95-105.

Wehkamp, J., Koch, N., Lübbers, S., Fuss, S., 2018. Governance and deforestation-a meta-analysis in economics. Ecol. Econ. 144, 214-227.

Wezel, A., Soboksa, G., Mcclelland, S., Delespesse, F., Boissau, A., 2015. The blurred boundaries of ecological, sustainable, and agroecological intensification: a review. Agron. Sustain. Dev. 35, 1283-1295.

Williams, M., Ryan, C., Rees, R., Sambane, E., Fernando, J., Grace, J., 2008. Carbon sequestration and biodiversity of re-growing miombo woodlands in Mozambique. For. Ecol. Manag. 254, 145-155.

Wilshusen, P.R., Brechin, S.R., Fortwangler, C.L., West, P.C., 2002. Reinventing a square wheel: critique of a resurgent" protection paradigm" in international biodiversity conservation. Soc. Nat. Resour. 15, 17-40.

Wong, B.F., 2004. Common Pool Resources Management: Are Common Property Rights a Good Alternative to External Regimes?

Worldbank, 2006. A Decade of Measuring the Quality of Governance. Governance Matters 2006. Worldwide Governance Indicators, Washington, D.C.

Worldpop, 2018. Global High Resolution Population Denominators Project - Funded by the Bill and Melinda Gates Foundation (OPP1134076). W. W. O.-S. O. G. A. E. S., University of Southampton; Department of Geography and Geosciences, University of Louisville; Departement de Geographie, Universite de Namur) and Center for International Earth Science Information Network (CIESIN), Columbia Universityhttps://doi.org/10.5258/SOTON/WP00645.

Wright, G.D., Andersson, K.P., Gibson, C.C., Evans, T.P., 2016. Decentralization can help reduce deforestation when user groups engage with local government. Proc. Natl. Acad. Sci. 113, 14958-14963.

Xie, L., Berck, P., Xu, J., 2016. The effect on forestation of the collective forest tenure reform in China. China Econ. Rev. 38, 116-129.

Zabala, A., 2018. Comparing Global Spatial Data on Deforestation for Institutional Analysis in Africa.

Zafirovski, M., 2003. The rational choice approach to human studies: a reexamination. Hum. Stud. 26, 41-66. 